\title{
AN IMPROVED MOULDLESS MANUFACTURING METHOD FOR FOAM-CORE COMPOSITE SANDWICH STRUCTURES
}

\author{
By \\ Mario Mahendran \\ A thesis submitted to \\ The Faculty of Graduate Studies and Research \\ in partial fulfillment of \\ the degree requirements of \\ Master of Applied Science \\ Ottawa-Carleton Institute for \\ Mechanical and Aerospace Engineering
}

Department of Mechanical and Aerospace Engineering

Carleton University

Ottawa, Ontario, Canada

December 2010

Copyright (C)

2010 - M. Mahendran 


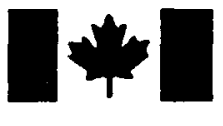

Library and Archives
Canada

Published Heritage

Branch

395 Wellington Street

Ottawa ON K1A 0N4

Canada
Bibliothèque et

Archives Canada

Direction du

Patrimoine de l'édition

395, rue Wellington

Ottawa ON K1A ON4

Canada
Your file Votre reférence

ISBN: 978-0-494-79537-8

Our file Notre référence

ISBN: 978-0-494-79537-8
NOTICE:

The author has granted a nonexclusive license allowing Library and Archives Canada to reproduce, publish, archive, preserve, conserve, communicate to the public by telecommunication or on the Internet, loan, distribute and sell theses worldwide, for commercial or noncommercial purposes, in microform, paper, electronic and/or any other formats.

The author retains copyright ownership and moral rights in this thesis. Neither the thesis nor substantial extracts from it may be printed or otherwise reproduced without the author's permission.
AVIS:

L'auteur a accordé une licence non exclusive permettant à la Bibliothèque et Archives Canada de reproduire, publier, archiver, sauvegarder, conserver, transmettre au public par télécommunication ou par l'Internet, prêter, distribuer et vendre des thèses partout dans le monde, à des fins commerciales ou autres, sur support microforme, papier, électronique et/ou autres formats.

L'auteur conserve la propriété du droit d'auteur et des droits moraux qui protège cette thèse. Ni la thèse ni des extraits substantiels de celle-ci ne doivent être imprimés ou autrement reproduits sans son autorisation.
In compliance with the Canadian Privacy Act some supporting forms may have been removed from this thesis.

While these forms may be included in the document page count, their removal does not represent any loss of content from the thesis.
Conformément à la loi canadienne sur la protection de la vie privée, quelques formulaires secondaires ont été enlevés de cette thèse.

Bien que ces formulaires aient inclus dans la pagination, il n'y aura aucun contenu manquant.

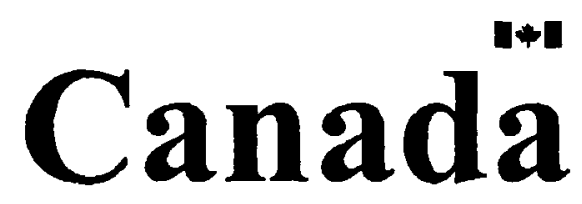




\section{ABSTRACT}

An improved mouldless Liquid Composite Moulding (LCM) manufacturing method for foamcore sandwich composite components was developed and utilized to manufacture a full scale fuselage for the GeoSurv II Unmanned Aircraft System (UAS). Implemented as part of the lowcost composite airframe research at Carleton University, this work intends to improve upon the previously implemented mouldless Vacuum Assisted Resin Transfer Moulding (VARTM), using effective design and manufacturing methods. Such methods will directly benefit small aerospace companies, especially those dealing with general aviation aircraft and UASs.

In this work, numerous state-of-the-art LCM processes were reviewed. These identified Closed Cavity Bag Moulding (CCBM) as a potential alternative to VARTM for mouldless manufacturing. A series of experiments was carried out on CCBM process to evaluate its feasibility, including investigations of various bag sealing and resin distribution strategies, followed by a Process Value Analysis (PVA). Subsequently, the fuselage was redesigned, for improved manufacturability. The new design was optimized using finite element analysis in Abaqus. Finally, a full scale GeoSurv II fuselage was manufactured to demonstrate the viability of the developed process. Results showed that this process is a viable option for manufacturing complex foam-core composite components in small quantities. Improved part quality, tolerances and weight reduction of $36 \%$ were achieved using the optimized design and manufacturing method. 


\section{DEDICATION}

Dedicated to my Mummy, Mary Rosaliya Mahendran and Dada, Kanesapillai

Julius Mahendran for their unconditional love and support. 


\section{ACKNOWLEDGMENTS}

First of all, I would like to thank my supervisors, Prof. Paul V. Straznicky and Prof. Jeremy Laliberté for giving me this research opportunity and offering continuous guidance. As much as I appreciate their expertise, I must thank them for their exceptional patience throughout the project.

I would like to acknowledge Sander Geophysics Ltd. (SGL), NSERC Collaborative Research and Development (CRD) Grant and NRC-IAR for providing the financial resources for this research.

I also extend my appreciation to research officers, Dr. Chun Li, Drazen Djokic and Dr.Peter Krimbalis at the National Research Council-Institute for Aerospace Research (NRC-IAR) for providing consultation and support throughout my Master's program. I must also thank Tom Kay at NRC-IAR for his support in cutting the fibreglass rods.

My sincere gratitude goes to the technical staff of the Mechanical and Aerospace Engineering Department at Carleton University: to Alex Proctor for his support with machining of the foam cores, to Kevin Sangster for his guidance in the machine shop and to Steve Truttmann for his useful insights and support in the structures lab.

I also thank Aaron Miller (Composites Canada), John Biron (DIAB Inc.), Larry Audette (Prairie Technology Group Inc.) and Dave Kindt (Kindt-Collins Company LLC) for their interesting technical insights and support to this project. My appreciation also goes to Michel Reid, at Progress Plastics and Compounds Inc. for providing me with the opportunity to participate in the CCBM demonstration.

I am truly thankful to Frank Cappelli, Eileen Ruddek and Russ Elkin at 3A Composites/Baltek Inc., for their kind support and material donation.

Some of the experimental work in this thesis was completed with the assistance of several undergraduate and graduate students of the GeoSurv II UAS project. I am particularly thankful to Quinn Murphy (undergraduate summer student May-Aug. 2009) for his assistance with mechanical testing and documentation, Alexandre Adcock and Mauricio Buschinelli (GeoSurv II UAS project-2009/2010) for their support with the fuselage redesign work, Alan Lares (continuing graduate student) for his assistance with mechanical testing and fuselage manufacturing, Shashank Pant (continuing graduate student), who was always present when an extra hand was needed, Jeff Teutsch and Jerry Mac Pherson (GeoSurv II UAS project-2010/2011) for their assistance with characterizing the dimensions and quality of the fuselage. I am also thankful to Laurent Loisy, an exchange student from France, who provided valuable help with the final fuselage manufacturing.

My heartfelt gratitude goes to my parents and all members of my family for their love, care and support. Success would have been far from reach, without your role.

Special mention needs to be made for the wonderful human beings, who, through invaluable friendship, kept nourishing my life, both inside and outside of Carleton. Specifically:

- Jeeva, for all the wonderful moments we encountered at Carleton. You truly are a pillar of success in my academic career. Thanks for being around whenever needed, pointing me towards the right direction.

- Shashank and Fady, for the memorable coffee times and wing nights, where many exciting 'principles of life' were exchanged. My only regret is not getting to know you guys earlier in my career.

- Masih \& Majed for being present 24/7 in the lab, exchanging ideas \& sharing stories of life.

- Dave, Henry and all other fellow graduate students in 2350 \& Grad Lab

- Mech \& Aero Crew and others who stopped by the lab every now and then.

- Sharmi \& Co. for all the Quality Time. I won't thank you guys, but here, I'll say this one time 'you are my best gift'.

- Not to be forgotten, I thank Nirth and Van for accompanying me in some labour intensive manufacturing tasks, without a shadow of hesitation.

Last but not least, big thanks to everyone who periodically questioned the status of my thesis. Bluffing those questions was a definite inspiration, when intruded by other intellectual aspects of life. 


\section{CONTENTS}

ABSTRACT

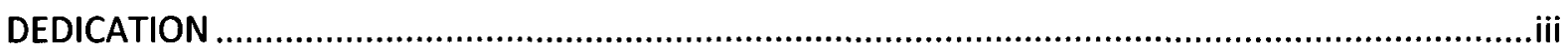

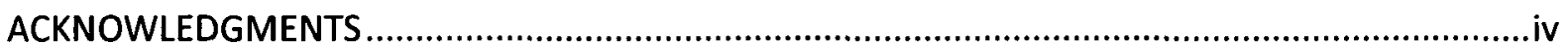

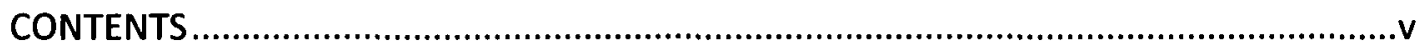

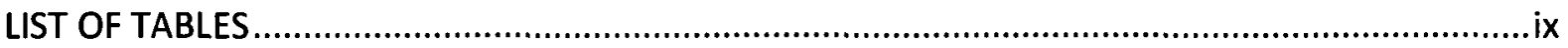

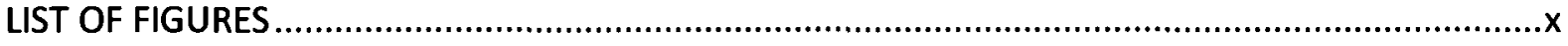

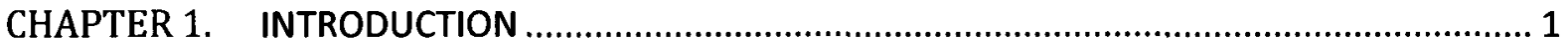

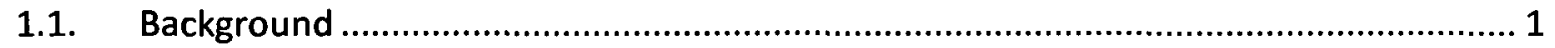

1.2. Overview of the Low-Cost Composite Airframe Research ............................................. 2

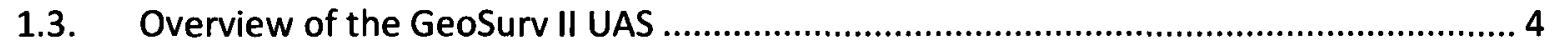

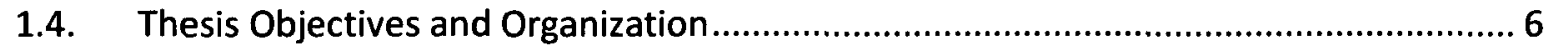

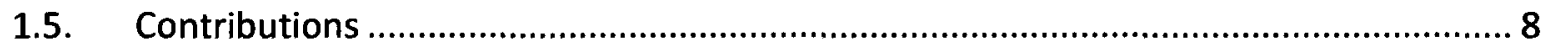

CHAPTER 2. OVERVIEW OF THE GEOSURV II FUSELAGE ..................................................... 10

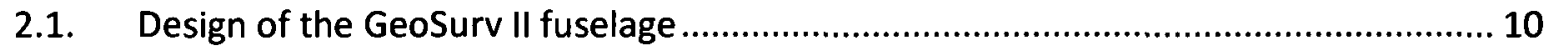

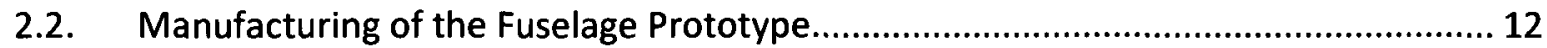

2.3. Post Process Assessment of the GeoSurv II Fuselage .................................................. 13

2.4. Design and Manufacturing Objectives for the New Fuselage …............................. 15

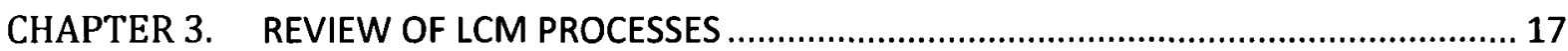

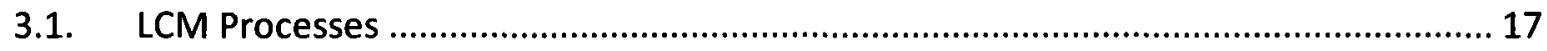

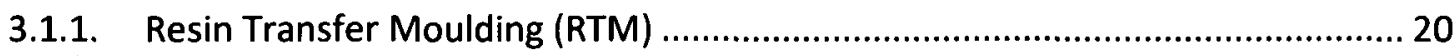

3.1.2. Structural Reaction Injection Moulding (SRIM) ......................................... 21

3.1.3. Vacuum Assisted Resin Transfer Moulding (VARTM) .................................... 22

3.1.4. Seemann Composite Resin Infusion Moulding Process (SCRIMP'M) .................... 26

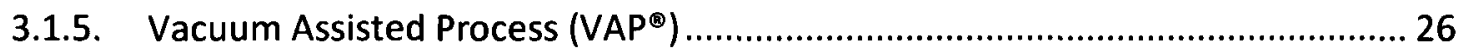

3.1.6. Fast Remotely Actuated Channelling (FASTRAC) ............................................. 27

3.1.7. Controlled Atmospheric Pressure Resin Infusion (CAPRI) ............................... 28

3.1.8. Double Bag VARTM .................................................................................... 29

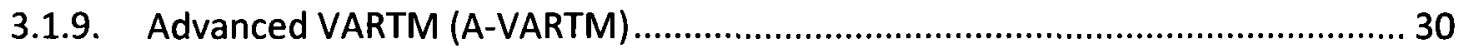

3.1.10. Single Line Injection (SLI) ........................................................................ 31

3.1.11. High Performance VARTM (Hyper-VARTM ${ }^{\top \mathrm{M}} /$ Hyper-RTM $^{\mathrm{TM}}$ ).......................... 32

3.1.12. Vibration Assisted Liquid Composite Moulding .............................................. 33 
3.1.13. Closed Cavity Bag Moulding (CCBM) ............................................................ 33

3.1.14. Co-Injection Resin Transfer Moulding (CIRTM) ........................................... 34

3.1.15. Euro Composites ${ }^{\circledast}$ Honeycomb Liquid Moulding (EC-HLM)............................ 35

3.1.16. VacFlo ${ }^{\oplus}$ Process ......................................................................................... 37

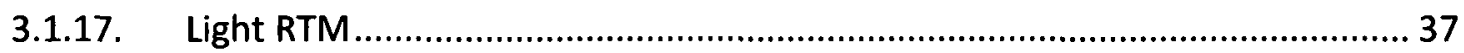

3.1.18. Resin Infusion between Double Flexible Tooling (RIDFT)............................... 38

3.1.19. Flexible Injection.................................................................................. 40

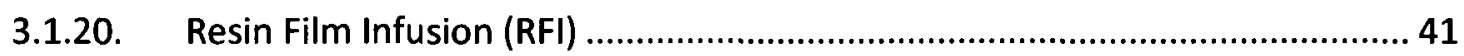

3.1.21. Semi-Preg Infusion.................................................................................. 42

3.2. Suitability LCM Processes for Mouldless Manufacturing ……...................................... 43

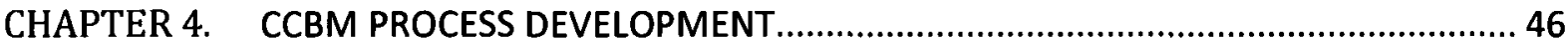

4.1. Mouldless CCBM manufacturing considerations............................................................ 46

4.1.1. Sealing Mechanisms for Mouldless CCBM ....................................................... 46

4.1.2. Resin Inlets and Outlets ................................................................................. 47

4.1.3. Resin Distribution in CCBM ....................................................................... 48

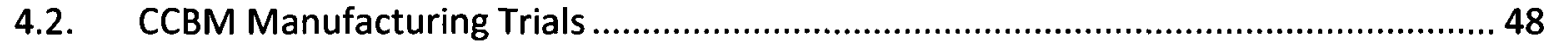

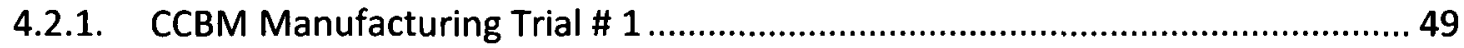

4.2.2. CCBM Manufacturing Trial \# 2 ……………................................................. 51

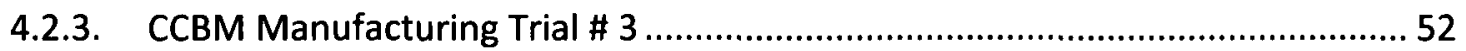

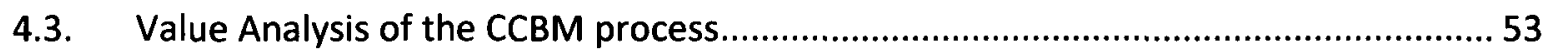

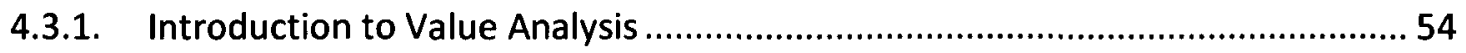

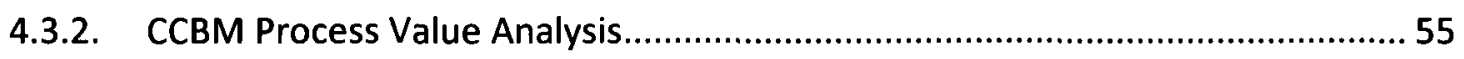

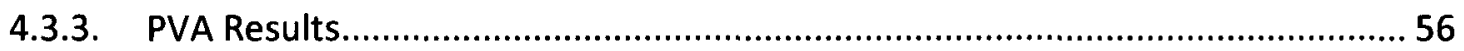

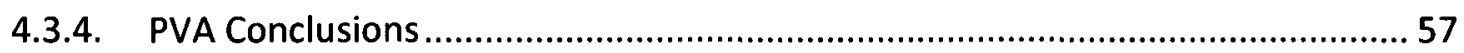

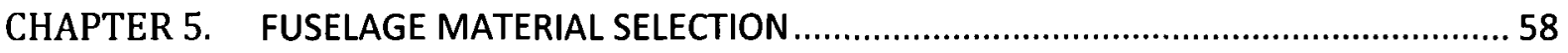

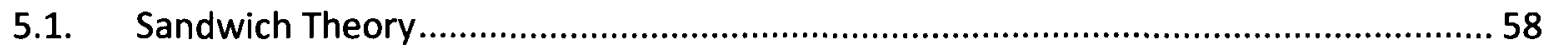

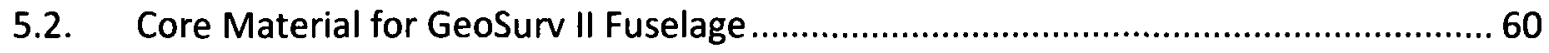

5.2.1. Structural Foam Core Materials ..................................................................... 61

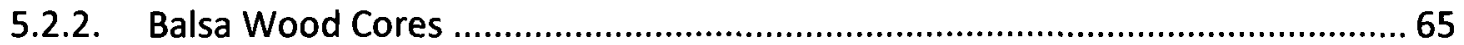

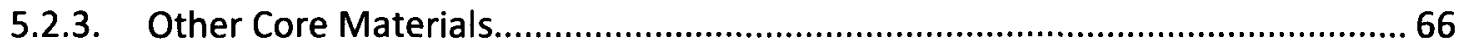

5.2.4. Core Selection for GeoSurv II Fuselage …….................................................. 67

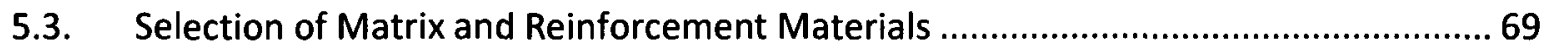

5.4. Material Selection for Rigid Inserts........................................................................... 70 


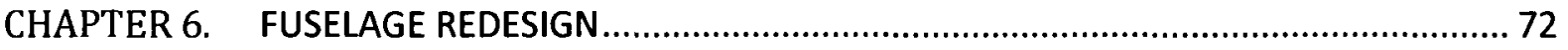

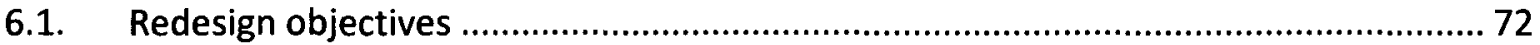

6.2. Design Changes to the GeoSurv II Fuselage........................................................... 73

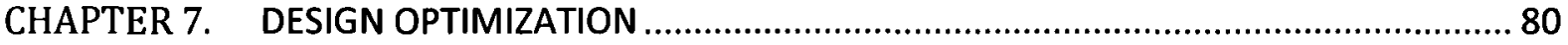

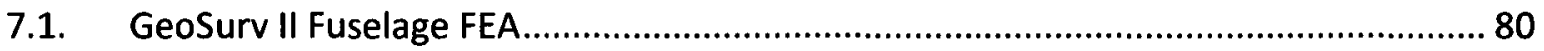

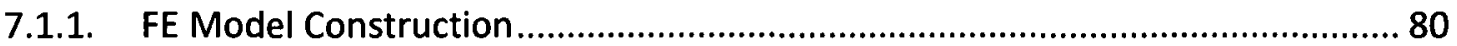

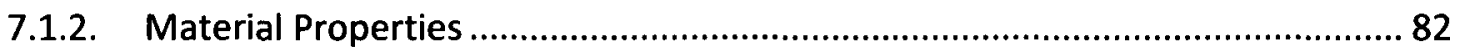

7.1.3. Part Meshing Considerations ...................................................................... 86

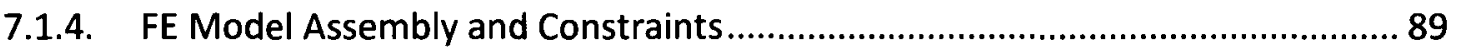

7.1.5. Analysis Steps, Loads and Boundary Conditions............................................ 90

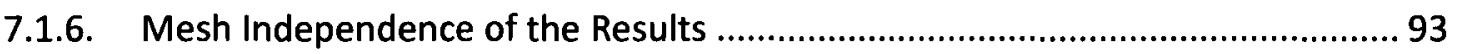

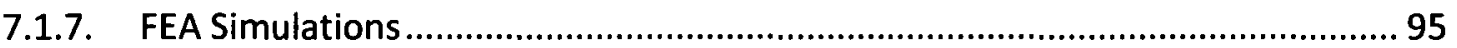

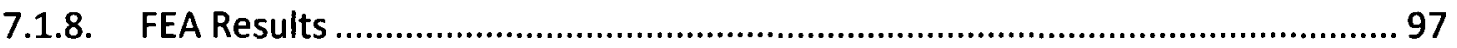

7.2. Experimental Verification of the FEA results ...................................................... 102

7.2.1. Test Matrix, Specimen Manufacturing and Test Procedure .......................... 103

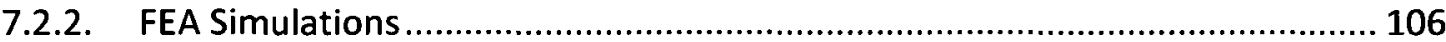

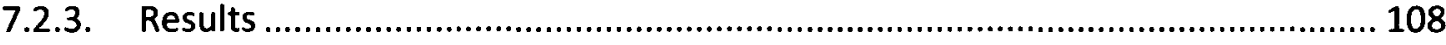

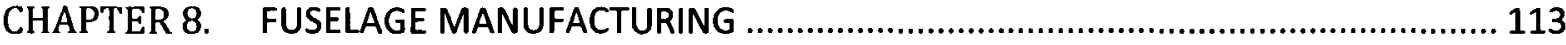

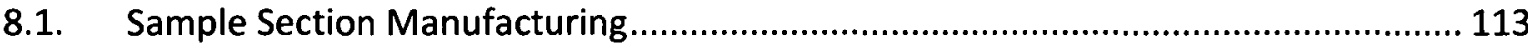

8.2. CCBM Experiments and Fuselage Manufacturing Model .................................... 117

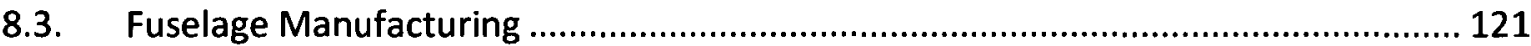

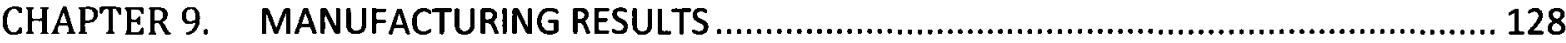

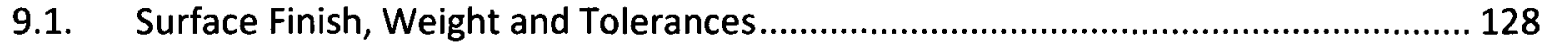

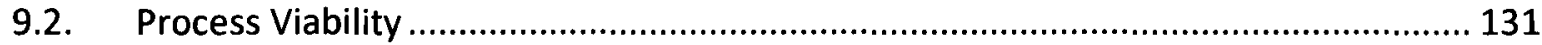

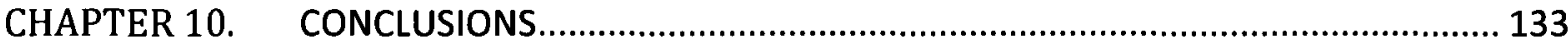

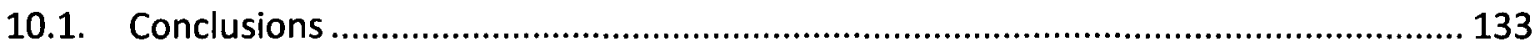

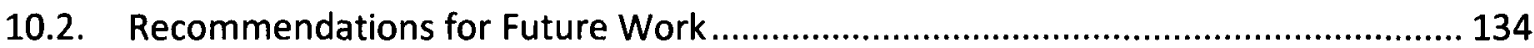

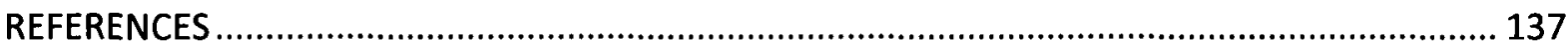

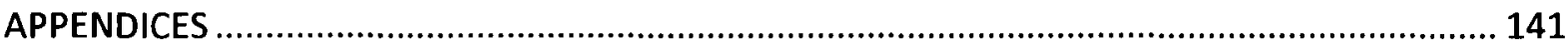

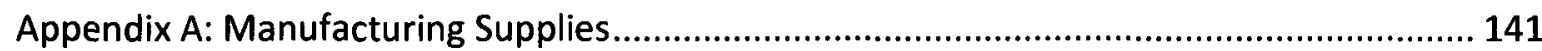

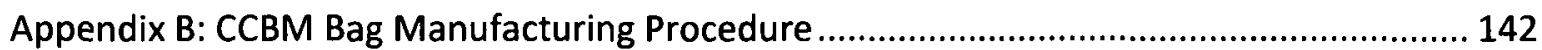

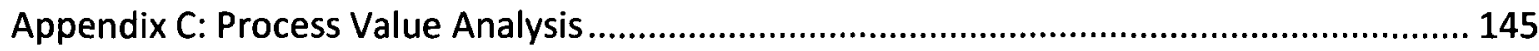

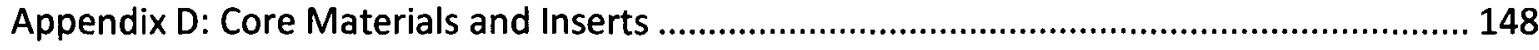




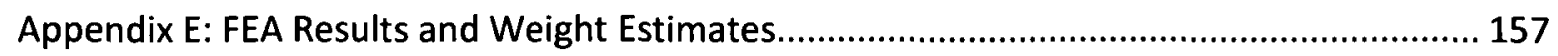

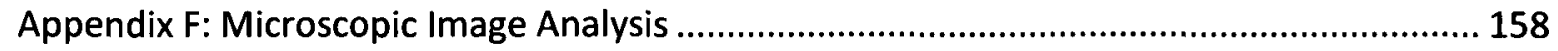

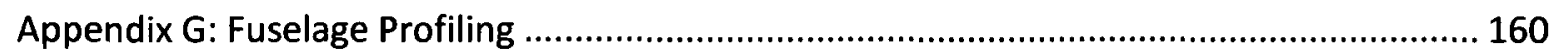

Appendix H: Fibre Volume Fraction Calculation ............................................................ 168 


\section{LIST OF TABLES}

Table 2.1: Airframe requirements for the GeoSurv II UAS [5] ............................................. 15

Table 2.2: Design and manufacturing objectives for the new fuselage .................................. 15

Table 3.1: Potential advantages of disadvantages of LCM processes [6-10] ............................ 18

Table 3.2: New materials and technologies developed to improve VARTM process ................ 25

Table 3.3: Advantages and Disadvantages of CCBM process [24]........................................ 44

Table 4.1: PVA matrix: processes for mouldless CCBM/VARTM ........................................... 55

Table 5.1: Manufacturing requirements for the core material ..............................................61 61

Table 5.2: Structural foam cores suitable for mouldless VARTM manufacturing ...................... 63

Table 5.3: Normalized mechanical properties of the most structural foam cores ....................68

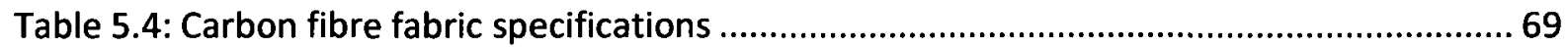

Table 6.1: GeoSurv II fuselage redesign: goals and limitations .............................................. 72

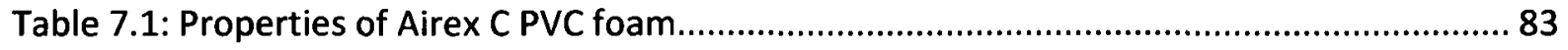

Table 7.2: Properties of the current fuselage materials.......................................................... 84

Table 7.3: Derivation of lamina properties for the new fuselage........................................... 85

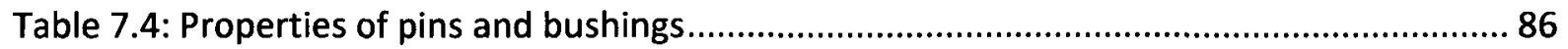

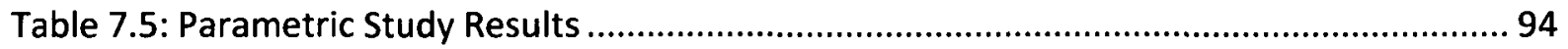

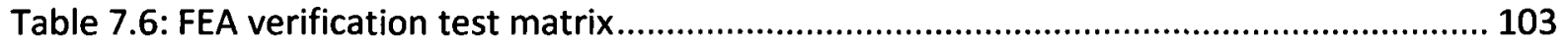

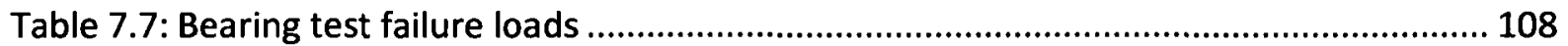

Table 7.8: Bearing test results: FEA predictions and Experiments ....................................... 109

Table 9.1: Comparison of major dimensions: fuselage design vs. current and new fuselages.. 130

Table 9.2: Comparison of the actual weight and predicted weight of the new fuselage .......... 131 


\section{LIST OF FIGURES}

Figure 1.1: Current configuration and specifications of GeoSurv II UAS (2009/2010) [4] ............ 5

Figure 1.2: GeoSurv II Prototype Assembly (February 2010) .................................................. 5

Figure 2.1: Main sections of the GeoSurv II fuselage [3] ................................................... 10

Figure 2.2: Cross-section of the fuselage structural $\mathrm{H}$ frame [3]....................................... 11

Figure 2.3: Sequence of the main steps employed in mouldless VARTM ................................ 12

Figure 2.4: Fuselage main frame manufactured by mouldless VARTM .................................. 14

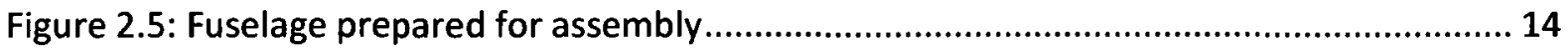

Figure 2.6: Work-flow diagram of the new fuselage development......................................... 16

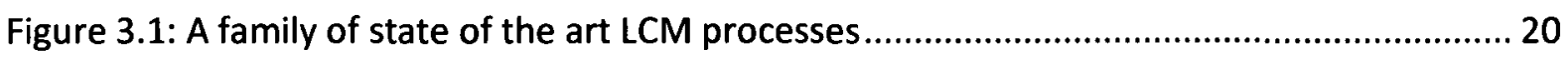

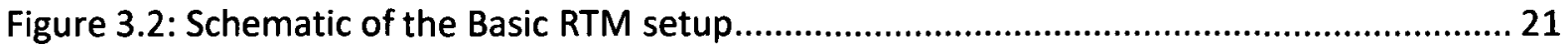

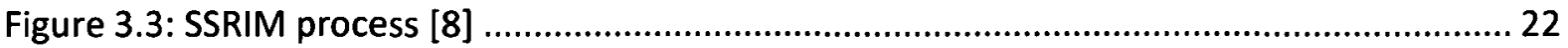

Figure 3.4: Schematic of basic VARTM process ................................................................ 23

Figure 3.5: Schematic of the EADS VAP ${ }^{\circledR}$ before (top) and after (bottom) infusion [10] ............ 26

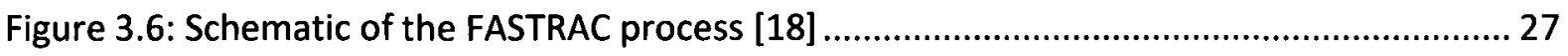

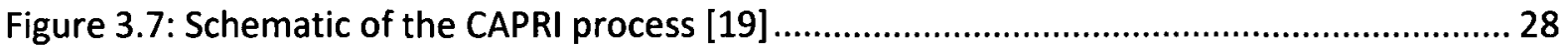

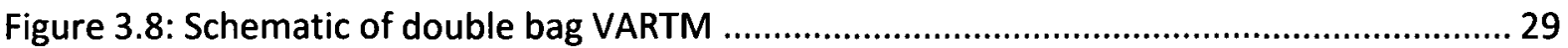

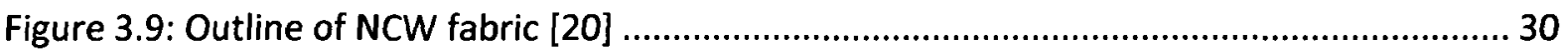

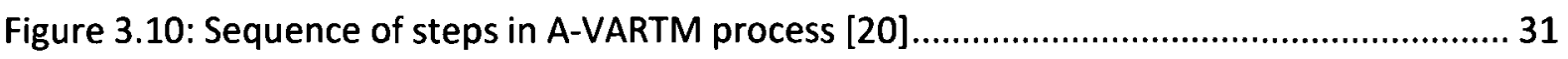

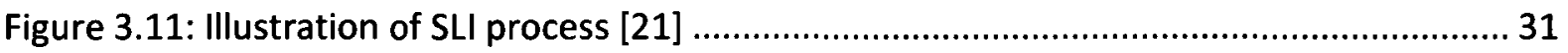

Figure 3.12: Pressure distribution during and after resin injection in SLI process [21] .............. 32

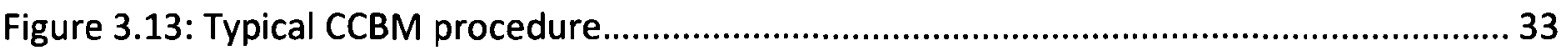

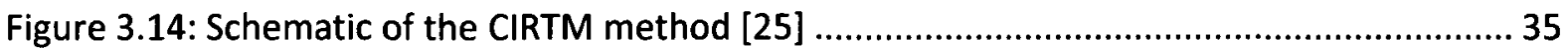

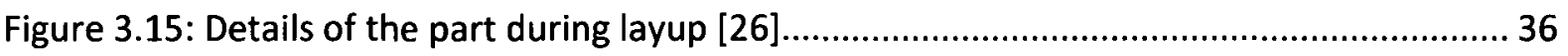

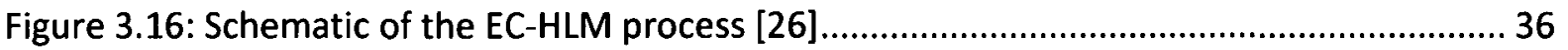

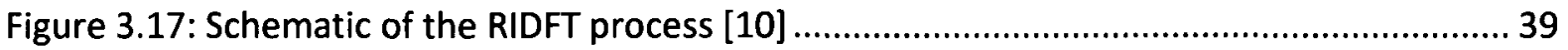

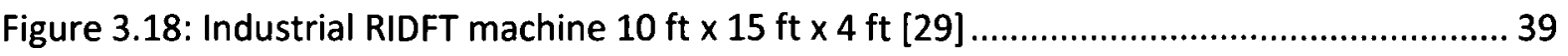

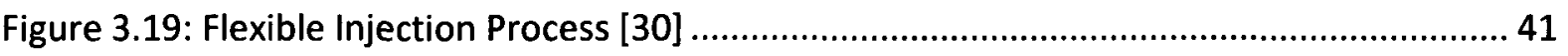

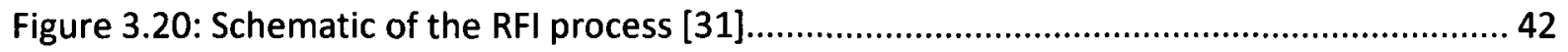

Figure 3.21: A part bagged with disposable vacuum bag [32] .............................................. 45 
Figure 4.1: Common reusable seal configuration for CCBM .............................................. 47

Figure 4.2: Components of Arctek CCBM system [35] .................................................... 49

Figure 4.3: CCBM bag manufacturing trial \#1: tool setup ..............................................50

Figure 4.4: CCBM bag manufacturing: trial \#1 results .......................................................50

Figure 4.5: CCBM bag manufacturing trial \#2: tool setup .................................................. 51

Figure 4.6: CCBM bag manufacturing: trial \#2 results ......................................................5 52

Figure 4.7: Sample CCBM bag section with resin distribution channels ................................. 52

Figure 4.8: Flow profiles of CIB method (a) and disposable distribution media (b).................. 53

Figure 4.9: Cost of the fuselage for increasing part count at labour rate of $20 \$ / \mathrm{hr} \ldots \ldots \ldots \ldots . . . . . . .56$

Figure 4.10: Cost of the fuselage for increasing part count at labour rate of $40 \$ / \mathrm{hr} . . . \ldots \ldots \ldots . . . .57$

Figure 5.1: Sandwich beam subjected to three point bend ................................................. 58

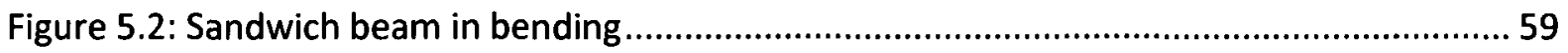

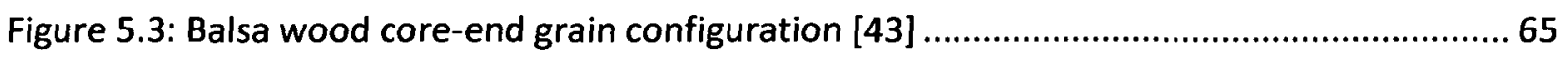

Figure 5.4: Comparison of the selected foam materials at $4 \mathrm{lbs} / \mathrm{ft}^{3}$ density ............................68

Figure 5.5: Comparison of inserts for sandwich assembly ................................................. 71

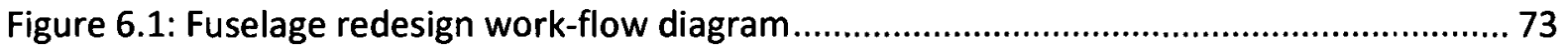

Figure 6.2: Current and the new fuselage wall design (units: in.) ........................................ 74

Figure 6.3: Current and the new bolted sandwich assembly .............................................. 75

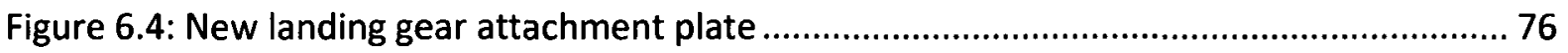

Figure 6.5: Current and the new landing gear configurations............................................. 76

Figure 6.6: Fuselage wall straight section extension ...................................................... 77

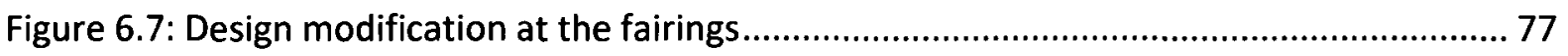

Figure 6.8: Increased core thickness at the locations of the fasteners .................................. 78

Figure 6.9: Core extension to mount the nosecone .......................................................... 78

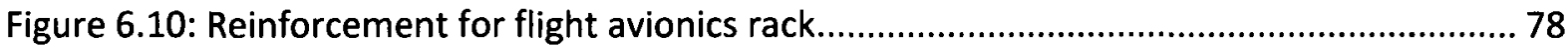

Figure 6.11: Current and the Modified fuselage concept models........................................ 79

Figure 7.1: Parts modelled for the fuselage FEA ............................................................. 81

Figure 7.2: Partitions created on the fuselage skin for meshing ........................................ 88

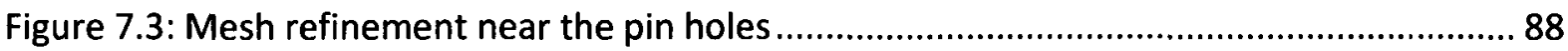

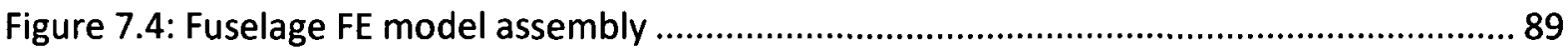

Figure 7.5: Tie constraints established between the pins and the fuselage structure .............. 90 


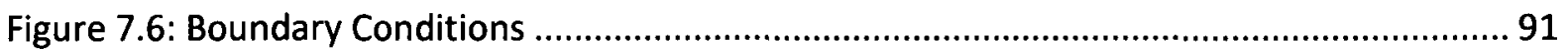

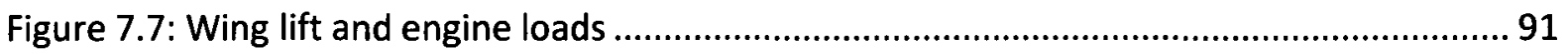

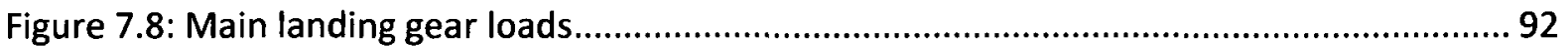

Figure 7.9: Mission avionics and nose landing gear loads................................................ 92

Figure 7.10: Substructure model used for parametric study ............................................... 93

Figure 7.11: Mesh refinement: parametric study level 1 to level 12 .................................. 94

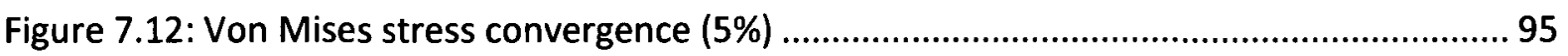

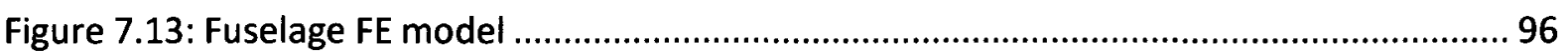

Figure 7.14: Optimized foam core for the new fuselage ................................................. 97

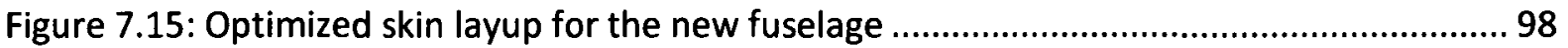

Figure 7.16: Von Mises (left) and in-plane shear (right) stresses (psi) in the skin under flight

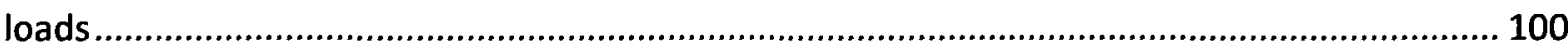

Figure 7.17: Von Mises stresses (psi) in the skin during the landing step............................. 101

Figure 7.18: Shear stresses (psi) in the skin under landing loads ........................................ 101

Figure 7.19: Loading modes chosen for experiments..................................................... 102

Figure 7.20: Geometry of the sandwich specimen ........................................................... 104

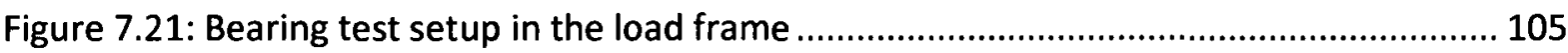

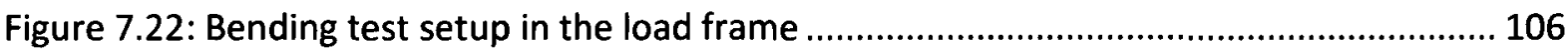

Figure 7.23: Abaqus model showing the loads and boundary condition of the specimens ..... 107

Figure 7.24: Abaqus FE model of the test specimens........................................................ 107

Figure 7.25: Bearing test: force-displacement data ......................................................... 109

Figure 7.26: Comparison of the failure loads in bearing test ............................................... 110

Figure 7.27: Close-up of the bearing failure mode ............................................................. 110

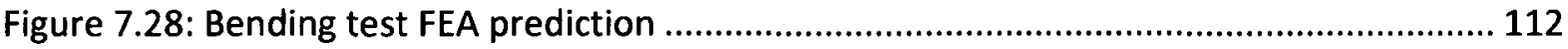

Figure 7.29: Bending test: force-displacement data ..................................................... 112

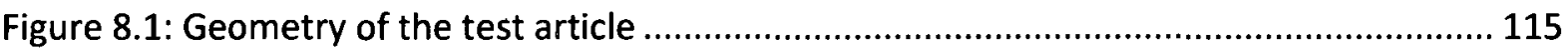

Figure 8.2: Important features of mouldless CCBM setup ................................................. 116

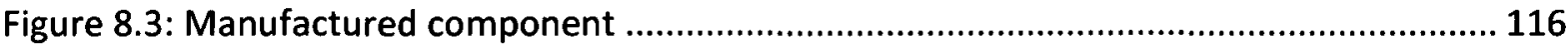

Figure 8.4: Bondline comparison of VARTM and CCBM manufactured sandwich coupons ...... 117

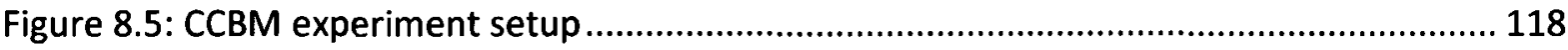

Figure 8.6: Conceptual CCBM Manufacturing Model....................................................... 120 


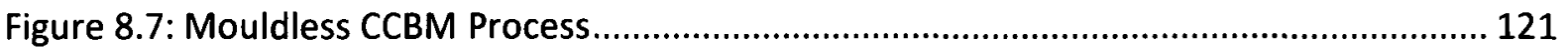

Figure 8.8: Machining of the foam parts on the CNC router table...................................... 122

Figure 8.9: Foam parts required for fuselage manufacturing ........................................... 123

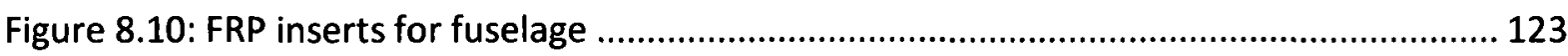

Figure 8.11: Bonding of foam parts in the fixture ....................................................... 124

Figure 8.12: Features included in the foam parts to facilitate precise assembly..................... 124

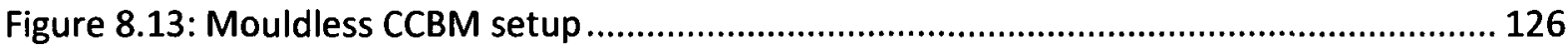

Figure 8.14: Resin starved regions observed during the infusion .................................... 127

Figure 9.1: Fuselage Manufactured by mouldless CCBM .................................................... 128

Figure 9.2: Revised PVA cost estimates based on actual labour required for fuselage

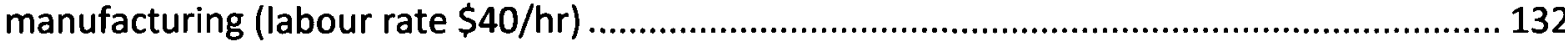




\section{CHAPTER 1. INTRODUCTION}

This chapter provides an overview of the ongoing low-cost composite airframe research at Carleton University. The structural demonstrator used in this research, the GeoSurv II Unmanned Aircraft System (UAS) is also discussed. The thesis objectives are outlined, followed by the procedure utilized to accomplish the objectives and the thesis contributions.

\subsection{Background}

Sandwich construction has been used in primary and secondary aircraft structures for many years. It consists of thin face-sheets or skins adhesively bonded to both surfaces of a relatively thick, low density core material. This leads to increased strength and stiffness for little added weight. A properly designed sandwich construction also offers many other advantages such as, thermal insulation, impact resistance and noise attenuation $[1,2]$.

For many decades, aluminum and Nomex ${ }^{\circledR}$ honeycomb have been the two most commonly used core materials in aerospace applications; they offer excellent specific strength-to-weight and stiffness-to-weight ratios. However, their open and anisotropic cell structure leads to several problems such as core crushing during shaping, curing or when subjected to lateral forces. Honeycomb based sandwich components also exhibit extensive moisture ingress and consequent corrosion, which lead to component service restrictions as well as increased life cycle costs. Additionally, processing of honeycomb sandwich components typically requires expensive autoclaves and the use of pre-impregnated composite fabrics (prepregs) [2].

Various foam and balsa core technologies have successfully addressed some of these issues at much lower costs, with their closed cells and chemically resistant constructions. The 
development of out-of-autoclave Liquid Composite Moulding (LCM) processes further enhances the cost savings, making sandwich construction an economical solution for many structural applications $[3,4]$.

Developing low cost manufacturing methods without sacrificing part quality, repeatability and performance, is always in the best interest of aerospace companies, specifically those dealing with small aircraft and UASs for civilian applications. Costs for small aerospace companies can be significantly reduced with the use of low cost manufacturing methods. This was the main driving factor for the inception of low-cost composite airframe research at Carleton University.

\subsection{Overview of the Low-Cost Composite Airframe Research}

Optimizing the design and manufacturing methods to reduce cost has been an ongoing area of research at Carleton University for the past four years. The research addresses one major barrier to widespread use of composite materials in aircraft structures: high material and manufacturing costs. Conventional prepreg layup and autoclave curing methods produce composite parts with optimum fibre volume fraction, low void content and excellent surface finish. However, the prepregs and autoclave infrastructure come with high initial and recurring costs, which are beyond the means of small companies. Hence, the aerospace industry is constantly searching for low cost, out-of-autoclave manufacturing methods capable of producing high quality components. Such manufacturing methods will directly benefit small companies, such as those that deal with general aviation aircraft and UAS $[3,4]$.

The early stages of this research were funded by the Ontario Government, through the Ontario Centre of Excellence (OCE) Interact program and Sander Geophysics Ltd. (SGL). Subsequent 
financial support was also provided by SGL, along with an NSERC Collaborative Research and Development (CRD) grant and support from the National Research Council - Institute of Aerospace Research (NRC-IAR).

The low-cost composite airframe research uses the GeoSurv II UAS as a technology demonstrator, to develop and implement the processes that are capable of producing structural components of varying complexity. GeoSurv II is an excellent demonstrator, due to its relatively small size and lower reliability requirements compared to a manned aircraft.

During the academic years 2006-2008, low cost processing of carbon-epoxy composite components was investigated by Maley [3] and Vacuum Assisted Resin Transfer Moulding (VARTM) was identified to be a suitable process for manufacturing most of the GeoSurv II UAS components. Maley also suggested that manufacturing of sandwich structure components in small quantities could be achieved economically through a single step "mouldless" infusion. This process uses the core material as the mould to fabricate composite sandwich structures, eliminating the material and labour costs associated with mould preparation. Hence, this process can be very beneficial to aerospace companies for producing small aircraft and UASs in low production quantities or for rapid prototyping of geometrically complex sandwich components.

In order to prove the viability of the process, Maley implemented mouldless VARTM on the full scale fuselage section of the GeoSurv II UAS [3]. The outcome showed a need for improvement in the process robustness, repeatability, and tolerances. The following sections provide a brief 
overview of the GeoSurv II UAS followed by the summary of thesis objectives, thesis organization and contributions.

\subsection{Overview of the GeoSurv II UAS}

GeoSurv II is an all-composite UAS, currently being developed at Carleton University as part of a fourth year undergraduate team project in the Department of Mechanical and Aerospace Engineering. It is designed to perform multi-purpose geophysical survey missions including high resolution magnetic surveys that are of particular interest to the industrial partner SGL, an Ottawa based company specializing in airborne geomagnetic, gravimetric and radiometric surveys around the world.

SGL currently flies airborne surveys using conventional manned fixed-wing aircraft and helicopters. A survey mission requires a minimum crew of four people: two pilots, a geophysicist and an aircraft maintenance engineer. The GeoSurv II is designed to be controlled autonomously with an autopilot featuring an on-board obstacle detection and avoidance system. This will enable geophysical surveys to be executed with two operators: a geophysicist and an aircraft maintenance engineer. The autonomous nature of the GeoSurv II will, in future, allow the execution of multiple aircraft operations using a single operator, thereby increasing the quantity of the data collected at reduced operational costs.

The composite airframe design of the GeoSurv II reduces undesirable magnetic noise within near proximity of the magnetometers mounted on the aircraft wing tips. Benefits of composite airframe construction coupled with the GeoSurv II's ability to fly slower and closer to the ground will substantially improve the quality of the acquired data at much lower capital and 
operational costs compared to its manned counterparts. Figure 1.1 shows the current configuration and specifications of the GeoSurv II [3].

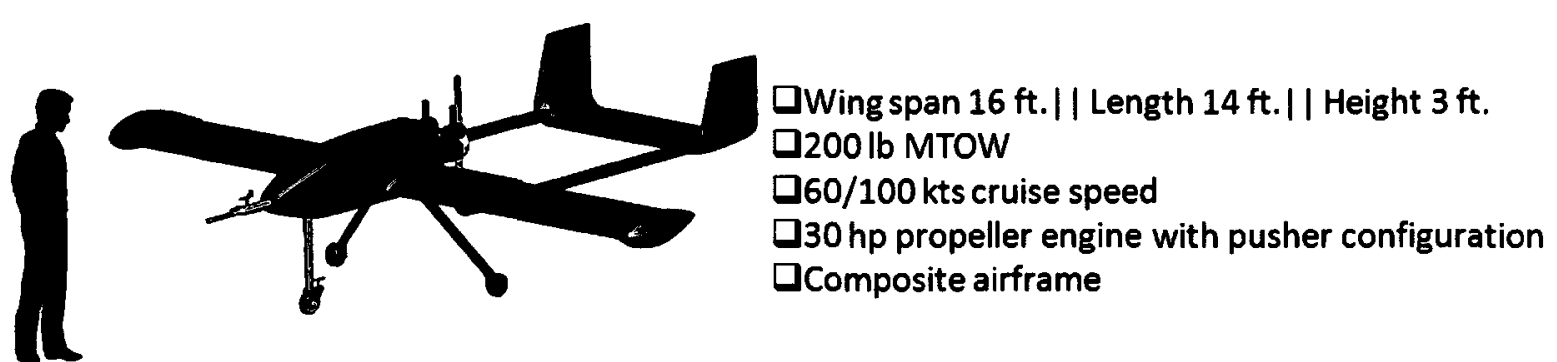

Figure 1.1: Current configuration and specifications of GeoSurv II UAS (2009/2010) [4]

The 2010/2011 academic year is the $7^{\text {th }}$ year of GeoSurv II development at Carleton University. Thus far, most of the design and analysis of GeoSurv II has been completed and a working prototype has been constructed. The prototype (Figure 1.2) is currently being prepared for initial flight testing.

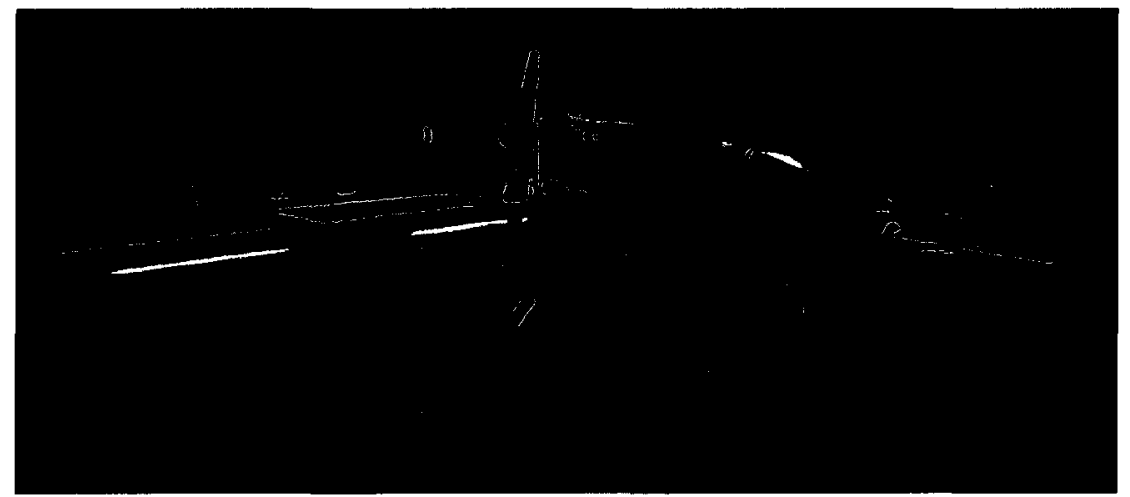

Figure 1.2: GeoSurv II Prototype Assembly (February 2010)

Low-cost composite airframe research is one of five critical areas, which required more advanced graduate level research during the course of the GeoSurv II development. Other graduate research topics include autonomous operation, obstacle detection and avoidance, flight control actuating systems with low magnetic signature and geomagnetic data acquisition. 


\subsection{Thesis Objectives and Organization}

This thesis work focuses on the design and manufacturing of geometrically complex, foam-core composite sandwich structures, by means of "mouldless" LCM method. The thesis objective is to develop a robust, low-cost mouldless LCM method for foam-core composite sandwich structures and utilize the method to manufacture a full scale GeoSurv II fuselage.

In this work, the design of GeoSurv II fuselage and previously implemented mouldless VARTM methods were studied to identify critical areas that require improvement. Based on this study, design and manufacturing objectives were proposed for the next generation fuselage. Then, state-of-the-art LCM processes found in literature were reviewed, which identified Closed Cavity Bag Moulding (CCBM) as a potential alternative to VARTM for mouldless manufacturing. A series of experiments was carried out using CCBM process to evaluate its feasibility for mouldless manufacturing, including investigations of various bag sealing and resin distribution methods. Feasibility of CCBM for mouldless manufacturing was assessed through a Process Value Analysis (PVA). Appropriate materials were selected for fuselage manufacturing through the mouldless CCBM method. Subsequently, the fuselage was redesigned for improved manufacturability. The new design was optimized using a Finite Element Analysis (FEA) implemented in Abaqus. The FEA predictions were verified by testing demonstrator coupons at specific loading conditions. Finally, a full scale GeoSurv II fuselage was manufactured to demonstrate the viability of the developed process. 
This work is organized into the following chapters:

Chapter 2: Overview of the GeoSurv II Fuselage

The design of the GeoSurv II fuselage is discussed. A mouldless VARTM method previously implemented on the fuselage prototype is presented. A post-process assessment is also provided in conjunction with the design and manufacturing objectives for the new fuselage.

\section{Chapter 3: Review of LCM Processes}

A summary of the available LCM technologies is presented. Various low cost LCM processes are assessed to select the most suitable process for mouldless manufacturing.

\section{Chapter 4: Mouldless CCBM Process Development}

A series of experiments carried out using the chosen CCBM method from Chapter 1 are discussed. Various bag sealing methods and infusion strategies are evaluated to determine the feasibility of CCBM for mouldless manufacturing. Finally, PVA carried out to determine the most feasible mouldless manufacturing method is presented.

\section{$>$ Chapter 5: Fuselage Material Selection}

State-of-the-art structural sandwich core materials are discussed and suitable core material for mouldless manufacturing is selected. Material choices for the matrix, reinforcement and inserts are also presented along with the rationale for selection.

\section{Chapter 6: Fuselage Redesign}

The design changes made to the GeoSurv II fuselage to improve its manufacturability are described. An improved GeoSurv II fuselage model is presented.

\section{$>$ Chapter 7: Design Optimization}

An FEA carried out on the new fuselage design, to optimize the composite layup is discussed. A weight estimate for the optimized structure is provided. Finally, an experimental verification of the FEA results using demonstrator test coupons is presented.

$>$ Chapter 8: Fuselage Manufacturing

Manufacturing of a full scale GeoSurv II fuselage by an improved mouldless CCBM method is discussed.

\section{Chapter 9: Manufacturing Results}

The outcomes of the fuselage manufacturing by mouldless CCBM method are discussed. The results are assessed against the design and manufacturing goals.

\section{Chapter 10: Conclusions}

Conclusions drawn from this research work are summarized. Recommendations and future work are discussed. 


\subsection{Contributions}

In this research, state-of-the-art LCM processes currently used for manufacturing composite components were studied and the processes applicable for mouldless manufacturing were identified. An in-depth assessment of the applicable processes showed that CCBM should be considered further for mouldless manufacturing.

CCBM is a relatively new process, currently popular in the marine industry. This resin infusion process uses silicone based elastomeric vacuum bags that are form-fitted to the shape of the part. CCBM infusion offers good vacuum integrity and better surface finish compared to traditional VARTM infusion using disposable vacuum bags. However, current CCBM methods are intended to be used for manufacturing with rigid moulds and hence can be expensive at the outset [4]. As part of this research, a series of experiments were carried out to develop CCBM techniques suitable for mouldless manufacturing. A PVA was used to assess the process variants and select the most suitable technique (section 4.3 ) for mouldless manufacturing. This research laid the foundation for further development of mouldless CCBM methods.

The use of Design for Manufacturing (DFM) principles and FEA for continuous design improvement was demonstrated. An effective methodology for creating bolted joints in foam core composite sandwich structures was developed and demonstrated.

DFM principles were applied to improve the manufacturability of the GeoSurv II fuselage. The new design was optimized using a simplified FEA carried out using Abaqus. An experimental study was conducted to verify selected FEA results. Approximately $36 \%$ weight savings were 
achieved with this design optimization work. The Abaqus FE model of the fuselage can later be expanded to include more realistic material property formulations and dynamic loading.

This thesis has contributed to the development of a unique mouldless manufacturing technique for foam-core composite components, using an improved CCBM method featuring Channel-InBag (CIB) infusion. A full scale GeoSurv II fuselage has been manufactured in a single infusion step, using this mouldless manufacturing method. This is a low cost LCM process suitable for producing complex geometry foam-core composite components with good part quality and process repeatability. The process is economical for part quantities below 10 and hence is beneficial for low to medium volume production runs and prototype development. This manufacturing method should be considered for small aircraft and UASs featuring foam-core composite designs.

This research has successfully addressed the major aspects of low cost composite structures including structural design with material selection, structural optimization, DFM, PVA, manufacturing process planning and development. 


\section{CHAPTER 2. OVERVIEW OF THE GEOSURV II FUSELAGE}

This chapter provides an overview of the GeoSurv II UAS fuselage and describes the mouldless VARTM method previously implemented for manufacturing the first fuselage prototype. A post process assessment is also provided followed by the design and manufacturing objectives for the new fuselage.

\subsection{Design of the GeoSurv II fuselage}

Major components of the current GeoSurv II fuselage assembly are shown in Figure 2.1. It consists of a structural main frame ("H-frame"), upper and lower access hatches, and a nosecone. The access hatches and the nosecone contribute mainly to aerodynamic drag reduction and are subjected to relatively low structural loads, with the exception of the lower access hatch, which carries 20 lbs of geomagnetic survey payload.

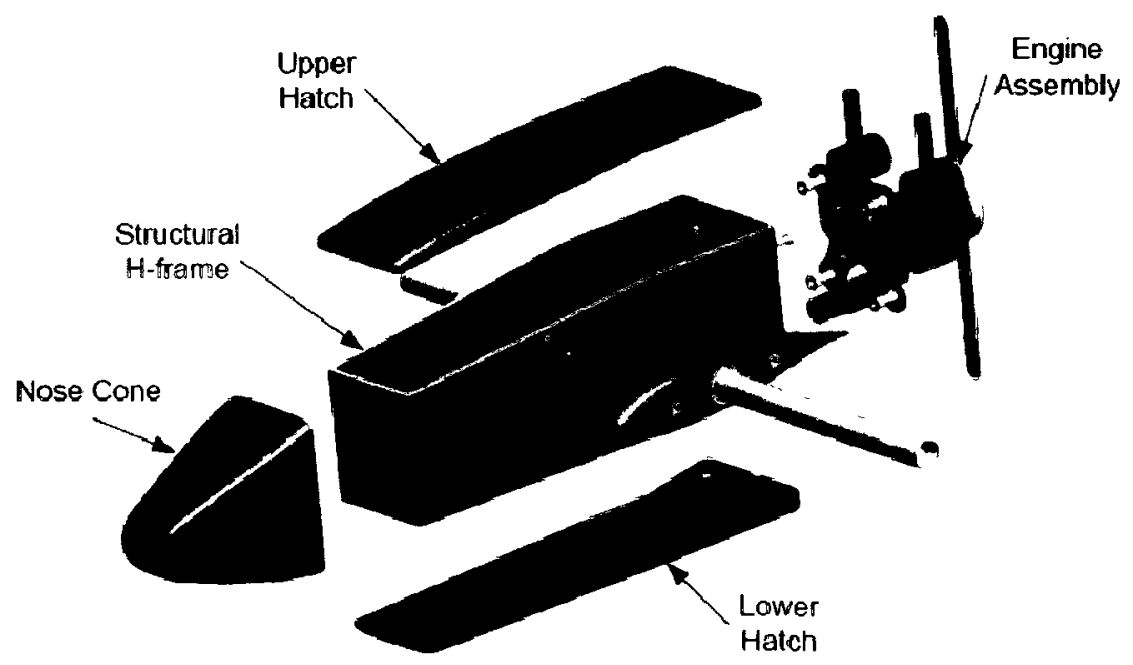

Figure 2.1: Main sections of the GeoSurv II fuselage [3] 
The structural main frame features an " $\mathrm{H}$ " cross-section with foam core carbon-epoxy sandwich construction. Figure 2.2 shows the cross-section of the main frame and highlights critical areas through which the in-flight and the landing loads are transferred into the fuselage. The in-flight bending stresses from the wings are transferred through the carry-through spar, while the aerodynamic moments are transferred through two shear pins located forward and aft of the spar.

The front and rear bulkheads carry the nose landing gear loads and the engine loads respectively. Two bolts directly above the carry-through spar location transfer loads from the main landing gear into the fuselage walls. An airfoil shaped fairing is incorporated in the design to provide smooth transition from the fuselage to the wings and thus minimize interference drag.

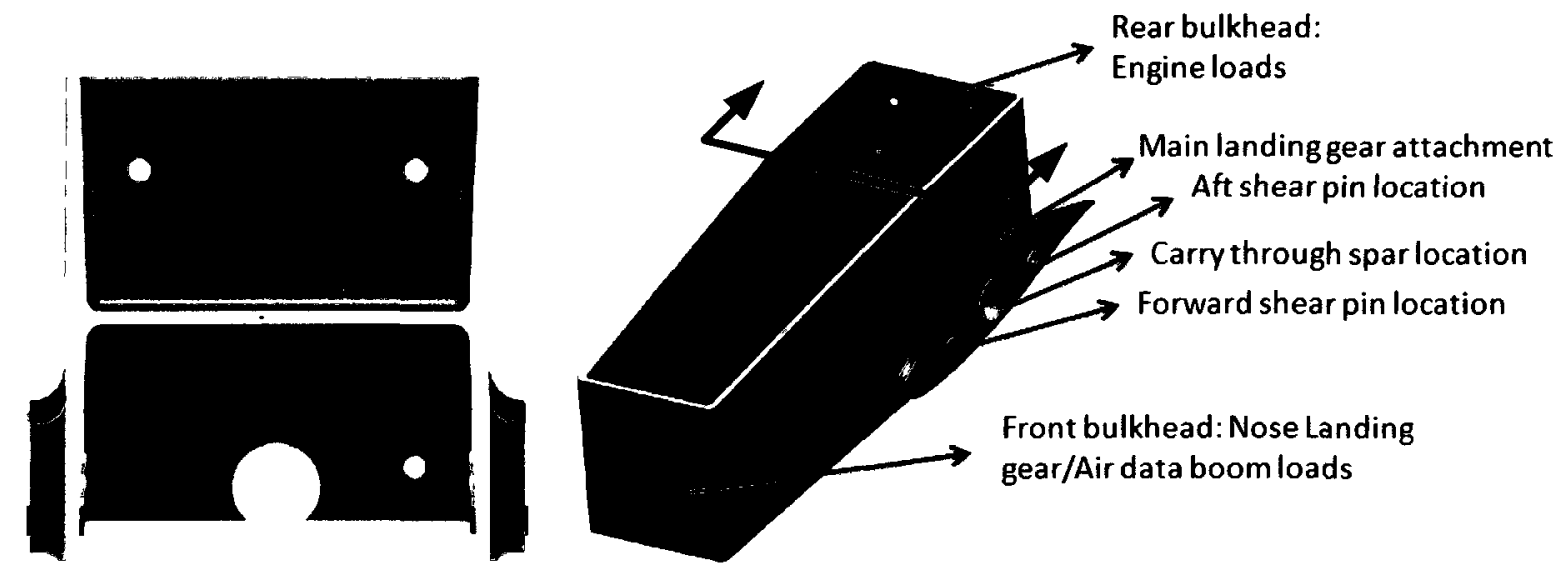

Figure 2.2: Cross-section of the fuselage structural $\mathrm{H}$ frame [3] 


\subsection{Manufacturing of the Fuselage Prototype}

A prototype of the fuselage main frame was manufactured using a mouldless VARTM method developed by Maley [3]. Mouldless VARTM is a low cost processing method applicable for composite sandwich components, in which the foam core is used as the mould during manufacturing. This manufacturing method includes three primary steps: core preparation, fabric layup and infusion, all of which are shown Figure 2.3. In step 1 "Core Preparation", the required components were machined from Extruded Poly Styrene (EPS) insulation foam ${ }^{1}$. These foam components were assembled using Airtac 2 spray adhesive. The foam assembly was then coated with a thin layer of West System 105 epoxy resin and finished with West System 407 (a low density fairing filler), both of which were used to increase the core stiffness. In step 2: "Fabric Layup", the prepared foam component (the core assembly) was laid-up with Hexcel AGP $3705 \mathrm{HS}$ fabric at $\left[(0 / 90)^{0},(+/-45)^{0} \text {, Foam Core }\right]_{\mathrm{SYM}}$ orientation.

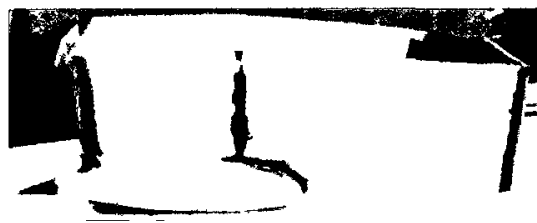

Step 1: Core Preparation

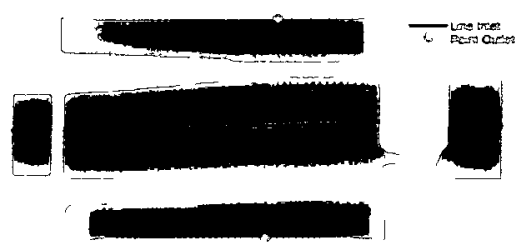

Flow Simulation

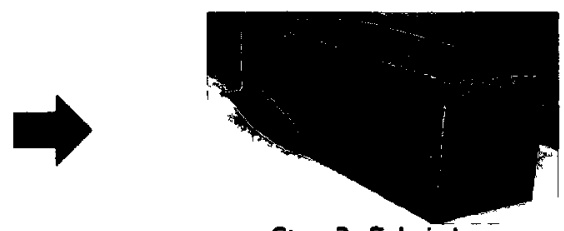

Step 2: Fabric Layup

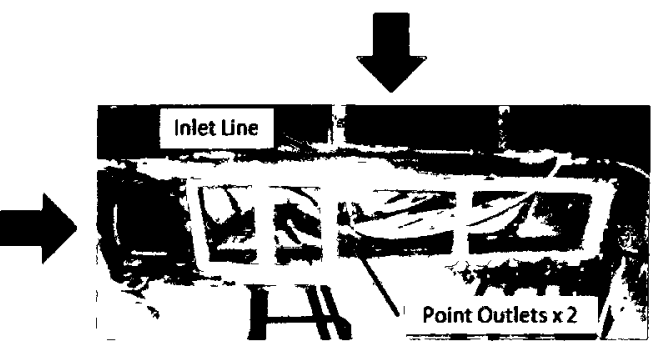

Step 3: Infusion

Figure 2.3: Sequence of the main steps employed in mouldless VARTM

\footnotetext{
${ }^{1}$ EPS (pink) foam was used in the GeoSurv II prototype, primarily to reduce cost. Using an aerospace grade structural core material would aid in better dimensional tolerances and may result in significant weight saving, as it eliminates the need to seal the foam prior to infusion.
} 
In step 3: "Infusion", optimum locations for resin inlets and outlets were determined through the use of Liquid Injection Moulding Simulation (LIMS) software [3]. In this process, 1-D permeability values were first measured for the fuselage layup. These permeability values were used with the LIMS software to simulate the resin flow during infusion. Simulation results were used to determine the optimal locations of both resin inlets and outlets, to improve infusion quality and to reduce infusion time. The infusion setup was prepared with the resin inlet and outlet lines placed at the locations suggested by the flow simulation. The fuselage was then manufactured in a single infusion step. A detailed description of this process simulation and manufacturing method can be found in [3].

\subsection{Post Process Assessment of the GeoSurv II Fuselage}

The prototype fuselage manufactured by mouldless VARTM, is shown in Figure 2.4. One of the major problems encountered was the occurrence of vacuum bag leaks during resin infusion. The leaks resulted in small air pockets at the corners of the cured fuselage. Furthermore, the foam core was distorted under the applied vacuum pressure, leading to an average deviation from flatness of 0.15 in. over the side wall (length: 44 in.) and up to 0.31 in. deviation from the target dimension at several locations [3]. The manufactured component was sanded and filled to reduce the dimensional variations and improve the surface finish. The access hatches and several other components that interface with the fuselage main frame were modified to mate with the distorted shape of the as-manufactured fuselage. Additionally, extensive labour was required to complete the fuselage assembly, shown in Figure 2.5. This included drilling holes and bonding rigid inserts into the holes to facilitate load transfer into the structure at various joints, manufacturing and bonding of the nose cone bridges, bay separator panel and mounting 
brackets for the mission avionics rack. Thus, the cost of labour required to carry the fuselage into a finished stage outweighed the economic advantages of mouldless VARTM. This indicated a need for improvement to both the structural design and the manufacturing process.

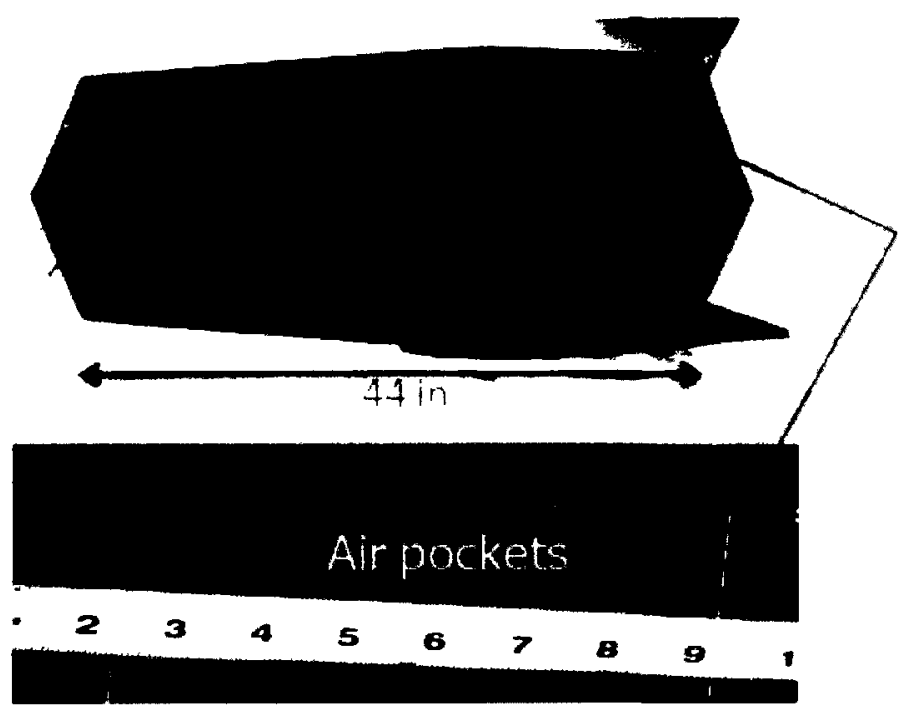

Figure 2.4: Fuselage main frame manufactured by mouldless VARTM

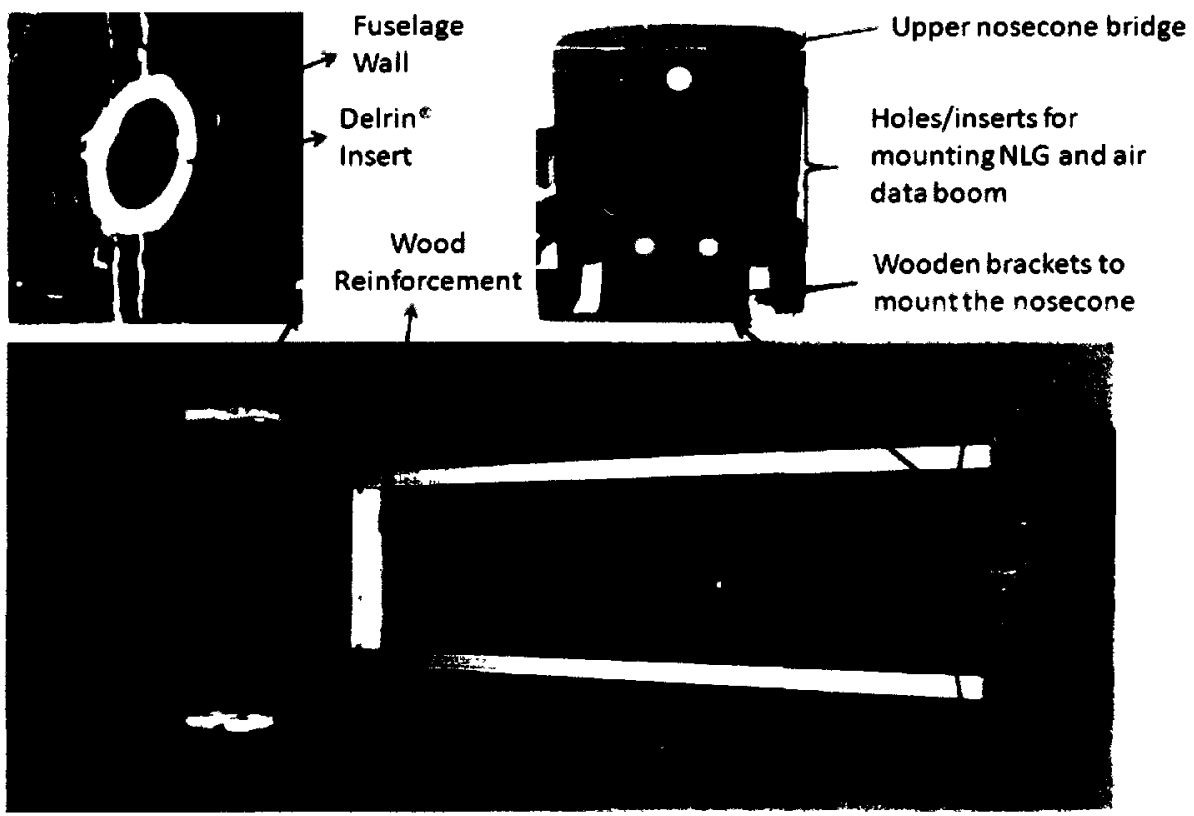

Figure 2.5: Fuselage prepared for assembly 


\subsection{Design and Manufacturing Objectives for the New Fuselage}

Enhanced with the appropriate selection of new materials and an improved processing method, the new fuselage shall replace the prototype in its present configuration. The new fuselage shall be manufactured using a low-cost, mouldless LCM method. The manufactured component shall comply with the GeoSurv II airframe requirements, listed in Table 2.1. The design and manufacturing objectives of the new fuselage are given in Table 2.2. The work-flow involved in the development of the new fuselage is shown in Figure 2.6.

Table 2.1: Airframe requirements for the GeoSurv II UAS [5]

\section{GeoSurv II UAS Airframe Requirements}

Materials used in the primary and secondary structures shall be non-ferrous to the greatest extent possible, to minimize magnetic noise.

$>$ Light weight modular airframe.

$>$ The structure shall be robust and relatively inexpensive to manufacture and maintain.

$>$ The UAS should operate within a temperature range of -49 to $104^{\circ} \mathrm{F}\left(-45\right.$ to $\left.40{ }^{\circ} \mathrm{C}\right)$

$>$ The UAS airframe should comply with Canadian Aviation Regulation, Part V, 523-VLA (Very Light Aircraft): Fire/smoke resistance, moisture, chemical corrosion resistance.

Table 2.2: Design and manufacturing objectives for the new fuselage

\begin{tabular}{|c|c|}
\hline Re-design Objectives & Manufacturing Objectives \\
\hline $\begin{array}{l}\text { Improve the design to reduce weight and } \\
\text { increase structural integrity. }\end{array}$ & $\begin{array}{l}\text { Improve part quality and tolerances (near-net } \\
\text { shape manufacturing). }\end{array}$ \\
\hline $\begin{array}{l}\text { Apply effective Design for Manufacturing } \\
\text { (DFM) and Integrated Manufacturing (IM) } \\
\text { principles to facilitate near-net-shape } \\
\text { manufacturing by mouldless LCM method. }\end{array}$ & Improve process repeatability. \\
\hline
\end{tabular}

Note: The first prototype of the GeoSurv II fuselage developed by Maley [3] is referred to as the current fuselage, and the fuselage developed as part of this research is referred to as the new fuselage throughout the rest of this thesis. 


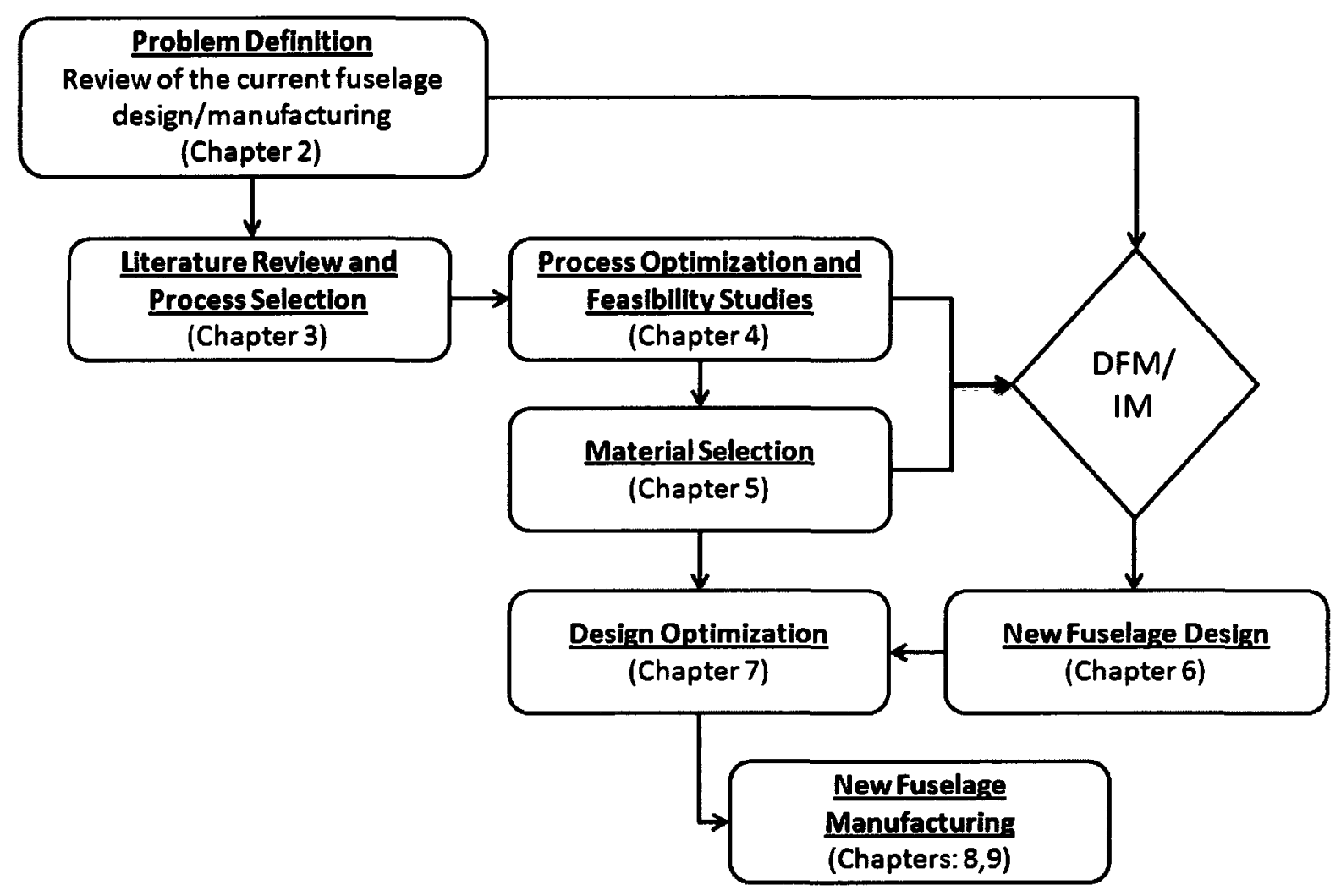

Figure 2.6: Work-flow diagram of the new fuselage development 


\section{CHAPTER 3. REVIEW OF LCM PROCESSES}

This chapter provides an introduction to LCM processes and discusses several LCM variants used in the industry, for manufacturing composite components. Following the review, low cost LCM processes applicable for mouldless manufacturing were assessed to identify the most suitable process.

\subsection{LCM Processes}

LCM refers to a family of processes, in which dry fibrous reinforcement materials placed in a mould cavity are impregnated with a liquid polymer matrix (typically thermoset resins) under a forcing pressure gradient (vacuum pressure, positive pressure or both). The resin is then allowed to cure; the part is demoulded and subjected to finishing operations as required, to create the final product. LCM processes can be implemented using many low-cost tooling and part constituents for a wide range of part size, complexity and production quantity. Characterized by a closed mould setup, LCM processes further offer an operator-friendly manufacturing environment, good fibre orientation control and improved process repeatability. Along with these benefits there exist some inevitable drawbacks, such as relatively complex processing steps and difficult quality control with in-house resin mixing [6-9]. The potential advantages and disadvantages of LCM processes compared to other traditional composite manufacturing methods are summarized in Table 3.1. 
Table 3.1: Potential advantages of disadvantages of LCM processes [6-10]

\begin{tabular}{|c|c|}
\hline Advantages & Disadvantages \\
\hline $\begin{array}{l}\text { Low material, initial equipment and recurring } \\
\text { costs compared to prepreg-autoclave method } \\
\text { Many material choices for reinforcement, } \\
\text { matrix and core } \\
>\text { No size restrictions: Integrated manufacturing } \\
\text { of large structural components is possible } \\
>\text { Low cost LCM methods yield more consistent } \\
\text { part quality than wet layup and vacuum } \\
\text { bagging, at similar costs } \\
>\text { Greater flexibility than any other processing } \\
\text { method } \\
>\text { Thick laminates can be processed easier than } \\
\text { with wet layup } \\
>\text { Produced laminates have } \\
\text { microstructure and minimum void content } \\
\text { compared to wet layup } \\
\text { Sandwich constructions can be produced in } \\
\text { single infusion process } \\
\text { Characterized by closed-mould operations, } \\
\text { the LCM methods reduce volatile organic } \\
\text { compounds (VOC) emission from resin by } \\
\text { more than 90\% as compared to open-mould } \\
\text { hand lamination methods }\end{array}$ & $\begin{array}{l}\text { Requirement for relatively complex/different } \\
\text { skills than wet layup } \\
\text { Requirement for resins with low viscosity may } \\
\text { compromise the thermal and mechanical } \\
\text { properties of some polyester/vinyl based } \\
\text { laminates } \\
\text { Low fibre volume fraction compared to } \\
\text { prepreg-autoclave method (Except for RTM } \\
\text { type processes) } \\
\text { Air leaks in the tool or bag and uneven resin } \\
\text { flow may result in resin rich/starved regions } \\
\text { and in turn cause expensive scrap parts } \\
\text { With the exception of RTM type processes } \\
\text { and LRTM, most other LCM processes } \\
\text { produce parts with moulded finish on one } \\
\text { side. } \\
\text { Difficult to implement on the honeycomb } \\
\text { cores }\end{array}$ \\
\hline
\end{tabular}

Attracted by the potential cost savings and process flexibility, manufacturers are increasingly researching and developing LCM techniques for producing their components. This has led to the evolution of many LCM process variants over the last few decades. Despite the complexities associated with specific process variants, all LCM processes share several distinctive features $[7,8]:$

A resin delivery system

$>$ A mould setup equipped with appropriate clamping and manipulation devices

A reinforcement handling system (i.e. fibre preforms, sheet/bulk mounding compounds)

A strategy for air displacement or evacuation and resin supply 
The functionality of these systems is determined by the scale of the part and complexity of the manufacturing operation.

Based on the forcing pressure gradient used to introduce the resin into the mould cavity, the LCM process variants can be grouped into two categories: Resin Transfer Moulding (RTM) and Vacuum Assisted Resin Transfer Moulding (VARTM). The former uses positive pressure to inject the resin into the mould cavity, while the latter uses a negative pressure gradient to draw the resin into the mould cavity. Figure 3.1 shows a family of state of the art LCM processes developed from RTM and VARTM. Unique features of each of these processes are described in the following sections. 
Liquid Composite

Moulding (LCM) Processes
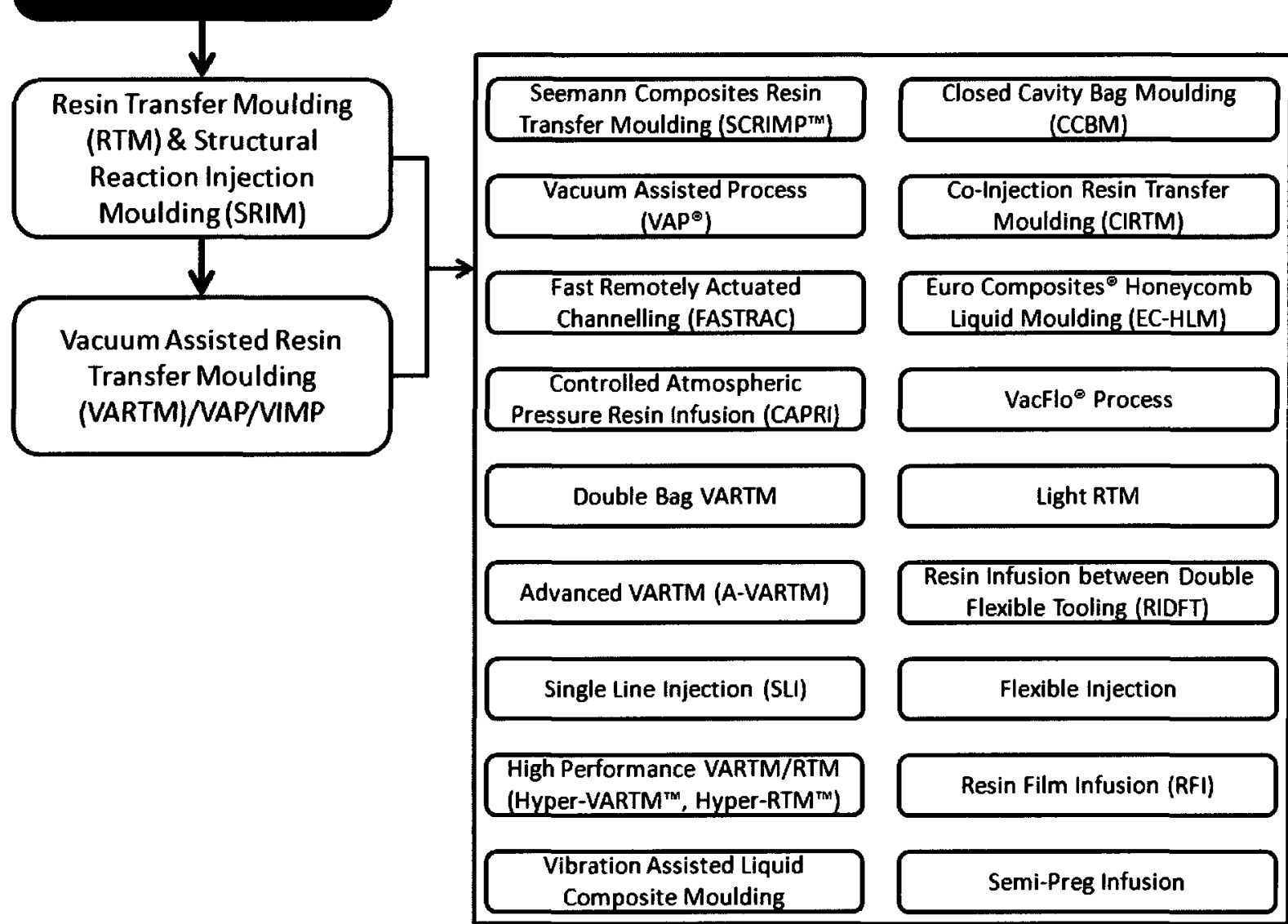

Figure 3.1: A family of state of the art LCM processes

\subsubsection{Resin Transfer Moulding (RTM)}

RTM is best known for its ability to fabricate large, complex parts to near-net shape with excellent surface finish on both sides. A schematic of a basic RTM setup is shown in Figure 3.2 . In this process, dry fibre preform is laid-up into a two part rigid mould, and resin is injected into the mould cavity until the preform is fully saturated. The part is then cured and removed from the mould. RTM produces near autoclave quality parts with void content $<1 \%$, at very short cycle times (typically 3-5 minutes). However, it requires matched, leak proof moulds capable of 
withstanding the injection pressures up to 1500 psi. Designing and manufacturing RTM moulds require high initial costs, making RTM economical for large production quantities, typically above 1000 units $[10,11]$.

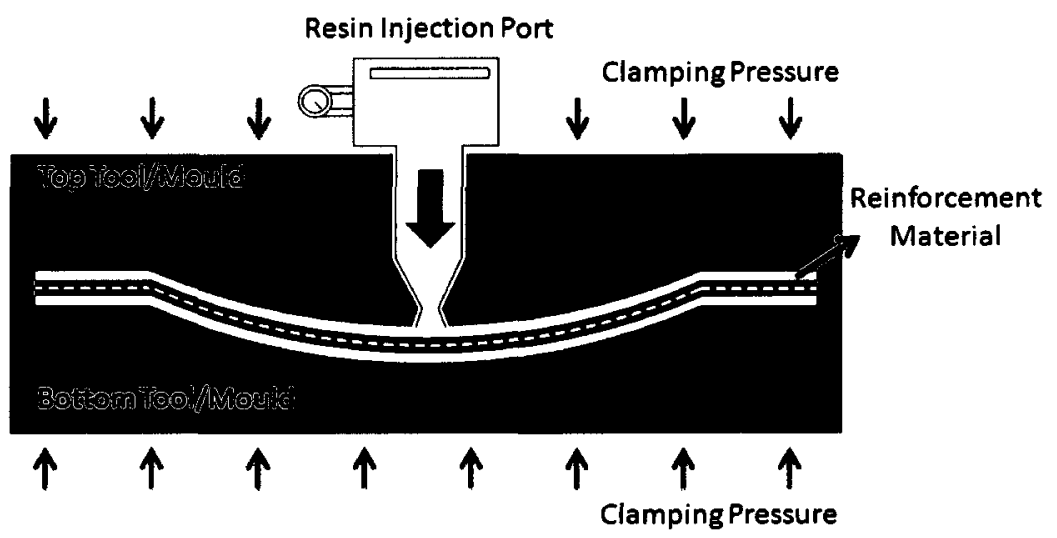

Figure 3.2: Schematic of the Basic RTM setup

\subsubsection{Structural Reaction Injection Moulding (SRIM)}

SRIM is an LCM process evolved from the family of Injection Moulding (IM) processes. IM is a process whereby liquid thermoplastic or partially polymerized thermoset resins are injected into mould cavity to produce non-reinforced polymeric components. This process is typically carried out at elevated temperatures and pressures for rapid part production in large quantities. A further development to IM is the Reaction Injection Moulding (RIM): a process in which two part thermoset resins are mixed and injected into the mould cavity to produce the final part. The processes take their name from the chemical reaction that takes place within the machine [8]. When short fibre reinforcements are included into the RIM, the process is called Reinforced Reaction Injection Moulding (RRIM). SRIM is a further development to RRIM, whereby preformed fibre mat reinforcements are impregnated with liquid resin to produce the 
final part. The sequence of steps employed in SRIM is shown in Figure 3.3. This process is characterized by mould fill times less than 1 minute and pressures greater than 1500 psi.

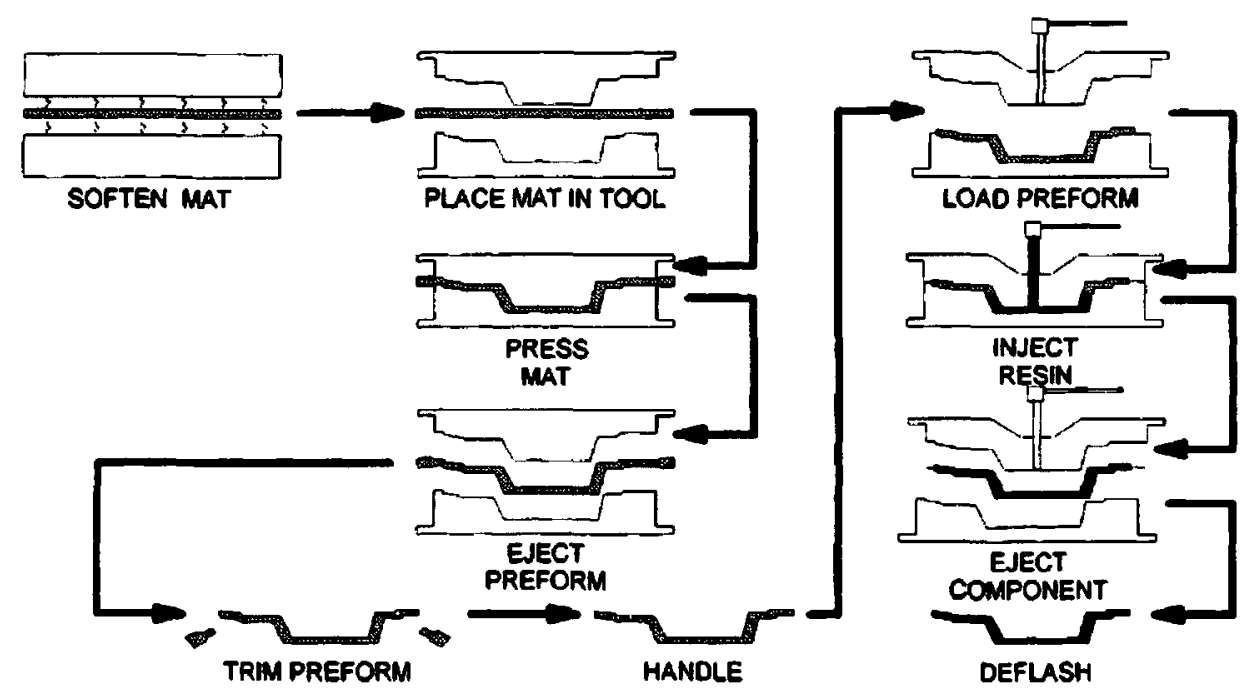

Figure 3.3: SSRIM process [8]

The RTM and SRIM equipments, though relatively inexpensive compared to an autoclave infrastructure, require somewhat high initial costs. Hence, they are efficient for high volume production runs. Since the primary focus of this research is low volume production by LCM process, RTM and its process variants were not studied in detail. Substantial reviews of RTM type processes can be found in references [8-11].

\subsubsection{Vacuum Assisted Resin Transfer Moulding (VARTM)}

The need for an LCM process for economic part production in low production quantities has resulted in the development of Vacuum Assisted Resin Transfer Moulding (VARTM). VARTM is a variation of RTM, in which resin is drawn into the preform under vacuum pressure, rather than being injected at positive pressure. A schematic of the VARTM process is shown in Figure 3.4. 
This process begins with preparation of a rigid mould and layup of dry reinforcement in the mould cavity. Then, a flexible vacuum bag is placed over the reinforcement and is sealed against the mould using sealant tape. A vacuum tight chamber is created inside the bag by connecting the outlet to a vacuum pump. Resin is then introduced into the mould via an inlet, which is typically on the opposite side of the outlet. The reinforcement is impregnated by the resin due to the pressure differential between the inlet and the outlet ports. When the reinforcement is fully impregnated, the resin is left to cure under the vacuum pressure to create the final part. In order to reduce the flow resistance and hence the filling time, a highly permeable distribution medium is introduced between the top layer of the reinforcement and the vacuum bag. During infusion, the resin distribution medium lifts the bag surface away from the preform, leaving a highly permeable path for resin to travel. Resin is distributed preferentially through the surface of the flow media and simultaneously through thickness of the preform $[3,12,13]$.

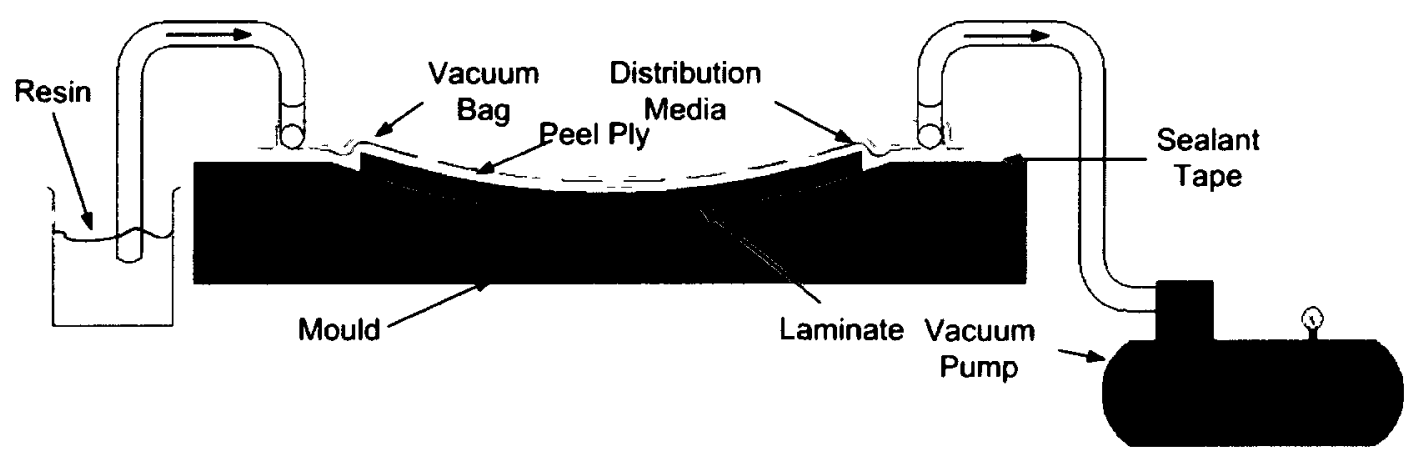

Figure 3.4: Schematic of basic VARTM process

VARTM is a low-cost process capable of manufacturing large-scale complex geometry composite parts with good surface finish and excellent dimensional tolerances. This processing 
method eliminates the need for expensive moulds required by the RTM and allows replacement of the upper mould with a flexible polymeric bag. Hence, VARTM is sometimes referred to as Resin Infusion under Flexible Tooling or RIFT. Other generic terms given for VARTM include Vacuum Infusion (VI), Vacuum Infusion Moulding (VIM) and Vacuum Assisted Resin Infusion Moulding (VARI/VARIM) [6].

Since the development of VARTM processes, researchers and manufacturers have focused on improving the resin infusion characteristics and processing methods to further reduce costs and improve part quality. This has led to the development of many materials and improved VARTM techniques for tooling setup, resin distribution and complete resin impregnation. Some important developments are outlined in Table 3.2. Many others combined new materials with innovative process modifications, while attempting to bring out solutions for existing challenges with conventional VARTM methods. The following sections consider some important VARTM process variants that originated from research and development work carried out worldwide, over the last two decades. 
Table 3.2: New materials and technologies developed to improve VARTM process

\begin{tabular}{|c|c|}
\hline Research Area & New Developments \\
\hline $\begin{array}{l}\text { Matrix/Core/ } \\
\text { Reinforcement } \\
\text { Materials }\end{array}$ & $\begin{array}{l}\text { Matrix: Epoxy, polyester and vinyl-ester resins available with viscosities below } 200 \\
\text { cps and wide range of working times and curing temperatures. Suppliers Include: } \\
\text { PTM\&W Industries Inc.-Epoxy-N-Fusion }{ }^{\circledast} \text {, Gougeon Brothers Inc-West System }{ }^{\circledR}, \text { Tri- } \\
\text { Tex Co. Inc. - East System }{ }^{\circledast}, \text { Polymer Tooling Systems Inc. - RenInfusion }{ }^{\circledR} \text { Epoxies, } \\
\text { Endurance Technologies Inc. -Endurance Epoxy Systems, Applied Poleramics Inc. } \\
\text { Woven Fabric Reinforcement: Carbon, Kevlar, Glass, Aramid or hybrid fabrics } \\
\text { available in different densities and variety of fabric styles for improved drapability. } \\
\text { Reinforcements are also available in roving, mat, knit and 3-D braided forms [6,10]. } \\
\text { Non-Crimp (NC) fabrics with or without tackifiers to facilitate easy layup [6]. } \\
\text { Suppliers of reinforcement materials include The Saertex Group, Metyx Composites, } \\
\text { Hexcel Corporation, Polynova }{ }^{\text {TM }} \text { Composites., Vectorply Corporation, and JB Martin } \\
\text { Variety of core materials available for infusion (Chapter 5). }\end{array}$ \\
\hline $\begin{array}{l}\text { Resin } \\
\text { Distribution }\end{array}$ & 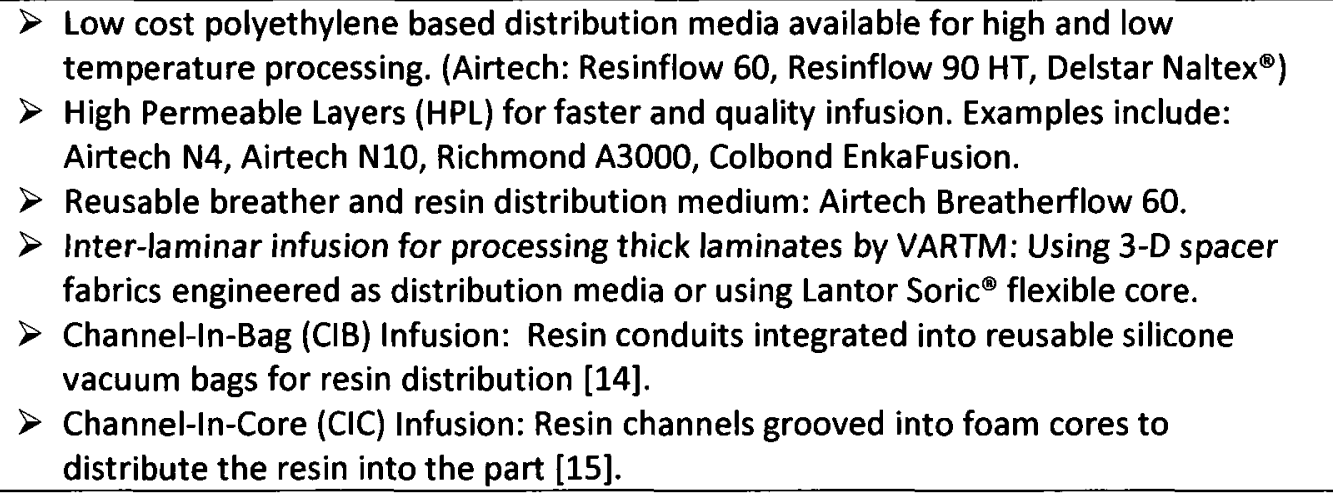 \\
\hline $\begin{array}{l}\text { Flow } \\
\text { Simulation }\end{array}$ & $\begin{array}{l}\text { Liquid Injection Moulding Simulation (LIMS): VARTM/RTM flow simulation software, } \\
\text { developed by the University of Delaware- Centre for Composite Materials. } \\
\text { PAM-RTM } 2004 \text { LCM simulation software: Flow simulation and process optimization } \\
\text { software for RTM and VARTM type processes developed by the ESI Group. } \\
\text { Simulation based Liquid Injection Control (SLIC): A software package that integrates } \\
\text { flow simulation, setup optimization and process automation and control to provide } \\
\text { optimum LCM design and manufacturing solutions; developed at the University of } \\
\text { Delaware- Centre for Composite Materials. } \\
\text { RTM-Worx: Flow simulation software capable of simulating and optimizing } \\
\text { RTM/VARTM type processes, developed and licensed by Polyworx Corporation. }\end{array}$ \\
\hline $\begin{array}{l}\text { Tooling/ } \\
\text { Vacuum } \\
\text { Bagging } \\
\text { Supplies }\end{array}$ & $\begin{array}{l}\text { Disposable/reusable vacuum bags available in various levels of conformability } \\
\left.\text { (i.e. Econolon }{ }^{\circledast}, \text { Stretcholon }{ }^{\circledast}, \text { Multibag}^{\oplus}\right) \text {. } \\
>\text { Peelplies: Polyester or nylon based, available for low and high temperature } \\
\text { processing; silicone or Teflon coated peelplies are also available for easier release. } \\
>\text { Resin infusion lines: Disposable spiral tubing and reusable Omega Flow Lines. } \\
>\text { Spray adhesives for holding fabrics together during layup (i.e. Airtac } 2 \text {, Econotac). } \\
>\text { Airtech Fusiontac: A preform tackifier compatible with polyester/vinyl ester resins } \\
>\text { Airtech TackStrip: An adhesive coated mesh for holding fabrics during layup- This is } \\
\text { an alternative to spray adhesives developed to prevent laminate contamination. } \\
\text { Suppliers of VARTM tooling materials include Airtech International Inc., Aerovac } \\
\text { Systems Inc., Advanced Composite Materials Inc., and Torr Technologies Inc. }\end{array}$ \\
\hline
\end{tabular}




\subsubsection{Seemann Composite Resin Infusion Moulding Process (SCRIMP'M)}

SCRIMP $^{\text {TM }}$ is a VARTM process variant developed in late $1980^{\prime}$ s by Bill Seemann and patented in 1990 by TPI technologies. SCRIMP ${ }^{\text {TM }}$ was developed to reduce infusion times for large and complex parts and thus improve the overall production rate. The sequence of steps involved in SCRIMP ${ }^{\text {TM }}$ is similar to VARTM except that TPI holds the patent for the particular flow media and flow process, thus being able to charge for using this particular infusion method $[3,16]$.

\subsubsection{Vacuum Assisted Process (VAP®)}

The Vacuum Assisted Process (VAP') was developed by EADS Deutschland and is protected by several worldwide patents for low cost manufacturing of primary aircraft structures. This process is characterized by inclusion of an additional Gore Composite Manufacturing (GCM) membrane, to the conventional VARTM setup, as shown in Figure 3.5. The GCM membrane is a selectively permeable material that acts as a barrier to resin but is highly permeable to air.

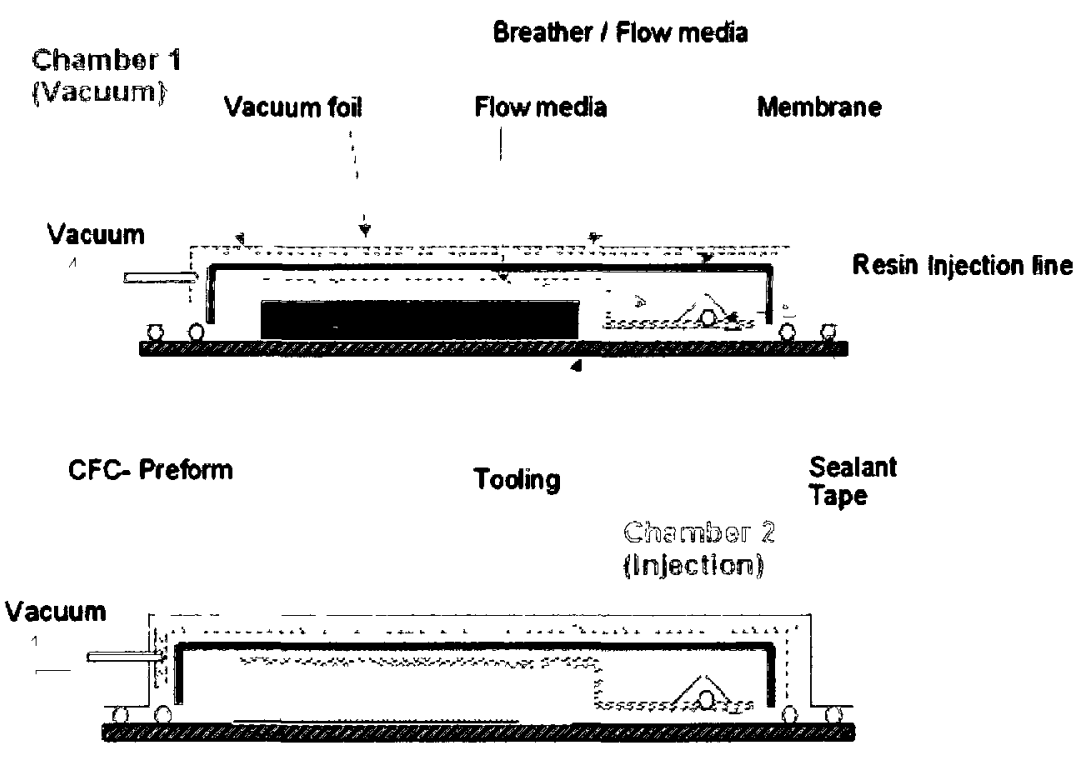

Figure 3.5: Schematic of the EADS VAP® before (top) and after (bottom) infusion [10] 
Adding this membrane over the distribution medium of a conventional VARTM setup leads to application of more uniform vacuum pressure on the laminate throughout the infusion process. This is claimed to result in uniform part thickness, low void content, minimum potential for dry spot formation and improved overall part quality $[10,17]$.

\subsubsection{Fast Remotely Actuated Channelling (FASTRAC)}

The FASTRAC process was first developed at the United States Army Research Laboratory (USARL). Instead of using a flow medium to accelerate the resin flow, this innovative process uses a low cost rigid or flexible tooling in a double vacuum bag setup, in order to create preferential resin flow channels along the part. A basic FASTRAC infusion setup is shown in Figure 3.6.

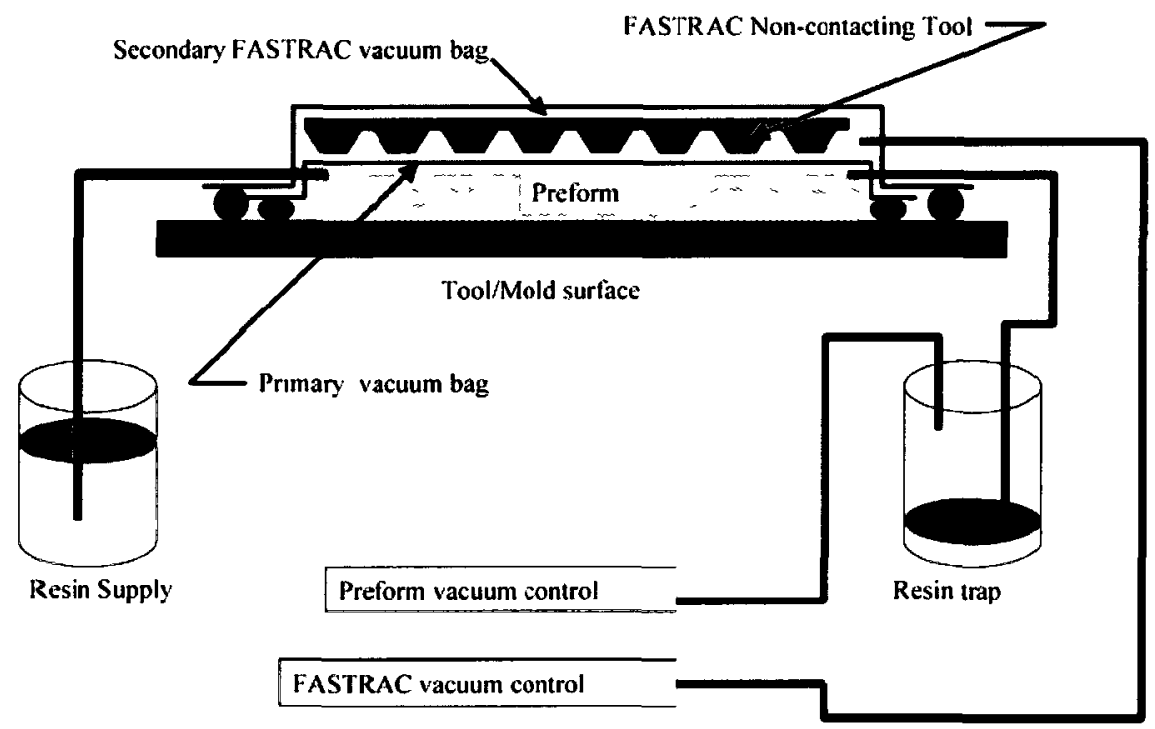

Figure 3.6: Schematic of the FASTRAC process [18]

In this process, the preform is placed under a primary vacuum bag and kept under full vacuum pressure (close to $-30 \mathrm{inHg}$ ). Then a secondary vacuum bag featuring a non-contacting FASTRAC tool is placed over this primary vacuum bag and sealed to the open mould surface. Vacuum is 
drawn inside this secondary vacuum bag to keep the FASTRAC tool under full vacuum pressure.

To create the highly permeable resin channels, vacuum pressure inside the primary vacuum bag is released to relax the bag for a moment and then drawn again to full vacuum pressure. This allows the primary vacuum bag to form into the FASTRAC tool and create highly permeable channels that preferentially distribute the resin over the part. Once the part is fully saturated with resin, the FASTRAC layer can be removed and the part can be cured [18].

\subsubsection{Controlled Atmospheric Pressure Resin Infusion (CAPRI)}

CAPRI is a VARTM process variant developed and patented by the Boeing Corporation. As shown schematically in Figure 3.7, CAPRI process includes two adjustments to conventional VARTM methods, aimed at improving the fibre volume fraction and reducing the thickness gradient of the final part.

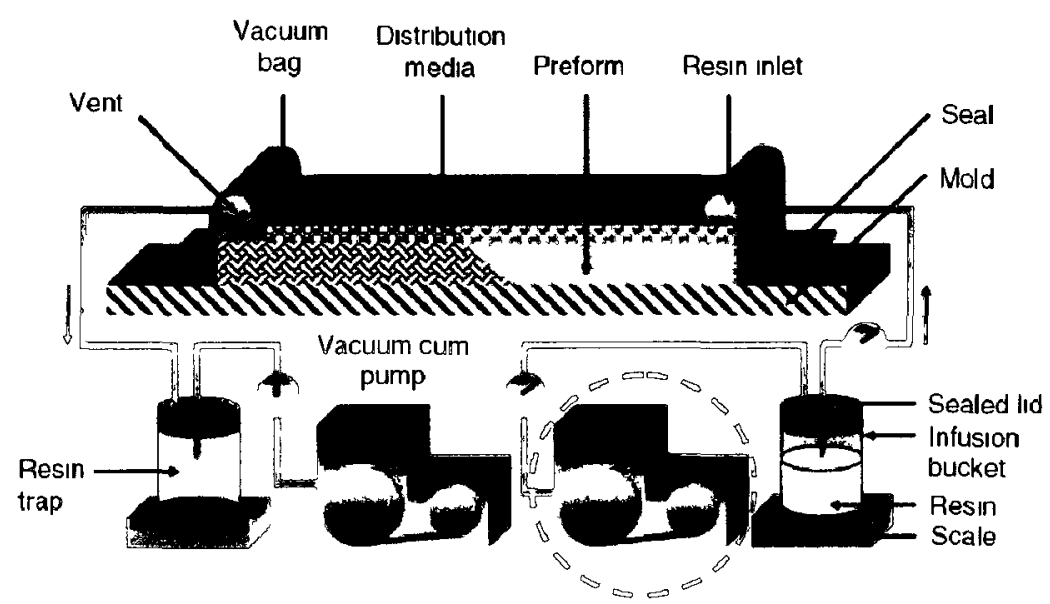

Figure 3.7: Schematic of the CAPRI process [19]

First, the dry preform is subjected to cyclic debulking under vacuum pressure, after bagging but prior to infusion. This is said to improve the fibre nesting, reduce the thickness of the laminate 
and hence, improve the overall fibre volume fraction. Additionally, the infusion bucket containing the resin is kept under partial vacuum using a secondary vacuum pump, while the outlet lines are kept under full vacuum. The partial vacuum applied to the resin chamber, though increasing the process complexity and infusion times, reduces the thickness gradient observed in conventional VARTM processing.

\subsubsection{Double Bag VARTM}

The Double bag VARTM process is an improved version of conventional VARTM developed and patented by the Boeing Company, to solve the bag relaxation and thickness gradient formation associated with conventional VARTM. This process adds a second vacuum bag separated by a layer of breather cloth to the conventional VARTM setup, as shown in Figure 3.8. The second vacuum bag applied around the part acts as a caul plate preventing the inner bag from relaxing behind the flow front. This added bag also restrains the first bag from stretching during and after the infusion, which helps in maintaining the vacuum integrity. The double bagging process is expected to reduce the thickness gradient, improve fibre volume fraction and hence the overall part quality [12].

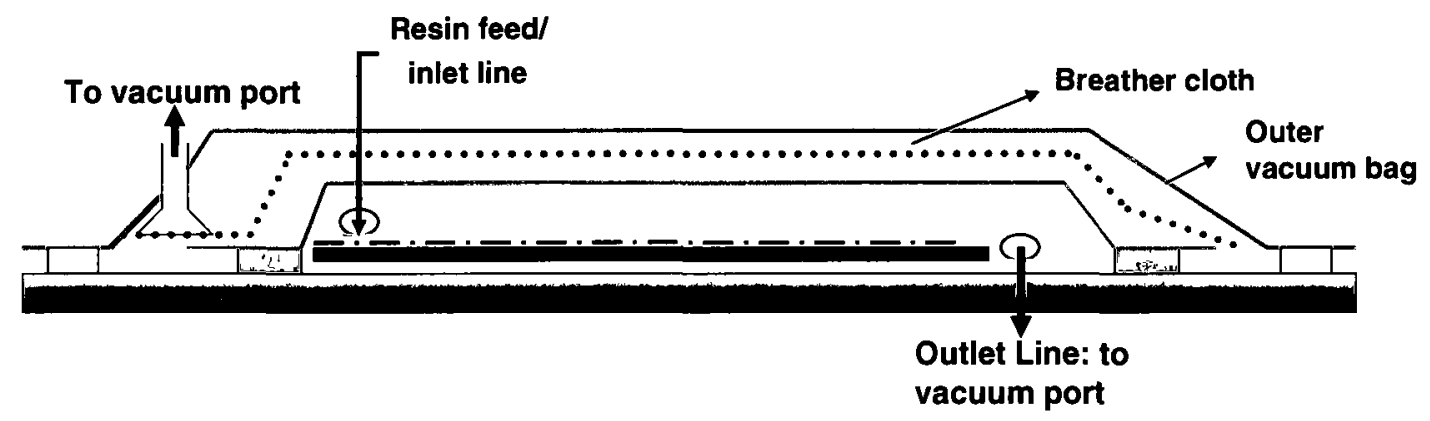

Figure 3.8: Schematic of double bag VARTM 


\subsubsection{Advanced VARTM (A-VARTM)}

The A-VARTM process is a variation of VARTM developed jointly by Mitsubishi Heavy Industries,

Ltd. and Toray Industries, Inc. for fabrication of aircraft primary structures. This process combines traditional VARTM methods with the addition of preform hot-compaction prior to infusion and resin bleed-off after infusion, in order to obtain nearly $60 \%$ fibre volume fraction. Enhanced unidirectional properties are attained with the use of advanced Non-Crimp Woven (NCW) fabrics (Figure 3.9). Primary aircraft structures are manufactured as integral components by applying co-bonding and advanced pre-forming techniques. Figure 3.10 shows an outline of the A-VARTM process [20].
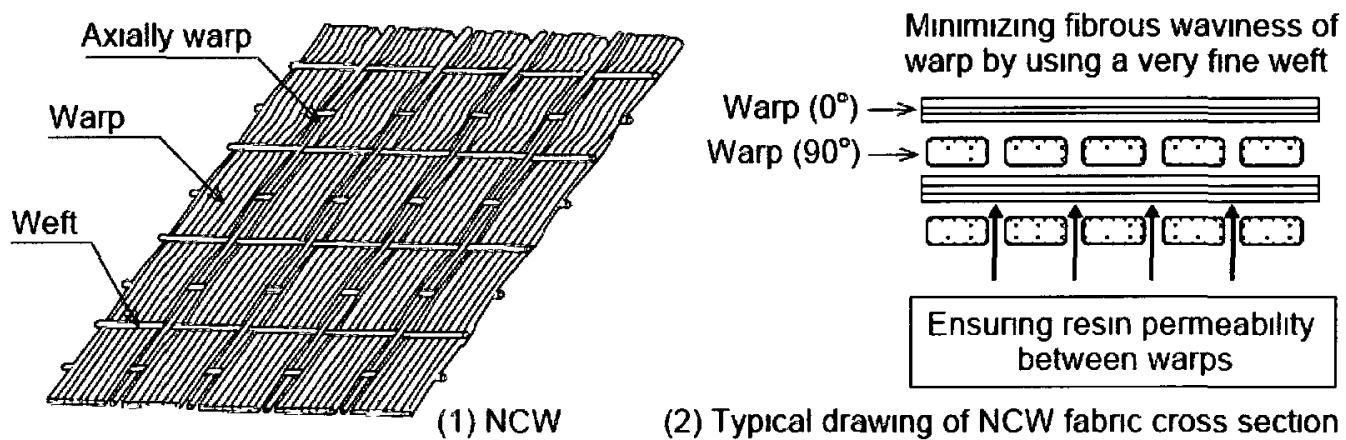

(1) NCW

(2) Typical drawing of NCW fabric cross section that is laminated alternately in $0^{\circ}$ and $90^{\circ}$ directions

Figure 3.9: Outline of NCW fabric [20] 


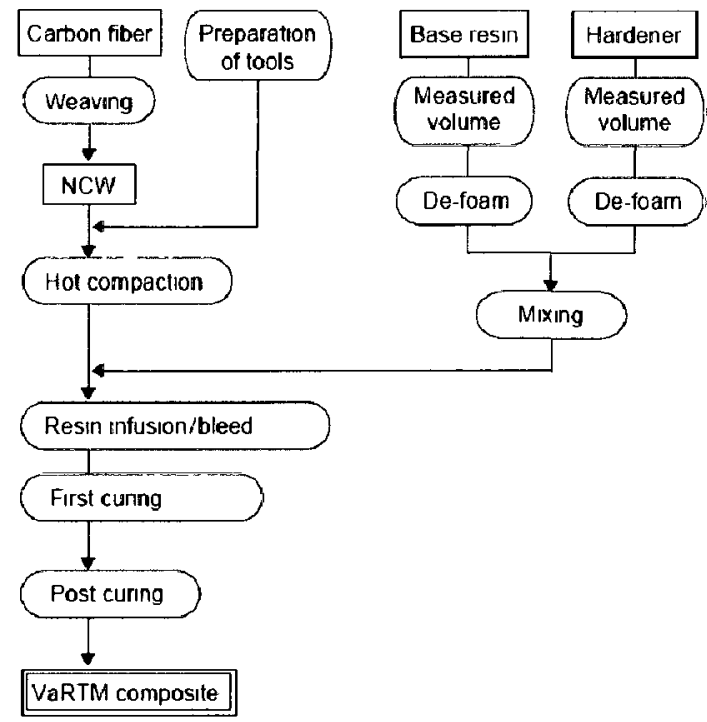

Figure 3.10: Sequence of steps in A-VARTM process [20]

\subsubsection{Single Line Injection (SLI)}

SLI is a cost-optimized Liquid Resin Injection (LRI) process to manufacture high quality composite components in the autoclave. Developed at the German Aerospace Centre (DLR) Institute for Structural Mechanics, the SLI process combines the advantages of the cost efficient materials and liquid resin injection processes to manufacture high quality parts in an autoclave. A schematic illustration of SLI is shown in Figure 3.11 and Figure 3.12.

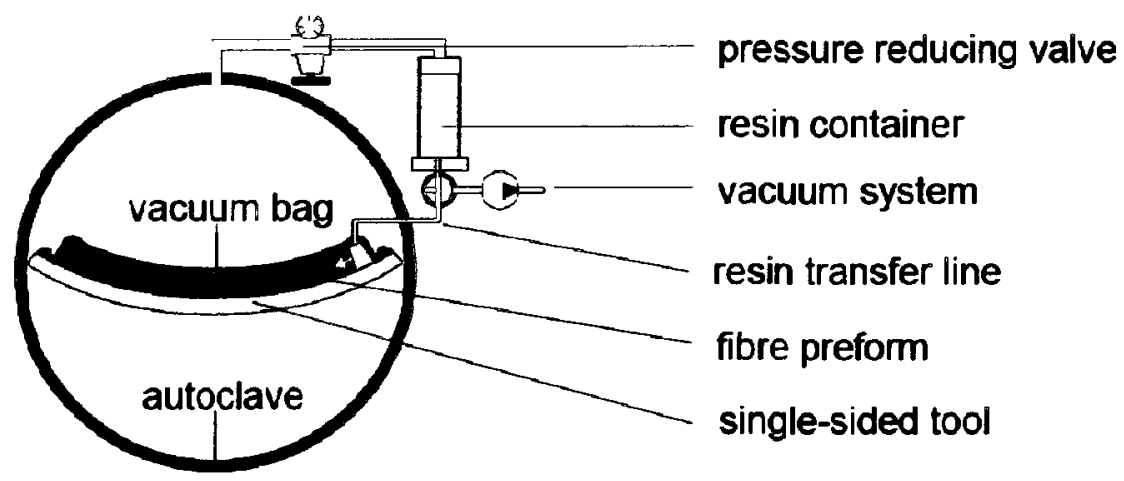

Figure 3.11: Illustration of SLI process [21] 


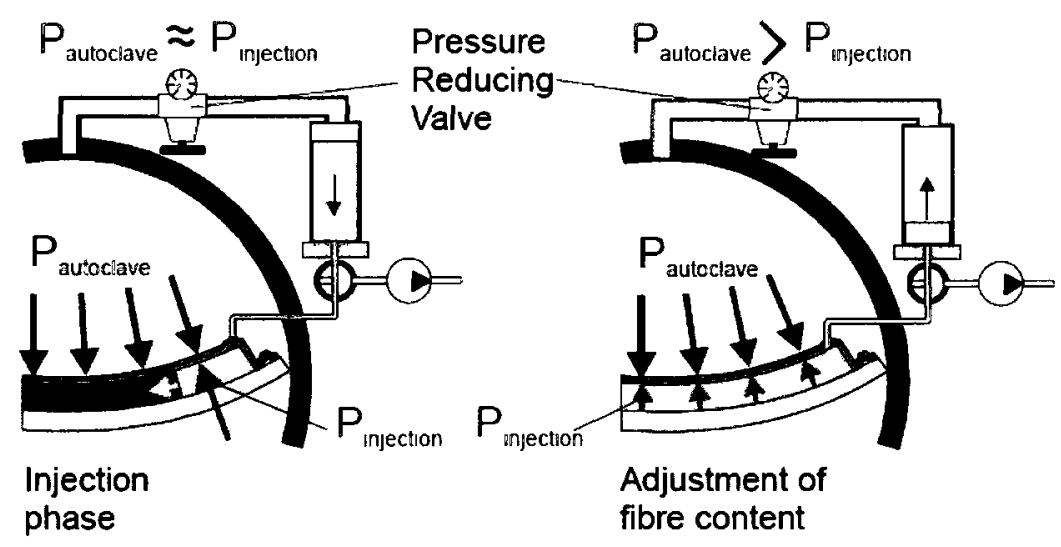

Figure 3.12: Pressure distribution during and after resin injection in SLI process [21]

SLI simplifies the traditional VARTM and RTM setups by utilizing a single resin transfer line for both evacuation of preform and resin injection. This is accomplished by adjusting the pressure accordingly at different stages as shown in Figure 3.12. Prior to resin injection, the autoclave is set at pressure level higher than full vacuum pressure while the mould cavity with fibrous reinforcement is kept under vacuum pressure. Then, resin is injected into the part at a pressure level equal to that of the autoclave pressure in order to impregnate the part. Following complete resin impregnation, the pressure inside the autoclave is increased until the desired fibre volume fraction (typically 60\%) is attained and excess resin is drawn out of the resin feed line with the assistance of the vacuum system. Depending on the part geometry and size, the placement of the resin feed line can be optimized [21].

\subsubsection{High Performance VARTM (Hyper-VARTM ${ }^{\top M} /$ Hyper-RTM $^{\top M}$ )}

Hyper-RTM ${ }^{T M}$ and Hyper-VARTM ${ }^{T M}$ are innovative LCM technologies patented by $V$ Systems Composites Inc. (VSC), San Diego, CA (US). These technologies incorporate the resin distribution system into the process' proprietary tooling technology, which allows controlled resin propagation along both in-plane and out-of-plane directions relative to the tool surface. 
Their tooling incorporates the so-called 'port runner devices' that are claimed to be universal, modular, reusable and provide a non-directional, high permeable system to facilitate the resin infusion. The result as claimed in the patent (US 6,964,561 B2, Nov 15, 2005), is consistent and high quality infusion with minimized setup labour and reduced potential for rework or scrap [22].

\subsubsection{Vibration Assisted Liquid Composite Moulding}

In this LCM method, either the mould or the resin stream is oscillated using electromagnetic shakers or motors during the infusion. Such vibrations assisted methods have been shown to reduce void contents in the final part, enhance flow rates and improve the fibre wetting [23].

\subsubsection{Closed Cavity Bag Moulding (CCBM)}

CCBM is a relatively new process for low cost manufacturing of FRP composites, patented by Arctek Inc. It utilizes a silicone based elastomeric material to manufacture flexible vacuum bags that are form fitted to the shape of the mould [24]. Once the bag is manufactured, the process follows conventional VARTM methods, as shown in Figure 3.13.

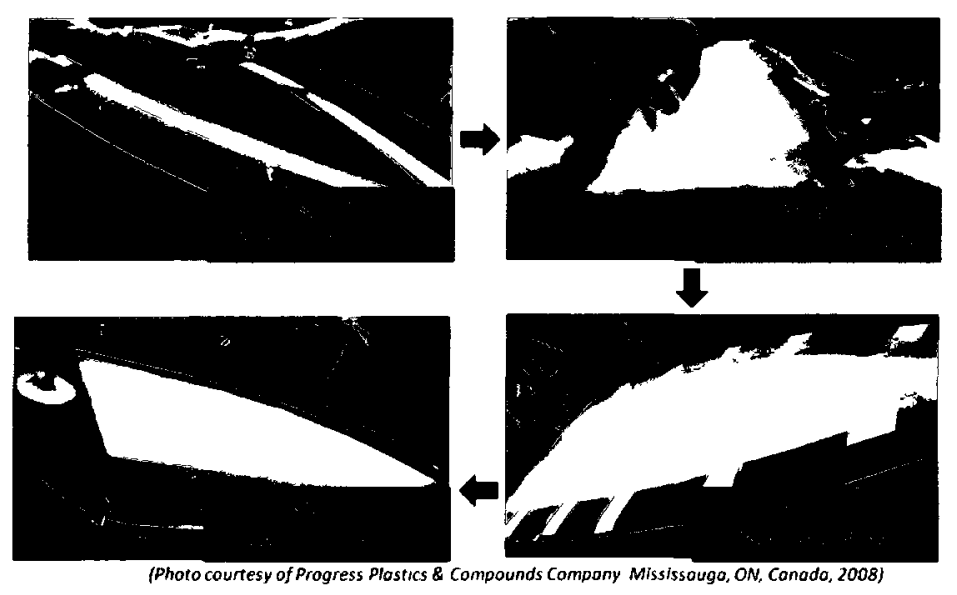

Figure 3.13: Typical CCBM procedure 
CCBM bags offer good vacuum integrity and better surface finish compared to traditional disposable vacuum bags. A properly made CCBM bag can last up to 1000 manufacturing cycles, leading to potentially significant cost savings in material and labour for small to medium production runs [24].

CCBM systems are typically supplied in sprayable or brushable forms. Sprayable CCBM systems generally involve an initial equipment cost, hence are somewhat expensive at the outset compared to the brushable CCBM systems that only require brushes and squeegees for manufacturing the bag. Commercially available CCBM type systems include, SWORL ${ }^{\mathrm{TM}}$, Sprayomer Elastomer $^{\mathrm{TM}}$, Airtech Multibag ${ }^{\mathrm{TM}}$ and Vacuspray $^{\mathrm{TM}}$.

\subsubsection{Co-Injection Resin Transfer Moulding (CIRTM)}

Co-Injection Resin Transfer Moulding (CIRTM) is an LCM method developed jointly by University of Delaware's Center for Composite Materials (UD-CCM) and Army Research Laboratory (ARL). In this process, manufacturing of hybrid composites in a single step is achieved by simultaneous injection of multiple resins into a multi-layer preform. This method can be utilized with conventional VARTM setup as shown in Figure 3.14. 


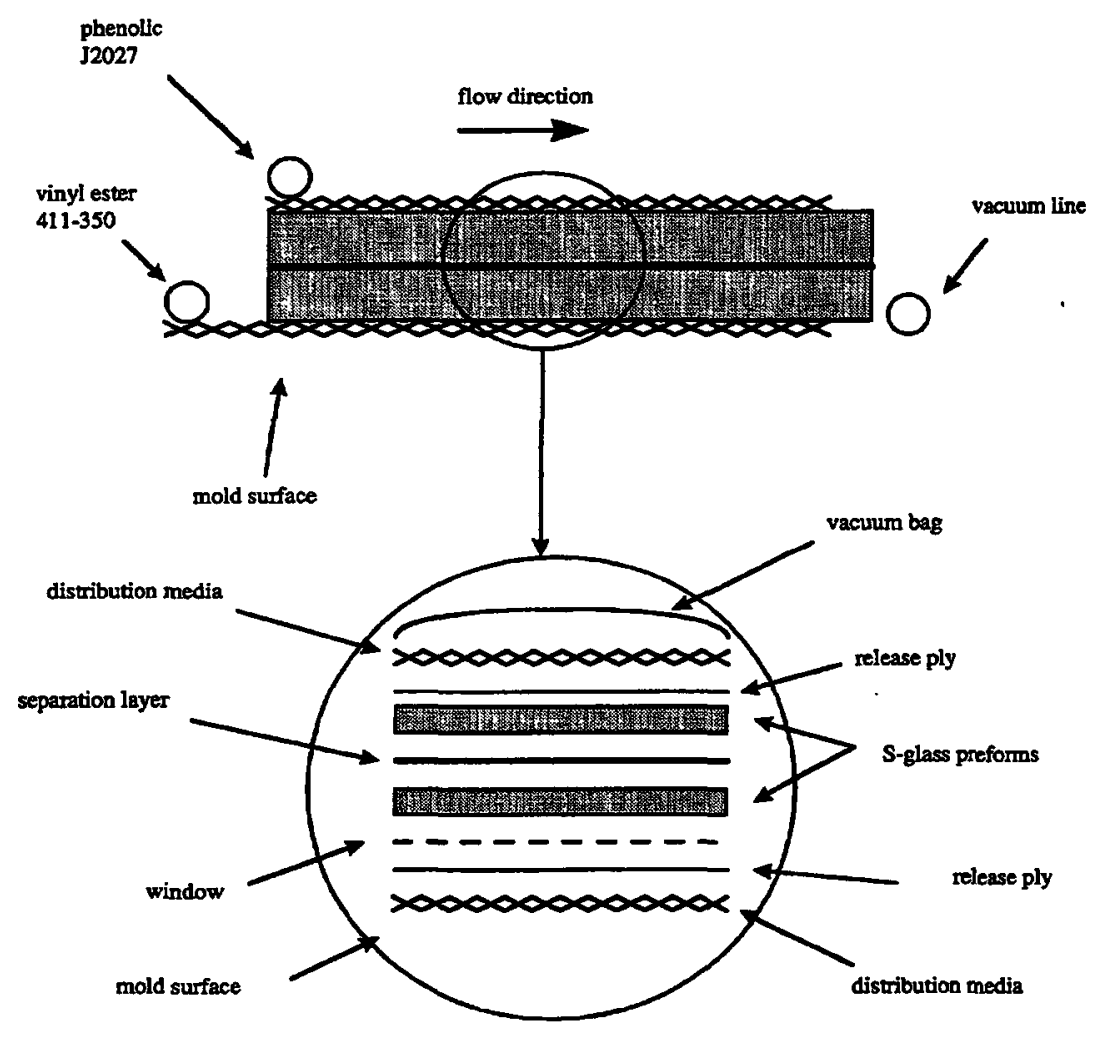

Figure 3.14: Schematic of the CIRTM method [25]

The hybrid structure is facilitated using a separation medium, which isolates the individual resins during infusion but forms a good structural bond upon cure. CIRTM results in substantial cost savings by the eliminating the need for multi-step processing and secondary bonding when manufacturing a hybrid composite structure [25].

\subsubsection{Euro Composites@ Honeycomb Liquid Moulding (EC-HLM)}

EC-HLM is a process in which sandwich constructions with honeycomb cores can be produced using the LCM method, without filling the honeycomb cells with resin. This is achieved by integrating a unique barrier layer into the fabric layup process as shown in Figure 3.15. The part is then vacuum bagged as shown in Figure 3.16. In an integrated infusion process, pre-curing of 
the barrier-core-bond takes place in an oven first. This is followed by resin infusion and final cure. The process is claimed to produce good quality, out-of-autoclave honeycomb structures [26].

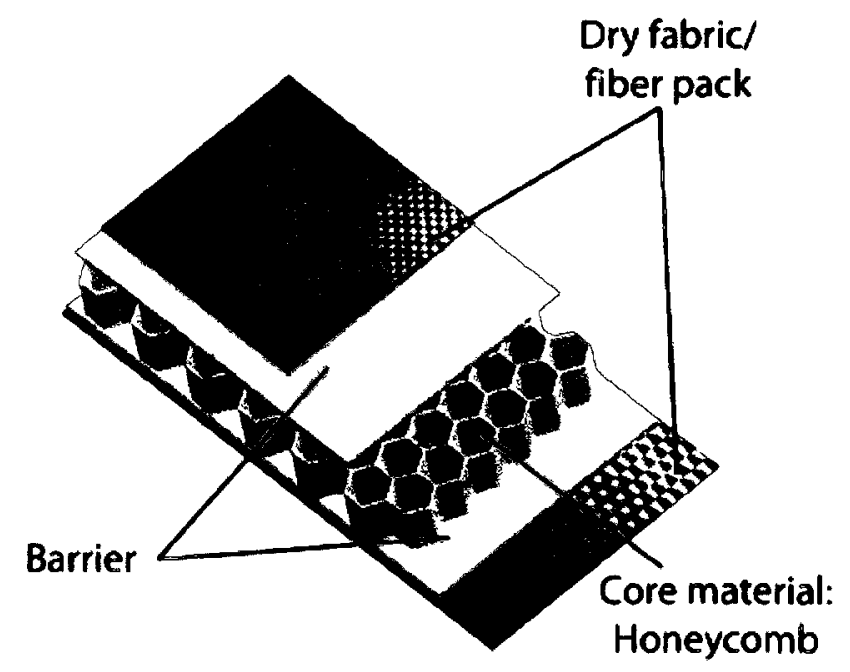

Figure 3.15: Details of the part during layup [26]
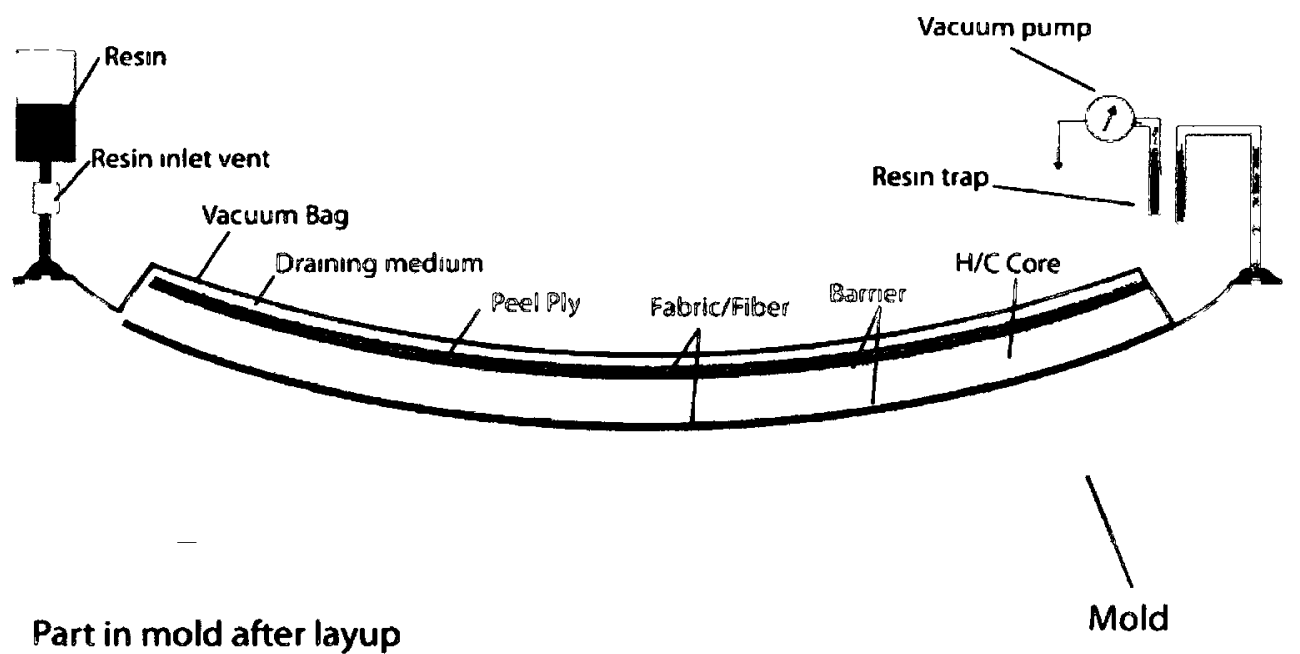

Figure 3.16: Schematic of the EC-HLM process [26] 


\subsubsection{VacFlo® Process}

The VacFlo ${ }^{\circledR}$ process was developed and patented by Scott Bader Company Ltd., for manufacturing vacuum infused parts with mould-finished surfaces on both sides. This is accomplished with the use of matched two-part moulds having a wider flange area that seats a double-vacuum seal arrangement. During infusion, a first vacuum source is used to draw vacuum through the flange seal and thus clamp the moulds, while a second vacuum source facilitates resin flow into the part. The moulds are light weight and typically manufactured using low cost, fibreglass reinforced laminates. The resulting parts are of same quality as those produced by VARTM, but show excellent surface finish on both sides [6].

\subsubsection{Light RTM}

LRTM processes combine certain RTM and VARTM principles to produce vacuum infused parts with mould-finished surfaces on both sides. This process involves low-cost, two-part moulds extended with flange-seals, a vacuum source, a low pressure resin injection pump and a pressure control unit. The vacuum source serves to clamp the moulds and facilitate resin flow into the part. Resin is introduced into the part using the injection pump, which pushes resin into the part at pressures that do not exceed the clamping pressure of the mould cavity. In a typical LRTM setting, the flange seal is clamped with full vacuum pressure (-14.7 psi gauge), while the mould cavity is maintained at approximately half-vacuum (-7.5 psi gauge). Resin delivery pressures are constantly controlled during infusion to prevent it from overpowering the clamping pressure. The push-pull resin infusion method results in complete resin consolidation of the part in shorter infusion times. This quality infusion comes with a slightly higher cost than conventional VARTM methods, but the use of low cost moulds and low 
pressure equipment makes LRTM relatively inexpensive compared to traditional RTM methods. Commercial suppliers of controlled LRTM systems include Magnum Venus Plastech (Lite-RTM), and JHM Technologies (Zero Injection Pressure (ZIP)-RTM) [6,26,27].

\subsubsection{Resin Infusion between Double Flexible Tooling (RIDFT)}

RIDFT is an innovative LCM process developed to reduce the infusion times associated with conventional VARTM. Figure 3.17 illustrates the steps involved in the RIDFT. This process begins with cutting of the dry preform to fit the desired mould shape. The preform is then placed in-between two flexible silicone membranes and sealed around the edges. Vacuum is then pulled between the flexible membranes and the preform is infused while remaining in flat configuration, as shown in Figure 3.17. The impregnated preform is then vacuum-formed to the shape of the mould by sealing and evacuating the cavity between the bottom silicone layer and the mould. Finally the part is cured and removed from the mould. Because the preform is flat during resin infusion, problems associated with wetting out complex geometry components are eliminated. Since the part stays over the flexible silicone layer at all times, less cleanup and premanufacturing mould preparation is required with each manufacturing cycle. This process is claimed to produce parts with low void content, at low emissions of Volatile Organic Compounds (VOCs) and lower tooling costs compared to conventional RTM methods. However, parts that can be manufactured with this method are of somewhat limited geometric complexity and size, due to the vacuum forming aspect of this process and the largest available machine size (10 ft $\times 15 \mathrm{ft} \times 4 \mathrm{ft}$ height- Figure 3.18) [29]. 


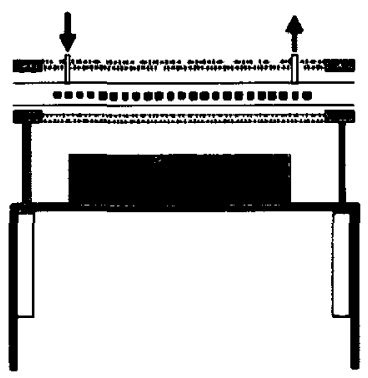

Step 1: Load fiber

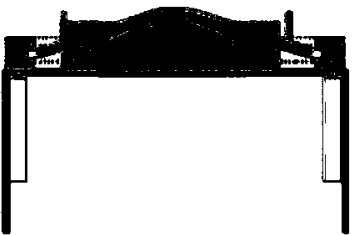

Step 4: Seal Vacuum Chamber

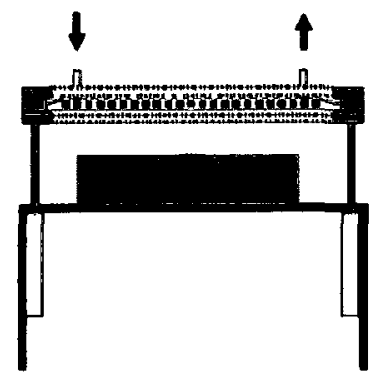

Step 2: Seal Resin Infusion Bag

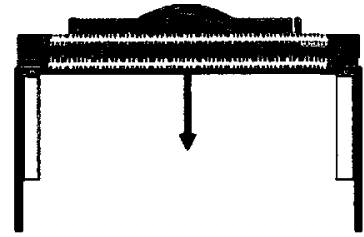

Step 5: Vacuum Form Part

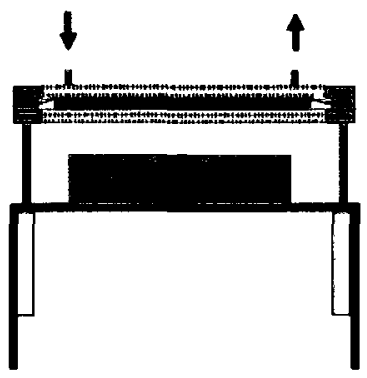

Step 3: Resin Infusion

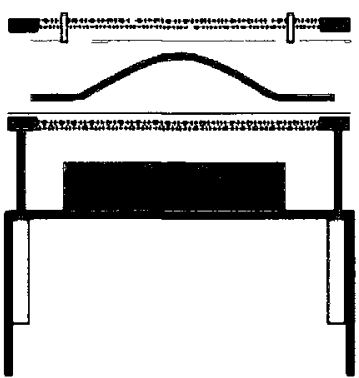

Step 6: Demold

Figure 3.17: Schematic of the RIDFT process [10]

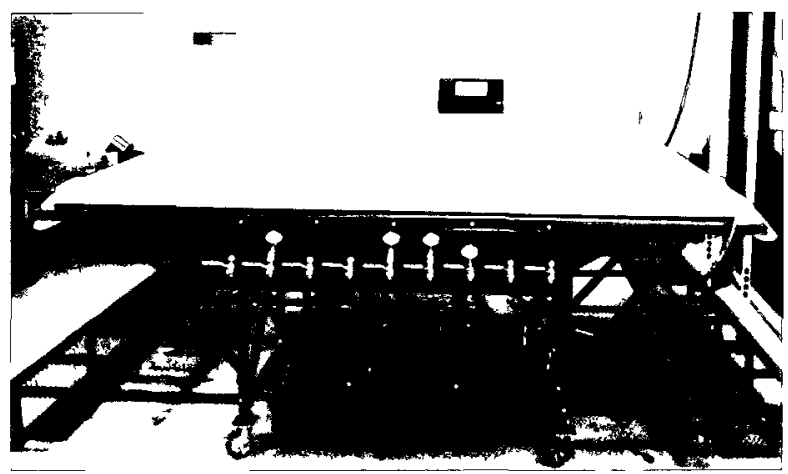

Figure 3.18: Industrial RIDFT machine $10 \mathrm{ft} \times 15 \mathrm{ft} \times 4 \mathrm{ft}$ [29] 


\subsubsection{Flexible Injection}

Flexible Injection is a new, patent pending LCM technology, developed and currently being researched at École Polytechnique de Montréal, in collaboration with General Motors (GM) of Canada Ltd. Flexible Injection can produce parts much faster than other LCM processes without compromising the part quality. The major steps involved in the Flexible Injection process are illustrated in Figure 3.19 [30].

The process begins with the placement of fibrous reinforcement into the injection chamber. Then a flexible membrane is placed over the reinforcement stack and sealed around the mould (Figure 3.19 - Step 1). Full or partial vacuum may be applied at one extremity of the injection chamber causing the flexible membrane to compress the reinforcement stack as shown in step 2. The required amount of resin is injected under pressure into the mould cavity, which fills the fraction of the mould cavity closer to the injection port as shown in step 3. The resin injection is immediately followed by injection of a non-reactive compaction fluid under pressure, into the upper mould chamber. This step accelerates the resin flow and impregnation into the fibrous reinforcement. After complete impregnation of resin into the reinforcement stack, resin vents are closed and the part is allowed to cure at the desired temperature and pressure. Once the part is cured, the compaction fluid is drained out of the cavity and the part is demoulded. The initial process development work demonstrates that the Flexible Injection technology offers faster and quality resin infusion [30]. 


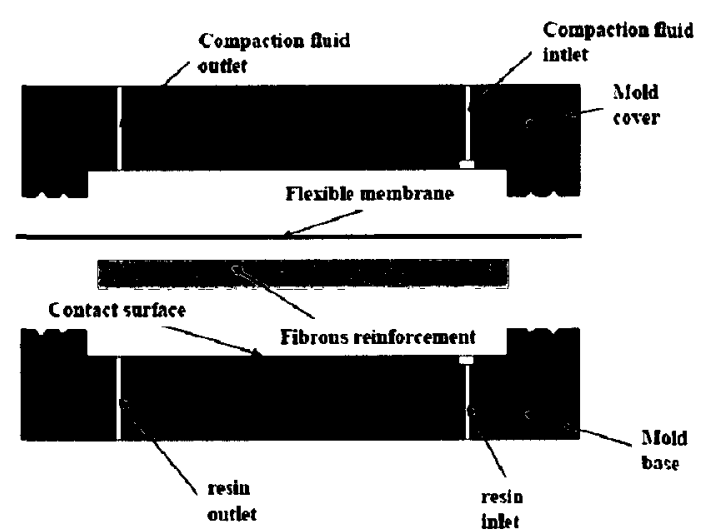

Step 1. Mould Setup

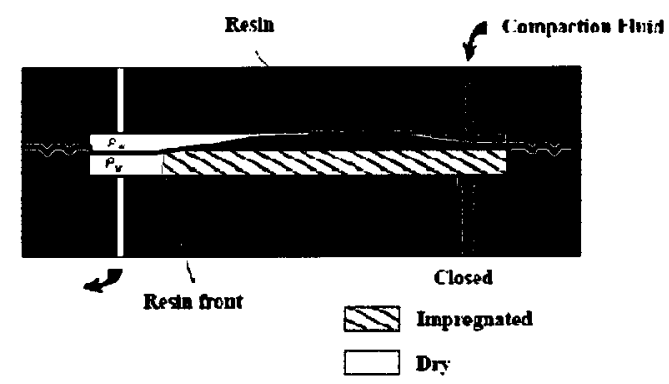

Step 3. Resin Injection

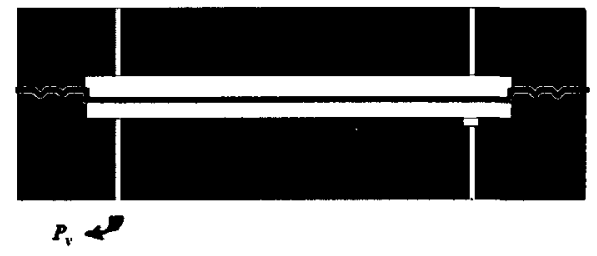

Step 2. Vacuum Application

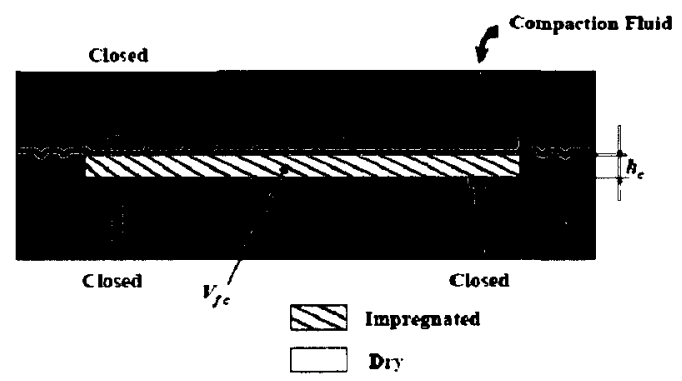

Step 4. Homogeneous compaction of impregnated fibres

Figure 3.19: Flexible Injection Process [30]

\subsubsection{Resin Film Infusion (RFI)}

RFI uses solid resin film or so called 'prepreg resin' to saturate the dry preform with resin. In the basic RFI process, the tool (mould) is covered with resin film of required thickness and dry preform is laid-up on top of this resin film as shown in Figure 3.20. The mould is then bagged with disposable materials. Subsequently, vacuum or autoclave pressure is applied to the setup, in conjunction with an appropriate thermal cure cycle. Upon curing, the resin viscosity lowers, allowing the resin to diffuse into the structural preform. With the RFI setup, the resin only infuses through thickness, providing considerably shorter infusion times versus traditional LCM 
processes. However, RFI requires high temperature rated moulds and at least an oven for curing, which makes this process somewhat expensive compared to conventional LCM methods [31].

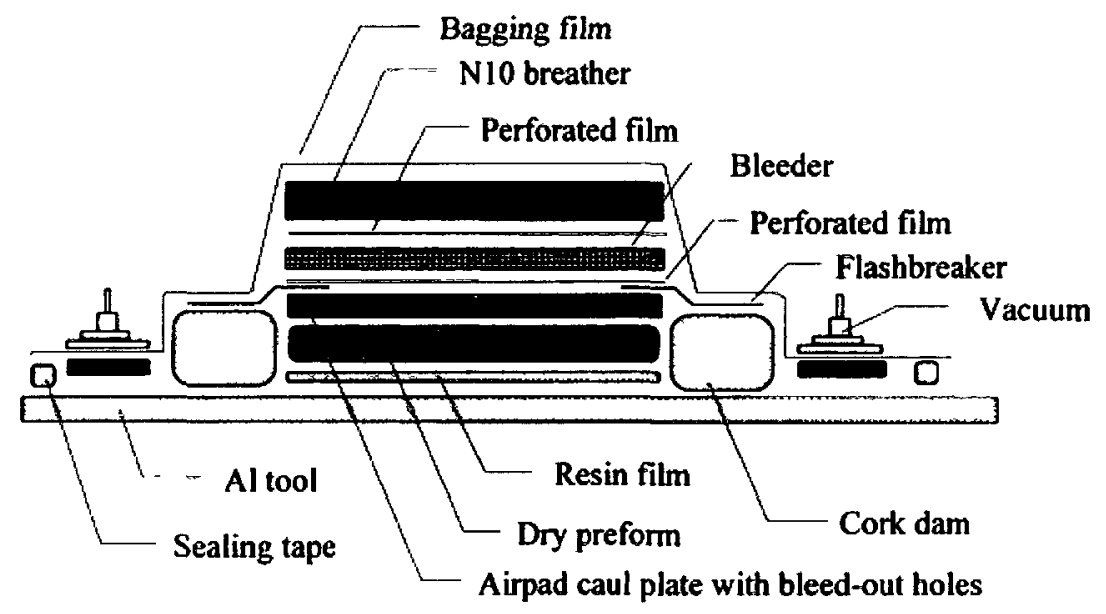

Figure 3.20: Schematic of the RFI process [31]

\subsubsection{Semi-Preg Infusion}

In this form of resin infusion, reinforcements partially impregnated with resin are used along with standard vacuum bagging methods and oven curing to produce the final part. These so called 'semi-pregs' or out-of-autoclave prepregs are low cost alternative to standard prepregs.

They exhibit shelf life of up to one year at room temperature. Commercially available semi-preg systems include [6]:

Advanced Composites Group ZPREG

- Resin stripes on one side of fabric

Cytec Carboform

- Resin impregnated random mat between the two fabric layers

$>$ SP Systems SPRINT ${ }^{\oplus}$ (SP-Resin Infusion New Technology)

- Resin between two fabric layers 


\subsection{Suitability LCM Processes for Mouldless Manufacturing}

The problems of vacuum leaks and foam core distortion under vacuum pressure experienced during previously implemented mouldless VARTM method (Chapter 2) can be addressed in two different ways. The first way is to use more robust bagging material and precise alignment fixtures for manufacturing. The second way is to select and apply a process variant that readily solves these problems.

The use of robust bagging material and precise alignment mechanisms will slightly increase the cost of mouldless manufacturing. Though this is undesirable, the added cost will likely result in better part quality. On the other hand, using an available technology usually comes with a licensing fee. For some processes developed with the intention of reducing costs, this licensing fee is usually small and is affordable by small or medium size companies. Thus, a process variant is worth considering if it promises to solve the problems encountered in mouldless VARTM.

VacFlo, Light RTM, RFI, and Semi-preg Infusion methods come with relatively high equipment and material costs compared to conventional VARTM. Hence these processes are not considered any further for mouldless manufacturing. Other processes such as VAP and Double Bag VARTM promise better vacuum integrity as compared to conventional VARTM, but will suffer similar core distortion under full vacuum pressure. Distortion of foam core under vacuum pressure is a direct consequence of excessive 'pleats' (Figure 3.21) in the vacuum bag, which conform onto the part unevenly when vacuum is applied to the part. Such pleats are unavoidable when bagging complex parts with tough, disposable vacuum bags. These methods will also have to rely on precise fixtures for controlling the part dimensions, which is somewhat 
difficult to achieve when the part is surrounded with uneven vacuum bag pleats. This leads to the conclusion that a vacuum bag that is form fitted to the shape of the part, will provide a better solution to part shape retention in mouldless manufacturing. A form fitted vacuum bag will allow application of uniform pressure around the entire tool, which may help minimize the deflection of the foam core under vacuum pressure experienced in previously implemented mouldless VARTM. CCBM is therefore a potential alternative to VARTM for mouldless manufacturing. The competitive advantages of the CCBM process are listed in Table 3.3.

Table 3.3: Advantages and Disadvantages of CCBM process [24]

\begin{tabular}{|c|c|}
\hline Advantages & Description \\
\hline Reusable & $\begin{array}{l}\text { Tough and self cleaning bags that can last over } 1000 \text { cycles without any } \\
\text { mould release application; improves the process repeatability. }\end{array}$ \\
\hline Repairable & $\begin{array}{l}\text { CCBM bags are easily repaired and restored to original condition when } \\
\text { damaged by accident or rough handling. }\end{array}$ \\
\hline $\begin{array}{l}\text { Many options for sealing } \\
\text { the bags }\end{array}$ & $\begin{array}{l}\text { Unlike disposable vacuum bags, CCBM bags can be sealed in many } \\
\text { different ways (i.e. flange seal, zipper seal etc.). }\end{array}$ \\
\hline Translucent & $\begin{array}{l}\text { Allows the operator to visually monitor the flow front and control the } \\
\text { infusion. }\end{array}$ \\
\hline $\begin{array}{l}\text { Low cost mould } \\
\text { requirements }\end{array}$ & $\begin{array}{l}\text { Existing moulds can be built up at low cost to make the mould for } \\
\text { CCBM bag fabrication. }\end{array}$ \\
\hline Less wastage & $\begin{array}{l}\text { CCBM reduces wastage of resin and bagging consumables compared to } \\
\text { conventional VARTM. }\end{array}$ \\
\hline Material compatibility & $\begin{array}{l}\text { CCBM is compatible with almost all available matrix and reinforcement } \\
\text { systems (i.e.: carbon-epoxy, fibreglass-polyester). }\end{array}$ \\
\hline $\begin{array}{l}\text { Integrated } \\
\text { manufacturing }\end{array}$ & $\begin{array}{l}\text { CCBM allows manufacturing with integrated cores and ribs without the } \\
\text { need for complex vacuum bag pleating. }\end{array}$ \\
\hline Workable & $\begin{array}{l}\text { Minimal odour, no VOC's, easy storage and handling, and readily } \\
\text { conforms to the shape of the mould. }\end{array}$ \\
\hline Robust & $\begin{array}{l}\text { CCBM infusion offers improved vacuum integrity, reduced risk of bag } \\
\text { leaks and eliminates the infusion complexities such as resin rich or } \\
\text { resin starved areas caused by disposable bags. }\end{array}$ \\
\hline $\begin{array}{l}\text { Suitable for all part sizes } \\
\text { and geometry }\end{array}$ & $\begin{array}{l}\text { As the complexity and size of the part increases, CCBM makes vacuum } \\
\text { bagging easier and cost efficient for low production quantities. }\end{array}$ \\
\hline Better part quality & $\begin{array}{l}\text { CCBM can create cosmetically attractive bag side surface with no } \\
\text { wrinkles. }\end{array}$ \\
\hline \multicolumn{2}{|r|}{ Disadvantages } \\
\hline \multicolumn{2}{|c|}{$\begin{array}{l}\text { - Relatively high initial costs compared to traditional VARTM with disposable materials. } \\
\text { - The durability of the bags is heavily dependent on the quality of bag manufacturing. }\end{array}$} \\
\hline
\end{tabular}




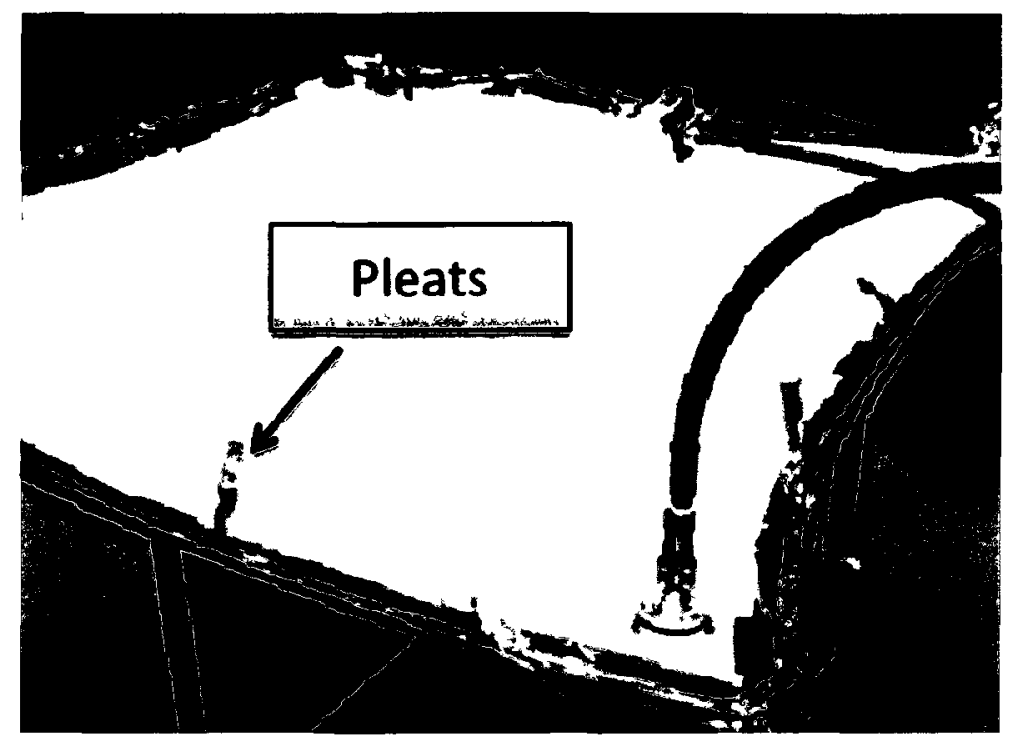

Figure 3.21: A part bagged with disposable vacuum bag [32]

CCBM bagging for the fuselage requires a multi-section bag, with a sealing mechanism adjustable to tightly seal the bag around the entire part. An additional requirement is such that the selected CCBM system and sealing method should be economical for part counts below 10 , in order to realize the economic advantages of mouldless manufacturing. From the review of current CCBM techniques, it becomes apparent that this process is intended to be used for manufacturing with rigid moulds, and hence can be expensive at the outset. Following the detailed review of LCM methods, the CCBM process was selected for demonstration of mouldless manufacturing; however, it was clear that significant process development and assessment would be required to determine the most efficient and economical mouldless CCBM setup. 


\section{CHAPTER 4. CCBM PROCESS DEVELOPMENT}

This chapter presents process development work carried out to develop a suitable CCBM technique for mouldless manufacturing. Various methods of bag-sealing and resin distribution for CCBM process were identified. A series of manufacturing trials were conducted using flat CCBM bags to determine the suitable techniques for mouldless manufacturing. Finally a Process Value Analysis (PVA) was performed to evaluate the feasibility of CCBM for mouldless manufacturing.

\subsection{Mouldless CCBM manufacturing considerations}

Applying CCBM in mouldless manufacturing setting requires a suitable bag sealing method that does not depend upon rigid flanges. Additionally, efficient resin distribution techniques and economic bag manufacturing strategies, if developed, would lead to further cost savings; hence would make CCBM economical for mouldless manufacturing in low production quantities. Several bag-sealing and resin distribution concepts for mouldless CCBM manufacturing, investigated as part of this research are described in the following sections.

\subsubsection{Sealing Mechanisms for Mouldless CCBM}

Conventional CCBM process often uses extruded silicone sections, such as the Flexseal " $D$ " to create the vacuum seal. Some of the sealing configurations commonly used in the CCBM process are shown in Figure 4.1. With the exception of interlocking seals, all seals require a rigid mould surface and a flange as shown in Figure 3.13. This leaves the interlocking seal as the most suitable sealing configuration for mouldless CCBM. However, this sealing method requires the two parts of the seal to be positioned accurately on the top and bottom halves of the bag to form an air-tight enclosure. This is somewhat difficult to attain considering the size and 
geometric complexity of the fuselage. Hence an alternative, more economical sealing method recommended in [34] was investigated. In this method, a tape with silicone based adhesive backing (i.e. Airtech Flashbreaker ${ }^{\circledast}$ or Teflease $^{\oplus}$ ) is permanently bonded to the CCBM bag. The taped surface of the bag is sealed against the tool using disposable sealant tape. This sealing technique eliminates the high initial costs associated with the extruded silicone seals.

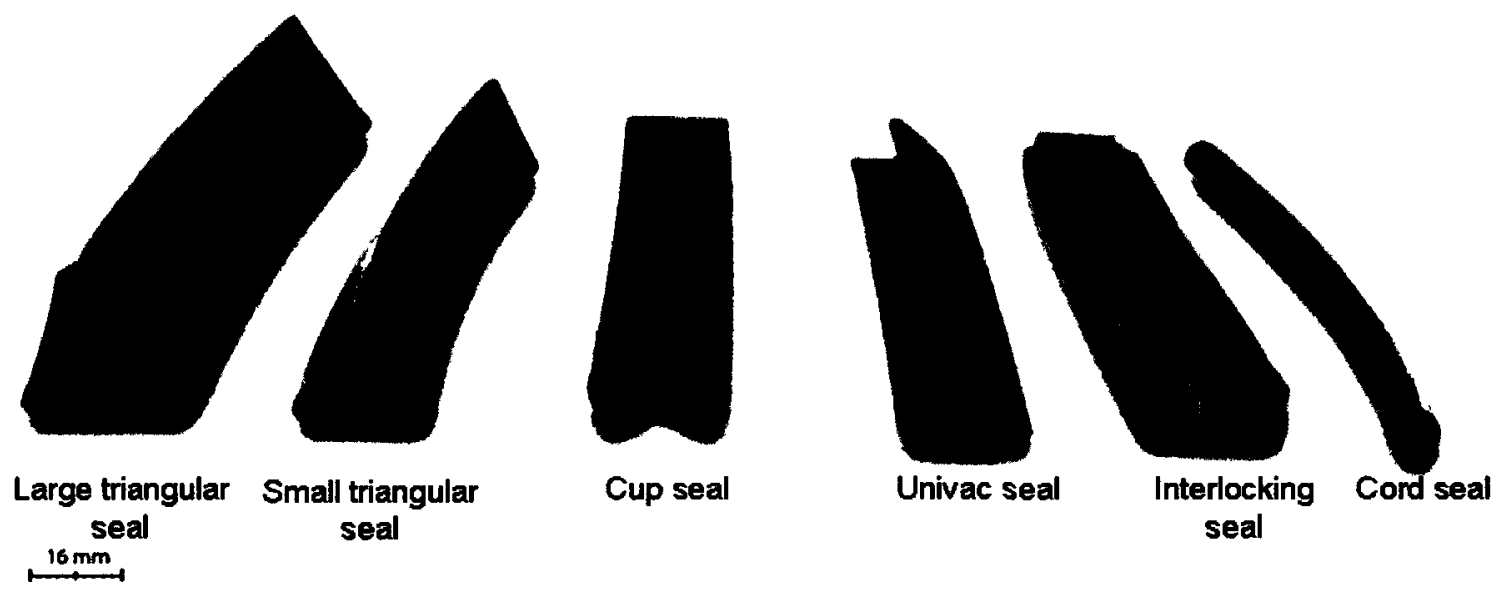

Photo courtesy of Airtech Advanced Materials Group, Rubber Silicone Seals, [Online Catalogue], 2009, [Cited 12 Oct 2010], Available: http://catalogue.airtech.lu/product.php?product id=29\&lang=EN Figure 4.1: Common reusable seal configuration for CCBM

\subsubsection{Resin Inlets and Outlets}

One way to reduce the material waste associated with traditional VARTM is to use reusable resin infusion lines. In the CCBM process, this is accomplished by permanently moulding the resin infusion channels into the vacuum bag. To do this, two options were considered. The first option was to mould the shape of tube into the bag by placing a waxed polymer tube on the tool and fabricating the bag over it. The region of resin channels can be locally reinforced with multiple layers of silicone to provide the necessary vacuum integrity. If this method was to prove unsuccessful, a more conservative second option can be considered, in which extruded 
silicone Omega Flow Lines (OF313) supplied by Airtech Corporation would be permanently embedded into the CCBM bag during manufacture.

\subsubsection{Resin Distribution in CCBM}

The resin can be distributed across the part using either a disposable resin distribution medium or by means of resin channels that are moulded into the CCBM bag (CIB infusion). The use of a distribution medium is more conventional and has been proven to work in conventional VARTM or CCBM settings [3,24]. On the other hand, CIB infusion is specifically advantageous for large, complicated parts as it eliminates material and labour costs associated with the use of disposable distribution medium. Additionally, the placement of such resin distribution channels can be optimized to shorten resin infusion time and reduce resin consumption.

\subsection{CCBM Manufacturing Trials}

Three flat CCBM bags were manufactured to evaluate the functionality of various bag sealing and resin distribution techniques discussed in section 4.1. The procedure employed in these manufacturing trials and their outcomes are discussed in the following sections. Supplier information of the materials used for this manufacturing trial is provided in Appendix A.

Arctek CCBM system [35] was chosen for these manufacturing trials, as it was the least expensive, brushable CCBM system available. The required materials can be purchased in small quantities. Important components of Arctek CCBM system are shown in Figure 4.2. It consists of Proflex NS ${ }^{\circledR}$ silicone, which is supplied in $850 \mathrm{ml}$ cartridges. This is a single-part, atmosphericmoisture cure silicone. For 0.025 in. thick layer of Proflex NS ${ }^{\circledR}$, the cure time is approximately 1 hour at $77^{\circ} \mathrm{F} / 50 \% \mathrm{RH}$. An Arctek CCBM bag is fabricated by applying several layers of Proflex 
NS $^{\circledR}$ silicone over a rigid mould. A layer of Confortex ${ }^{\circledR}$ fabric is applied in-between the silicone layers, which increases strength and tear resistance of the CCBM bag. Technical details and manufacturing methods of this product can be found in [24].

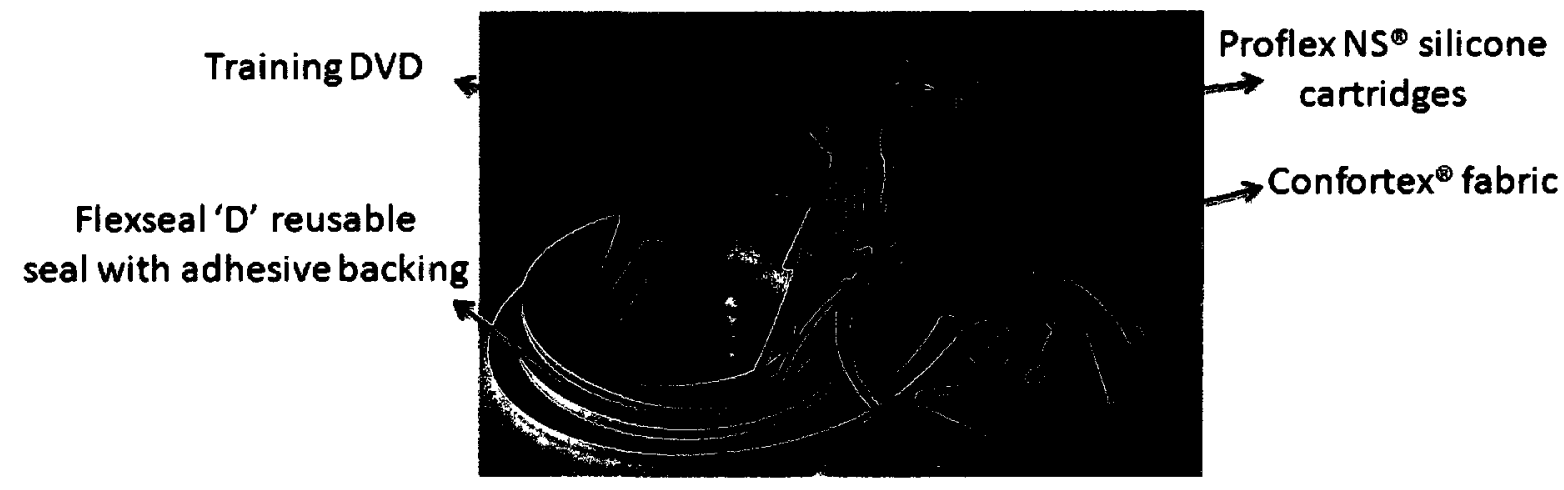

Figure 4.2: Components of Arctek CCBM system [35]

\subsubsection{CCBM Manufacturing Trial \# 1}

In this trial, a 9 in. $\times 20$ in. CCBM bag was manufactured for infusing a flat panel with the assistance of disposable distribution medium. The bag featured Airtech Flashbreaker tape bonded around the perimeter to facilitate sealing using disposable sealant tape. Half-circular profiles were moulded into the bag to create resin inlet and outlet as shown in Figure 4.3. The manufactured CCBM bag is shown in Figure 4.4. Step by step manufacturing method is provided in Appendix B. 


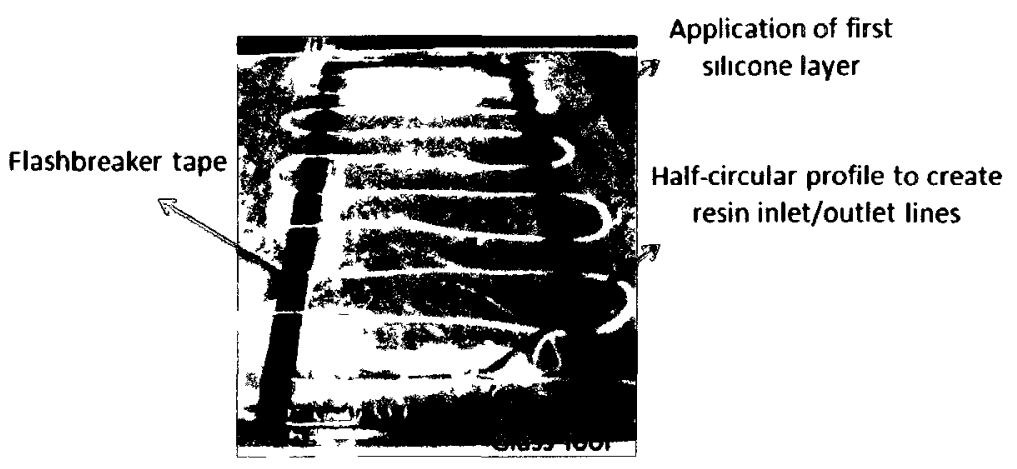

Figure 4.3: CCBM bag manufacturing trial \#1: tool setup

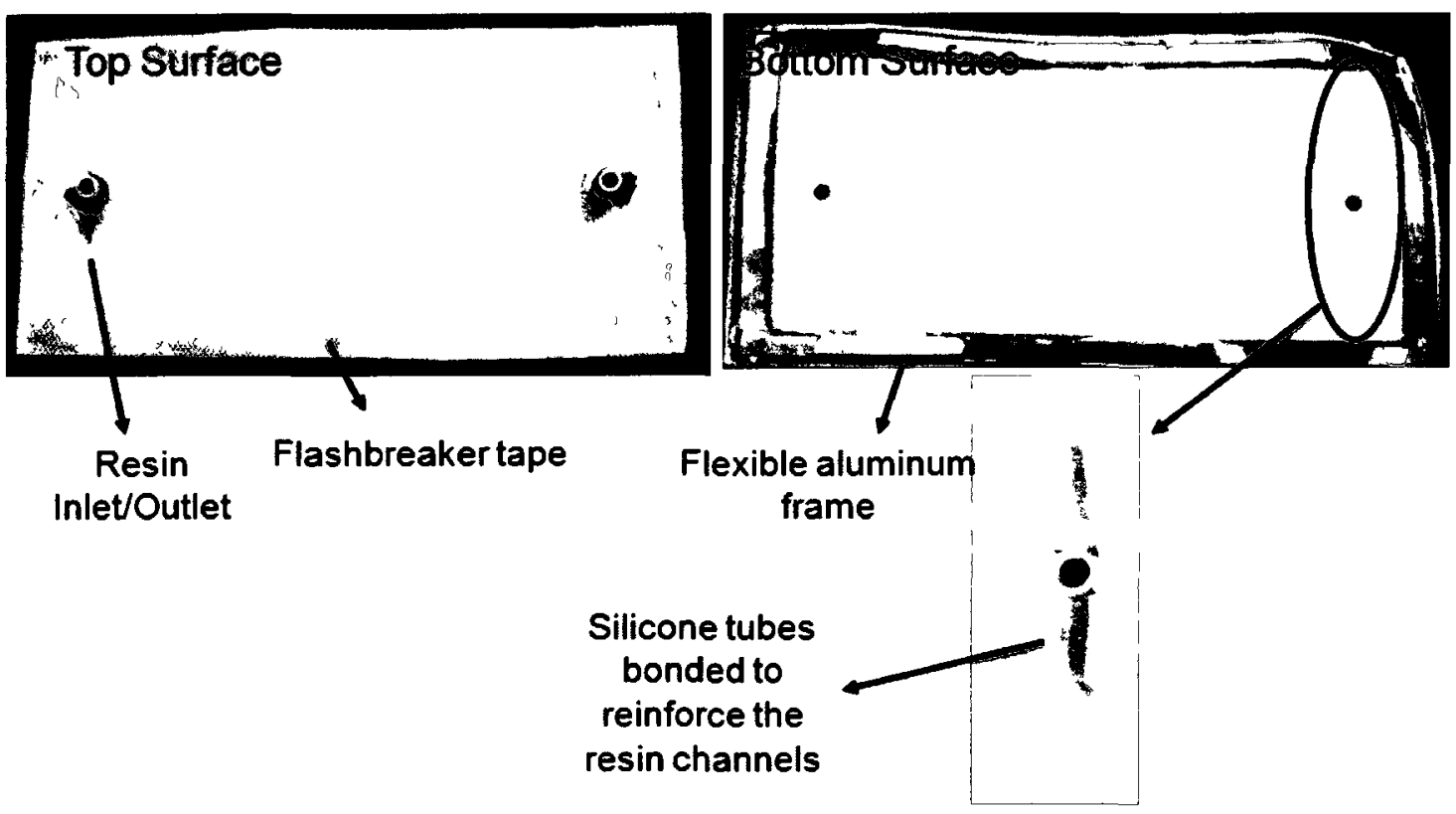

Figure 4.4: CCBM bag manufacturing: trial \#1 results

The results showed that using Airtac 2 spray adhesive to hold the Flashbreaker tape against the tool (Appendix B) does not work for this sealing mechanism. Indeed, the spray adhesive contaminated the surface of the tape, leading to permanent adhesion of the sealant tape to the bag. Further, the half circular resin channels moulded into the bag collapsed under the applied vacuum pressure. This bag was recovered by attaching a flexible aluminum frame around the perimeter and bonding silicone tubes to locally reinforce the resin channels, as shown in Figure 
4.4. This CCBM bag used Airtech Resinflow 60, disposable resin distribution media to speed-up the infusion process.

\subsubsection{CCBM Manufacturing Trial \# 2}

A second CCBM bag was manufactured with slightly modified procedure to overcome the difficulties in trial \#1. In this trial, Airtech OF313 omega flow lines were embedded into the bag to create the resin flow lines, and Teflease tape was bonded along the perimeter of the bag to form the seal as illustrated in Figure 4.5. During manufacturing of the bag, Teflease tape was held down to the tool surface with the use of a double-sided tape to prevent surface contamination. The manufactured CCBM bag is shown in Figure 4.6. The problems encountered in trial \#1 were solved and much better quality bag (Figure 4.6) was produced in trial \#2. Resin infusion was facilitated with disposable resin distribution media. This bag is still in good condition after 10 manufacturing cycles.

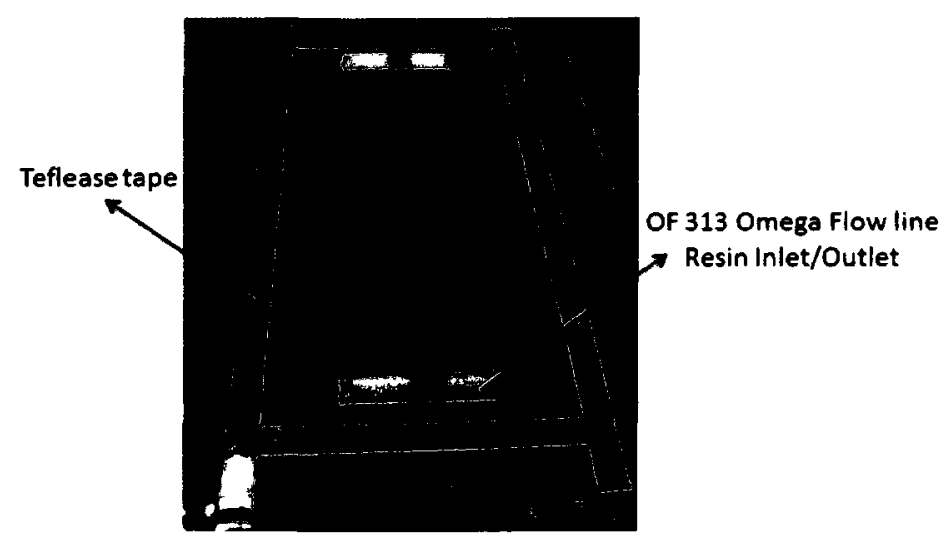

Figure 4.5: CCBM bag manufacturing trial \#2: tool setup 


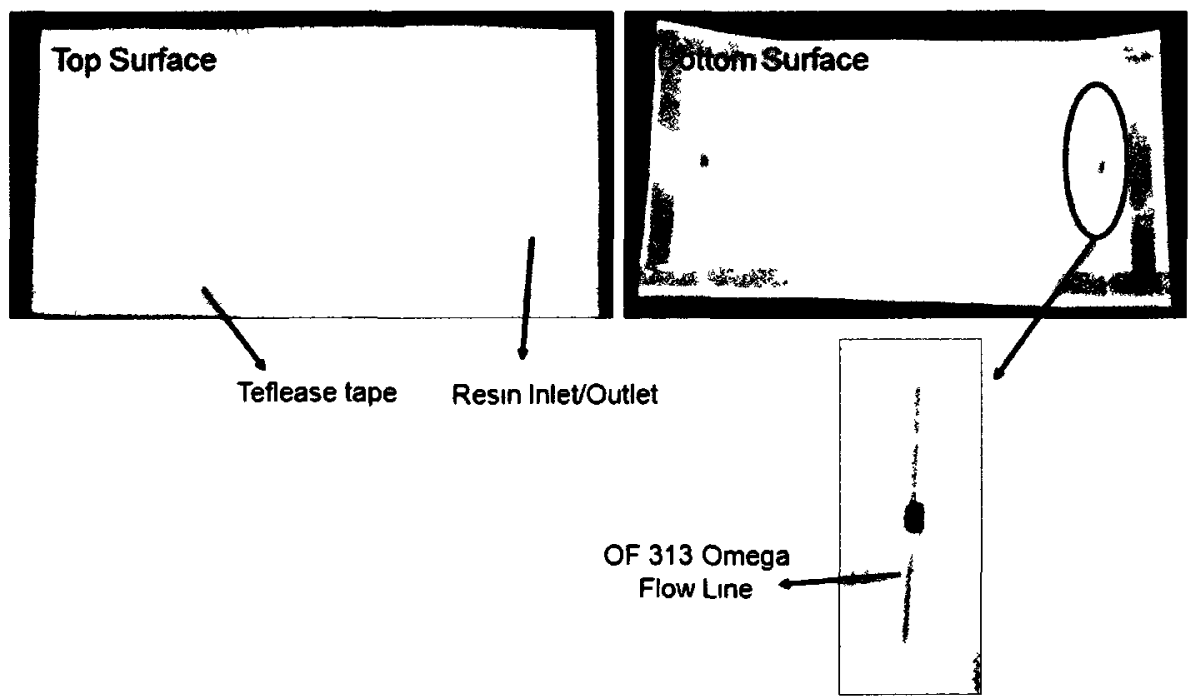

Figure 4.6: ССВM bag manufacturing: trial $\# 2$ results

\subsubsection{CCBM Manufacturing Trial \# 3}

A third manufacturing trial was carried out to determine the feasibility of moulding resin distribution channels into the bag. In this attempt, 0.125 in. diameter wire wax was placed onto the flat tool using double-sided tape. Mould release wax was then applied on the tool surface and CCBM bag section was manufactured over this setup, as shown in Figure 4.7.

0.125 in. diameter mire was
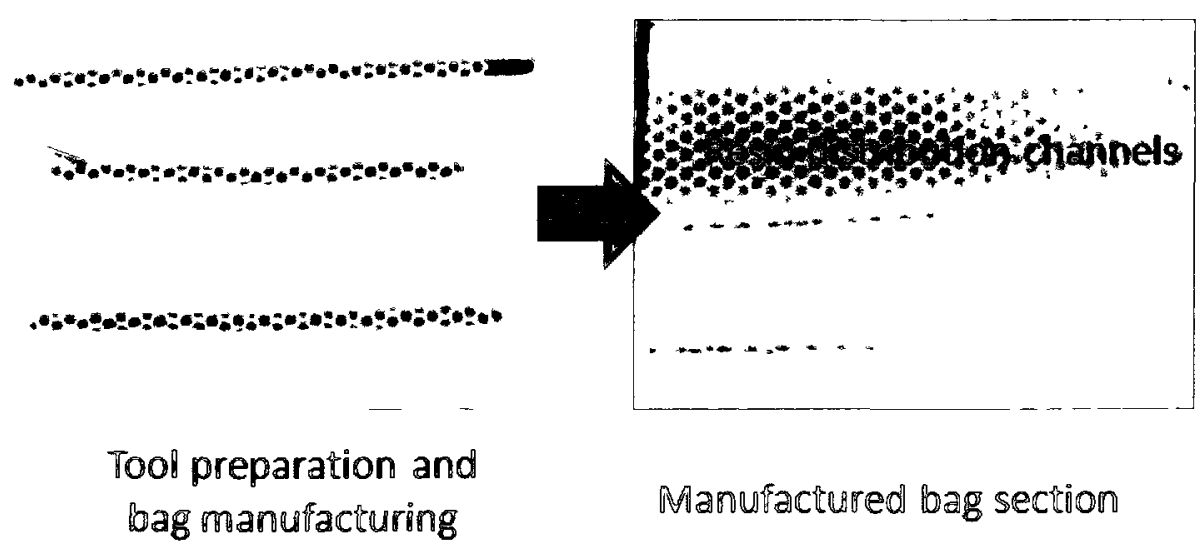

Tool preparation and

Manufactured bag section

Figure 4.7: Sampie CCBM bag section with resin distribution channels 
Following this trial, a complete bag section was manufactured to compare the infusion characteristics and the part quality. Infusions with $\mathrm{CIB}$ method and disposable distribution media are compared in Figure 4.8. In CIB infusion, the resin travels preferentially through the distribution channels and then into the part, resulting in a flow front pattern as shown in Figure 4.8-(a). Resin infusion with disposable distribution medium results in a linear flow front as shown in Figure 4.8-(b).

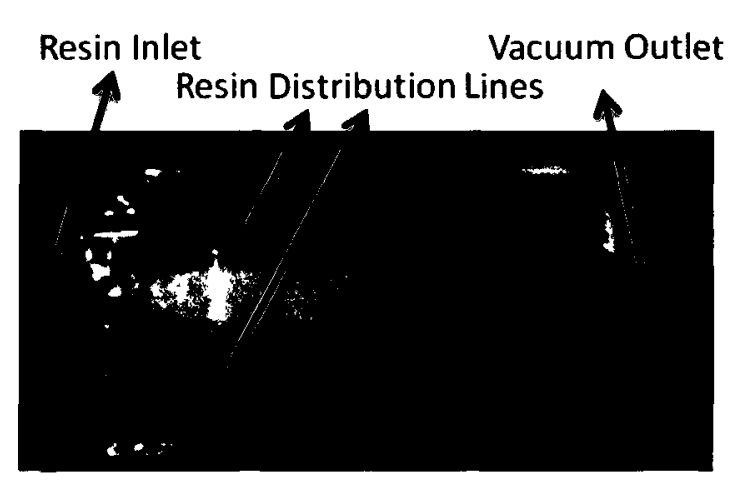

(a)

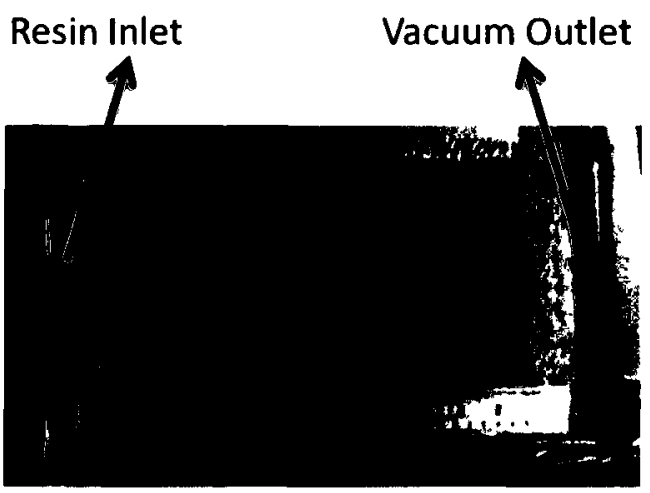

(b)

Figure 4.8: Flow profiles of CIB method (a) and disposable distribution media (b)

\subsection{Value Analysis of the CCBM process}

CCBM manufacturing trials showed that with appropriate use of materials and low-cost bag manufacturing techniques, CCBM can be made suitable for mouldless manufacturing of complex geometry components. In order to determine the most economic CCBM setup for mouldless manufacturing and assess its feasibility against mouldless VARTM method, a Process Value Analysis (PVA) was conducted. 


\subsubsection{Introduction to Value Analysis}

A product is considered valuable if it shows excellent performance characteristics and good physical appearance, relative to its cost. In mathematical terms, the value of a product can be expressed as [36].

$$
\begin{aligned}
\text { Value } & =\frac{(\text { Performance }+ \text { Capability })}{\text { Cost }} \\
& =\frac{\text { Function }}{\text { Cost }}
\end{aligned}
$$

The above expression shows that the value of a product can be increased either by minimizing the cost or by maximizing the performance. In other words, the most valuable product will have the highest functional worth (lowest cost to perform a given function). The concept of Value Analysis was first developed in 1945, by Lawrence D. Miles, an engineer from General Electric (GE) Company [37]. Mr. Miles found that with a systematic approach and clear understanding of functional worth of the product, one could meet or improve product performance and reduce its manufacturing costs. His approach to continuous improvement was called the Value Analysis. The Value Analysis can be carried out on designs or processes, as an improvement effort at any stage of a product life cycle. When several process variations exist, the Process Value Analysis (PVA) is employed to determine the net value of each process variation. The value of each process variation is then assessed to draw conclusions on the process feasibility. Potential benefits of PVA include reduced material use and costs, reduced waste, reduced distribution costs, improved profit margin, and improved customer satisfaction [36,37]. 


\subsubsection{CCBM Process Value Analysis}

The first step of the PVA was to identify the processes suitable for mouldless manufacturing and develop a PVA matrix. Various sealing and resin infusion techniques investigated as part of the manufacturing trials were assessed, to identify process variants applicable for mouldless manufacturing (Table 4.1). In this PVA, it is assumed that each method described in Table 4.1 would yield similar part quality. Considering performance, the CCBM bag I, with extruded silicone seal is easier to install during manufacturing than CCBM bag with sealant tape. This benefit of the CСВM bag-1 is realized at a slightly higher initial cost. In order to express the functional worth as monetary values, all functional characteristics of the process variants were grouped in terms of material and labour costs, with an initial labour rate of $20 \$ /$ hour.

Table 4.1: PVA matrix: processes for mouldless CCBM/VARTM

\begin{tabular}{|l|l|}
\hline Process Variation & Description \\
\hline CCBM bag I & CCBM with extruded silicone seal and distribution medium \\
\hline CCBM bag II & CCBM with sealant tape and distribution medium \\
\hline CCBM bag III & $\begin{array}{l}\text { CCBM with sealant tape and resin distribution channels } \\
\text { embedded in the bag }\end{array}$ \\
\hline VARTM & Traditional VARTM with disposable materials \\
\hline
\end{tabular}

Since CCBM bags are reusable for up to 1000 manufacturing cycles, the functional worth of these processes were determined by estimating the cost per part for increasing part counts. The total manufacturing cost per part was calculated by adding the fixed and variable costs associated with the processes. All value assessment calculations were carried out using a custom Microsoft Excel template created for this PVA. The assumptions made combined with the equations used and the estimated values of each process are provided in Appendix C. 


\subsubsection{PVA Results}

The total costs of manufacturing the fuselage for increasing part count were plotted at a labour rate of $\$ 20 /$ hour (Figure 4.9). The results show that the process development work, which evolves to CCBM III, makes CCBM economical for 4 fuselages. This is an improvement from the published manufacturer's data, which justifies the cost of CCBM for over 5 complex parts in a conventional CCBM setting [35]. Thus, CCBM appears to be economical for mouldless manufacturing. In order to assess the sensitivity of these results to labour cost, the cost estimates were regenerated with a labour rate of $\$ 40 / \mathrm{hr}$. The results shown in Figure 4.10 , suggests that doubling the labour rate increases the cost of the first part, but makes CCBM economical for fewer parts ( 3 parts). This is primarily due to the significant labour cost savings offered by CCBM for increasing part counts.

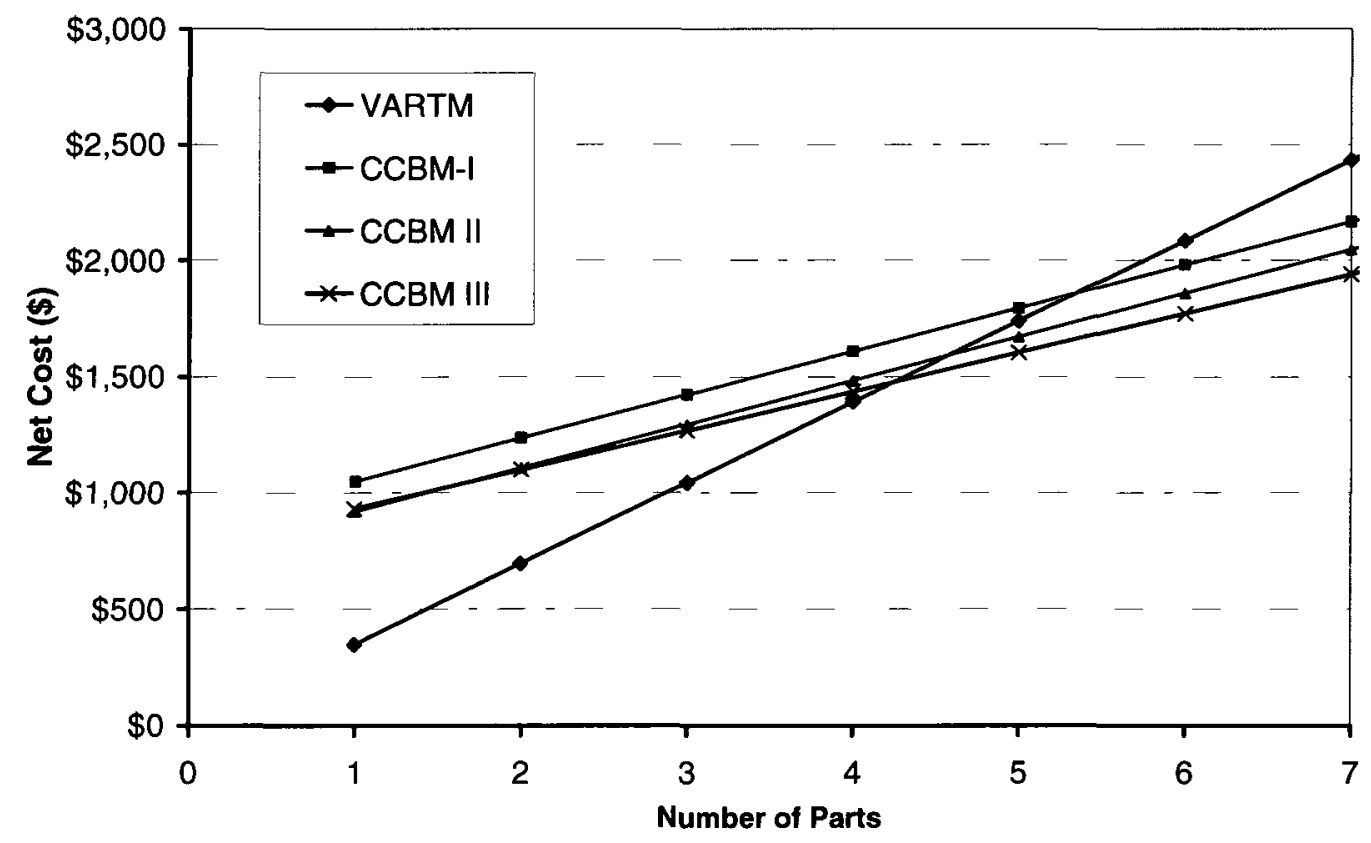

Figure 4.9: Cost of the fuselage for increasing part count at labour rate of $20 \$ / \mathrm{hr}$ 


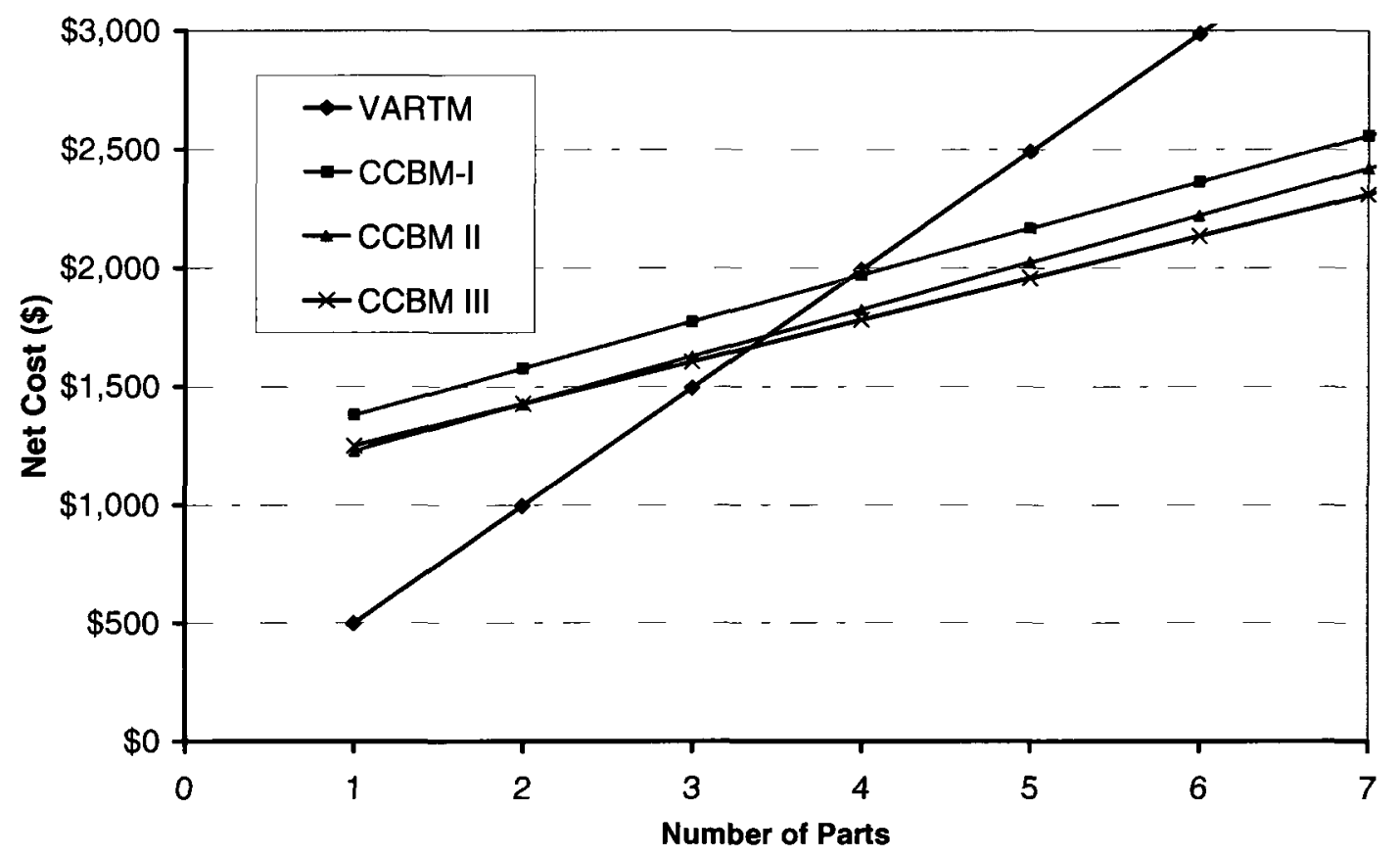

Figure 4.10: Cost of the fuselage for increasing part count at labour rate of $40 \$ / \mathrm{hr}$

\subsubsection{PVA Conclusions}

Mouldless CCBM is a viable option for manufacturing large complex geometry components. CCBM III is cost effective after manufacturing 3 to 4 parts. Process robustness, repeatability and part quality are likely to improve with proper implementation of mouldless CCBM. 


\section{CHAPTER 5. FUSELAGE MATERIAL SELECTION}

This chapter provides a brief overview of the sandwich theory and discusses the choice of materials for the new GeoSurv II fuselage.

\subsection{Sandwich Theory}

Sandwich constructions are widely used in many structural applications of advanced composite materials. They consist of thin face sheets or skins adhesively bonded to both surfaces of a relatively thick, low density core material. The core serves to increase the overall laminate thickness, thereby keeping the Fibre Reinforced Polymer (FRP) skins apart. This leads to a dramatic increase in flexural rigidity of the laminate for a small added weight. To illustrate the sandwich principle, consider a symmetric sandwich beam in bending (Figure 5.1).

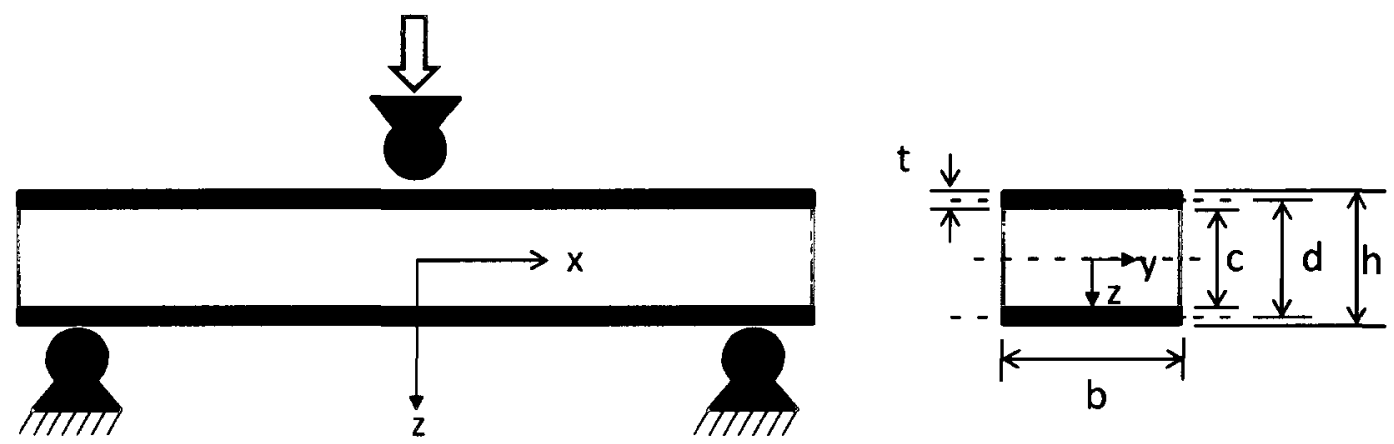

Figure 5.1: Sandwich beam subjected to three point bend

The stiffness coefficient (D) of this beam is given by [1]:

$$
\begin{aligned}
& D_{\text {beam }}=(E I)_{\text {beam }} \\
& =(E I)_{\text {core }}+(E I)_{\text {skns }} \\
& =E_{s} \frac{b t^{3}}{6}+E_{s} \frac{b t d^{2}}{2}+E_{c} \frac{b c^{3}}{12}
\end{aligned}
$$


Where, $E$ is the Young's Modulus of the material and $I$ is the area moment of inertia of the beam. For sandwich constructions featuring relatively thin skins $\left(\frac{d}{t}>5.77\right)$ and relatively weak core $\left(\frac{E_{s}}{E_{c}} \frac{t d^{2}}{c^{3}}>16.7\right)$, the expression for $\mathrm{D}$ can be approximated as:

$$
D_{\text {beam }} \approx E_{s} \frac{b t d^{2}}{2}
$$

The above expression shows that the distance between the skins, " $d$ " has greater influence on the flexural rigidity of the beam compared to other variables in equation 5.2. The core effectively increases this distance for a small increase in weight, thus making sandwich construction stronger and stiffer than the corresponding monolithic counterparts. In bending of a sandwich beam, the skin bears most of the bending stresses while the core predominantly carries shear loads (Figure 5.2).

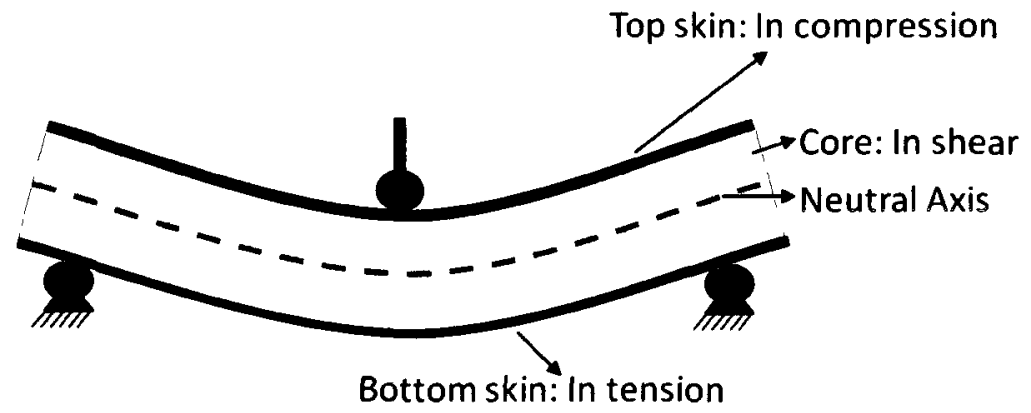

Figure 5.2: Sandwich beam in bending

The core also serves to distribute the local loads to be carried by the skins over the entire structure, without causing local failure; this makes sandwich construction an excellent design solution for components exposed to impact and dynamic loading. The compression strength of 
the core prevents local buckling of the skins and the shear strength coupled with good adhesion between the skin and core aids in holding the skins in place under dynamic bending loads. The latest core materials also offer excellent heat insulation, acoustic insulation, vibration damping and fire resistance characteristics [2]. Detailed theory of sandwich structures can be found in the literature e.g. [39-41].

\subsection{Core Material for GeoSurv II Fuselage}

The current fuselage uses Celfort ${ }^{\circledR} 300$ EPS foam as the core material. This choice was primarily driven by the lower cost of EPS foam and the proof of concept nature of the initial manufacturing trials (Maley, [3]). Celfort ${ }^{\circledR} 300$ has a nominal density of $1.42 \mathrm{lbs} / \mathrm{ft}^{3}$ and compression strength of 30 psi. Initial infusions on test articles revealed that Celfort ${ }^{\circledR 3} 300$ degraded due to surface resin absorption. Indeed, the infused sections distorted under full vacuum pressure about 10 minutes after resin impregnation. Hence, during manufacturing of the current fuselage, the foam parts were assembled and primed with a layer of fast cure epoxy (West System 105) prior to infusion. The added resin layer allowed better handling of the core during manufacturing and slightly increased its flexural stiffness and dimensional stability, at the cost of increased weight. The manufactured component had up to $0.31 \mathrm{in}$. (7.8 $\mathrm{mm}$ ) deviation from the desired dimension, at several locations [3].

Replacing Celfort ${ }^{\circledR} 300$ with an aerospace grade, structural core material promises potential weight savings by eliminating the need to seal the foam surface prior to infusion. Core materials specially formulated for structural applications and VARTM processing offer good mechanical properties, lower surface resin absorption and could potentially improve the dimensional 
tolerances of mouldless VARTM manufacturing. Hence, an investigation into state-of-the-art structural core materials was performed to select a suitable core material for the new fuselage.

A wide range of foam, balsa wood and honeycomb core materials are available, with various densities and finishes; all designed to meet specific structural and manufacturing requirements of aerospace, marine, wind energy and transportation industries. The choice of core material for the GeoSurv II fuselage must meet the requirements imposed by the nature of mouldless VARTM manufacturing, listed in Table 5.1, in addition to complying with the UAS airframe requirements outlined in Table 2.1. The following sections discuss various candidate structural foam and balsa core materials that could be used for mouldless VARTM manufacturing.

Table 5.1: Manufacturing requirements for the core material

\section{Requirements for Core Material}

1. The core material shall be resistant to vacuum pressure (Compression Strength $>14.5 \mathrm{psi}$ ).

2. The core material shall feature nearly $100 \%$ closed-cell structure.

3. The core material shall be compatible with epoxy resins.

4. The surface finish of the core material shall lead to excellent skin-core adhesion.

5. The core material shall have excellent specific flexural stiffness to allow for near net shaped manufacturing.

6. The core material shall remain dimensionally stable after machining and during processing.

\subsubsection{Structural Foam Core Materials}

Structural foam cores are often preferred for Liquid Composite Moulding (LCM) processes. This is mainly because most foam materials are easily machined or thermoformed. Their surface finishes and cell packing densities can be tailored to meet a wide range of design requirements. 
Also, most foam cores are readily available with optimized grooves and scrim-backings to enable faster and better resin infusion.

Structural foams are processed from a variety of thermoset and thermoplastic polymers including Polyvinyl Chloride (PVC), Polyurethane (PU), Styrene Acrylo-Nitrile (SAN), and Polymethacrylimide (PMI), Polyethylene Terephthalate (PET), Polyester and Polyisocyanurate. The mechanical properties, density and service temperature of structural foam cores can be modified significantly by changing the ratios of chemical additives and various process parameters such as pressure and temperature. The latest manufacturing technologies have produced foam cores in densities ranging from $2 \mathrm{lbs} / \mathrm{ft}^{3}$ to $50 \mathrm{lbs} / \mathrm{ft}^{3}$, suitable for service temperatures in the range of $-184^{\circ} \mathrm{C}$ to $260^{\circ} \mathrm{C}\left(-300^{\circ} \mathrm{F}\right.$ to $\left.500^{\circ} \mathrm{F}\right)$. They are available in sheets of thicknesses up to 4 in. Some structural foam cores are also available in large block form to allow for components to be machined as single integral bodies [42].

The selection process should carefully consider the mechanical properties, chemical resistance, toxicity and costs of the available structural core materials. Table 5.2 describes some closedcell, semi-rigid foam cores that are potential candidates for the new fuselage. All of these materials have better overall structural performance than Celfort 300 EPS foam utilized in the current fuselage. They are available in various grades to meet the UAS certification standards for fire, smoke and toxicity. The core selection for the new fuselage took into consideration, the mechanical properties and costs of various structural foam materials, as described in section 5.2.4. 
Table 5.2: Structural foam cores suitable for mouldless VARTM manufacturing ${ }^{23}$

\begin{tabular}{|c|c|c|c|c|}
\hline Material & Cross-Linked PVC & Linear PVC & PU & SAN \\
\hline Trade Names & $\begin{array}{l}\text { AIREX-C } \\
\text { DIVINYCELL -H } \\
\text { KLEGECELL-R }\end{array}$ & AIREX - R & $\begin{array}{l}\text { LAST-A-FOAM } \\
\text { NIDA FOAM PU }\end{array}$ & CORECELL \\
\hline $\begin{array}{l}\text { Chemical } \\
\text { Composition }\end{array}$ & $\begin{array}{l}\text { Polymer based on } \\
\text { cross linked Poly-Vinyl } \\
\text { Chloride system }\end{array}$ & $\begin{array}{l}\text { Polymer based on } \\
\text { linear Poly-Vinyl } \\
\text { Chloride system }\end{array}$ & $\begin{array}{l}\text { Polyurethane based } \\
\text { chemical system }\end{array}$ & $\begin{array}{l}\text { Styrene Acrylo- } \\
\text { Nitrile based } \\
\text { chemical system }\end{array}$ \\
\hline Manufacturer & $\begin{array}{l}\text { - Alcan Composites } \\
\text { - Diab Inc. }\end{array}$ & - Alcan Composites & $\begin{array}{l}\text { - General Plastics } \\
\text { - Nida-Core Corp. }\end{array}$ & $\begin{array}{l}\text { SP Systems } \\
\text { (North America) }\end{array}$ \\
\hline $\begin{array}{l}\text { Unique } \\
\text { Features }\end{array}$ & $\begin{array}{l}\text { - Good peel strength } \\
\text { - Compatible with most } \\
\text { resin systems } \\
\text { - High thermal stability } \\
\text { - Thermoformable above } \\
212^{0} \mathrm{~F} \\
\text { - Low water/resin } \\
\text { absorption } \\
\text { - Contain gas under } \\
\text { pressure; possibility of } \\
\text { out-gassing over time }\end{array}$ & $\begin{array}{l}\text { - More elastic than } \\
\text { cross linked PVC } \\
\text { - Good fatigue and } \\
\text { impact resistance } \\
\text { - Thermoformable } \\
\text { - Slightly lower } \\
\text { mechanical and } \\
\text { thermal properties } \\
\text { compared to cross } \\
\text { linked PVC }\end{array}$ & $\begin{array}{l}\text { - Resistant to most } \\
\text { chemicals and } \\
\text { solvents } \\
\text { - More brittle and } \\
\text { less fatigue } \\
\text { resistant than } \\
\text { PVC and SAN } \\
\text { - The surface at } \\
\text { the resin-core } \\
\text { interface tends } \\
\text { to deteriorate } \\
\text { over time }\end{array}$ & $\begin{array}{l}\text { - Good } \\
\text { machinability } \\
\text { - Resistance to } \\
\text { water and fuel } \\
\text { oil } \\
\text { - Minimal density } \\
\text { variation } \\
\text { - No out-gassing } \\
\text { problems } \\
\text { - Compatible with } \\
\text { most resin types } \\
\text { - Thermoformable }\end{array}$ \\
\hline $\begin{array}{l}\text { Closed-Cell } \\
\text { Content }\end{array}$ & $>95 \%$ & $>95 \%$ & $>95 \%$ & $>95 \%$ \\
\hline $\begin{array}{l}\text { Density Range } \\
\left.\text { (lbs/ft }{ }^{3}\right)\end{array}$ & 2 to 15.61 & 3.75 to 8.70 & 2 to 40 & 3.6 to 19.7 \\
\hline $\begin{array}{l}\text { Continuous } \\
\text { thermal } \\
\left.\text { stability }{ }^{0} \mathrm{~F}\right)\end{array}$ & $\begin{array}{l}-328 \text { to } 158, \\
284 \text { (High Temp.) }\end{array}$ & 131 & $\begin{array}{l}275,320 \text { (High } \\
\text { Temp.) }\end{array}$ & $\begin{array}{l}185,230 \text { High } \\
\text { Temp.) }\end{array}$ \\
\hline Grades & $\begin{array}{l}\rightarrow \text { AIREX } \\
\text { - C70: Universally } \\
\text { structural } \\
\text { - C71: Elevated temp. } \\
\text { - C52: Industrial } \\
\text { processing } \\
\rightarrow \text { DIVINYCELL } \\
\text { - H: High performance } \\
\text { - HT: Aerospace grade } \\
\text { - HP: Prepreg processing } \\
\text { - F: low FST (Fire, Smoke } \\
\text { and Toxicity) } \\
\text { - HCP: High density }\end{array}$ & $\begin{array}{l}\text { - AIREX R63: } \\
\text { Damage tolerant } \\
\text { foam }\end{array}$ & $\begin{array}{l}\text { - FR 6700: Aircraft } \\
\text { grade } \\
\text { - FR 7100: } \\
\text { Modelling grade } \\
\text { - FR 10100: } \\
\text { High temp. } \\
\text { - FR 4300: } \\
\text { Formable } \\
\text { - TR: Marine grade }\end{array}$ & $\begin{array}{l}\text { - Core-Cell A: For } \\
\text { dynamically } \\
\text { loaded } \\
\text { structures } \\
\text { - Core-CellP: } \\
\text { Prepreg } \\
\text { processing } \\
\text { - Core-Cell T: For } \\
\text { decks and } \\
\text { interiors } \\
\text { - Core-Cell S: sub- } \\
\text { sea applications }\end{array}$ \\
\hline
\end{tabular}

${ }^{2}$ Information provided in this table were obtained from the manufacturers' data. The references are provided in Appendix D.

${ }^{3}$ Problem areas are identified in bold and italicized font. 
Table 5.2 Continued...

\begin{tabular}{|c|c|c|c|c|}
\hline Material & PMI & PET & Polyester & Polyisocyanurate \\
\hline Trade Names & ROHACELL & $\begin{array}{l}\text { AIREX-T } \\
\text { NIDA FOAM PET }\end{array}$ & AIRCELL & ELFOAM \\
\hline $\begin{array}{l}\text { Chemical } \\
\text { Composition }\end{array}$ & $\begin{array}{l}\text { Polymethacrylimide } \\
\text { based chemical system }\end{array}$ & $\begin{array}{l}\text { Poly Ethylene } \\
\text { Terephthalate based } \\
\text { chemical system }\end{array}$ & $\begin{array}{l}\text { Polymerized cross- } \\
\text { linked aromatic } \\
\text { polyester system }\end{array}$ & $\begin{array}{l}\text { Polyisocyanurate } \\
\text { based chemical } \\
\text { system }\end{array}$ \\
\hline Manufacturer & $\begin{array}{l}\text { Evonik Industries } \\
\text { /Degussa }\end{array}$ & $\begin{array}{l}\text { - Alcan Composites } \\
\text { - Nida-Core Corp. }\end{array}$ & - Polyumac Inc. & $\begin{array}{l}\text { - Elliott } \\
\text { Company }\end{array}$ \\
\hline $\begin{array}{l}\text { Unique } \\
\text { Features }\end{array}$ & $\begin{array}{l}\text { - Resistant to organic } \\
\text { solvents such as } \\
\text { benzene, xylene and } \\
\text { monostyrene } \\
\text { - Resistant to fuel } \\
\text { constituents and } \\
\text { solvents for paints } \\
\text { - Features better } \\
\text { mechanical properties } \\
\text { compared to other } \\
\text { structural foam cores } \\
\text { - Optimized for LCM } \\
\text { processes }\end{array}$ & $\begin{array}{l}\text { Good high temp. } \\
\text { stability } \\
\text { Easily machined } \\
\text { and } \\
\text { thermoformed } \\
\text { - Chemically stable }\end{array}$ & $\begin{array}{l}\text { - Good impact and } \\
\text { fatigue resistance } \\
\text { - Durable and } \\
\text { resilient } \\
\text { - flame retardant, } \\
\text { non-friable }\end{array}$ & $\begin{array}{l}\text { - Excellent } \\
\text { chemical } \\
\text { resistance and } \\
\text { resin } \\
\text { compatibility } \\
\text { - Easily } \\
\text { machined, } \\
\text { perforated and } \\
\text { cut } \\
\text { - Class I } \\
\text { flammability } \\
\text { rating } \\
\text { - Good thermal } \\
\text { insulation }\end{array}$ \\
\hline $\begin{array}{l}\text { Closed-Cell } \\
\text { Content }\end{array}$ & $\begin{array}{l}\text { Relatively lower resin } \\
\text { absorption than other } \\
\text { foams }\end{array}$ & $>95 \%$ & $\begin{array}{l}\text { Closed content cell } \\
\text { comparable to PVC }\end{array}$ & $\begin{array}{l}\text { Closed-cell } \\
\text { content } \\
\text { comparable to PU }\end{array}$ \\
\hline $\begin{array}{l}\text { Density Range } \\
\left(\mathrm{lbs} / \mathrm{ft}^{3}\right)\end{array}$ & 2.0 to 6.9 & 6.3 to 20 & 4 to 36 & 2 to 6 \\
\hline $\begin{array}{l}\text { Continuous } \\
\text { thermal } \\
\text { stability }\left({ }^{\circ} \mathrm{F}\right)\end{array}$ & 320 & $\begin{array}{l}212,302-392 \text { (High } \\
\text { Temp.) }\end{array}$ & -320 to 165 & -297 to 298 \\
\hline Grades & $\begin{array}{l}\rightarrow \text { Rohacell } \\
\text { - RIST: Low surface resin } \\
\text { absorption } \\
\text { - RIMA: Finest cells for } \\
\text { minimum surface resin } \\
\text { absorption } \\
\text { - IG: Industrial grade } \\
\text { - A: Aircraft grade } \\
\text { - WF: Heat resistance } \\
\text { grade } \\
\text { - XT: Extended temp. } \\
\text { - S: Easy to shape and } \\
\text { machine }\end{array}$ & $\begin{array}{l}\text { AIREX-T 90: Easy } \\
\text { processing } \\
\text { AIREX-T 91: Easy } \\
\text { processing } \\
\text { Nida Foam } \\
\text { PET100/150: } \\
\text { Structural }\end{array}$ & - Aircell T: structural & $\begin{array}{l}\text { - Elfoam P: } \\
\text { Structural } \\
\text { series }\end{array}$ \\
\hline
\end{tabular}




\subsubsection{Balsa Wood Cores}

Balsa wood is another core material known for its high specific compression strength and stiffness. It is dried and prepared from naturally harvested balsa lumber in the end-grain configuration, as shown in Figure 5.3. In the end-grain configuration, balsa core features lean closed cells tightly packed and oriented perpendicular to the plane, forming a closed-cell, honeycomb like structure at microscopic level. This leads to its ability to resist high compression and dynamic loads. Apart from this, balsa cores are fire resistant and act as thermal and acoustic insulators in sandwich constructions $[42,44]$.

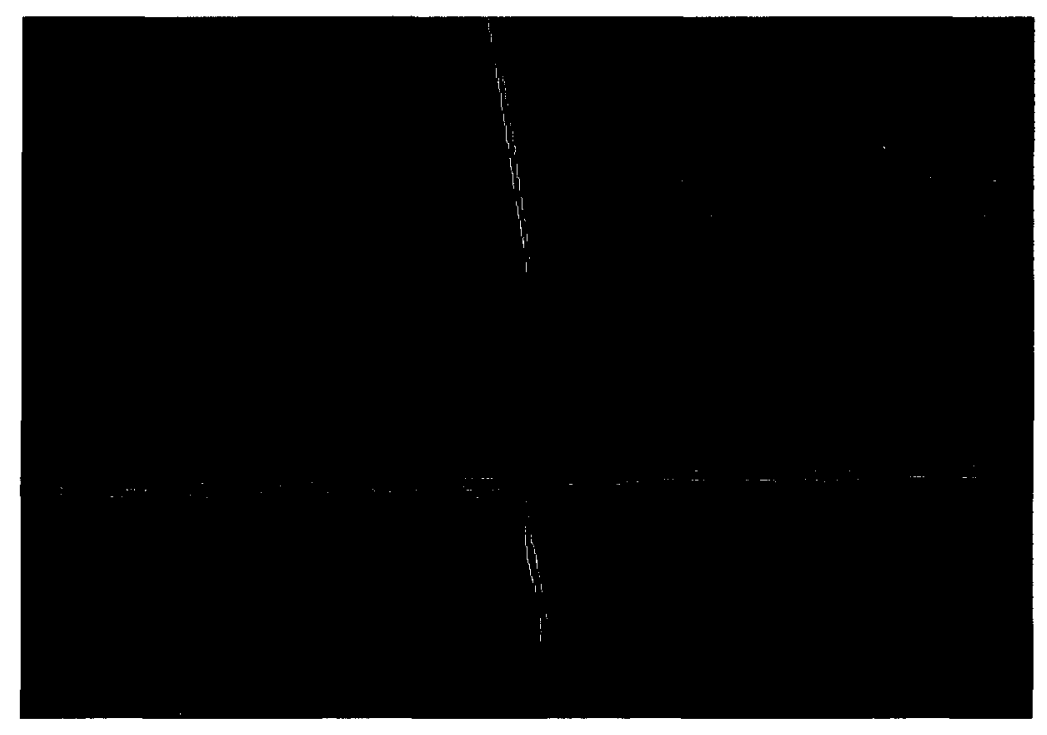

Figure 5.3: Balsa wood core-end grain configuration [43]

The main disadvantage of balsa core is its high density, with lowest minimum values ranging between $5.5 \mathrm{lbs} / \mathrm{ft}^{3}-6 \mathrm{lbs} / \mathrm{ft}^{3}$. The density factor is further aggravated with balsa's high surface resin absorption characteristics, making it non-preferable for weight critical applications. The three main manufacturers of advanced structural core materials, Diab Corporation, Alcan Composites and Nida Core Corporation are competing to produce lightweight-consistent 
density balsa cores by utilizing advanced processing techniques. Balsa cores are now pre-sealed with primers specifically formulated for lower surface resin absorption, and are available in sheets of thicknesses up to 4 in. or as contoured blocks held together with fibreglass scrim [44].

\subsubsection{Other Core Materials}

Other core materials that may be utilized in VARTM applications include the following:

$>$ Cedar wood: It is a natural lumber often used as core material in strip-plank construction. It features grains running parallel to the plane, offering some stand alone bending rigidity compared to balsa wood. However, it exhibits poor impact resistance, low torsional rigidity and compression strength compared to balsa wood [44].

Airex PXc ${ }^{\circledR}$ : It is glass fibre reinforced PU foam supplied by Alcan Composites. The foam exhibits exceptional dimensional stability, chemical and thermal resistance. This material is available on custom order and hence is very expensive. Also, the minimum available density of this material is higher than $6 \mathrm{lbs} / \mathrm{ft}^{3}$ density range [45].

Airex PXw': It is continuous glass fibre fabric reinforced PU foam supplied by Alcan composites. The foam is uniquely formulated to exhibit good flexural rigidity on its own, allowing it to be used with or without face sheets. Airex PXw ${ }^{\circledR}$ also offers exceptional dimensional stability, chemical and thermal resistance. This material is available on custom orders and therefore is very expensive. Further, its minimum available density is larger than $6 \mathrm{lbs} / \mathrm{ft}^{3}$ range [46]. 
Foam Filled Honeycomb: Nida Core Corporation and MGI Inc. supply PU foam filled honeycomb core materials at densities ranging from $5 \mathrm{lbs} / \mathrm{ft}^{3}$ to $20 \mathrm{lbs} / \mathrm{ft}^{3}$. They combine the properties of honeycomb and foam materials to offer exceptional compression and shear performance. It is a closed-cell core that can be used with VARTM and other closed moulding processes. Sealing the honeycomb with foam imparts increased stand-alone flexural rigidity to this material, which makes it preferable for mouldless VARTM application. The major drawback is that manufacturing of PU filled honeycomb is an emerging technology; hence the flexural rigidity has not yet been quantified. The mechanical properties of $5.56 \mathrm{lbs} / \mathrm{ft}^{3}$ density material from MGI Inc. were found to be lower than the cross linked PVC cores at the same density. Also, its machinability, workability and resin absorption characteristics need to be characterized prior to using them for VARTM applications $[47,48]$.

\subsubsection{Core Selection for GeoSurv II Fuselage}

The mechanical properties and costs of the structural core materials were considered in order to select an appropriate core material for mouldless manufacturing. Complete profile of mechanical properties attributed to various foam and balsa core materials, along with the supplier details are given in Appendix D. Balsa cores, though exhibiting mechanical properties superior to foam cores, were not considered in the selection process, as they are too heavy in their lowest available density. Foam filled honeycombs Airex $\mathrm{PXC}^{\oplus}$ and $\mathrm{PXW}$ were also excluded from the selection process due to limited supply and high costs. This narrowed the list down to structural foam cores as the primary candidates for the new fuselage. 
The structural foams listed in Table 5.2 were assessed for their performance in shear and compression. This assessment identified PMI (Rohacell), crossed linked PVC (Airex C, Divinycell), and SAN (Corecell A) as the top three candidates for the new fuselage. Their properties relative to cost were compared to make the final choice. Since not all of the materials are available at the same densities, the mechanical properties of the top three foam cores were first normalized at $4 \mathrm{lbs} / \mathrm{ft}^{3}$ using linear relations. The normalized properties of the top three foam cores along with their nominal costs are given in Table 5.3. These findings are compared in Figure 5.4.

Table 5.3: Normalized mechanical properties of the most structural foam cores

\begin{tabular}{|l|c|c|c|c|c|c|}
\hline $\begin{array}{c}\text { Material } \\
\left(\mathbf{4} \mathrm{lbs} / \mathrm{ft}^{\mathbf{3}}\right)\end{array}$ & $\begin{array}{c}\text { Compression } \\
\text { Strength } \\
(\mathbf{p s i})\end{array}$ & $\begin{array}{c}\text { Percent } \\
\text { difference } \\
\text { compared to } \\
\text { Corecell A (\%) }\end{array}$ & $\begin{array}{c}\text { Shear } \\
\text { Strength } \\
(\mathbf{p s i})\end{array}$ & $\begin{array}{c}\text { Percent } \\
\text { difference } \\
\text { compared to } \\
\text { Corecell A (\%) }\end{array}$ & $\begin{array}{c}\text { Cost of } \\
\mathbf{0 . 5} \text { in } \\
\text { thick } \\
\text { material } \\
\left(\mathbf{\$} / \mathrm{ft}^{2}\right)\end{array}$ & $\begin{array}{c}\text { Percent } \\
\text { difference } \\
\text { compared to } \\
\text { Corecell A (\%) }\end{array}$ \\
\hline Rohacell & 189 & 238 & 157 & 77 & 11.35 & 173.58 \\
\hline Airex C & 144 & 157 & 132 & 48 & 2.50 & -39.76 \\
\hline Corecell A & 56 & 0 & 89 & 0 & 4.15 & 0.00 \\
\hline
\end{tabular}

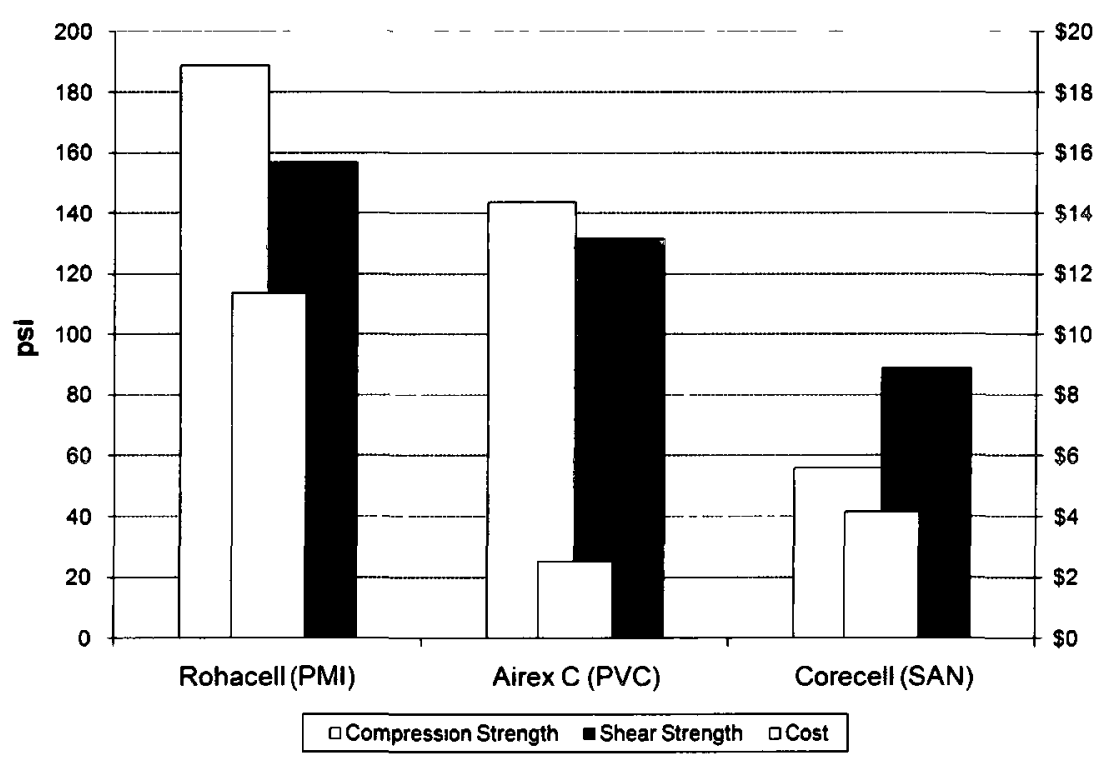

Figure 5.4: Comparison of the selected foam materials at $4 \mathrm{lbs} / \mathrm{ft}^{3}$ density 
The results demonstrate that cross-linked PVC (Airex C) foam cores offer good mechanical properties at a reasonable cost. Though the latest PMI (Rohacell) foams exhibit $20 \%$ better overall structural performance, their costs are significantly higher than the PVC cores. This would be a definite concern for the low-cost aspect of this process development work. Hence, cross-linked PVC foam was chosen as the core material for the new fuselage. Alcan Airex C 70 series structural PVC foam at various density grades, donated by Alcan Composites Inc. was used throughout this research.

\subsection{Selection of Matrix and Reinforcement Materials}

The current fuselage (Maley, [3]) was manufactured with SC-780 toughened epoxy matrix supplied by Applied Poleramic Inc. (API) and AGP-370-5H satin carbon fibre fabric reinforcement supplied by Hexcel Corporation. The trade studies for the choice of these materials were carried out as part of the previous mouldless VARTM research and can be found in [3]. Preliminary Finite Element Analysis (FEA) carried out in [49] showed that most of the current fuselage structure was overdesigned. In order to reduce the structural weight, Style\# 94132-4H satin carbon fibre fabric supplied by BGF industries was selected for the new fuselage. Additionally, BGF Style\# 106-Plain E-glass fabric was chosen as the finishing layer to provide a smooth surface finish on the outside surfaces of the fuselage. The specifications of the current and the newly selected fabrics are compared in Table 5.4.

Table 5.4: Carbon fibre fabric specifications

\begin{tabular}{|l|l|l|l|}
\hline \multicolumn{1}{|c|}{ Specification } & \multicolumn{1}{|c|}{ Hexcel-AGP 370 5H Satin } & \multicolumn{1}{c|}{ BGF-94132-4H Satin } & \multicolumn{1}{c|}{ BGF-106-Plain } \\
\hline Supplier & Hexcel Corporation & BGF Industries & BGF Industries \\
\hline Fibre Type & AS4 (Medium Modulus) & T300 (Medium Modulus) & E-glass \\
\hline Tow & $6 \mathrm{~K}$ & $4 \mathrm{~K}$ & $1 \mathrm{~K}$ \\
\hline Weave Style & $5 \mathrm{H}$ Satin & $4 \mathrm{H}$ satin & Plain \\
\hline Weight & $11.1 \mathrm{oz} / \mathrm{yd}^{2}$ & $5.8 \mathrm{oz} / \mathrm{yd}^{2}$ & $0.72 \mathrm{oz} / \mathrm{yd}^{2}$ \\
\hline
\end{tabular}


In the new fuselage, PR 2712 infusion epoxy from PTM\&W Industries Inc. was substituted for SC-780 epoxy. Both resin systems are comparable in terms of infusion characteristics and mechanical properties. The choice was primarily attributed to the lower cost and supply of PR 2712 epoxy from local distributor Composites Canada. The material supplier details for the matrix and reinforcement materials are given in Appendix A.

\subsection{Material Selection for Rigid Inserts}

The GeoSurv II fuselage has several structural joints (i.e. bolted pin-joints) through which discrete loads are introduced into the sandwich structure. Due to the relatively low strength of the foam core, such locations are susceptible to local failure and must be reinforced with rigid inserts. The current fuselage uses Delrin ${ }^{\otimes}$ inserts, which were bonded using a structural epoxy adhesive. Delrin ${ }^{\circledast}$ is machinable and exhibits high specific strength. However, it does not adhere well to epoxy, often causing failure in the bondline where the insert interfaces with the fuselage. Hence, alternatives including Fibreglass Reinforced Polymer (FRP), Poly-Ether Ether Ketone (PEEK ${ }^{\mathrm{TM}}$ ) and glass filled PEEK inserts were considered for the new fuselage. Costs and mechanical properties of the aforementioned materials are shown in Figure 5.5. 


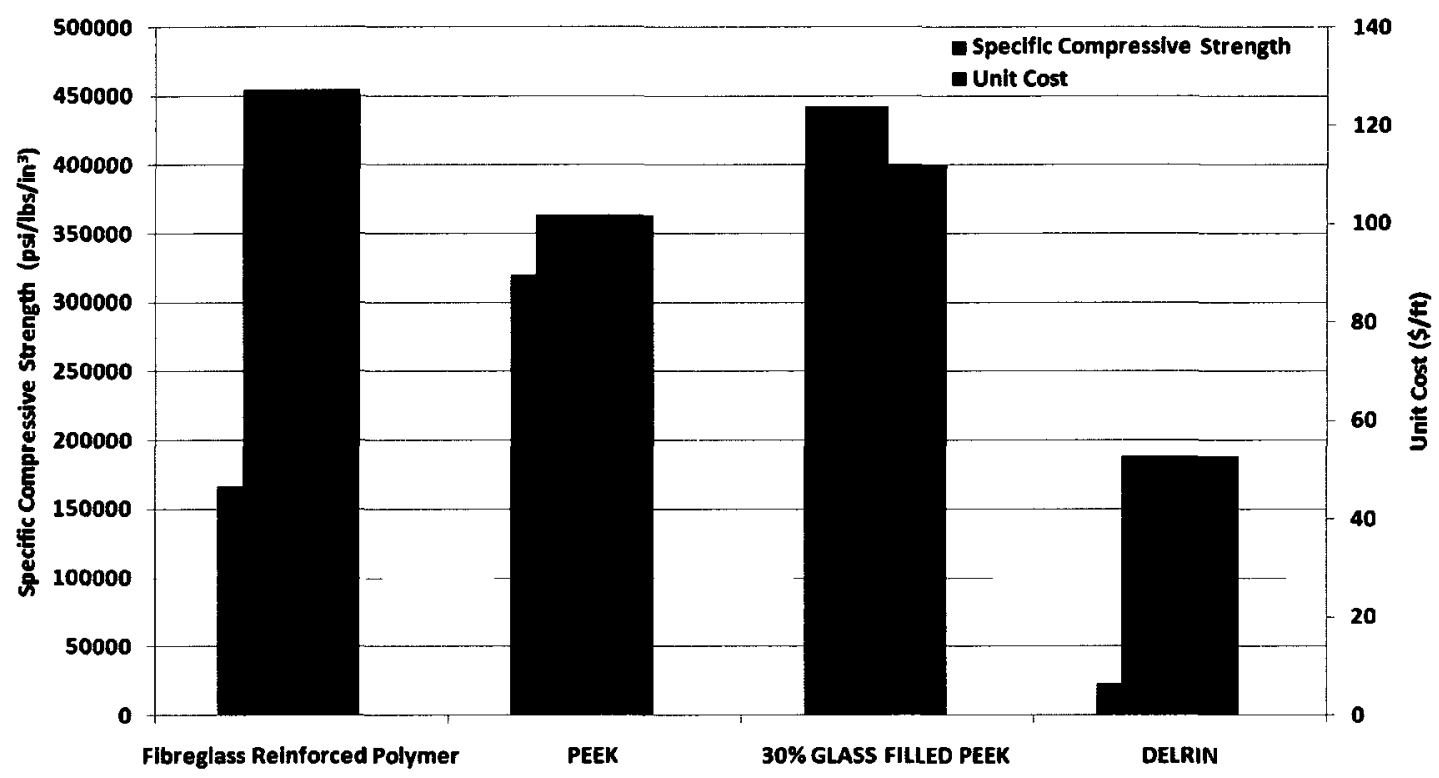

Figure 5.5: Comparison of inserts for sandwich assembly ${ }^{4}$

PEEK and Glass Filled PEEK are both considerably lighter than FRP and meet the strength requirements of the fuselage. However, they are relatively expensive, difficult to machine and exhibit poor impact characteristics. FRP inserts are relatively inexpensive compared to PEEK and exhibit good impact properties, specific strength and machinability. Hence, FRP inserts were selected for the new fuselage. The specifications and supplier information of the inserts are included in Appendix D.

\footnotetext{
${ }^{4}$ Note: the unit cost was estimated for 1 in. diameter rods.
} 


\section{CHAPTER 6. FUSELAGE REDESIGN}

The redesign objectives and design changes made to the GeoSurv II fuselage are described in this chapter. An improved GeoSurv II fuselage model is also presented.

\subsection{Redesign objectives}

The main objective of the fuselage redesign is to improve upon the current design with the intention of producing a near-net-shape fuselage by mouldless manufacturing. The new fuselage shall replace the current fuselage in the GeoSurv II prototype, while interfacing with already manufactured sub-assemblies, such as the wing. The redesign goals and limitations established based on these intentions are summarized in Table 6.1.

Table 6.1: GeoSurv II fuselage redesign: goals and limitations

\begin{tabular}{|l|l|}
\hline \multicolumn{1}{|c|}{ Redesign Goals } & \multicolumn{1}{c|}{ Redesign Limitations } \\
\hline$>$ Reduce weight and improve part quality & $>$ Design for mouldless manufacturing: foam \\
core sandwich construction
\end{tabular}

The fuselage redesign work-flow diagram is shown in Figure 6.1. DFM and IM principles were applied to improve the manufacturability of the current fuselage by mouldless CCBM. The underlying principle behind this work is continuous product and quality improvement, while ensuring that the proposed design specifications are in fact achievable with the selected process. In this work, several DFM and IM principles outlined in [50] were considered, including minimum part count, ease of fabrication and assembly. The following section presents the design changes and the improved design concept of the new fuselage. 


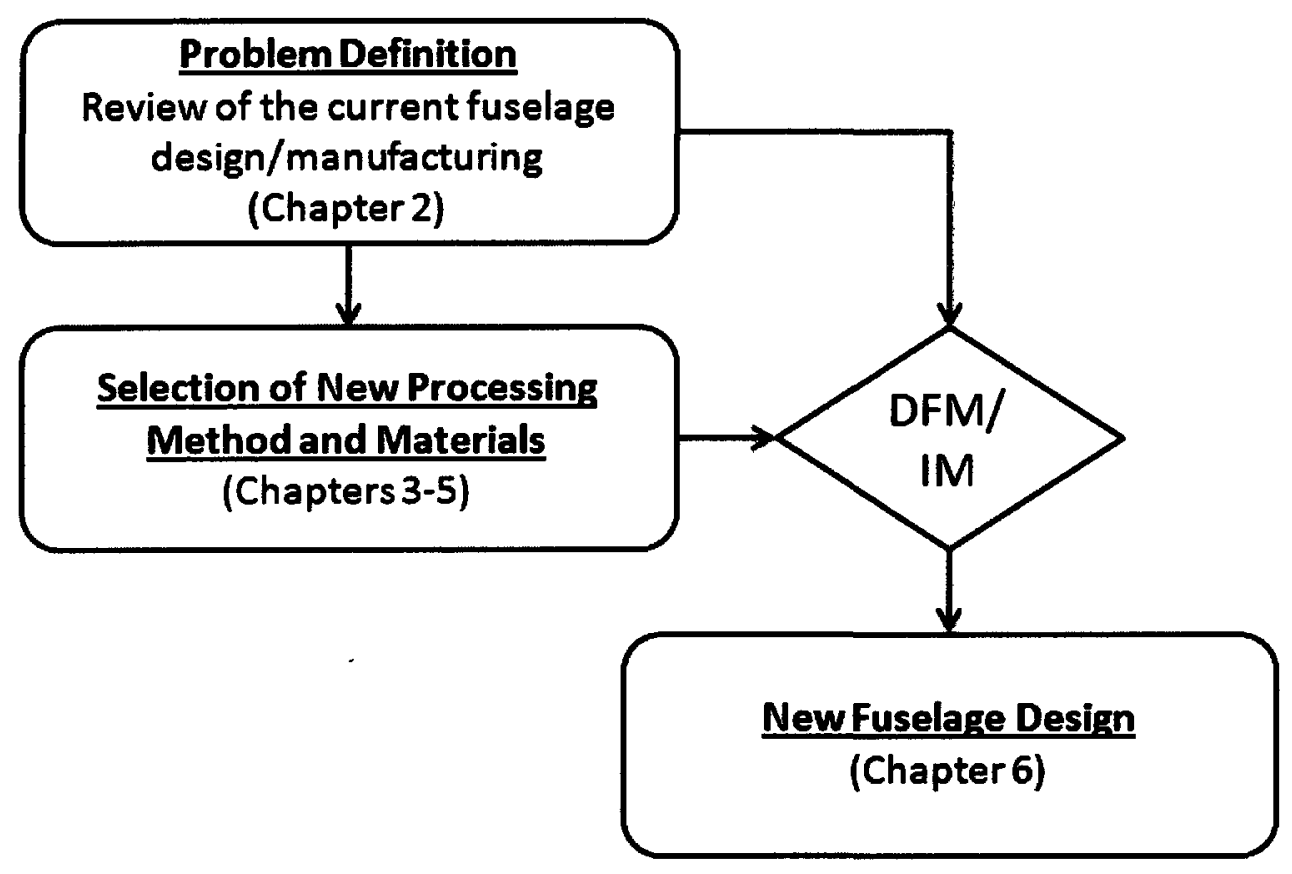

Figure 6.1: Fuselage redesign work-flow diagram

\subsection{Design Changes to the GeoSurv II Fuselage}

The new fuselage walls were designed with edge-stiffened panels in place of the current 'tapered' panels, as shown in Figure 6.2. The required flexural rigidity can be achieved with thinner edge-stiffened panels than with tapered panels (validated through FEA), resulting in potential weight reduction and increased internal volume of the fuselage. Additionally, the use of edge-stiffened panels increases the lengthwise stiffness of the fuselage walls and might potentially reduce the part distortion experienced during mouldless manufacturing. 


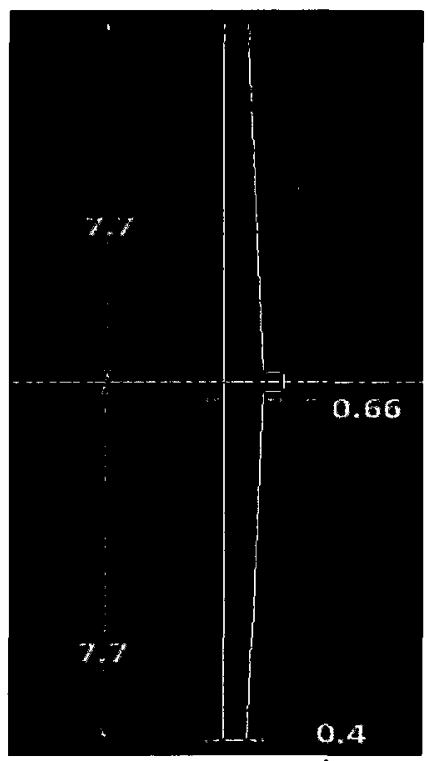

Current Fuselage

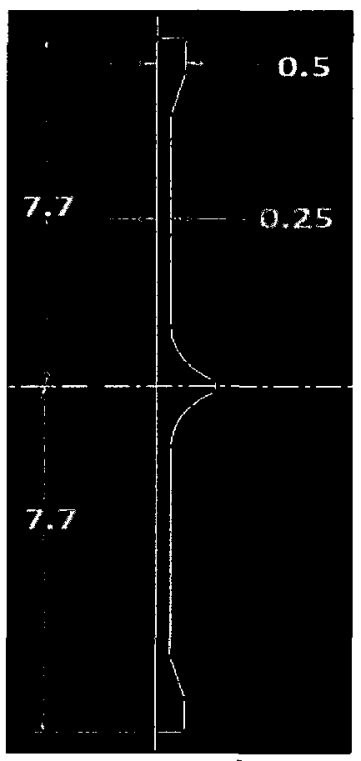

New Fuselage

Figure 6.2: Current and the new fuselage wall design (units: in.)

In the new design, rigid inserts will be embedded into the foam core prior to fabric layup and infusion. A bolted sandwich joint that results from this approach is compared to a current fuselage joint in Figure 6.3. In its current configuration, rigid inserts are secondarily bonded into the fuselage and washers are sandwiched in-between the nut and bolt. This approach requires oversized washers to properly transfer out-of-plane loads into the fuselage. The reason is to minimize stresses within the secondary bond line at the outer surface of the insert. In the new joint design, the loads are transferred into the fuselage through normal contact of the bolt with the skin and the insert. Additionally, the bonded area at the skin-insert interface also aids in distributing the loads into the structure, thereby eliminating the need for oversized washers. The use of small washers combined with in-situ bonding of skin and inserts is expected to result in a lighter yet structurally sound bolted joints. 


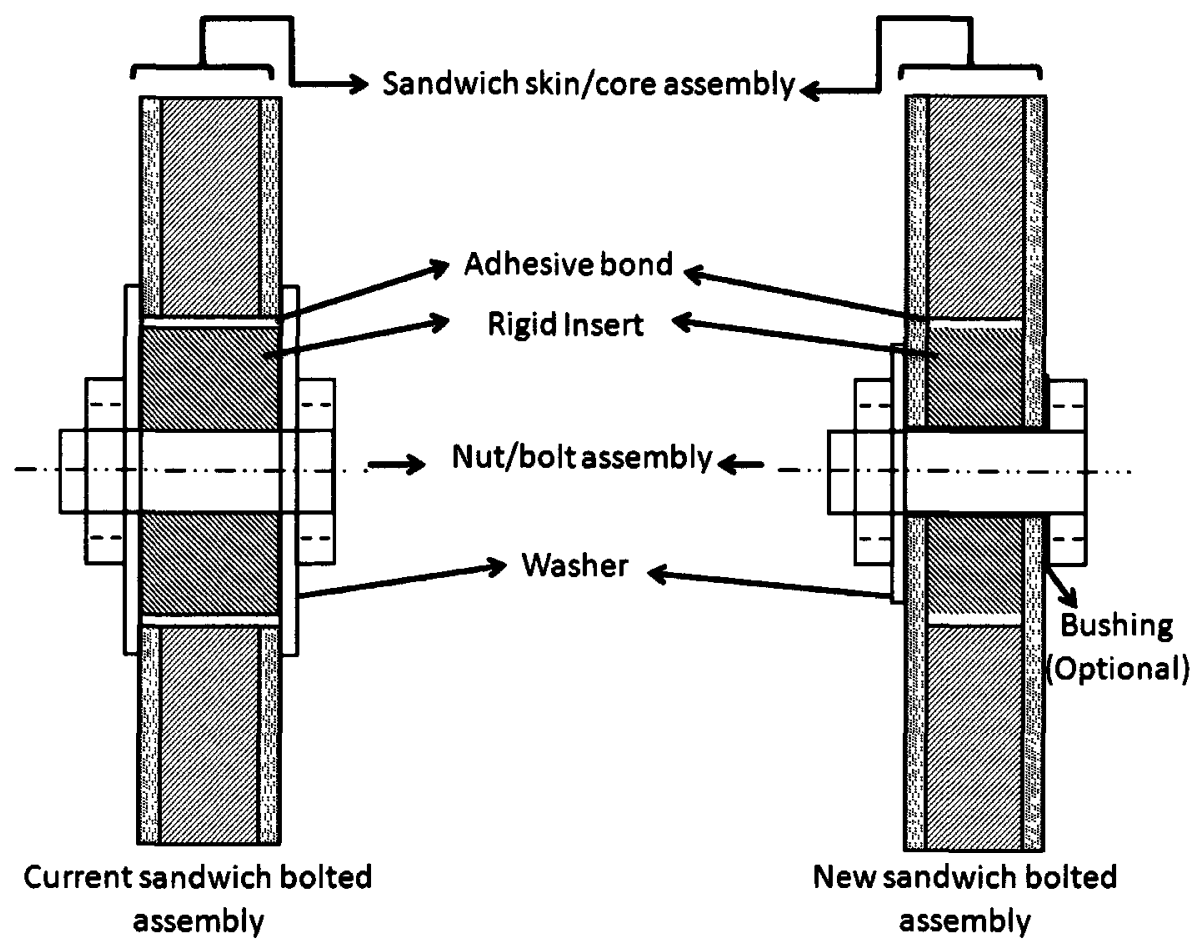

Figure 6.3: Current and the new bolted sandwich assembly

The new fuselage also incorporates a landing gear attachment plate to facilitate mounting of the main landing gear, as shown in Figure 6.4. The new design shifts the attachment point of the landing gear $5.5 \mathrm{in}$. aft of the current design. This design change simplifies the complex swept-back main landing gear design into a straight-beam configuration, as shown in Figure 6.5. Eliminating the sweep from the landing gear also reduces the moment experienced during one wheel landing from 12500 in-lbs to 9200 in-lbs. Thus, this design change offers potential weight savings in the main landing gear strut and the landing gear attachment panel. 

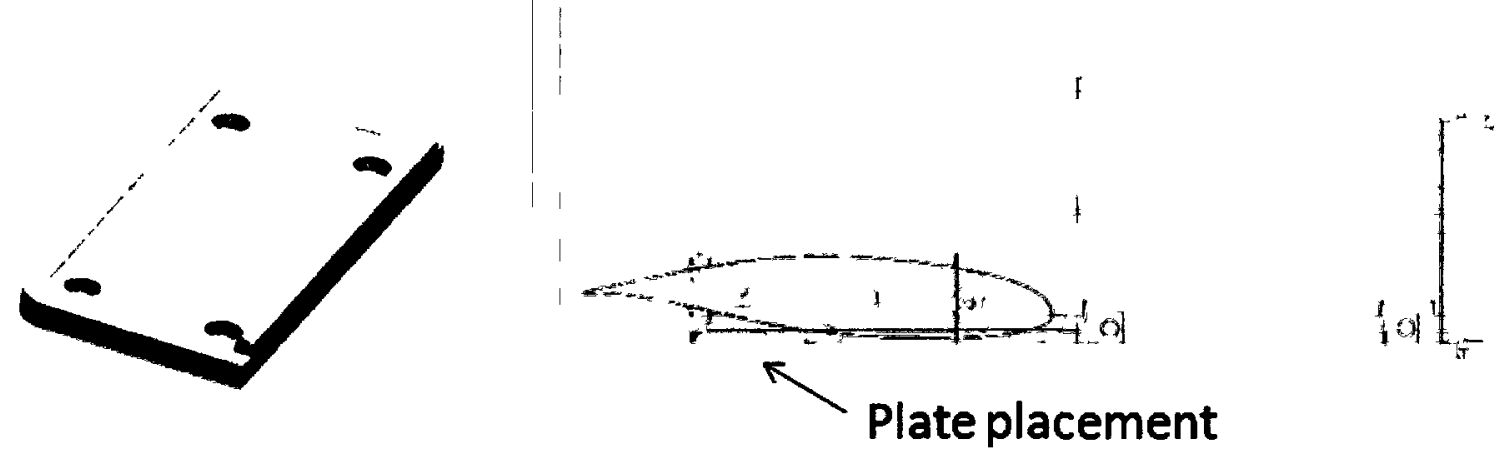

\section{Landing Gear Attachment Plate}

Figure 6.4: New landing gear attachment plate

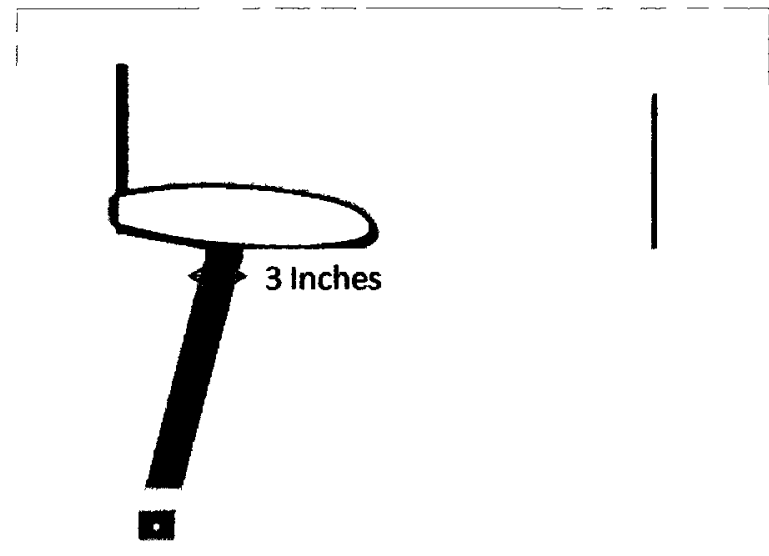

Current Landing Gear Configuration

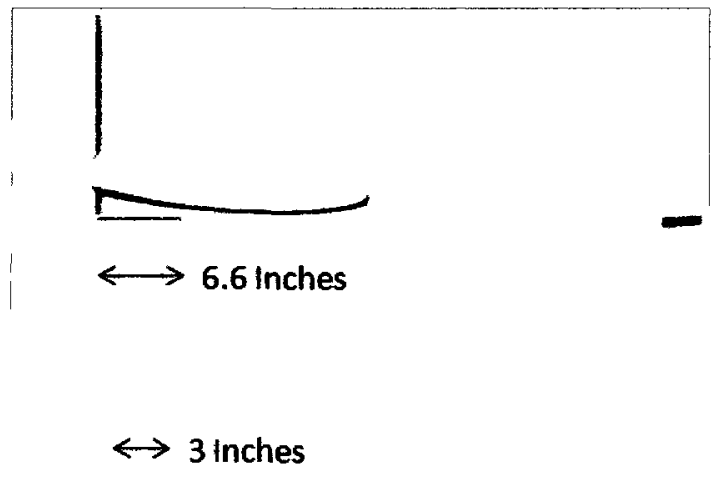

New Landing Gear Configuration

Figure 6.5: Current and the new landing gear configurations

Several other design changes were made to improve the manufacturability and minimize the effort required to prepare the fuselage for assembly. These include: extension of the straight section of the fuselage wall (Figure 6.6), geometry modification to facilitate mounting of the shear-pins (Figure 6.7), increased core thickness at the location of the fasteners (Figure 6.8), an extension on the front bulkhead to substitute for the secondary bonded nosecone bridge 
(Figure 6.9) and reinforcement for mounting of the flight avionics rack (Figure 6.10). In the process of applying Integrated Manufacturing (IM) principles, the bay separator panel, shown in Figure 2.5 was not included in the foam components, as it would complicate the vacuum bagging process. The redesigned fuselage model is shown in Figure 6.11.

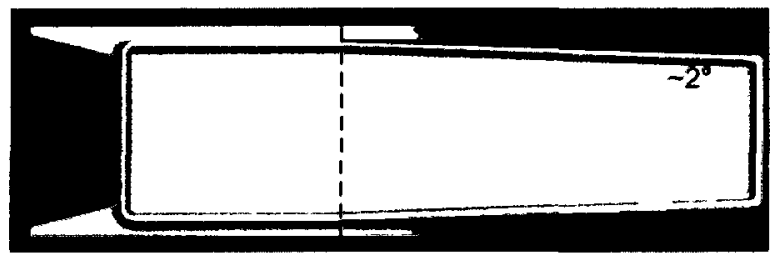

Current Fuselage

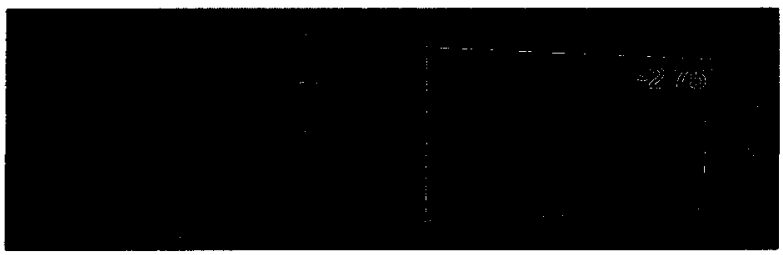

New Fuselage

Figure 6.6: Fuselage wall straight section extension

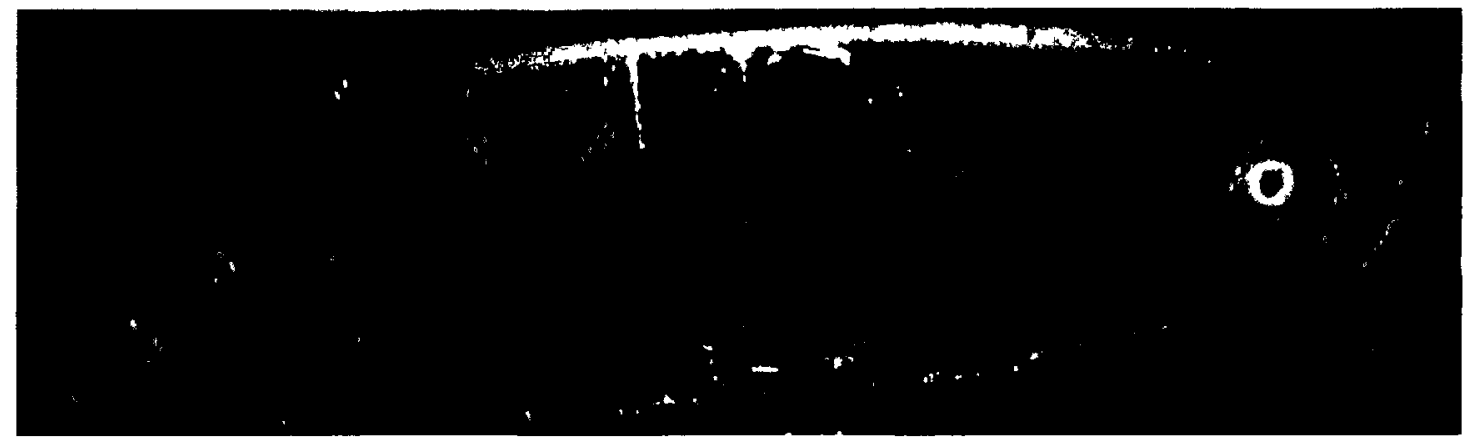

Current Design

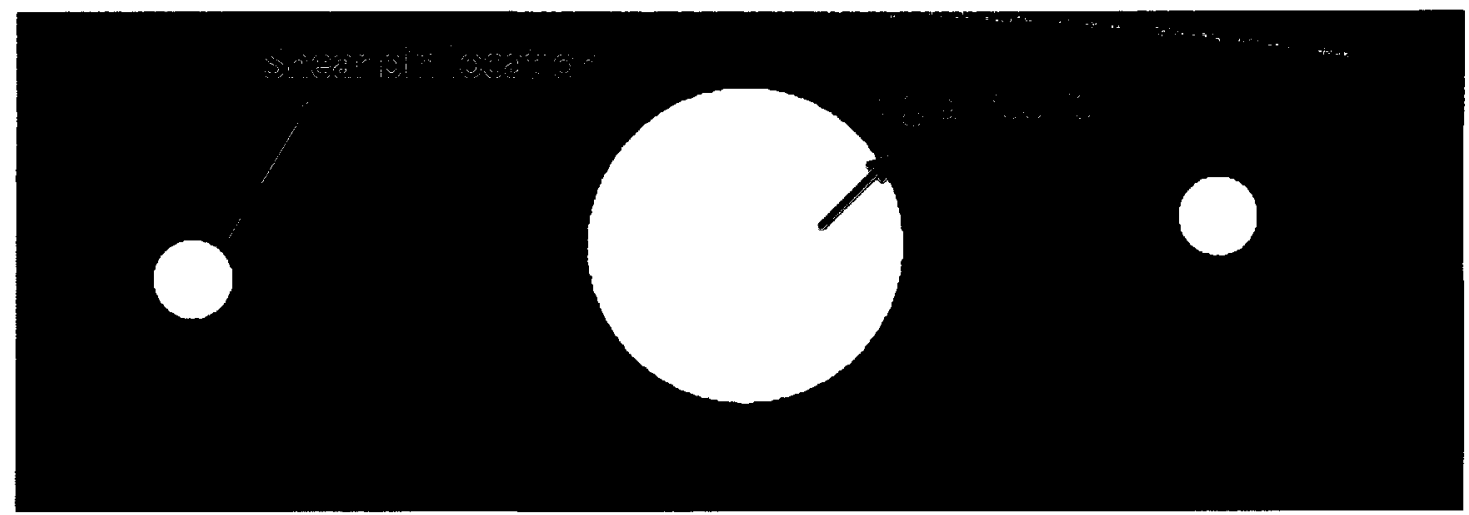

New Design

Figure 6.7: Design modification at the fairings 


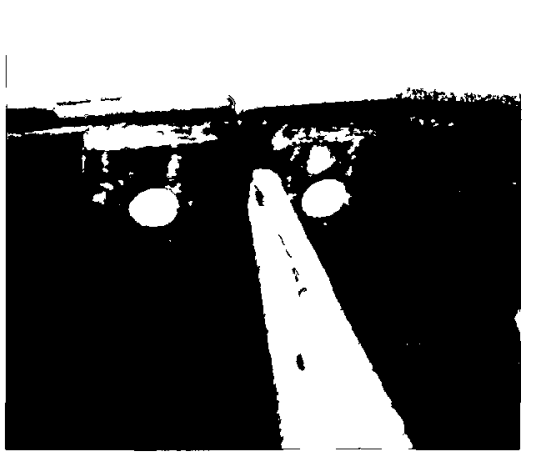

Current Fuselage

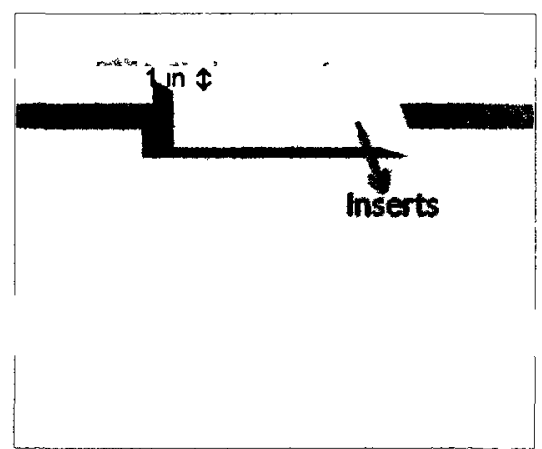

New Fuselage

Figure 6.8: Increased core thickness at the locations of the fasteners

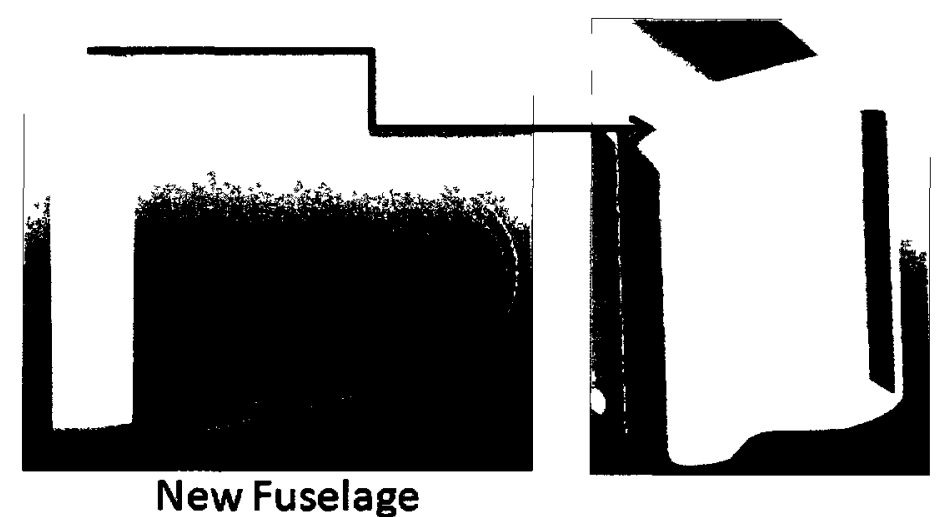

\section{Current Fuselage New Fuselage}

Figure 6.9: Core extension to mount the nosecone

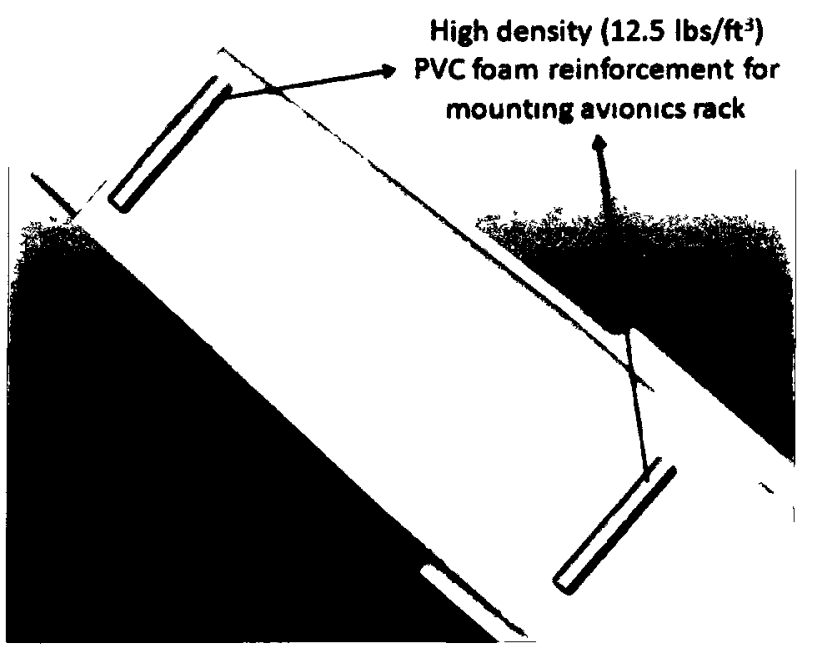

Figure 6.10: Reinforcement for flight avionics rack 


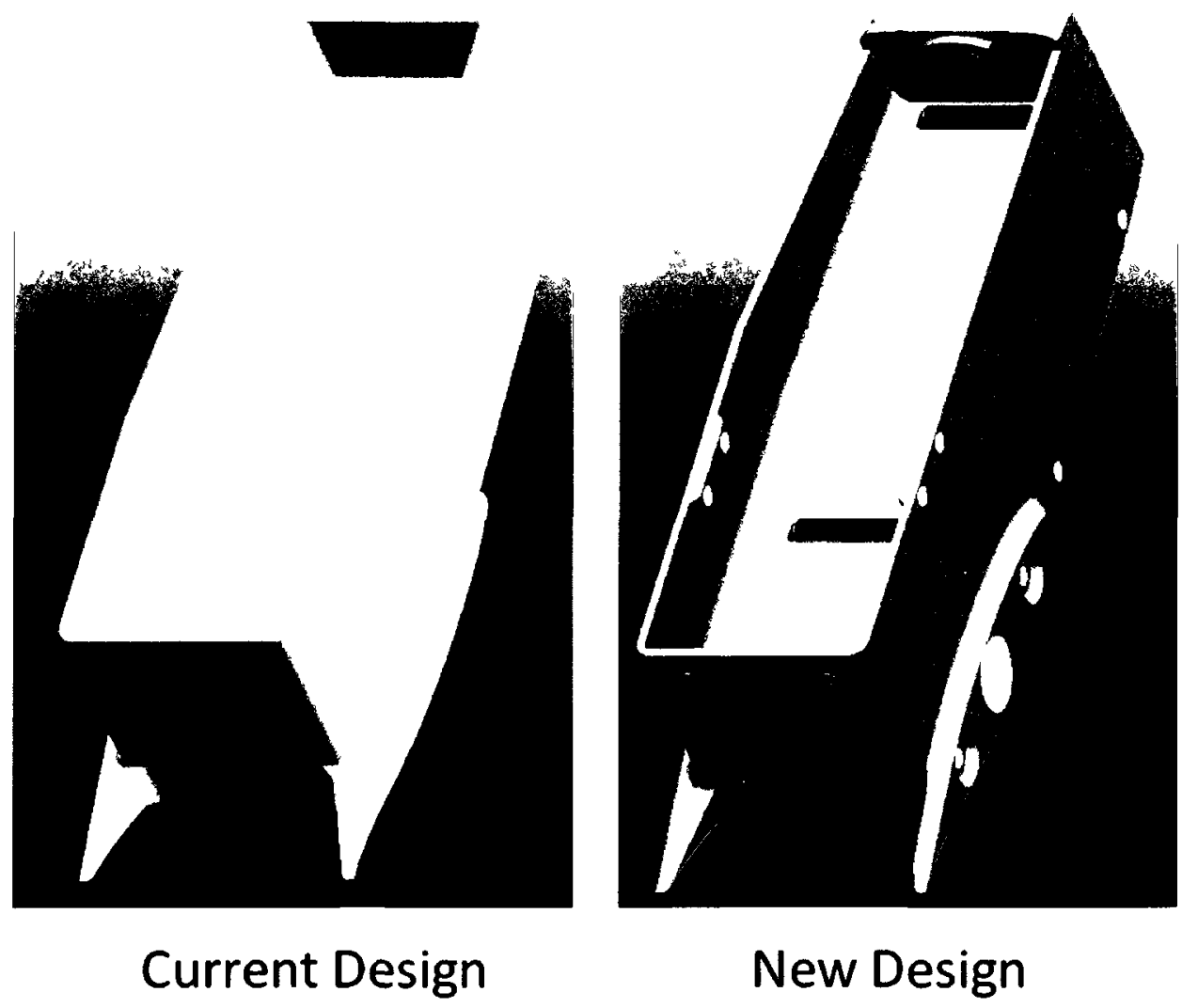

Figure 6.11: Current and the Modified fuselage concept models 


\section{CHAPTER 7. DESIGN OPTIMIZATION}

This chapter presents the Finite Element Analysis (FEA) carried out to optimize the new fuselage and the experimental study conducted to verify selected FEA results.

\subsection{GeoSurv II Fuselage FEA}

A Finite Element Analysis (FEA) was carried out on the GeoSurv II fuselage, to simulate the structural performance of the new design under flight manoeuvre and landing loads. The objective of this FEA was to obtain complete stress-strain profiles at critically loaded areas of the fuselage, to allow for failure predictions and layup optimization of the new design. The FEA was carried out using Abaqus 6.8-2, as a linear-elastic stress analysis with several other simplifying assumptions (discussed in the following sections). The FEA results for selected loading conditions were verified experimentally using test coupons. The following sections describe the FEA procedure and results.

\subsubsection{FE Model Construction}

The parts required to create one half of the fuselage assembly were modelled using the Abaqus CAE modeller. The parts list includes foam core, skin, wing carry-through spar, bushing, engine pins, nose and main landing gear pins and wing shear pins. The foam core was modelled as one 3-D deformable solid part and the skin was created from the core, using the "create shell: from solid" feature available in Abaqus CAE modeller. The carry-through spar was modelled as a circular shell extrusion and all other components were created as 3-D deformable solids with appropriate features, as shown in Figure 7.1. 
The rationale behind the half model was to impose the symmetry condition in the FEA and hence, reduce the computational time required to run the simulations. To further reduce the simulation times and expedite the meshing process, several simplifications were made to the part geometries. The geometric simplifications were as follows:

$>$ Pins were modelled as circular extrusions.

Fillets and chamfers farther away from the highly loaded areas were excluded from the part geometry.

Skins at the top and bottom edges of the fuselage that do not contribute to its load carrying capabilities were not modelled.

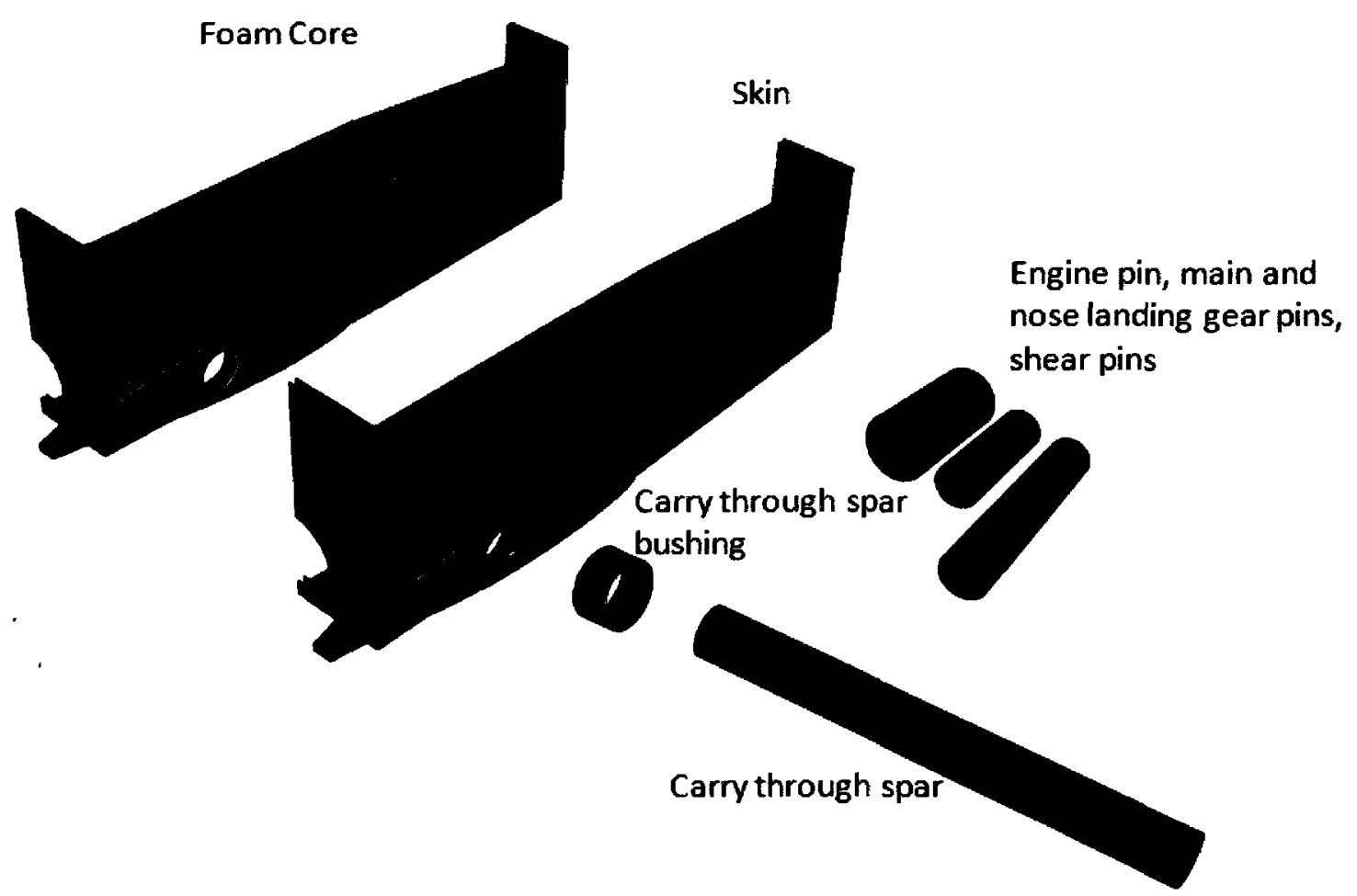

Figure 7.1: Parts modelled for the fuselage FEA 


\subsubsection{Material Properties}

The following sections describe the material properties and assumptions employed for various parts of the fuselage assembly.

\section{Foam Core:}

Airex C structural PVC foam at different density grades, supplied by Alcan Composites was used as the core material for the new fuselage. Previous research in [51] has shown that PVC foams are transversely isotropic. However, the variation of material properties along different directions, which is caused by the differences in the cellular development during the foam expansion process, is rather small and hence ignored for the purpose of this FEA. Thus, the conditions: $E_{1}=E_{2}=E_{3}$ and $G_{12}=G_{13}=G_{23}$ were established in the FEA. The values of $E$ and $G$ were obtained from the material properties published by the manufacturer.

There was no measured or published value of Poisson's ratio ( $v$ ) for PVC foams. This was because under uniaxial loading, PVC foams show nearly no deformation along the transverse axis of the test direction and the respective strains are rather difficult to measure. Additionally, the PVC foams do not exactly obey the linear-elastic relation between $E, G$ and $U$. For this reason, a Poisson's ratio of 0.32 was assumed [52] along with the condition $v_{12}=v_{13}=v_{23}$. Various density grade PVC foams were modelled with properties as shown in Table 7.1. Material sections having properties of various density PVC foams were established in the FEA using the "Engineering Constants" entry, found in the property module of Abaqus CAE. Subsequently, the parts were assigned appropriate material orientations using local coordinate systems. 
The foam core was created as one solid component and was partitioned into different sections. These partitions were assigned different section properties to represent the parts made with different density PVC foams (Table 7.1). Thus, a multi-part fuselage foam assembly was created as single part in the FE model. This section property formulation assumes a perfect bond between different foam parts, which is a reasonable assumption, given that the adhesive used to bond the foam parts is stronger than the foam.

Table 7.1: Properties of Airex C PVC foam

\begin{tabular}{|c|c|c|c|c|}
\hline $\begin{array}{c}\text { Airex C Structural } \\
\text { PVC Foam }\end{array}$ & $\begin{array}{c}\text { Density } \\
\left(\mathbf{l b s} / \mathrm{ft}^{3}\right)\end{array}$ & $\begin{array}{c}\mathbf{E}_{\mathbf{1}}=\mathrm{E}_{\mathbf{2}}=\mathrm{E}_{\mathbf{3}} \\
(\mathbf{p s i})\end{array}$ & $\mathrm{v}_{\mathbf{1 2}}=\mathrm{v}_{\mathbf{1 3}}=\mathrm{v}_{\mathbf{2 3}}$ & $\begin{array}{c}\mathbf{G}_{\mathbf{1 2}}=\mathbf{G}_{\mathbf{1 3}}=\mathbf{G}_{\mathbf{2 3}} \\
(\mathbf{p s i})\end{array}$ \\
\hline C70.40 & 2.5 & 5947 & 0.32 & 1900 \\
\hline C70.55 & 3.7 & 10000 & 0.32 & 3190 \\
\hline C70.75 & 5.0 & 15080 & 0.32 & 4350 \\
\hline C70.90 & 6.2 & 18850 & 0.32 & 5802 \\
\hline C70. 200 & 12.5 & 40600 & 0.32 & 10900 \\
\hline
\end{tabular}

\section{Skin:}

The new fuselage features carbon-epoxy composite skins with BGF-Style\# 94132-4 H satin carbon fibre fabrics and PTM\&W-PR 2712 epoxy. In the FEA, each ply of the woven fabric was modelled as two unidirectional laminae, with half the total ply thickness. Since no characterization data were available for these materials at the time of this analysis, the lamina properties were derived from in-house coupon test data (Table 7.2) available for the current fuselage materials. The current fuselage skin features Hexcel-AGP-370 5H satin carbon fibre fabric and API-SC-780 epoxy. Both SC-780 and PR 2712 resin systems have similar mechanical properties and are compatible with carbon fibre fabrics. The major difference between Style\# 
94132 and AGP 370 fabrics lies in the fibre type and the crimp angle. The AGP 370 fabric features AS4C type fibres with 6k tow count while the Style\# 94132 fabric features T300 fibres with $3 k$ tows. However, both fabrics are compatible with epoxy resins, which allows for realistic prediction of lamina properties for the new fabric-resin combination, from the test data available for the previous reinforcement and matrix materials. The derivation of the new lamina properties used in the FEA is described in Table 7.3.

Table 7.2: Properties of the current fuselage materials

\begin{tabular}{|l|c|c|c|c|c|c|}
\hline Material & $\begin{array}{c}\text { Tensile } \\
\text { Strength } \\
\text { (psi) }\end{array}$ & $\begin{array}{c}\text { Tensile } \\
\text { Modulus } \\
\text { (psi) }\end{array}$ & $\begin{array}{c}\text { Strain to } \\
\text { Failure } \\
\text { (Tension) }\end{array}$ & $\begin{array}{c}\text { Shear } \\
\text { Strength } \\
\text { (psi) }\end{array}$ & $\begin{array}{c}\text { Shear } \\
\text { Modulus } \\
\text { (psi) }\end{array}$ & $\begin{array}{c}\text { Strain to } \\
\text { Failure } \\
\text { (In-plane } \\
\text { shear) }\end{array}$ \\
\hline $\begin{array}{l}\text { AGP370 5H satin carbon } \\
\text { fibre fabric /SC-780 epoxy }\end{array}$ & 122400 & 9325900 & 0.013 & 8600 & 102250 & 0.05 \\
\hline
\end{tabular}


Table 7.3: Derivation of lamina properties for the new fuselage

\begin{tabular}{|c|c|c|c|}
\hline $\begin{array}{l}\text { Available/Estimated } \\
\text { Properties }\end{array}$ & Source & Knock Down Factor and Rationale & Derived properties \\
\hline E $1=9325900 \mathrm{psi}$ & $\begin{array}{l}\text { In-house coupon } \\
\text { testing }\end{array}$ & $\begin{array}{l}\text { N/A: T } 300 \text { and AS4C fibres have } \\
\text { similar moduli }\end{array}$ & E $1=9325900$ psi \\
\hline$E 2=932590$ & $\begin{array}{l}\text { Hart Smith's } 10 \% \\
\text { rule [53] }\end{array}$ & N/A & $E 2=932590$ psi \\
\hline$G_{12}=102250$ & $\begin{array}{l}\text { In-house coupon } \\
\text { testing }\end{array}$ & $\begin{array}{l}\text { N/A: In-plane shear is a matrix } \\
\text { dominated property }\end{array}$ & $G_{12}=102250 \mathrm{psi}$ \\
\hline$G_{13}=10225$ & $\begin{array}{l}\text { Hart Smith's } 10 \% \\
\text { rule [53] }\end{array}$ & N/A & $G_{13}=10225$ psi \\
\hline$G_{23}=10225$ & $\begin{array}{l}\text { Hart Smith's } 10 \% \\
\text { rule [53] }\end{array}$ & N/A & $\mathrm{G}_{23}=10225 \mathrm{psi}$ \\
\hline$v=0.3$ & $\begin{array}{l}\text { Typical for carbon- } \\
\text { epoxy composites }\end{array}$ & N/A & $v=0.3$ \\
\hline $\begin{array}{l}\text { Tensile strength }= \\
122400 \text { psi }\end{array}$ & $\begin{array}{l}\text { In-house coupon } \\
\text { testing }\end{array}$ & $\begin{array}{l}-10 \% \text { (T300 vs. AS4) } \\
+10 \% \text { (Crimp angle: } 3 \mathrm{k} \text { vs. } 6 \mathrm{k} \text { ) } \\
-10 \% \text { (Woven fabric = Unidirectional } \\
\text { lamina assumption in the FEA) [54] }\end{array}$ & $\begin{array}{l}\text { Tensile strength }= \\
101160 \text { psi }\end{array}$ \\
\hline $\begin{array}{l}\text { Strain to failure } \\
\text { (Tension) }=0.013\end{array}$ & $\begin{array}{l}\text { In-house coupon } \\
\text { testing }\end{array}$ & $\begin{array}{l}+10 \%(\text { T300 vs. AS4) } \\
-20 \% \text { (Woven fabric = Unidirectional } \\
\text { lamina assumption in the FEA and } \\
\text { additional safety factor of } 10 \%)[54]\end{array}$ & $\begin{array}{l}\text { Strain to failure } \\
\text { (Tension) }=0.011\end{array}$ \\
\hline $\begin{array}{l}\text { Shear strength }=8600 \\
\text { psi }\end{array}$ & $\begin{array}{l}\text { In-house coupon } \\
\text { testing }\end{array}$ & $\begin{array}{l}15 \% \text { of the tensile strength; based on } \\
\text { in-house test data [3] }\end{array}$ & $\begin{array}{l}\text { Shear strength }= \\
15174 \text { psi }\end{array}$ \\
\hline $\begin{array}{l}\text { Strain to failure (In- } \\
\text { plane shear) }=0.05\end{array}$ & $\begin{array}{l}\text { In-house coupon } \\
\text { testing }\end{array}$ & $\begin{array}{l}-20 \% \text { (Woven fabric = Unidirectional } \\
\text { lamina assumption in the FEA and } \\
\text { additional safety factor of } 10 \% \text { ) [54] }\end{array}$ & $\begin{array}{l}\text { Strain to failure }(\mathrm{In}- \\
\text { plane shear) }=0.04\end{array}$ \\
\hline
\end{tabular}

Similar to the foam core, the skin was modelled as a single piece conventional shell in Abaqus and was partitioned into small sections to facilitate section property assignments and local mesh refinements. Highly loaded areas of the skin were locally reinforced by assigning different composite layups.

\section{Carry-through spar, inserts, bushings and pins:}

The carry-through spar was assigned conventional shell composite properties (Table 7.2) with layup $\left[0^{\circ} / 90^{\circ}\right]_{8}$. The steel pins, Delrin ${ }^{\circledR}$ bushings and fibreglass inserts were modelled as 
isotropic materials with properties given in Table 7.4. Since the pins and bushings were employed as connecting elements, to distribute the loads into the structure, an isotropic property formulation was sufficient for this FEA. The inserts were included in the FE model as partitioned sections of the foam core, while the pins and bushings were modelled as separate parts and were assigned their respective material properties. The FEA representation of the inserts assumes a bondline stronger than the foam, at the insert-foam interface. This assumption is acceptable, when a structural epoxy adhesive is used for bonding the inserts into the foam core. Additionally, the inserts are much stronger than the foam and are not expected to fail before the core or the skin. Hence, to simplify the FEA process, they were also modelled with isotropic element properties.

Table 7.4: Properties of pins and bushings

\begin{tabular}{|c|c|c|c|}
\hline Part & Material & $\begin{array}{c}\text { Young's Modulus } \\
\text { (psi) }\end{array}$ & Poisson's Ratio(u) \\
\hline Pins & Stainless Steel (SS) 316 & 27992283 & 0.3 \\
\hline Bushings & Delrin ${ }^{\otimes}$ & 430000 & 0.3 \\
\hline Inserts & Fibreglass Rod & 2800000 & 0.3 \\
\hline
\end{tabular}

\subsubsection{Part Meshing Considerations}

The foam core, inserts, bushing and pins were meshed with C3D8R elements, which are 8-node linear bricks with reduced integration and hourglass control. This is a solid, 3-D stress element in Abaqus that is computationally effective for simplified linear-elastic analysis. The composite skin around the foam core represents a typical plane-stress scenario, in which the thickness of the skin is significantly smaller than the other in-plane dimensions. Hence, they were modelled with S4R elements, which are 4-node, quadrilateral conventional shell elements, featuring reduced integration, hourglass control and finite membrane strains. It is a common practice to 
model plane stress states in this fashion due to improved computational efficiency and lack of through-thickness effects. With the conventional shell formulation, the skin geometry was modelled as a shell and its thickness was defined by specifying a value and a stacking direction in the property module of Abaqus. Similar to the skin, the carry-through spar, which features 8 plies of carbon-epoxy composite, was also modelled as a conventional shell using S4R elements.

The fuselage main frame was meshed by creating a series of partitions to sub-divide the geometry into simple and compatible sections. These partitions (Figure 7.2) facilitate the mesh propagation in a uniform manner through the entire fuselage geometry. Partitions were required in the regions where geometric changes or interactions occur. Additionally, the pin holes were partitioned to be contained in simple square sections, having partitions in a radial fashion towards the holes. This partitioning strategy, illustrated in Figure 7.3, allows biasing the mesh seeds and locally refining the mesh near the highly stressed pin-holes. Thus, the areas away from the critically stressed regions can be meshed in a coarser yet uniform manner to improve the computational efficiency. All other components of the fuselage assembly were relatively simple geometries and were meshed by creating partitions, in a similar manner. 


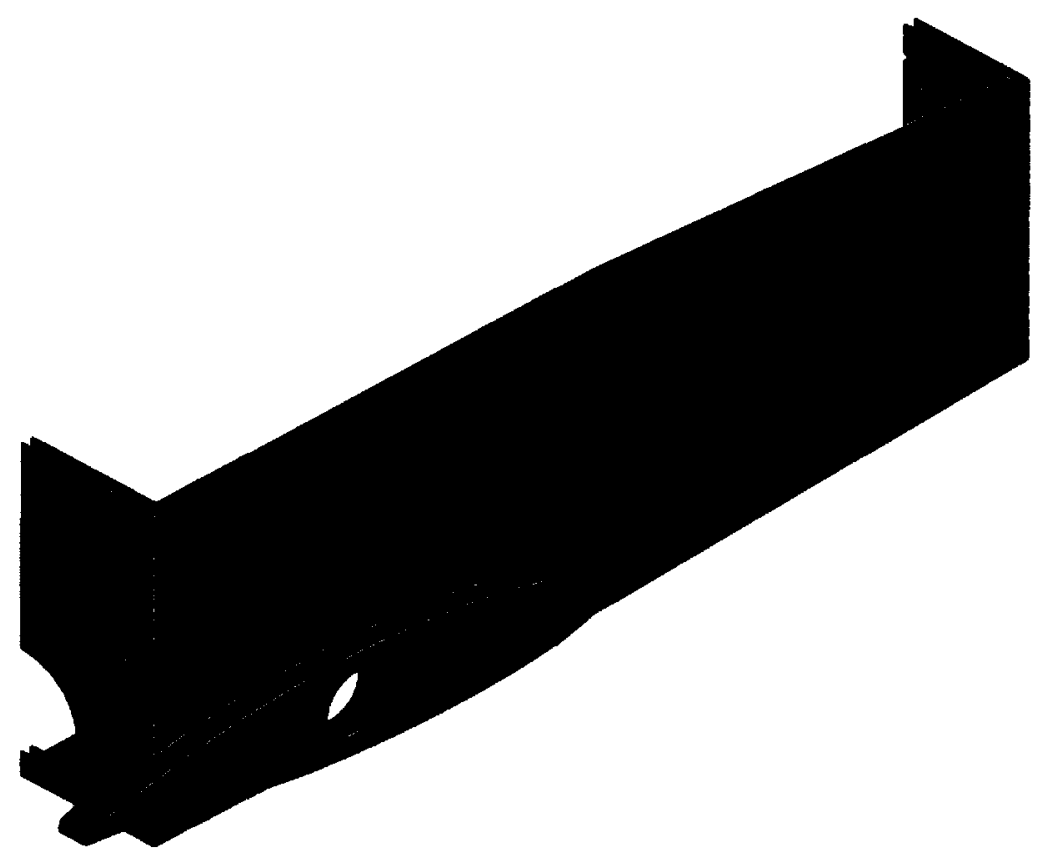

Figure 7.2: Partitions created on the fuselage skin for meshing

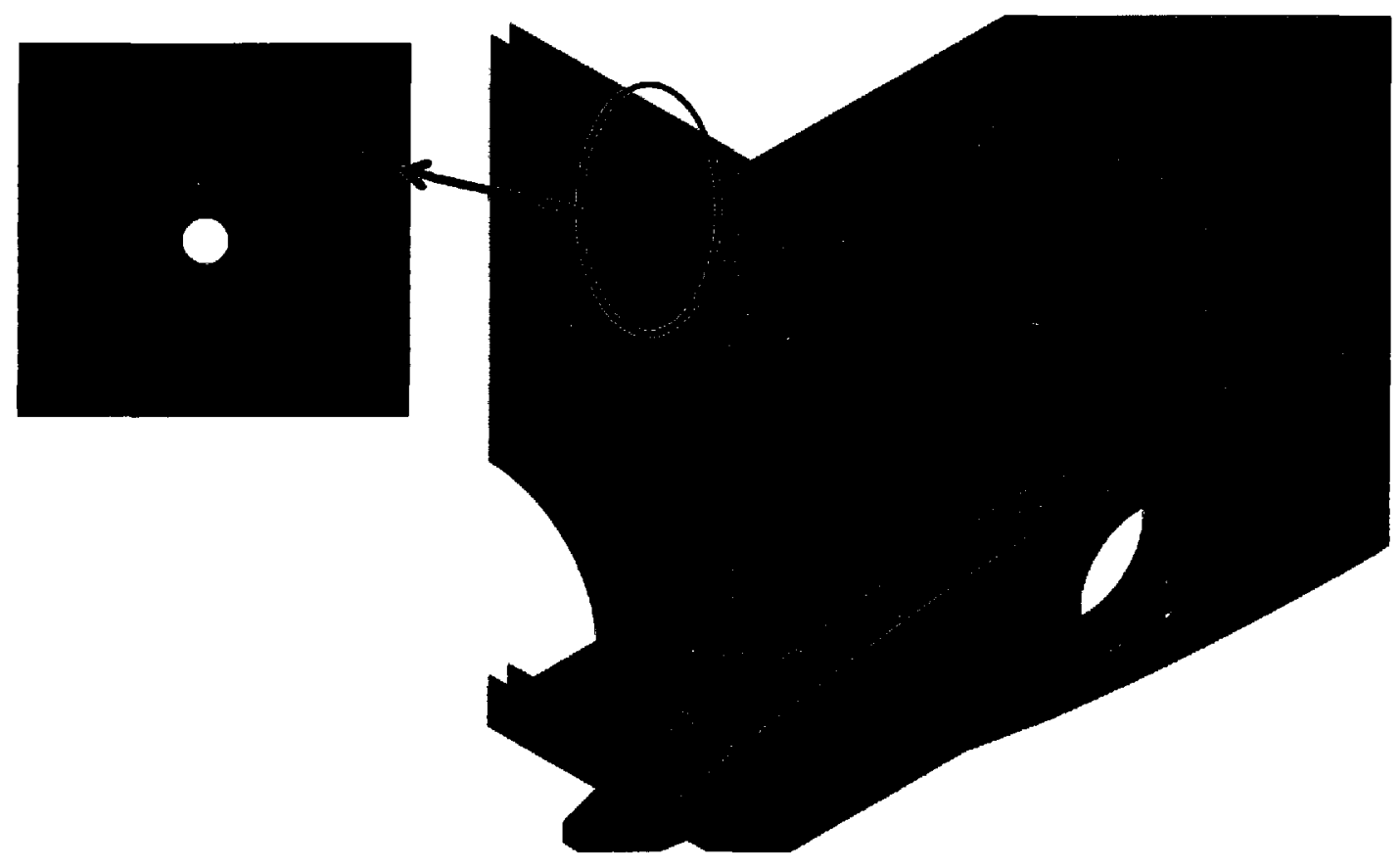

Figure 7.3: Mesh refinement near the pin holes 


\subsubsection{FE Model Assembly and Constraints}

The assembly of the fuselage model was created by importing the required part instances into the Assembly module of Abaqus and applying appropriate position constraints. The final FE model assembly of the fuselage is shown in Figure 7.4. Following the assembly process, tie constraints were established at the regions where the pins and the bushings come in contact with the fuselage structure. In a more realistic attempt to represent bolted pin joints, an analyst would introduce a contact algorithm in the analysis. This approach is more complex and beyond the scope of this FEA. In order to keep the tie constraints formulation realistic for bolted joints, the surface to be tied were carefully chosen based on the loading conditions. Thus, for loading along a particular direction, as in the case of shear pins, only one half of the pin surface was tied to the fuselage structure. For all other pins subjected to simultaneous loads in different directions, the entire pin surface was tied to the fuselage structure, as shown in Figure 7.5.

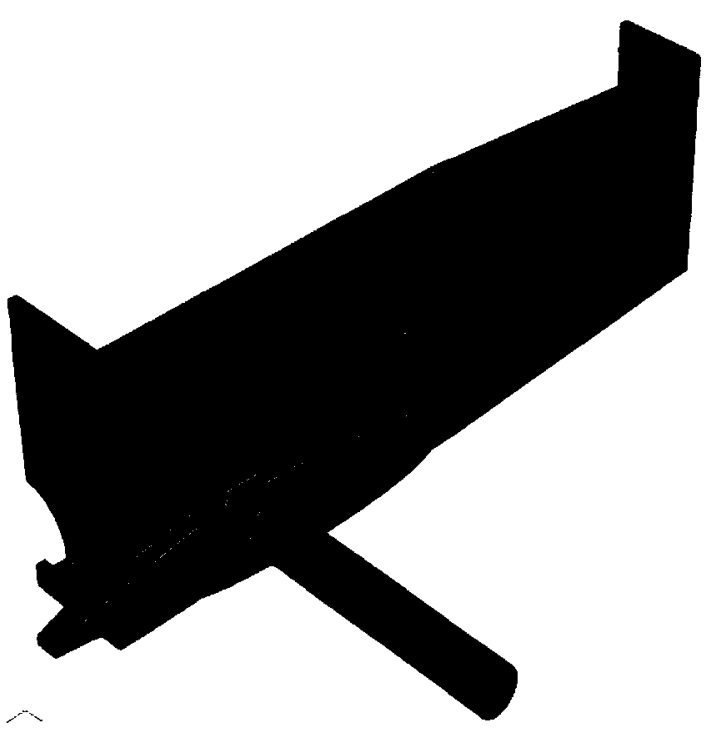

Figure 7.4: Fuselage FE model assembly 

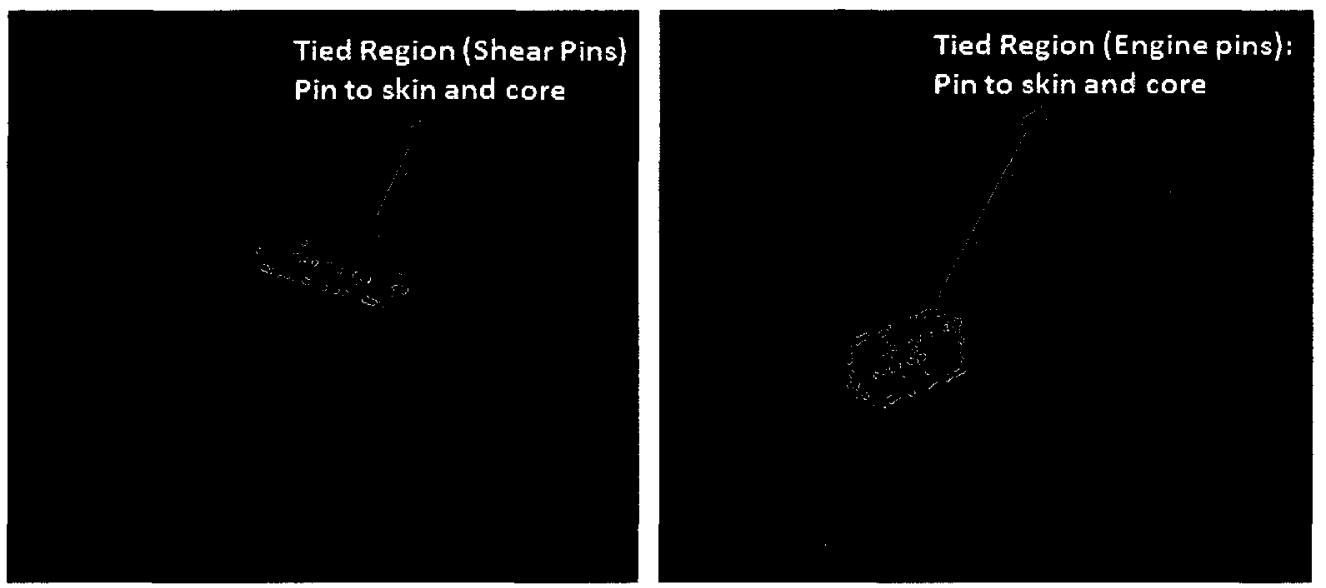

Figure 7.5: Tie constraints established between the pins and the fuselage structure

\subsubsection{Analysis Steps, Loads and Boundary Conditions}

The FEA was implemented in two general static analysis steps: an in-flight step and a landing step. During the in-flight step, the loads from the wings, engine and payload were applied at the maximum design ultimate load (DUL) factor of 10.1, which stems from the maximum positive design limit load (DLL) factor of 6.75 multiplied by the safety factor of $1.5[55,56]$. During the landing step, all in-flight loads were reduced to the maximum landing load factor of 3.5 and the landing loads were introduced. During both analysis steps, the base plate and the top of surface of the fuselage were fixed and symmetry conditions were applied across the surface as shown in Figure 7.6. The load cases considered are illustrated in Figure 7.7 to Figure 7.9. The load factors and the loads were obtained from the GeoSurv II design report registry references [55-57]. 


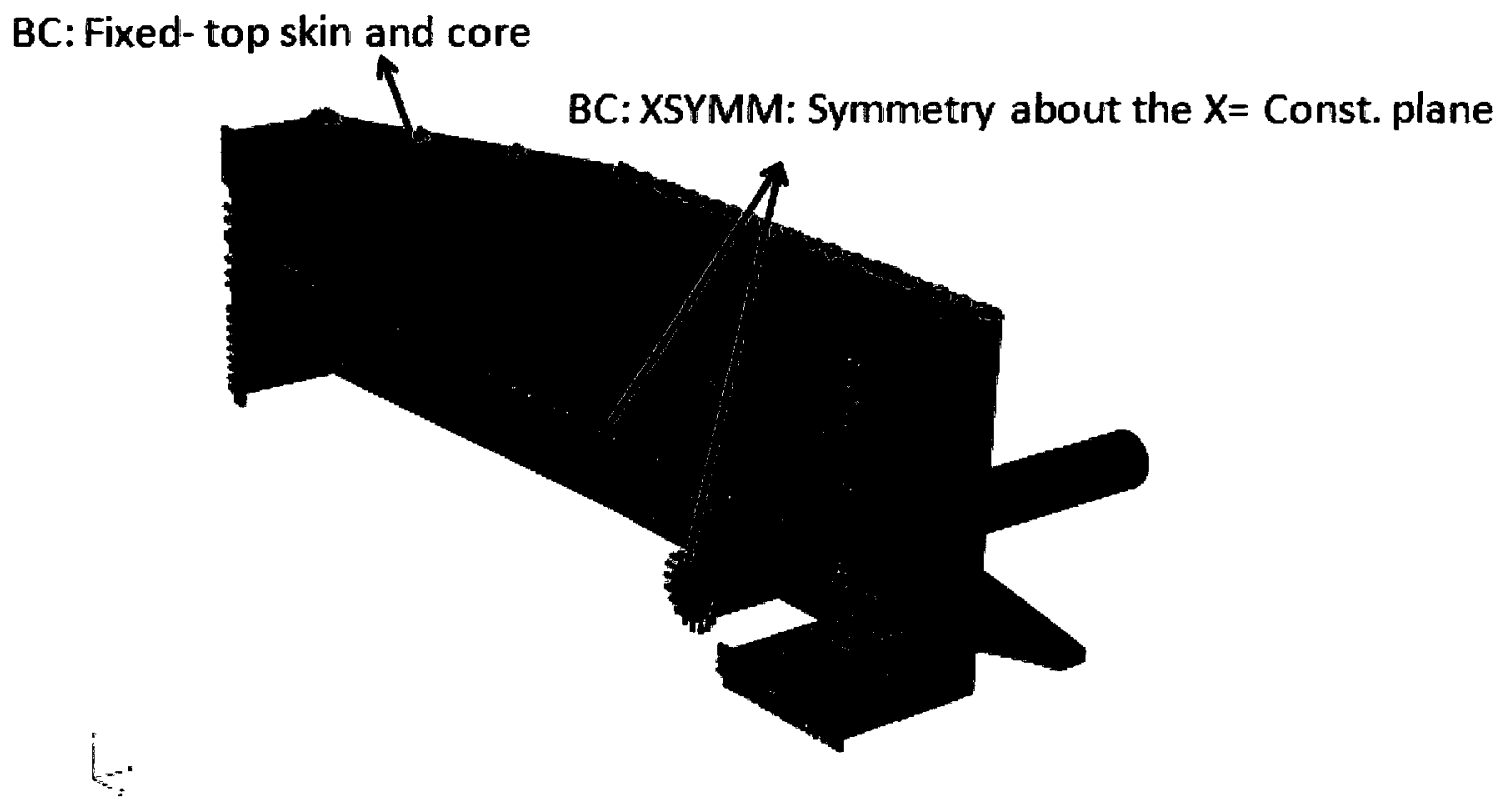

Figure 7.6: Boundary Conditions

Engine Loads:

$\rightarrow$ Torque at $0.8 \mathrm{RPM} 921$ in $\mathrm{lb} / \mathrm{bolt}$

$\rightarrow$ Weight 239 lbs 59.75 lbs/bolt

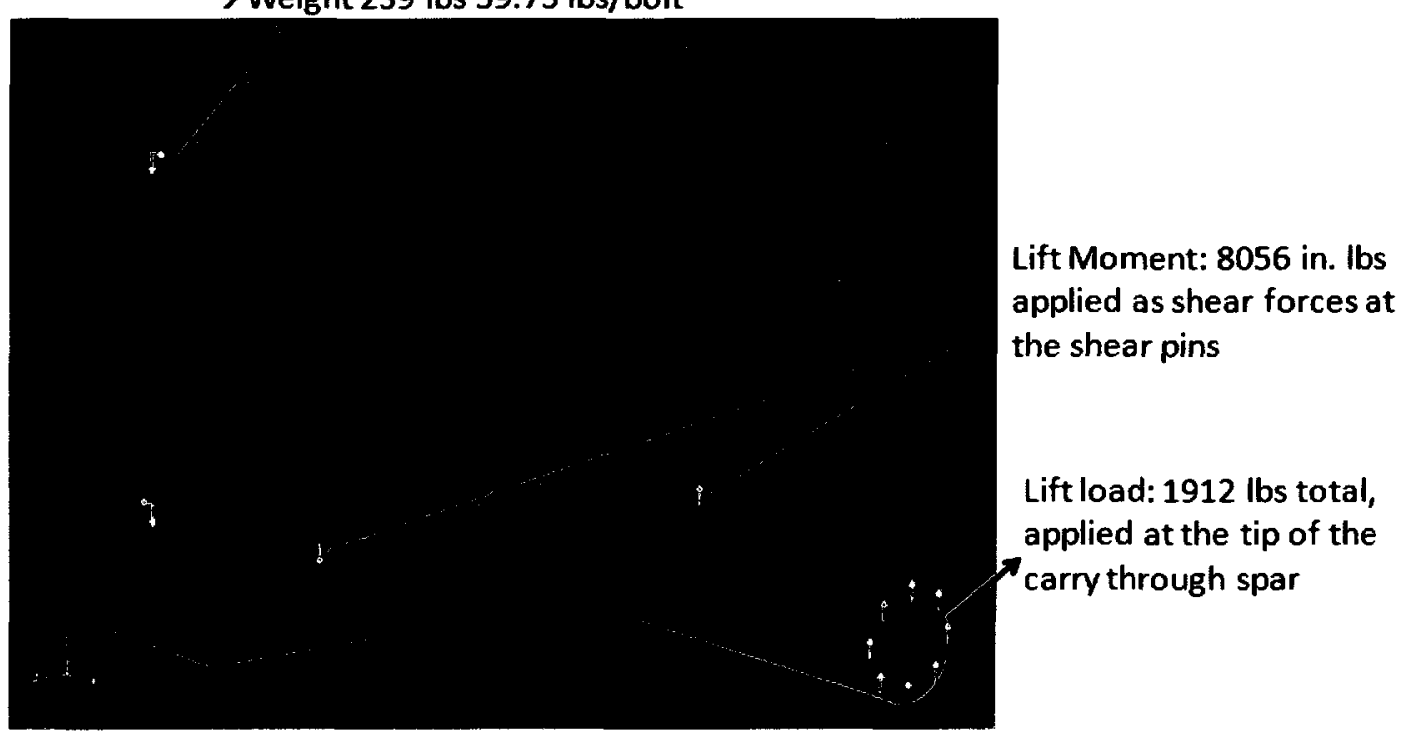

Figure 7.7: Wing lift and engine loads 


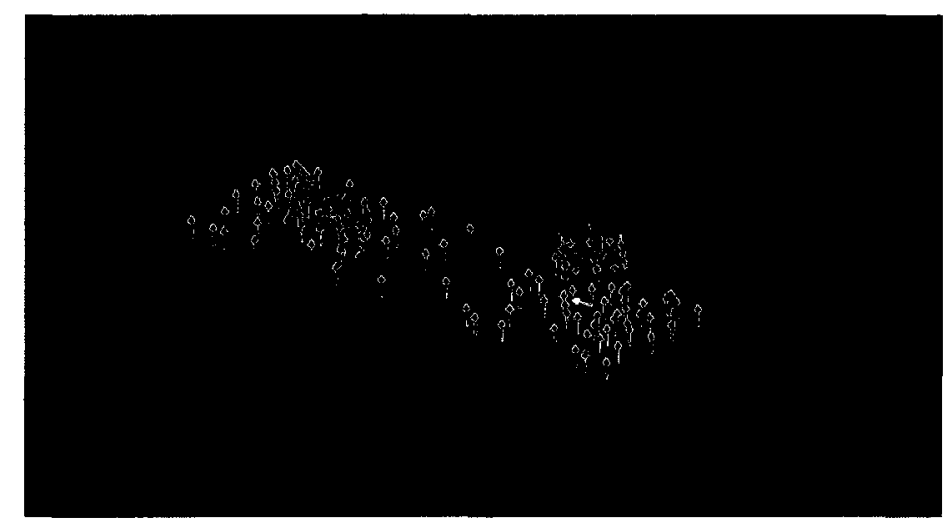

Main Landing Gear Loads:

$\rightarrow$ Vertical Landing load: $400 \mathrm{lbs}$ or $100 \mathrm{lbs} / \mathrm{in}$. applied on the pins $\rightarrow$ Side Moment: 9200 in. Ibs applied on the area of the washer $\rightarrow$ Vertical landing load $600 \mathrm{lbs}$ applied as the pressure load on the area where the landing gear contacts the attachment bracket

Figure 7.8: Main landing gear loads

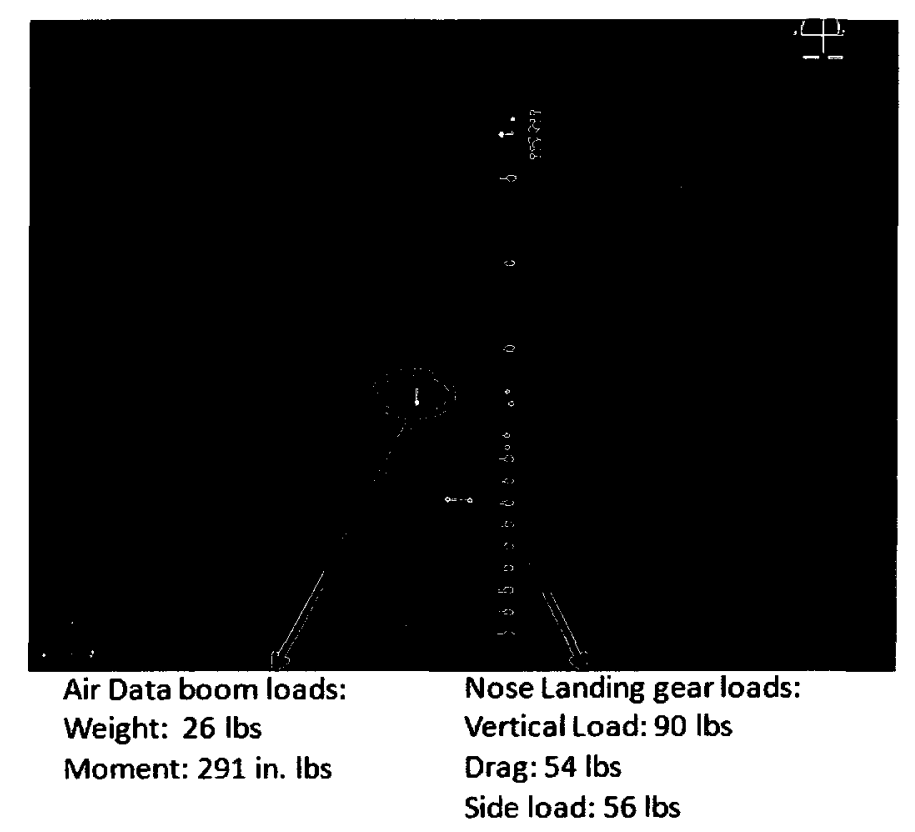

Figure 7.9: Mission avionics and nose landing gear loads 


\subsubsection{Mesh Independence of the Results}

A parametric study was performed on the substructure model (Figure 7.10), to determine the density of the mesh at which the results converge. Throughout the study, the skin and the core were refined at the same rate, starting from a coarser mesh (1880 total elements), as shown in Table 7.5. The mesh refinement on the skin is illustrated in Figure 7.11. This study revealed that the mesh independence of the results with $5 \%$ convergence on the Von-Mises stress and $0.2 \%$ convergence on the displacement occurs at element size of 0.09 in. with the curvature factor of 0.003 in. The corresponding mesh convergence graph is shown in Figure 7.12.

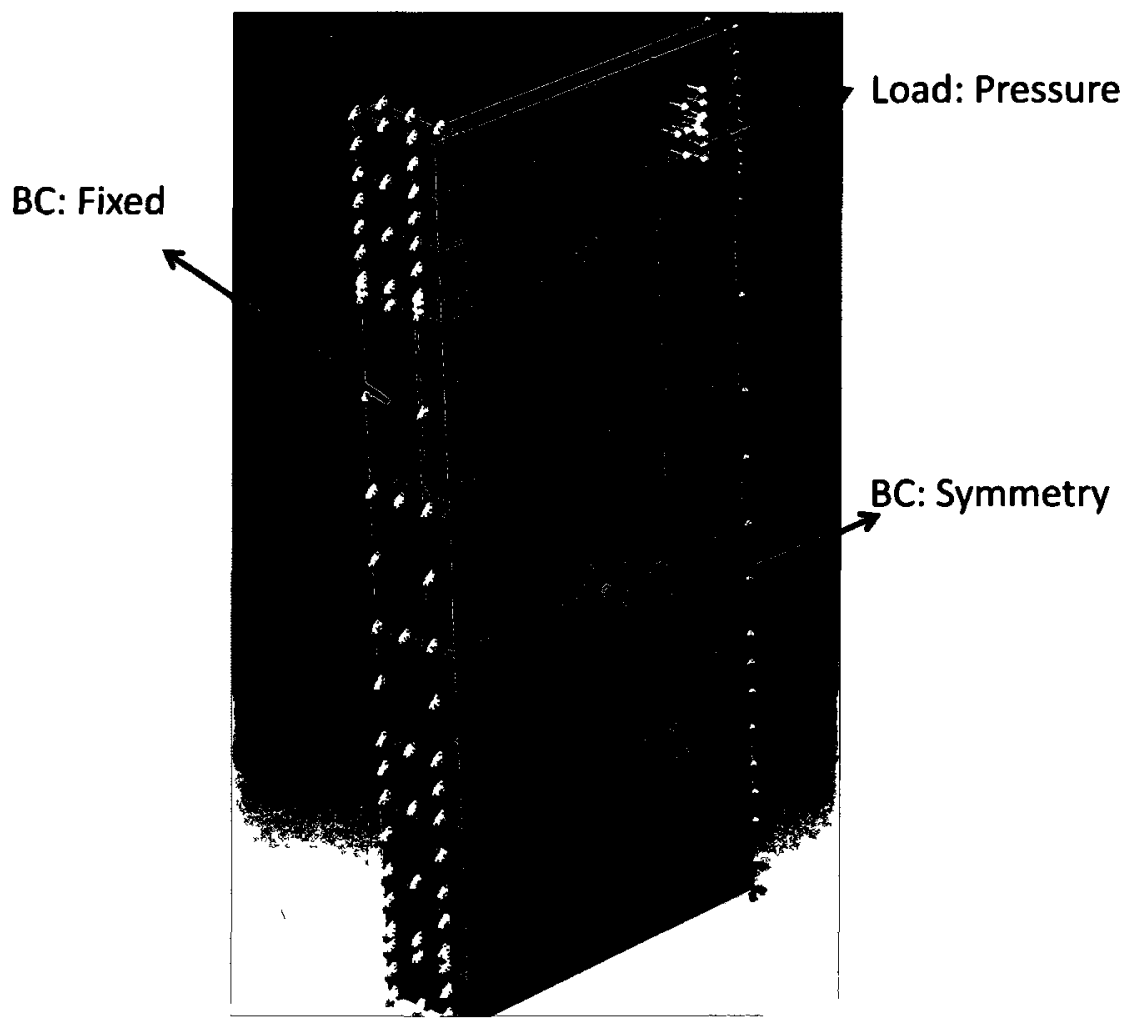

Figure 7.10: Substructure model used for parametric study 


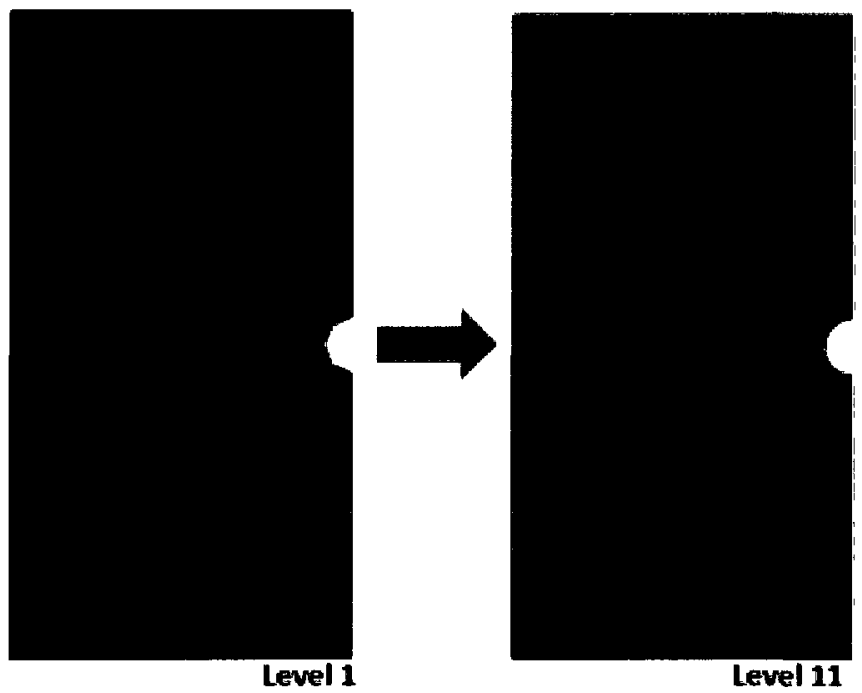

Figure 7.11: Mesh refinement: parametric study level 1 to level 12

Table 7.5: Parametric Study Results

\begin{tabular}{|c|c|c|c|c|c|c|}
\hline Level & $\begin{array}{c}\text { Element } \\
\text { Size/Curvature } \\
\text { control }\end{array}$ & $\begin{array}{c}\text { Number of } \\
\text { Elements } \\
(\mathbf{n})\end{array}$ & $\begin{array}{c}\text { Nodal } \\
\text { Displacement } \\
\left.\mathbf{( U}_{\mathbf{3}}\right)\end{array}$ & $\begin{array}{c}\% \\
\text { Difference }\end{array}$ & $\begin{array}{c}\text { Max Von } \\
\text { Mises } \\
\text { Stress } \\
\text { (psi) }\end{array}$ & $\begin{array}{c}\% \\
\text { Difference }\end{array}$ \\
\hline 1 & $0.5 / 0.1$ & 1880 & 0.0716217 & & 8350 & \\
\hline 2 & $0.25 / 0.05$ & 5994 & 0.0776539 & $8.08 \%$ & 9774 & $15.71 \%$ \\
\hline 3 & $0.2 / 0.01$ & 13564 & 0.0786073 & $1.22 \%$ & 7970 & $20.33 \%$ \\
\hline 4 & $0.15 / 0.01$ & 23058 & 0.0787259 & $0.15 \%$ & 7946 & $0.30 \%$ \\
\hline 5 & $0.125 / 0.01$ & 36421 & 0.0785697 & $0.20 \%$ & 11220 & $34.16 \%$ \\
\hline 6 & $0.11 / 0.01$ & 52879 & 0.0786482 & $0.10 \%$ & 9549 & $16.09 \%$ \\
\hline 7 & $0.1 / 0.005$ & 72459 & 0.0785664 & $0.10 \%$ & 10510 & $9.58 \%$ \\
\hline 8 & $0.1 / 0.003$ & 85764 & 0.0785424 & $0.03 \%$ & 10690 & $1.70 \%$ \\
\hline 9 & $0.09 / 0.003$ & 111886 & 0.0786624 & $0.15 \%$ & 10320 & $3.52 \%$ \\
\hline 10 & $0.0875 / 0.001$ & 146282 & 0.0786709 & $0.01 \%$ & 10320 & $0.00 \%$ \\
\hline 11 & $0.085 / 0.001$ & 154510 & 0.0786694 & $0.00 \%$ & 10310 & $0.10 \%$ \\
\hline
\end{tabular}




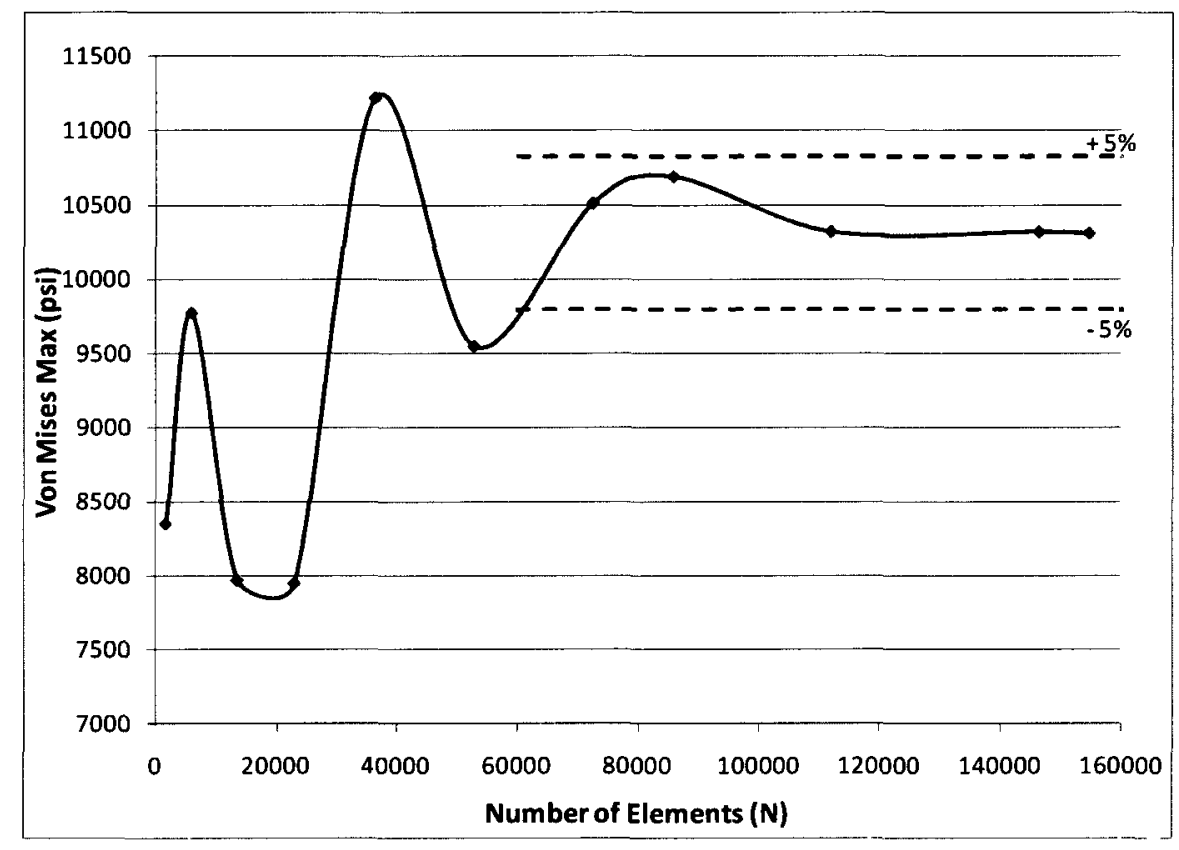

Figure 7.12: Von Mises stress convergence (5\%)

Following the convergence study the fuselage was meshed in accordance to the partitioning and meshing strategies discussed in section 7.1.3. Highly loaded areas were meshed with fine elements (size 0.09 in. or smaller) and all other regions were meshed in a slightly coarser yet uniform fashion to improve the computational efficiency. Upon completion, meshes were verified to correct the elements with poor aspect ratios and internal angles.

\subsubsection{FEA Simulations}

A series of FEA simulations was executed in order to determine the optimum fuselage layup. Starting from a base single ply layup, the simulations were iterated with modified layups until an optimum layup for the fuselage was found. After each simulation, the Von Mises stress, $\mathrm{S}_{12}$ 
and results were compared against the available material properties, based on which the layups were modified for the next simulation run.

The final FE model (Figure 7.13) was constructed with 1,213,298 structural elements and required a minimum of $16 \mathrm{~GB}$ computer memory to run the simulation. These simulations were executed using computer clusters featuring quad-core processors and maximum memory capacity of $32 \mathrm{~GB}$. At this configuration, each simulation run took approximately 9 hours to completion.

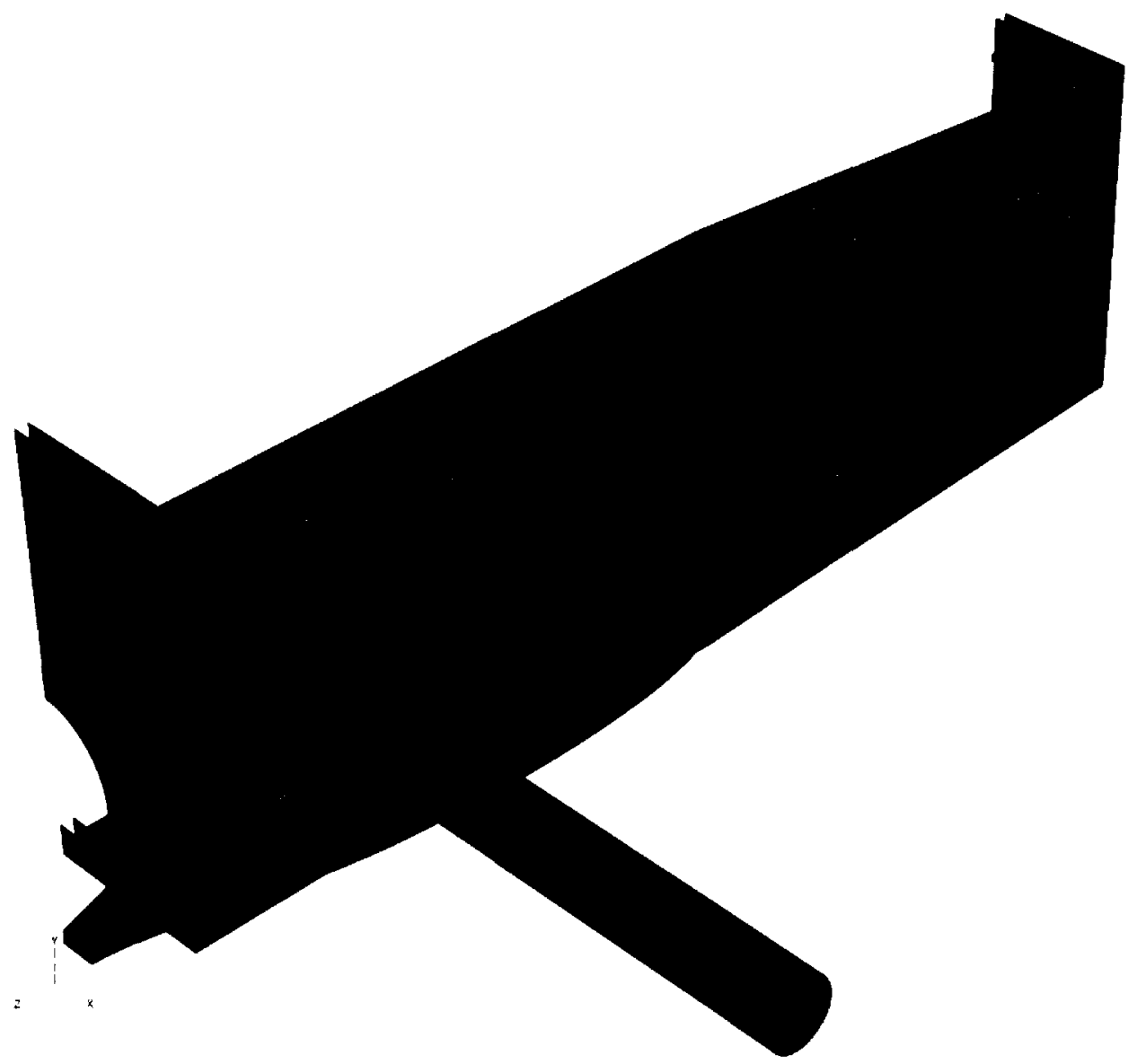

Figure 7.13: Fuselage FE model 


\subsubsection{FEA Results}

The optimized structural foam core components of the new fuselage are shown in Figure 7.14. Medium to high density PVC foam $\left(5 \mathrm{lbs} / \mathrm{ft}^{3}-12.5 \mathrm{lbs} / \mathrm{ft}^{3}\right)$ is used at highly loaded areas such as the front bulkhead, rear bulkhead, rear walls and the landing gear attachment. The base plate and the front walls that do not experience high flight manoeuvre or landing loads were constructed with low density, $3.7 \mathrm{lbs} / \mathrm{ft}^{3}$ PVC foam. The locations of bolted pin-joints were reinforced with FRP inserts to prevent core crushing under discrete loads.

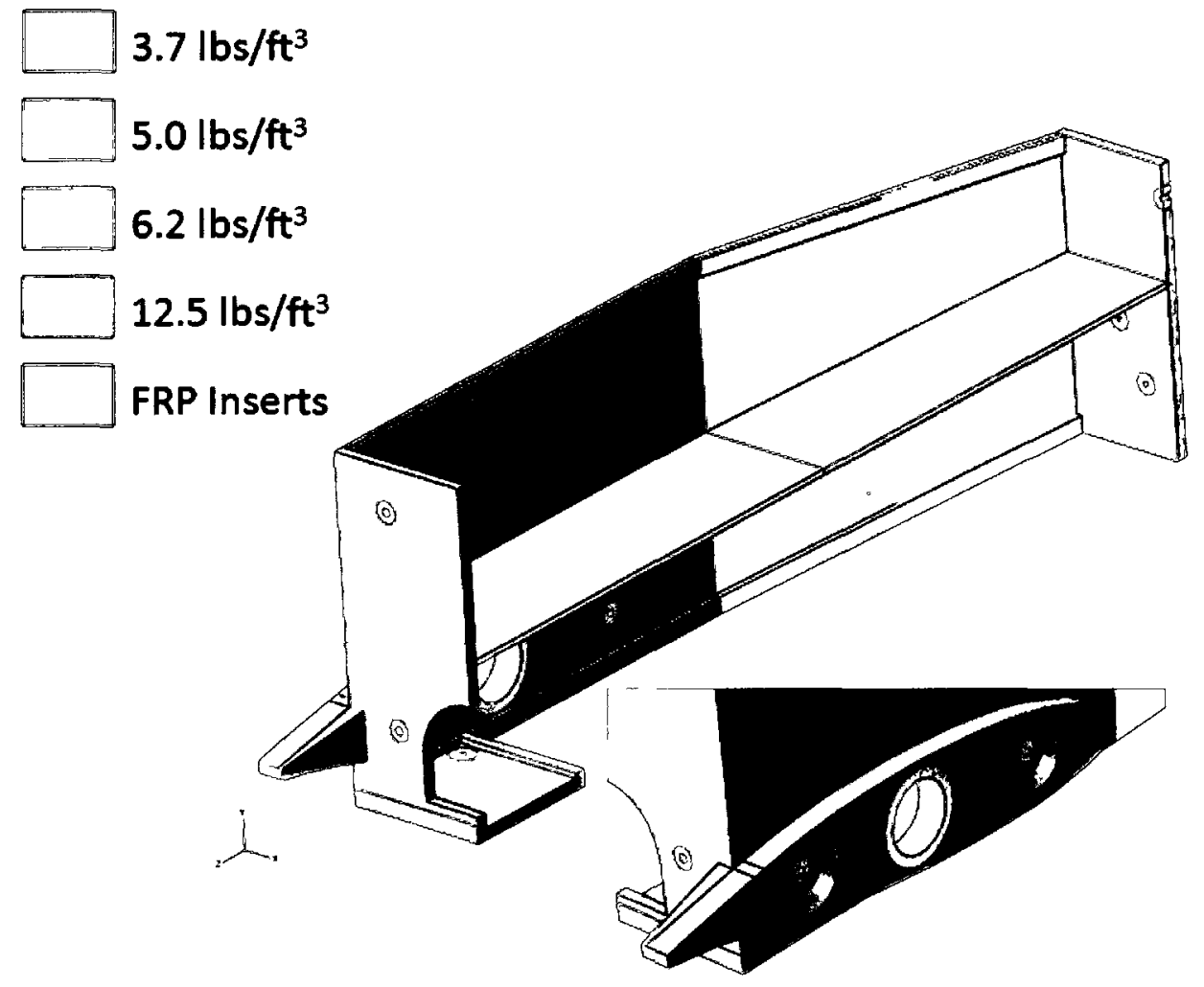

Figure 7.14: Optimized foam core for the new fuselage 


\section{1 ply $\left[ \pm 45^{\circ}\right]$}

$t=0.012$ in.

2 plies $\left[ \pm 45^{\circ}, 0^{\circ} / 90^{\circ}\right]$

$t=0.024$ in.

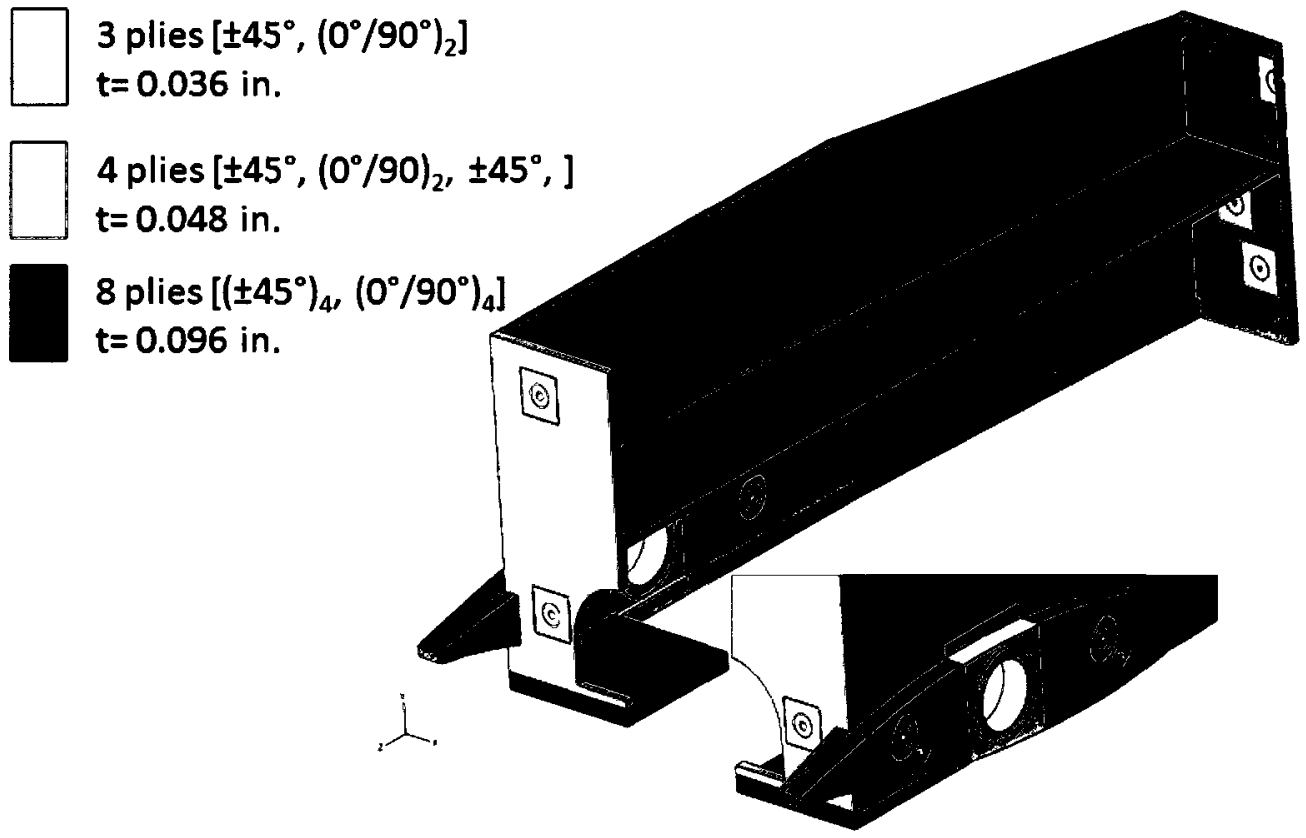

Figure 7.15: Optimized skin layup for the new fuselage

Shown in Figure 7.15 is the optimized skin layup for the new fuselage. The locations of pinjoints and carry-through spar were reinforced with either three or four plies of the carbon fibre fabric. The landing gear attachment panel was reinforced with eight plies, to allow the structure to withstand the landing loads. All other regions, those that experience low in-flight and landing loads were laid-up with one or two plies, depending on the locations and loading conditions.

During the in-flight analysis step, the carry-through spar attachment and the rear bulkhead pin attachment locations were found to be the highly stressed. Corresponding Von Mises stress and in-plane shear stress distributions are illustrated in Figure 7.16. 
The Margin of Safety ${ }^{5}$ (MS) for each of the Von Mises stress and shear stress conditions was 0.450 and 0.104 respectively. In the landing analysis step, the maximum Von Mises stresses were experienced at the location where the landing gear attachment bracket interfaces with the fuselage wall, as shown in Figure 7.17. Its MS was determined to be 0.018 , the lowest in the analysis. The shear stresses experienced by the skin upon landing are shown in Figure 7.18. The corresponding MS was found to be 0.124 . Higher MS values (MS > 0.1) at several locations suggest that the fuselage layup can be optimized further to reduce weight. However, no more FEA iterations were performed to bring the MS values down at these locations, in order to leave provisions for the uncertainties associated with the material property formulations and modelling assumptions. Full scale destructive testing of the fuselage and further design optimization were recommended for future research.

In both analysis steps, the stresses in the core were considerably lower than the material strengths, indicating that core failure is unlikely to occur. This is mainly due to the rigid inserts distributing the applied discrete loads over a larger surface area within the core. Maximum inplane strains on the skin, under in-flight and landing loads were also well below the ultimate strain of the material (0.011). This showed that the linear-elastic FEA assumption is reasonable. These results are available in Appendix E.

\footnotetext{
${ }^{5}$ Margin of Safety (MS) $=\frac{\text { Failure Load }}{\text { Design Load }}-1$, is a measure of the structural capacity. MS value of zero means that the structure will not take any additional loads before it fails. Design optimization work targets to achieve small positive MS values close to zero. Large positive MS values would mean that the structure is overdesigned and negative MS values would mean that the structure will fail before reaching its maximum design load. (Ref: Burr, A and Cheatham, J: Mechanical Design and Analysis, 2nd edition, section 5.2. Prentice-Hall, 1995)
} 
The optimized fuselage structure was estimated to weigh approximately $12.8 \mathrm{lbs}$. This is $42 \%$ lower compared to its current prototype counterpart, which weighed $22 \mathrm{lbs}$. The estimates were based on the surface area and volume of the foam parts used to construct the fuselage structure. Details on the calculation procedures and the weights estimates of the individual fuselage panels are also available in Appendix E.

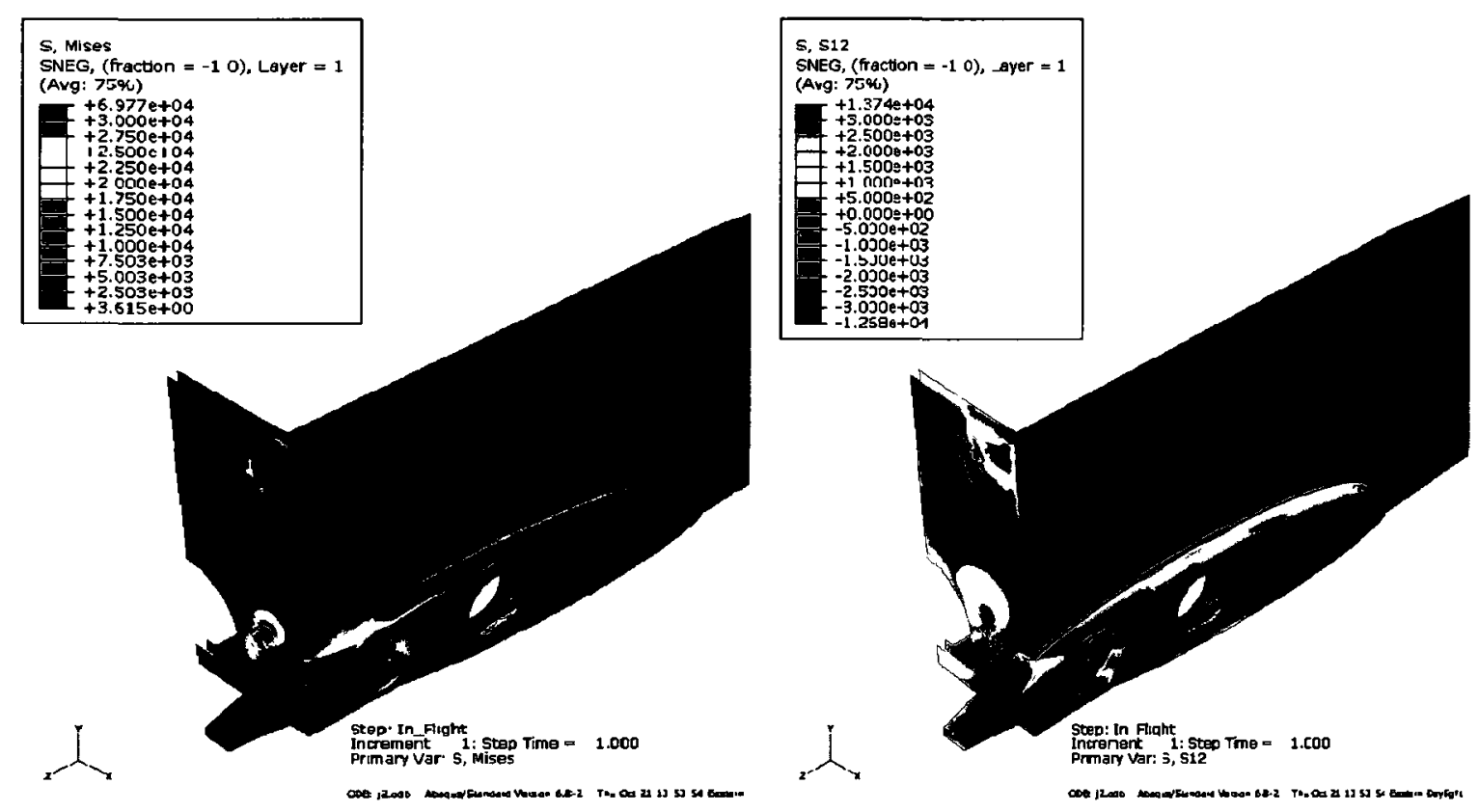

Figure 7.16: Von Mises (left) and in-plane shear (right) stresses (psi) in the skin under flight loads 


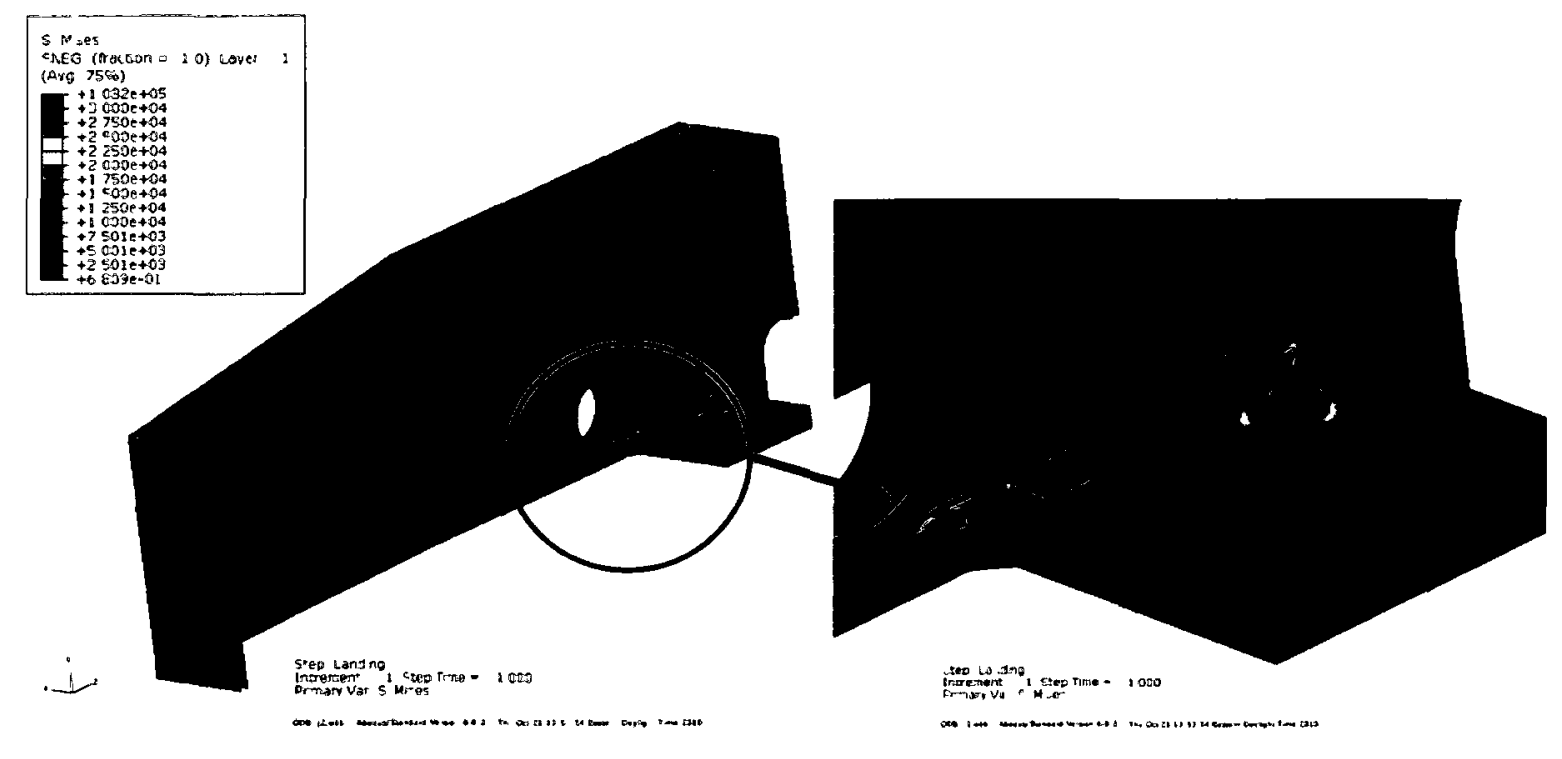

Figure 7.17: Von Mises stresses (psi) in the skin during the landing step

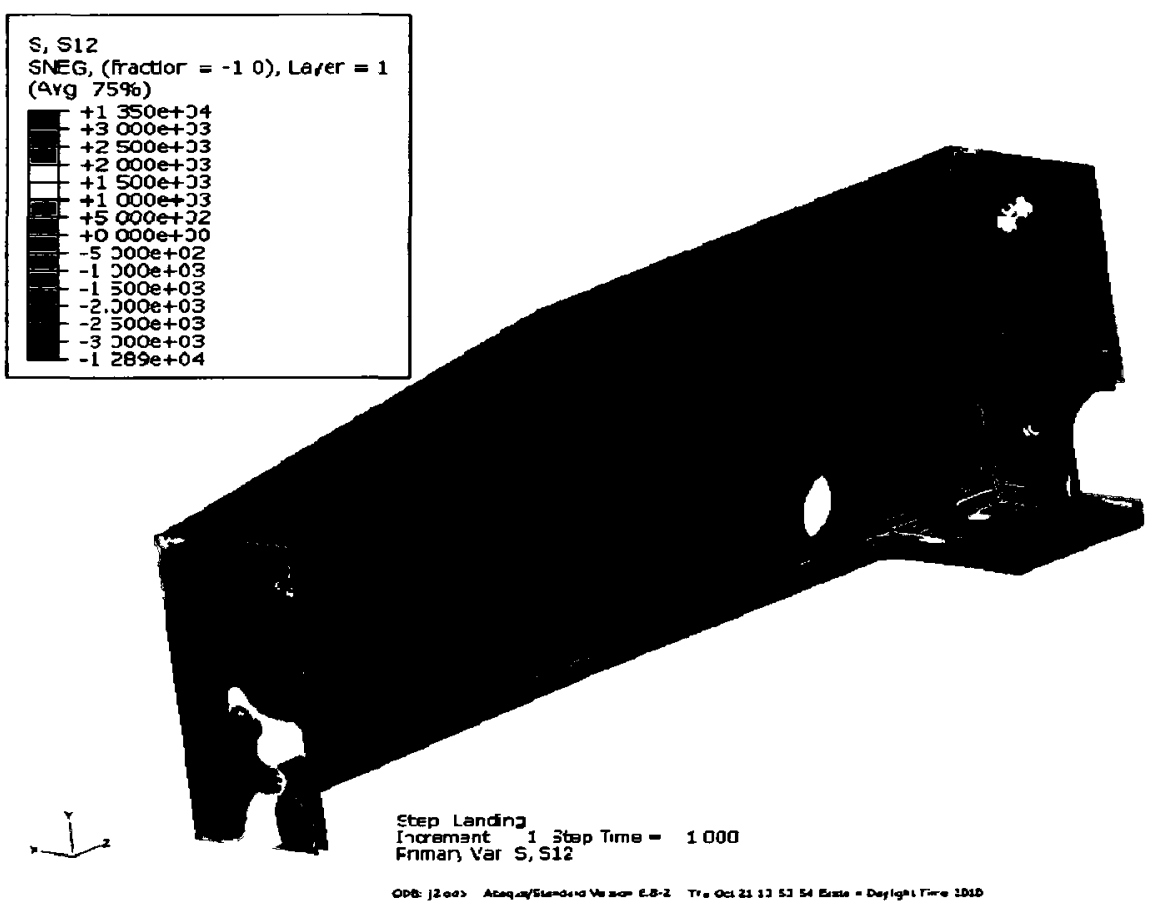

Figure 7.18: Shear stresses (psi) in the skin under landing loads 


\subsection{Experimental Verification of the FEA results}

An experimental study was carried out to verify the selected FEA results. This was required due to the simplifying assumptions made in the FEA, as explained in section 7.1. The study aimed to evaluate two major local loading conditions experienced by the fuselage: in-plane bearing and out-of-plane bending (Figure 7.19). These conditions were present at the location of shear pin and on the rear bulkhead. Flat sandwich specimens representing these locations on the fuselage were loaded until failure and the results were compared with the FEA predictions. The test matrix and the procedure employed in this study along with the results are discussed in the following sections.

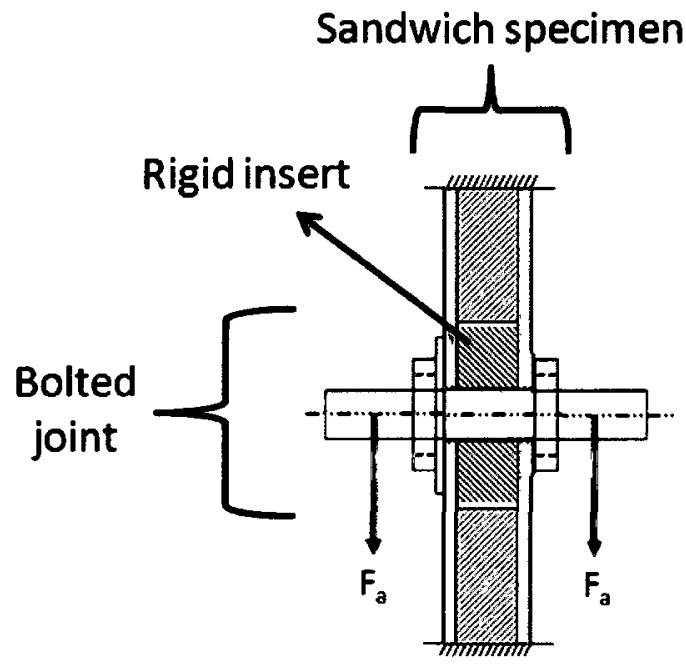

(a) Bearing load

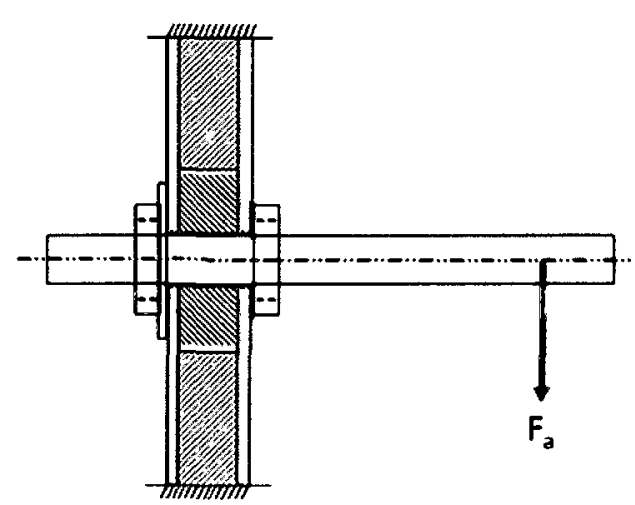

(b) Bending load

Figure 7.19: Loading modes chosen for experiments 


\subsubsection{Test Matrix, Specimen Manufacturing and Test Procedure}

The FEA verification test matrix is given in Table 7.6. All specimens were manufactured with the materials selected for the new fuselage (Chapter 5). The bearing test specimens featured $6.2 \mathrm{lbs} / \mathrm{ft}^{3}$ density PVC foam core having thickness of 0.85 in. and dimensions 6 in. (L) $\times 6$ in. (W). At the centre of these specimens, the foam core was reinforced with 1 in. diameter FRP inserts. The specimen thickness was chosen to represent the actual shear pin location in the new fuselage. Dimensions for the test specimens were chosen based on previous research [5860] to avoid edge effects and provide sufficient surface area for clamping of the specimen in the fixture.

Table 7.6: FEA verification test matrix

\begin{tabular}{|c|l|c|l|l|}
\hline $\begin{array}{c}\text { Number of } \\
\text { specimens } \\
\text { Tested }\end{array}$ & $\begin{array}{c}\text { Test } \\
\text { Type }\end{array}$ & $\begin{array}{c}\text { Specimen } \\
\text { Dimensions: } \\
\mathrm{L} \times \mathrm{W} \times \mathrm{T} \text { (in.) }\end{array}$ & Layup & \multicolumn{1}{|c|}{$\begin{array}{c}\text { Insert } \\
\text { Dimension/Material }\end{array}$} \\
\hline 4 & Bearing & $6 \times 6 \times 0.85$ & {$\left[ \pm 45^{\circ}, 0^{\circ} / 90^{\circ}, \text { Core }\right]_{\mathrm{SYM}}$} & 1 in. diameter GFRP \\
\hline 1 & Bearing & $6 \times 6 \times 0.85$ & {$\left[ \pm 45^{\circ}, 0^{\circ} / 90^{\circ}, 0^{\circ} / 90, \text { Core }\right]_{\mathrm{SYM}}$} & 1 in. diameter GFRP \\
\hline 3 & Bearing & $6 \times 6 \times 0.85$ & {$\left[ \pm 45^{\circ}, 0^{\circ} / 90^{\circ}, 0^{\circ} / 90^{\circ}, \pm 45^{\circ}, \text { Core }\right]_{\mathrm{SYM}}$} & 1 in. diameter GFRP \\
\hline & & & & 1 in. diameter GFRP \\
\hline 3 & Bending & $6 \times 6 \times 0.5$ & {$\left[ \pm 45^{\circ}, 0^{\circ} / 90^{\circ}, 0^{\circ} / 90^{\circ}, \text { Core }\right]_{\mathrm{SYM}}$} & 1 in. diameter GFRP \\
\hline
\end{tabular}




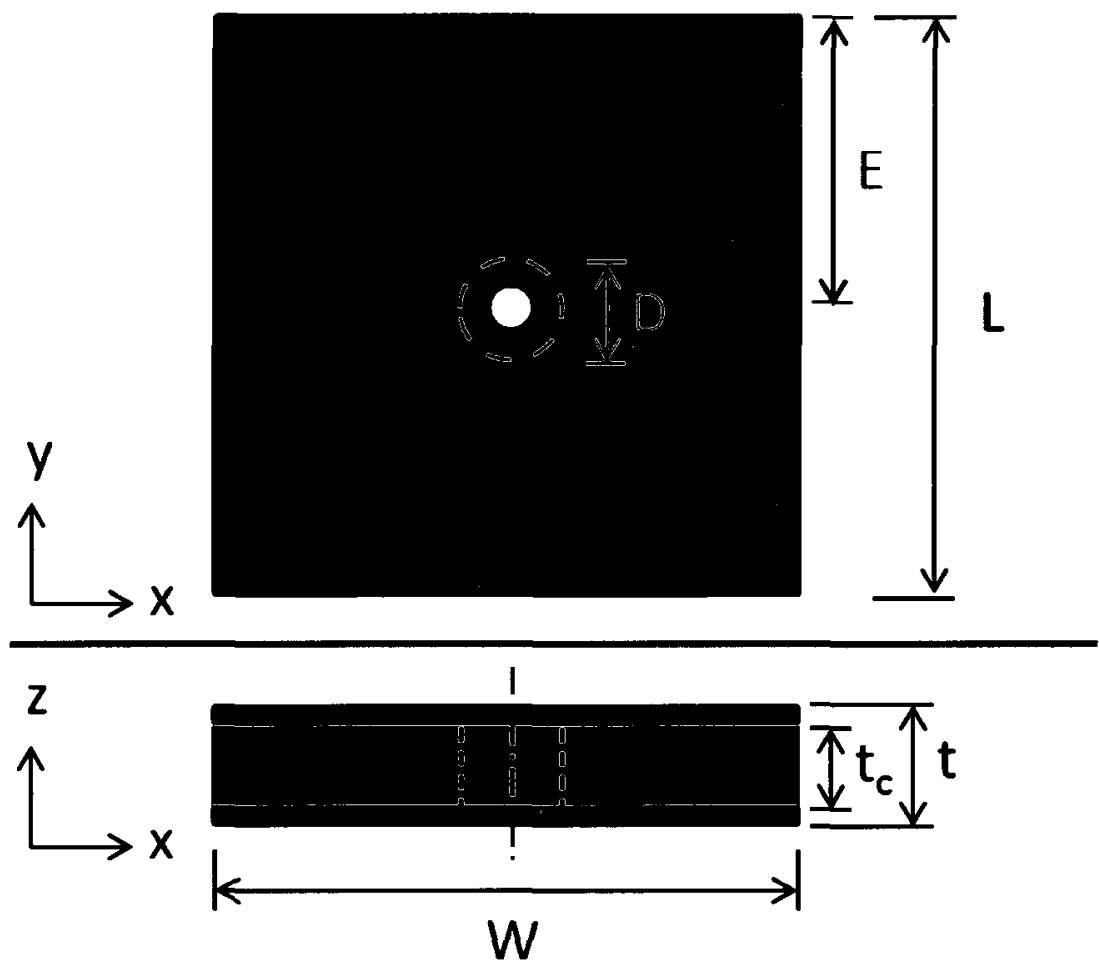

Figure 7.20: Geometry of the sandwich specimen

During specimen manufacture, the foam cores were cut into 6 in. $\times 6$ in. pieces. This was followed by drilling of 1 in. diameter through-hole at the centre of these foam specimens and bonding the FRP inserts into the holes using structural epoxy adhesive. These foam specimens were then laid-up with carbon fibre fabric, vacuum bagged and infused with epoxy resin as per the conventional VARTM method. All specimens were infused under the same vacuum bag simultaneously, to avoid any inconsistencies in part quality. After curing, the edges of the specimens were sanded to create smooth, flat edges to facilitate proper installation in the load frame. A 0.31 in. diameter through-hole was drilled into each specimen to allow insertion of a tight-fit aluminum bushing. The specimens were then loaded with $0.25 \mathrm{in}$. diameter steel pins, 
using a hydraulic Material Testing System (MTS) frame (22 kip capacity, Model 647.10A-01, Serial \#: 1305166). The bearing test setup in the load frame is shown in Figure 7.21.

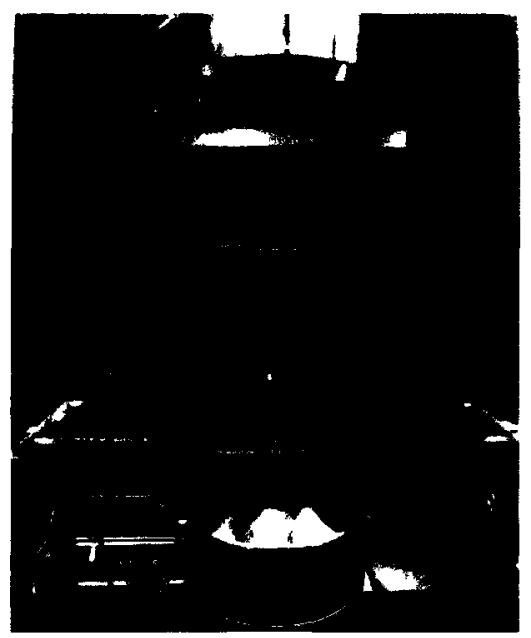

(a) Front view

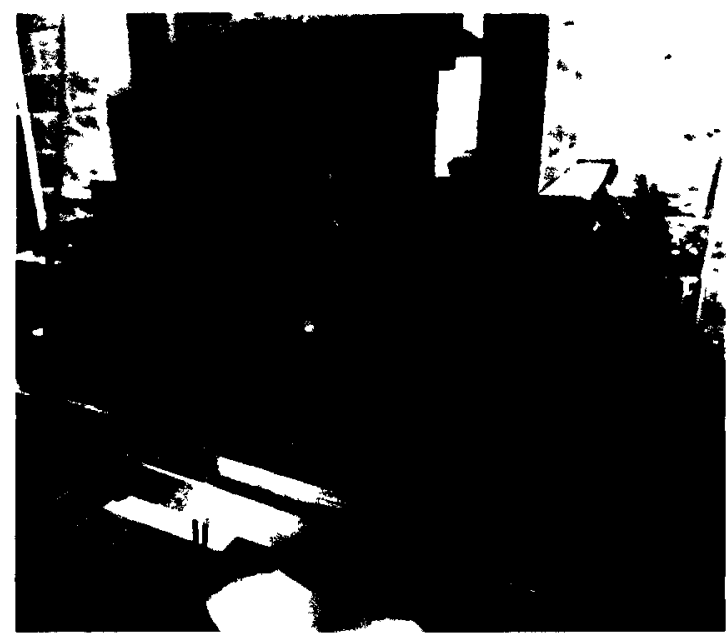

(b) Isometric view

Figure 7.21: Bearing test setup in the load frame

Bending test specimens were manufactured with 0.5 in. thick PVC foam core and loaded at 2.75 in. away from the centerline, using 0.375 in. diameter steel pin to represent the engine pin joint at the fuselage rear bulkhead. These specimens were prepared for testing by following the same procedures employed for the bearing specimens. The bending test setup in the load frame is shown in Figure 7.22. All specimens were loaded at a cross-head displacement rate of $0.19 \frac{\mathrm{ln}}{\mathrm{m} \mathrm{n}^{\mathrm{n}}}$, while the force and displacement data were collected at $10 \mathrm{~Hz}$. 


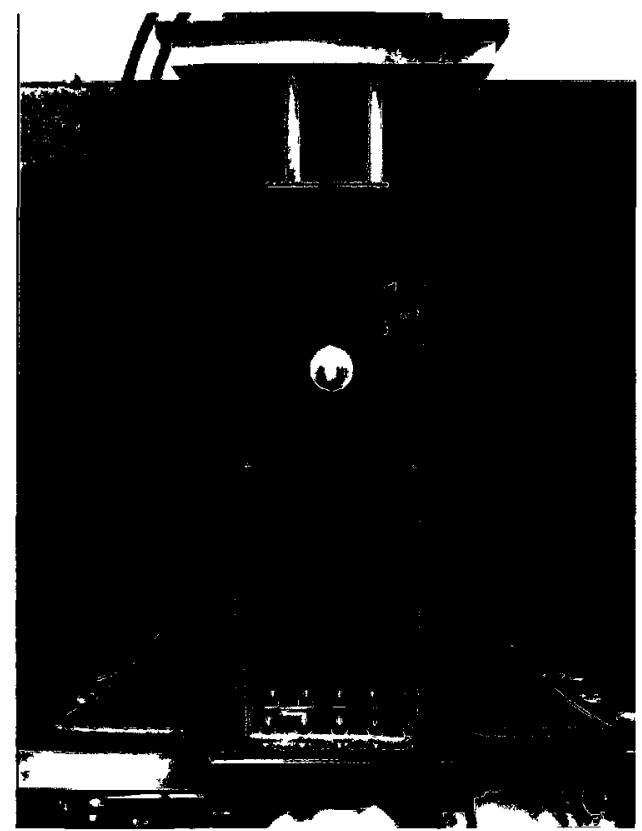

(a) Front view

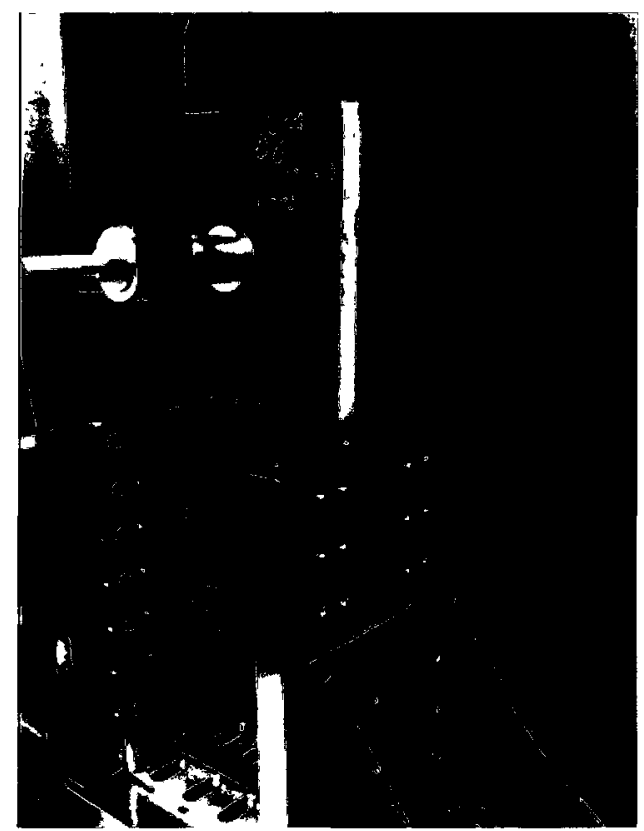

(a) Isometric view

Figure 7.22: Bending test setup in the load frame

\subsubsection{FEA Simulations}

FE models of the test specimens were created in Abaqus following same procedures employed in the fuselage FEA. Loads and boundary conditions were applied as shown in Figure 7.23. The models were meshed uniformly using the optimum element size obtained from the mesh refinement study. Meshed models are presented in Figure 7.24. First, a range of loads during which failure might occur, was determined for each layup and specimen type using trial simulations. This allowed determination of the highest and lowest load to be applied in the simulations. Then, different FE models were setup for the specimen types discussed in the test matrix (Table 7.6), each with seven analysis steps. In every analysis step, the applied load was increased by $50 \mathrm{lbs}$, starting from the lowest load determined from the trial simulations. 


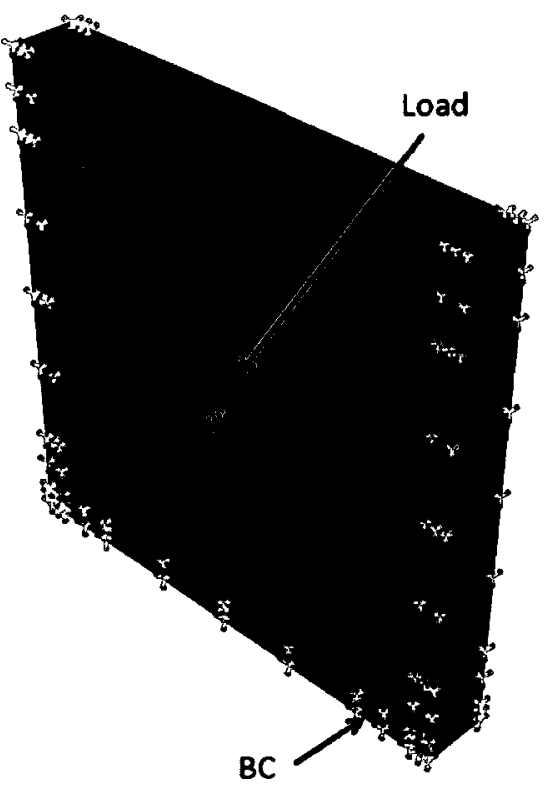

(a) Bearing specimen

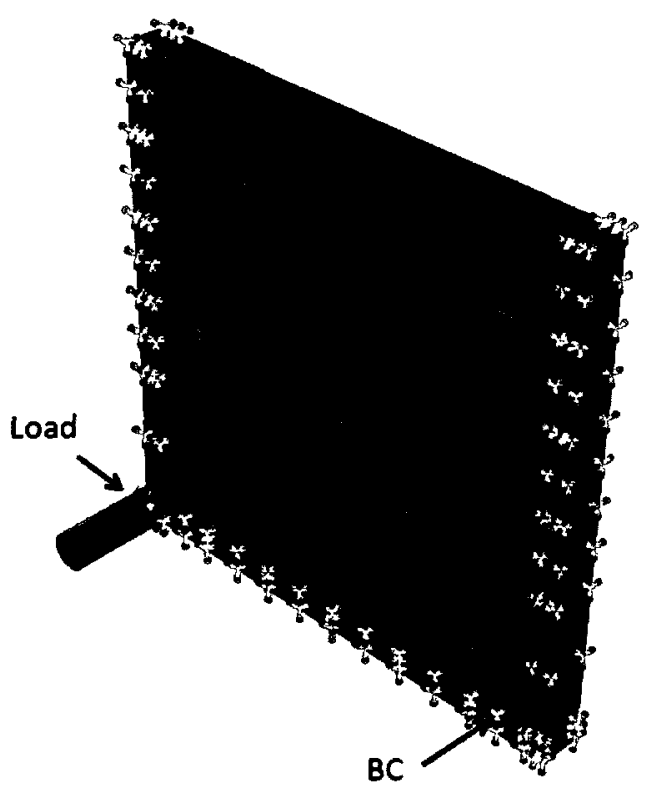

(b) Bending specimen

Figure 7.23: Abaqus model showing the loads and boundary condition of the specimens

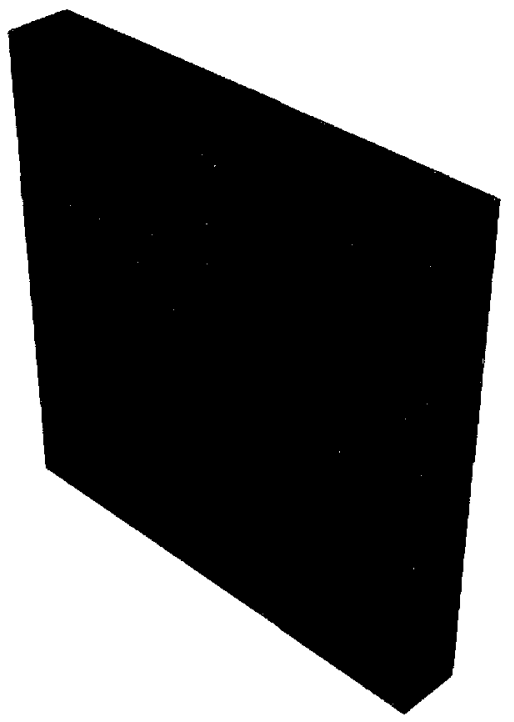

(a) Bearing specimen

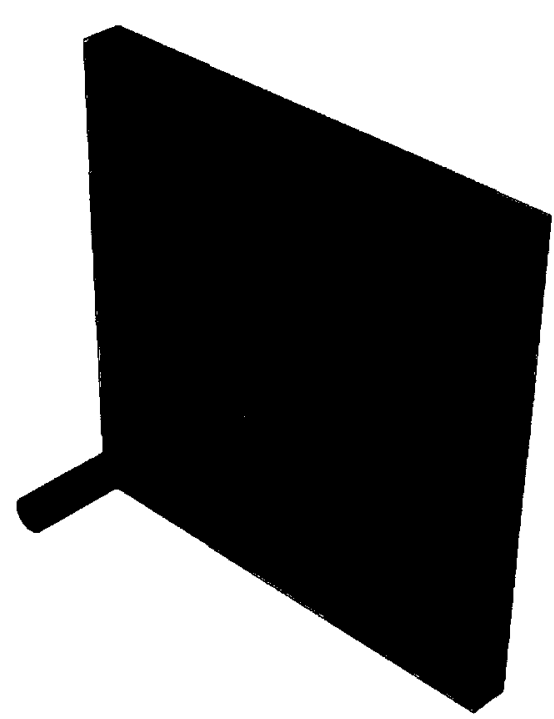

(b) Bending specimen

Figure 7.24: Abaqus FE model of the test specimens 


\subsubsection{Results}

Force-displacement curves obtained from the bearing test specimens are shown in figure 7.25. The curves are shifted along the $\mathrm{x}$-axis for clarity. Similar loading profiles of the specimens suggested consistent specimen behaviour. The failure load for each specimen tested is given in Table 7.7. Specimen 7 was discarded as it was an obvious outlier in the group of four-ply specimens. This was due to misaligned installation of the specimen in the test fixture. This specimen misalignment caused local crumpling of the specimen edges during the test, leading to premature failure.

Table 7.7: Bearing test failure loads

\begin{tabular}{|c|c|c|}
\hline Specimen ID & Number of Plies & Load to Failure (lbs) \\
\hline SP \#1 & 2 & 983.34 \\
\hline SP \#2 & 2 & 926.65 \\
\hline SP \#3 & 2 & 931.62 \\
\hline SP \#4 & 2 & 971.19 \\
\hline SP \#5 & 4 & 1264.16 \\
\hline SP \#6 & 4 & 1196.14 \\
\hline SP\#7 & 4 & 867.719 \\
\hline SP \#8 & 3 & 1069.49 \\
\hline
\end{tabular}




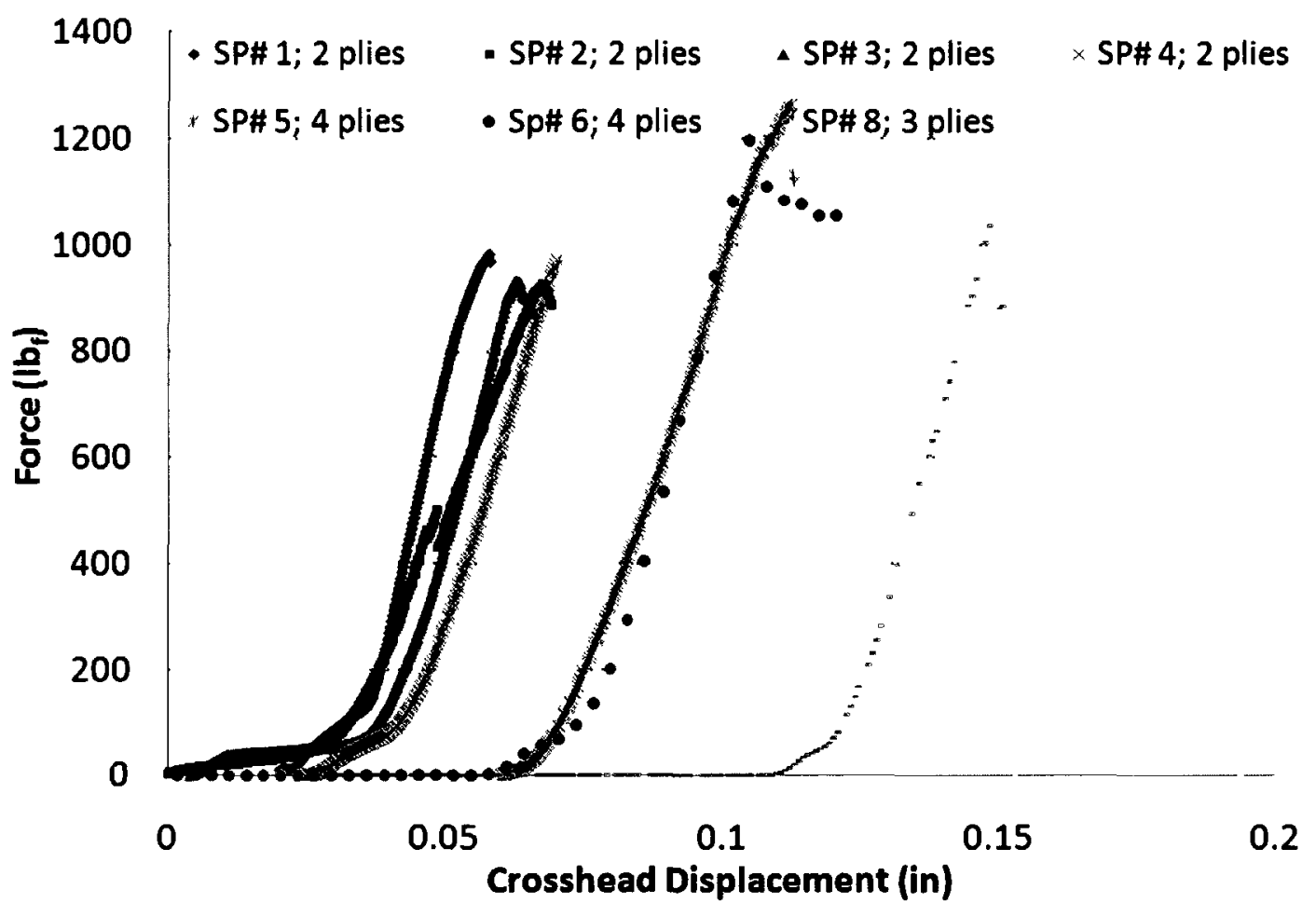

Figure 7.25: Bearing test: force-displacement data

Table 7.8 and Figure 7.26 compare average experimental failure loads to those predicted by the FEA. The experimental failure was defined as the maximum load prior to the abrupt loss of stiffness in the load-displacement curve. The FEA predicts failure when the in-plane shear stress on the skin exceeds the material shear strength. The failure modes are compared in Figure 7.27. For all layups, experimental values were within $10 \%$ of the FEA predictions. This correlation suggests that the assumptions made in the FEA were acceptable for this loading condition.

Table 7.8: Bearing test results: FEA predictions and Experiments

\begin{tabular}{|c|c|c|c|c|}
\hline \# of plies & $\begin{array}{c}\text { \# of specimens } \\
\text { tested }\end{array}$ & $\begin{array}{c}\text { Failure load } \\
\text { predicted by FEA } \\
\text { (lbs) }\end{array}$ & $\begin{array}{c}\text { Average } \\
\text { experimental } \\
\text { failure load (lbs) }\end{array}$ & \% Difference \\
\hline 2 & 4 & 983 & 953 & $3 \%$ \\
\hline 3 & 1 & 1154 & 1069 & $8 \%$ \\
\hline 4 & 2 & 1202 & 1230 & $2 \%$ \\
\hline
\end{tabular}




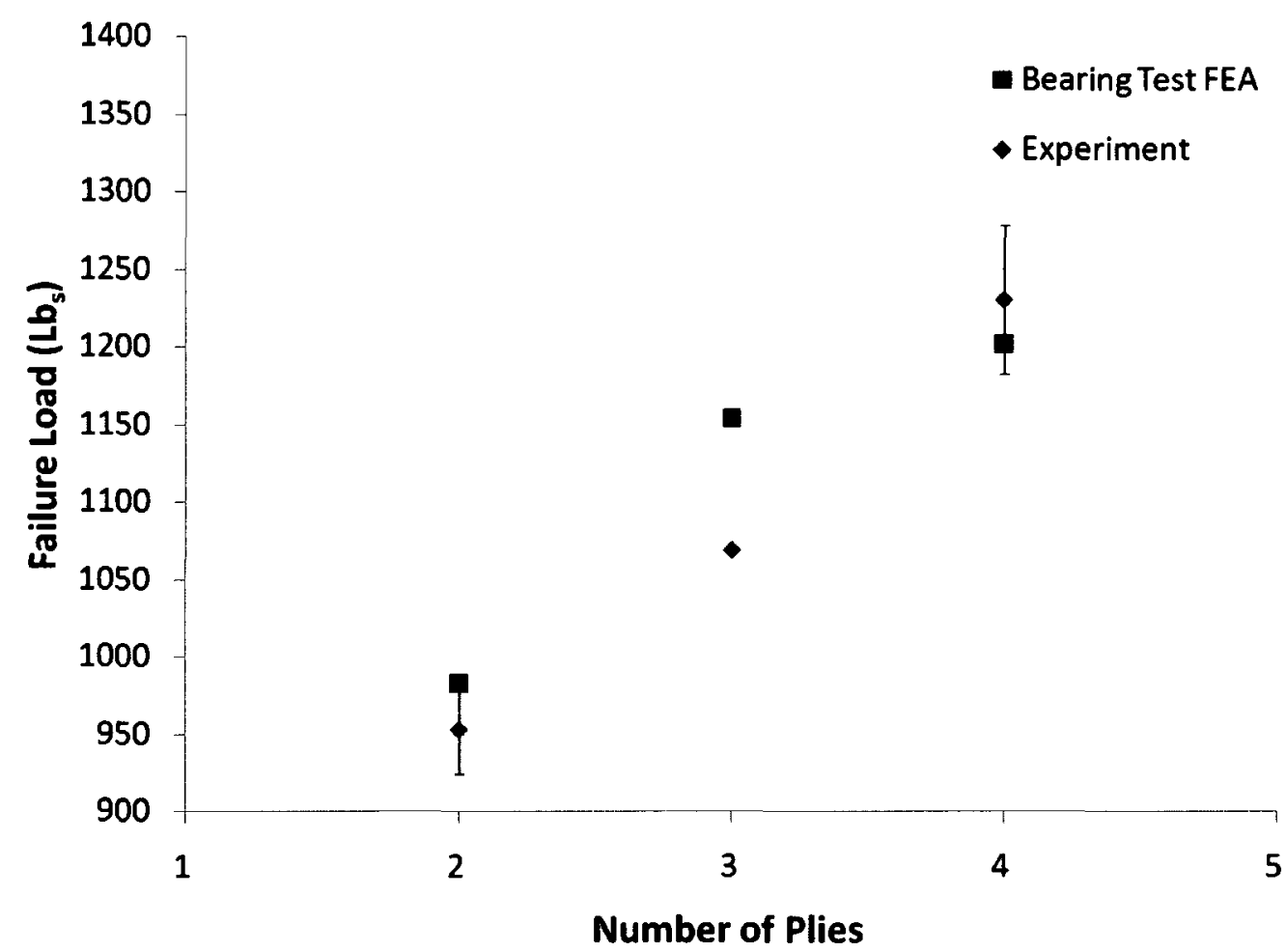

Figure 7.26: Comparison of the failure loads in bearing test
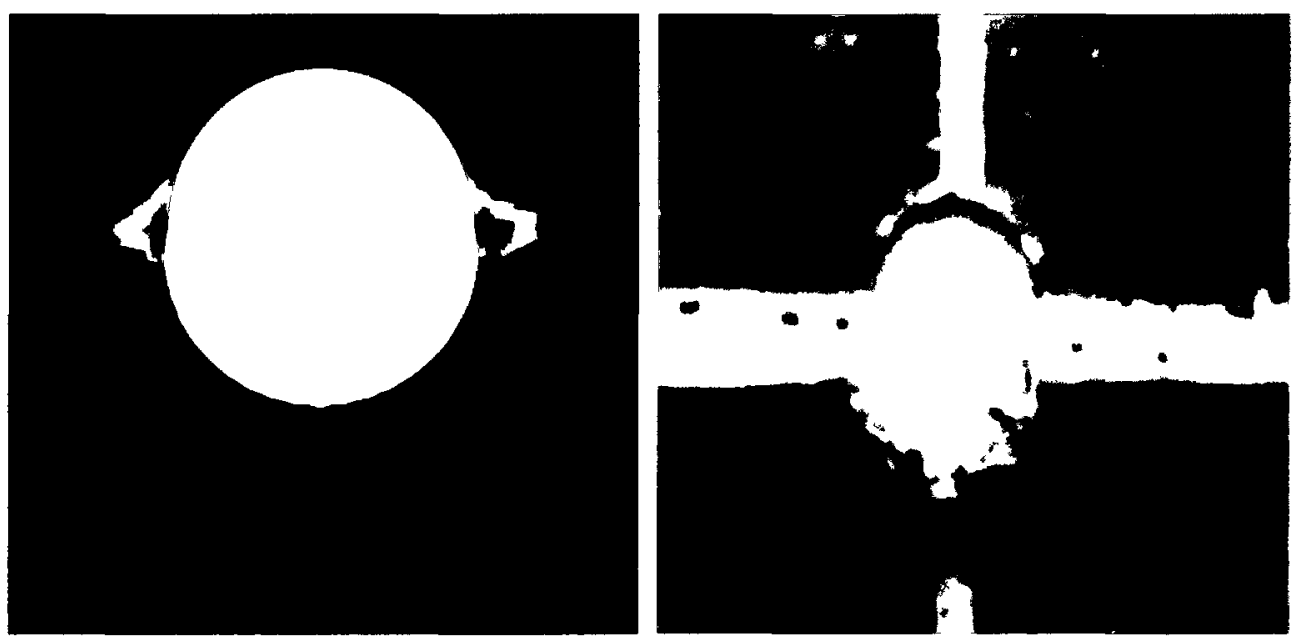

(a) FEA [25x deformation factor]

(b) Experiment [Loaded beyond failure for clarity]

Figure 7.27: Close-up of the bearing failure mode 
FEA of the bending tests showed failure due to shear stress in the skin, as shown in Figure 7.28. Predicted failure load of the three-ply and four-ply specimens was $300 \mathrm{lbs}$ and $375 \mathrm{lbs}$, respectively. The experiment results were rather interesting. Figure 7.29 shows the forcedisplacement curves of the specimens tested. The data obtained for specimen 1 (SP\# 1) was non-linear due to the pin bending and plastically deforming as the applied load was increased. In second test (SP \#2) the pin was reinforced to prevent bending, but the resulting curve was still non-linear though there was no specimen failure. This time it was due to the fixture bending and deforming at high loads. Thus, in subsequent tests a reinforced fixture and pin were used. This test process refinement is evidenced through the increasingly linear slopes SP \#1 to SP\# 3. The test setup in SP\# 3 was most representative of the actual setup on the rear bulkhead. The rest of the tests were carried out with this setup (Figure 7.22).

In the bending tests, all specimens carried $600 \mathrm{lbs}$ (1650 in.lbs) without failure, which was well beyond the loads experienced by the fuselage. This showed that the assumptions made in FEA, specifically the tie constraints between the pin and the sandwich structure, were too conservative. Perhaps a better correlation would have been obtained between the FEA predictions and the experiments if the joint configuration was modelled with proper contact formulation.

The specimens not failing beyond ultimate loads signifies that the limiting factor in the design was not the insert or the sandwich structure, but the 3/8" bolt itself. Performing extensive FEA was not the primary scope of this research. Hence, the specimens were saved for later, more 
detailed FEA analysis and this research proceeded with manufacturing of the demonstrator fuselage.

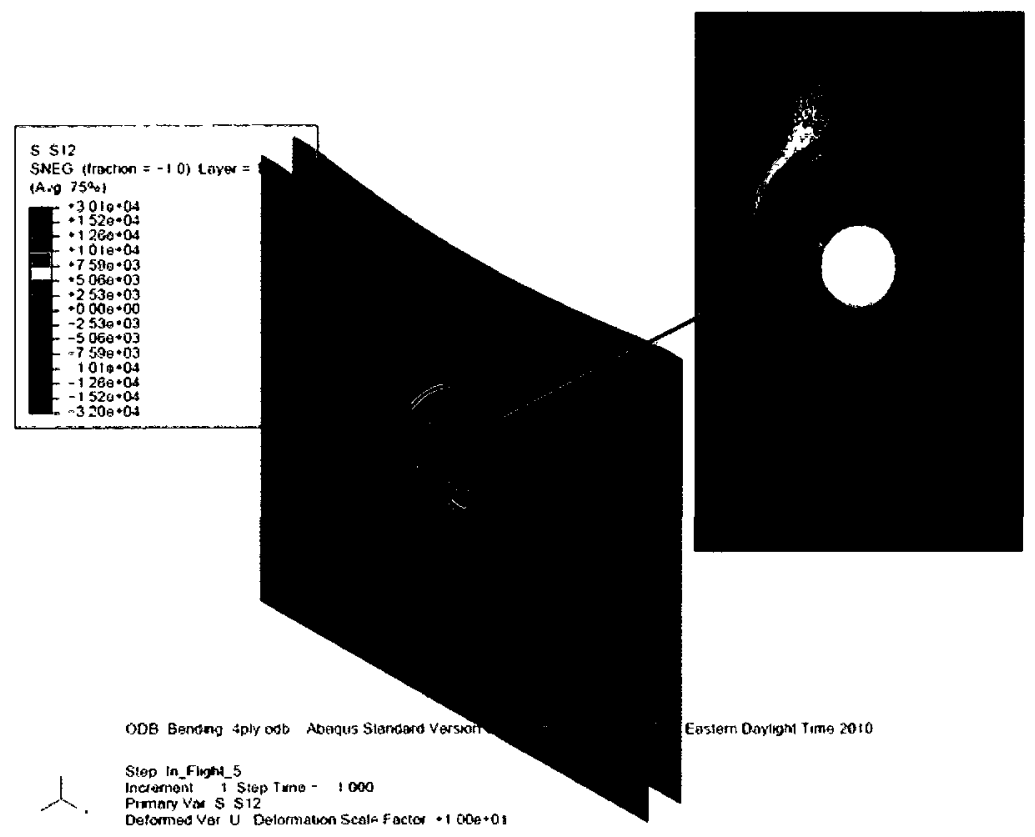

Figure 7.28: Bending test FEA prediction

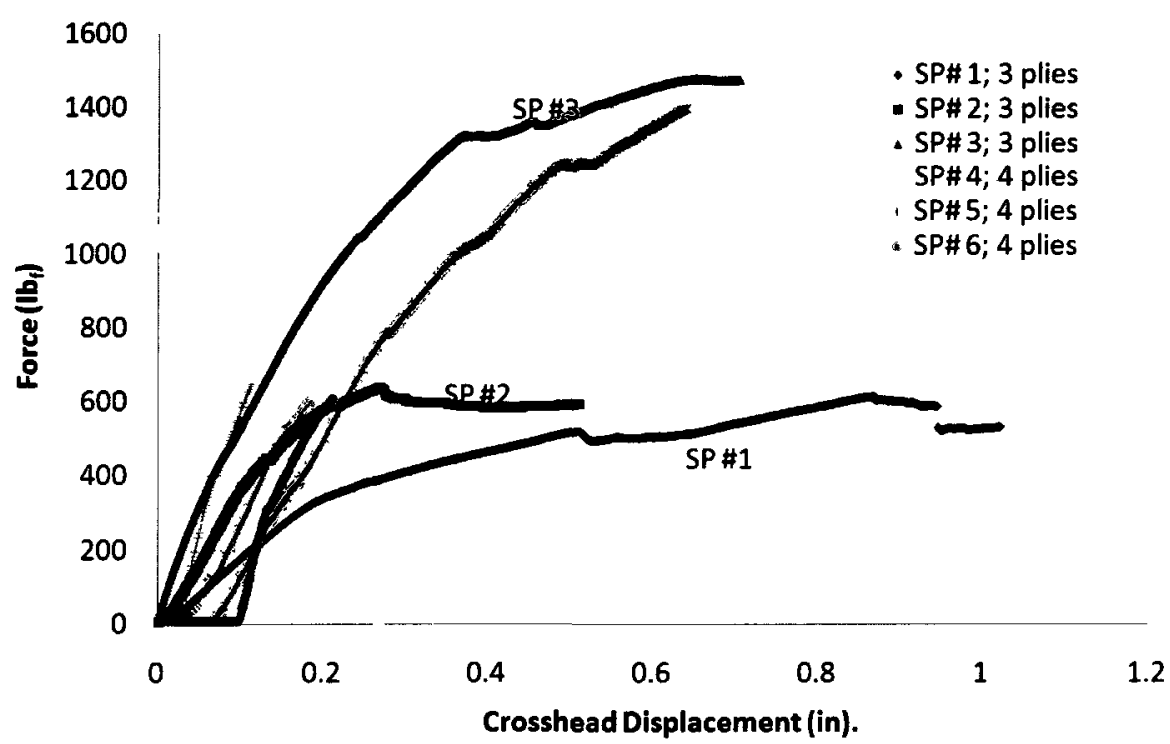

Figure 7.29: Bending test: force-displacement data 


\section{CHAPTER 8. FUSELAGE MANUFACTURING}

This chapter discusses manufacturing of the demonstrator fuselage using mouldless CCBM method discussed in Chapter 4. The GeoSurv II fuselage, as shown in Figure 6.11, is a large component with complex geometry, measuring approximately 44 in. x 15 in. $x 13$ in. Therefore, any significant error made during manufacturing of the fuselage would result in an expensive scrap part. Hence, prior to manufacturing of the full scale fuselage, a sample test section was manufactured to practice and study the mouldless CCBM techniques. This trial component was sectioned into small pieces and their cross-sections were examined under the microscope to assess the quality of the CCBM manufacturing. Then, a series of CCBM experiments were carried out on flat laminates to determine the optimum spacing between the resin distribution lines in a CIB infusion. Results from these experiments were utilized to develop a conceptual manufacturing model in Pro/E, followed by the actual fuselage manufacturing. This work is discussed in the following sections.

\subsection{Sample Section Manufacturing}

An $\mathrm{H}$-shaped structure representative of the fuselage rear wall assembly was manufactured using the CCBM method developed for mouldless manufacturing. This was required to assess the mouldless CCBM and to identify critical areas that may require process refinement. In this work, the foam parts shown in Figure 8.1 were machined using a 3-axis Computer Numerical Control (CNC) router. Rabbet features with male-female profiles were integrated into these parts to ensure precise-fit assembly of the base plate and side walls. The manufactured foam part (Figure 8.2 (a)) was laid-up with one ply of carbon fibre fabric and a layer of peel ply. Subsequently, the sandwich layup was wrapped with a layer of static cling PVC (Type I) film 
(Translucent, Low Tack, 0.002" Thick, McMaster Carr Inc.). The CCBM bag was manufactured over this setup, with inlets, outlets and resin distribution lines positioned as shown in Figure $\mathbf{8 . 2}$ (b). The PVC film protects the part from silicone contamination during bag manufacturing while providing a smooth surface finish to the bag. The chemical resistant nature of the PVC film allowed the bag to be peeled off easily without using any additional release agents. The low tack adhesive backing of the PVC film eases the wrapping process, while allowing easy removal from the setup, after bag manufacturing. The CСBM bag was manufactured over this setup, following the procedure outlined in Appendix B.

The manufactured CCBM bag (Figure 8.2 (c)) featured two resin distribution lines 3 in. apart, which distributed the resin from the inlet lines located at the top and bottom surfaces of the base plate into the part. A layer of $1 \mathrm{in}$. wide Teflease tape was bonded along the perimeter of the $\mathrm{H}$ profile. Once cured, the bag was cut-opened over the taped surface, using an Olfa® utility knife. The bag was precisely cut, without damaging the fabric reinforcement, in order to retain the structural integrity of the component. Upon opening and removing the bag, the PVC film was peeled from the part. This was followed by re-installing the bag over the part and sealing the split-ends using disposable sealant tape. Then, the inlet lines were clamped-off and the outlet lines were connected to vacuum ports. Upon vacuum application, it was noticed that the side walls warped under the applied pressure, due to the unsupported nature of the part geometry. This problem was solved with the insertion of rigid spacers between the side walls.

Once the setup was complete, resin was introduced into the part via the inlet line. The infusion of this test component took approximately 6 minutes. Following the infusion, the inlet lines 
were attached to vacuum ports to remove any excess resin from the part. The part was cured under vacuum pressure for 24 hours.

Figure 8.3 shows the cured component before and after removal of the peel ply. There was some residue of cured resin left in the resin distribution channels and inlet lines, which is normal in CIB infusion. As the peel ply was removed, the cured resin channels snapped off from the part, leaving negligible marks on the surface. Significant improvement in the surface quality was observed around the corner regions, compared to the current fuselage [3]. The part retained nicely formed corner radii with very few resin starved regions. This improvement in quality can be attributed to the form-fitted nature of the CCBM bags.

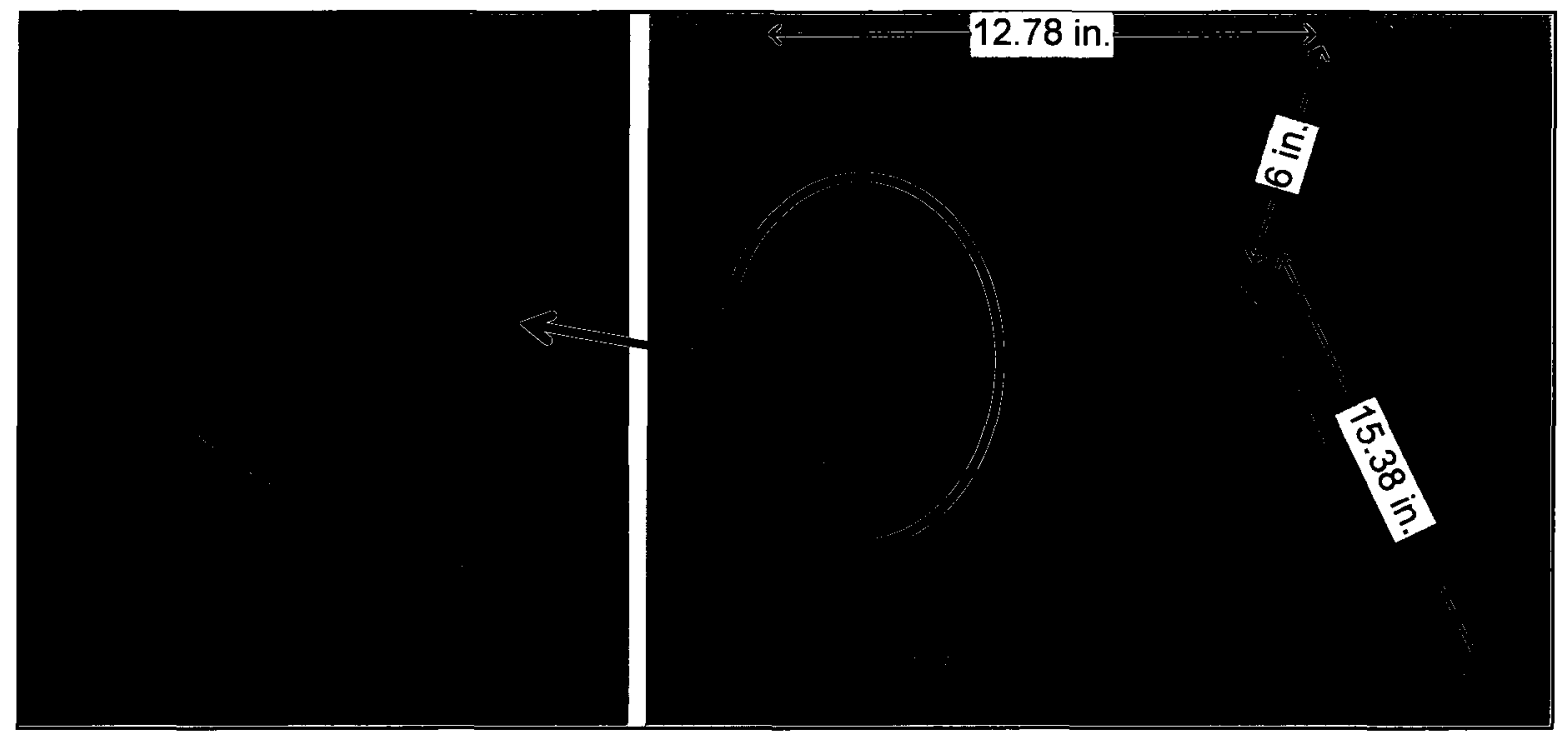

Figure 8.1: Geometry of the test article

In order to assess the quality of the sandwich structure manufactured by the mouldless CCBM method, the test article was sectioned into small pieces and their cross-sections were examined under the microscope. In this analysis, images taken from the test specimens were compared 
against the images of coupons manufactured using conventional VARTM method. A sample comparison is shown Figure 8.4. The partially open cells at the skin-core interface were found to be filled with resin and the trends were comparable between the VARTM and the CCBM specimens. This is required for good adhesion and proper load transfer between the skin and the core. More microscopic images of the VARTM and the CCBM specimens are available in Appendix F.

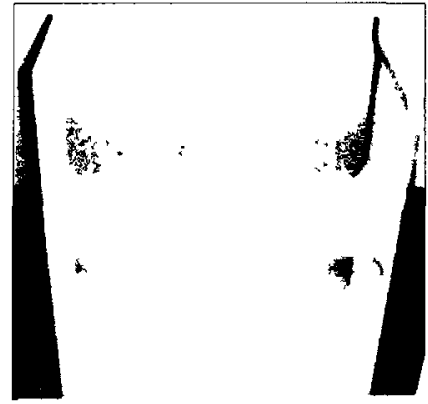

(a) Sample H-Section

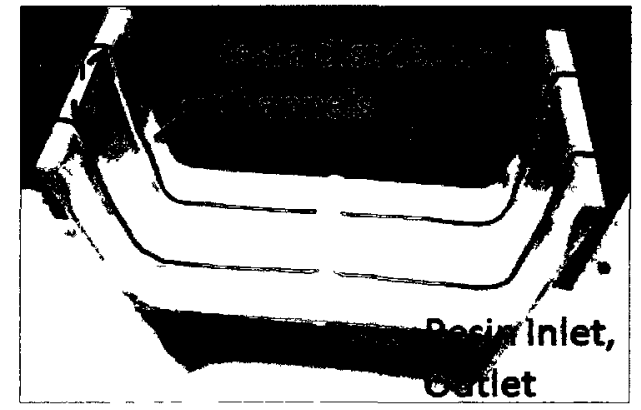

(b) CCBM Bag Manufacturing

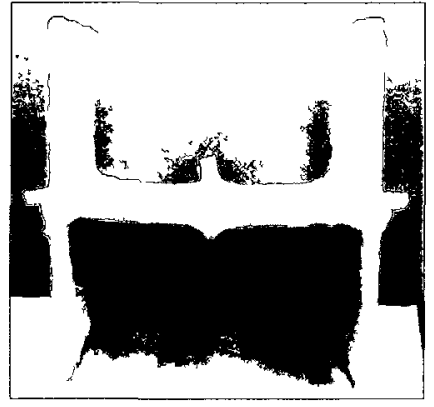

(c) CCBM-CIB Infusion

Figure 8.2: Important features of mouldless CCBM setup

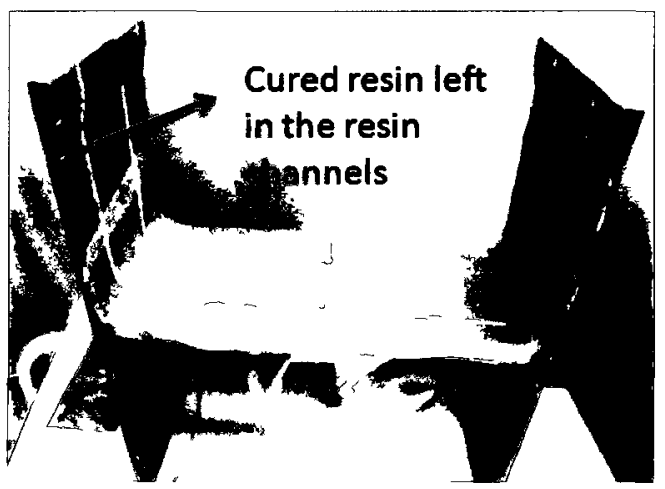

(a) Manufactured test article prior to removal of peel ply

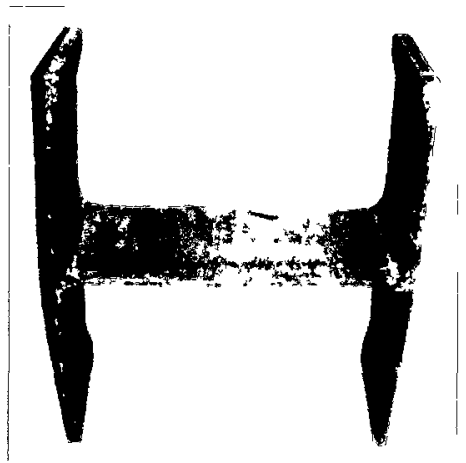

(b) Manufactured rest article

Figure 8.3: Manufactured component 

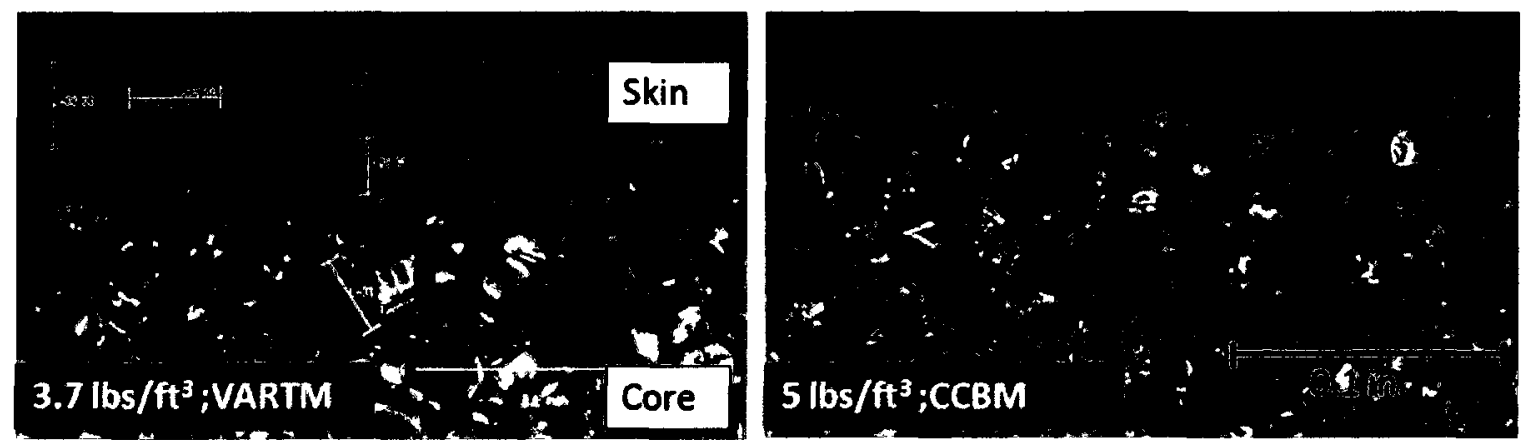

Figure 8.4: Bondline comparison of VARTM and CCBM manufactured sandwich coupons

\subsection{CCBM Experiments and Fuselage Manufacturing Model}

In this work, an appropriate spacing between resin distribution lines was determined based on flat panel experiments. Results from these experiments were combined with the knowledge acquired from the current prototype manufacturing (Maley, [3]), to develop a conceptual fuselage manufacturing model. The objective of this work was not shortening the infusion time, but rather creating a robust and efficient manufacturing setup.

Two flat panel CIB-CCBM experiments were carried out to determine the optimum separation between the resin distribution lines. Each CCBM bag had a resin inlet, a vacuum outlet and two resin distribution lines. Important parameters of the test setup are shown in Figure 8.5. Setups of the two experiments were identical except for the separation between the resin distribution lines (variable (d) in Figure 8.5 ), which were 6 in. for the first experiment and $10 \mathrm{in.}$ for the second. The distance between the resin inlet and vacuum outlet was set approximately at 24 in. This distance was chosen to represent the maximum distance from the centreline of the fuselage to the centre of the side wall. The resin distribution lines moulded into the bag were kept 3 in. short of the vacuum outlet line. If this separation was not present, the resin would 
travel preferentially from the inlet to outlet rather than infusing the part. The infusions were carried out on a flat tool surface with four ply carbon fibre fabric preform, at $\left[\left( \pm 45^{\circ}\right)_{2},\left(0^{\circ} / 90^{\circ}\right)_{2}\right]$ layup.

The CCBM setup that featured 6 in. separation between the resin distribution lines infused the part in approximately 13 minutes, while the other setup took 25 minutes for complete infusion. From manufacturing of the test section, it was found that 3 in. spacing between the resin distribution lines would require 6 minutes for infusion. From these results, it was decided that the maximum separation between any two resin distribution lines on the fuselage should be no more than 8 in. This would result in infusion time of approximately 20 minutes. Though the infusion time associated with this option was not the shortest, the infusion can be accomplished with fewer resin distribution lines. This reduces the complexity of the manufacturing setup and, in turn, makes the additional infusion time tolerable.

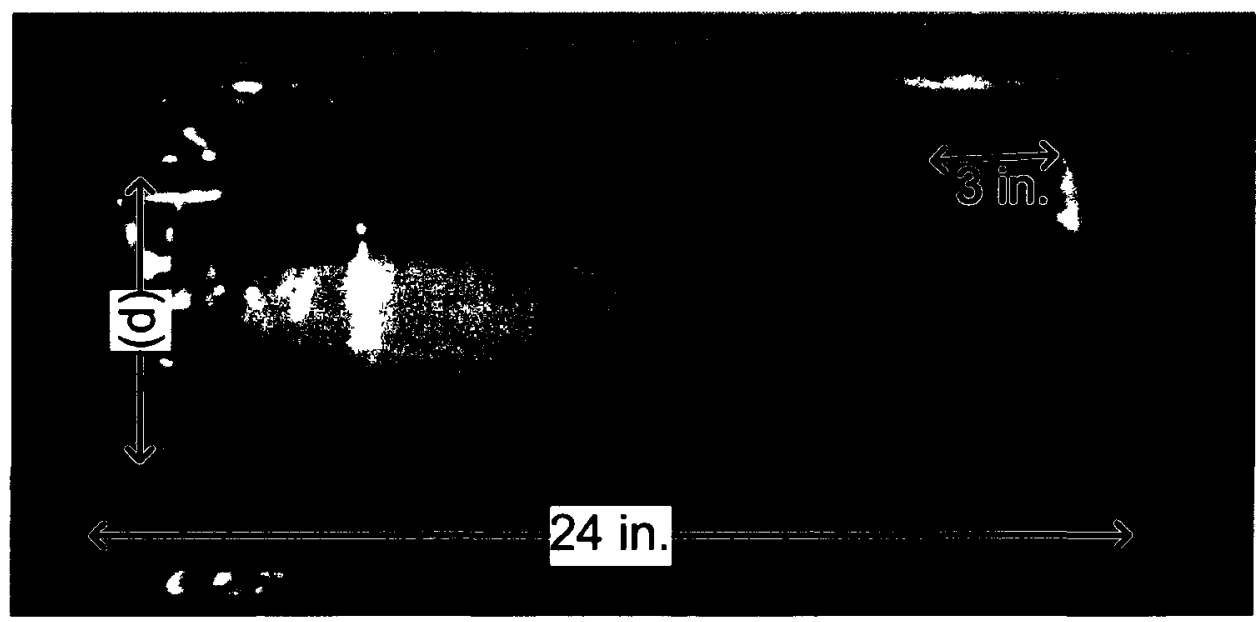

Figure 8.5: CCBM experiment setup 
Following the experiments, a conceptual CCBM manufacturing model was developed using Pro/E. The final manufacturing model shown in Figure 8.6 had resin distribution lines at various spacings along the fuselage walls. Areas of single ply layups had resin distribution lines 8 in. apart. As the ply count increased towards the rear bulkhead and the front bulkhead of the fuselage, this spacing was reduced to facilitate simultaneous infusion, as shown in Figure 8.6. Resin inlet lines were positioned along the centerline of the base plate and over the landing gear attachment panel, while vacuum outlet lines were placed around the perimeter of the fuselage. Approximately 2.5 in. distance was kept between the outlet line and the resin distribution lines. 


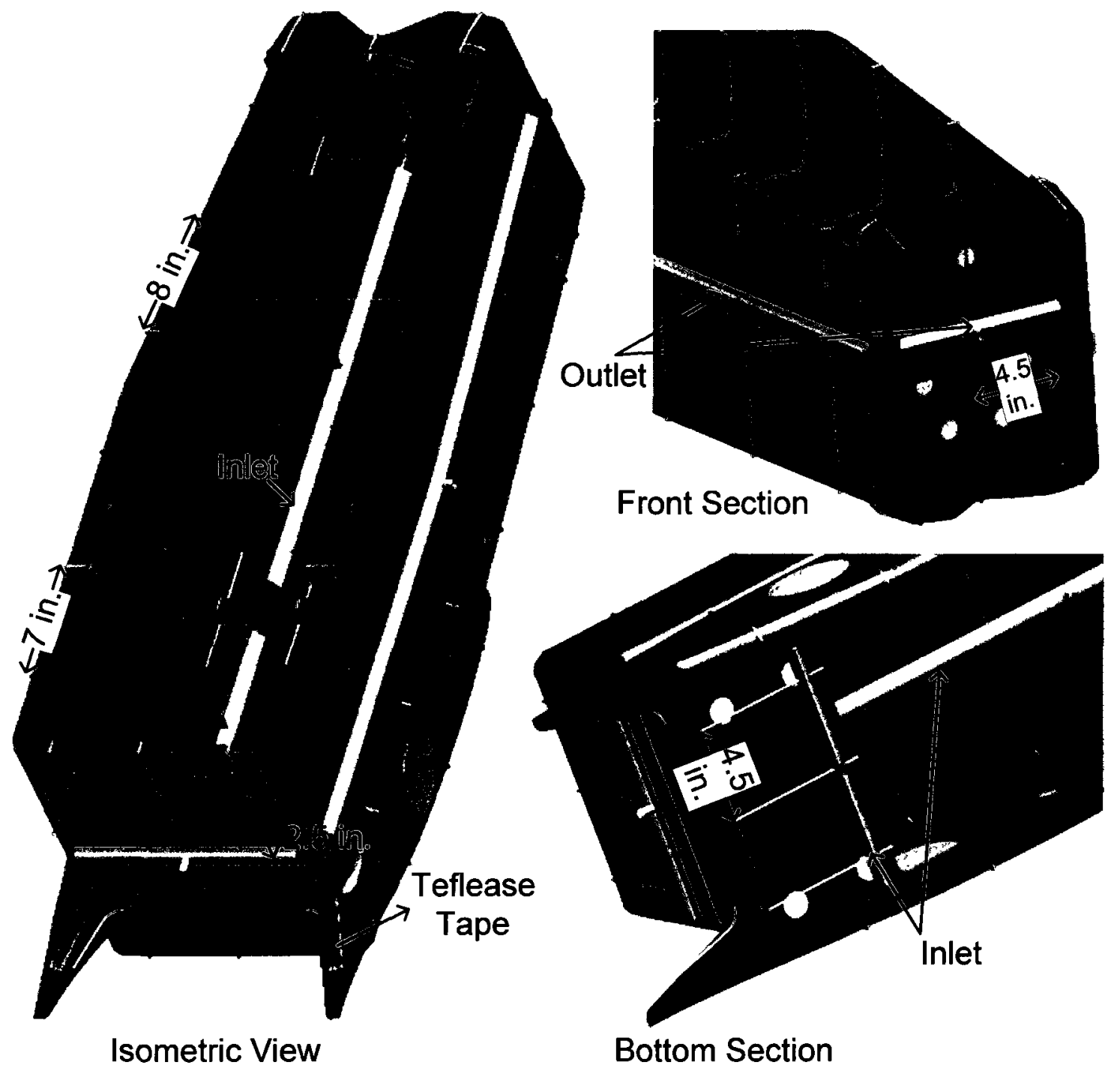

Figure 8.6: Conceptual CCBM Manufacturing Model 


\subsection{Fuselage Manufacturing}

Fuselage manufacturing involved three primary steps: foam core preparation and layup, bag manufacturing and CCBM infusion. The manufacturing sequence is illustrated in Figure 8.7.

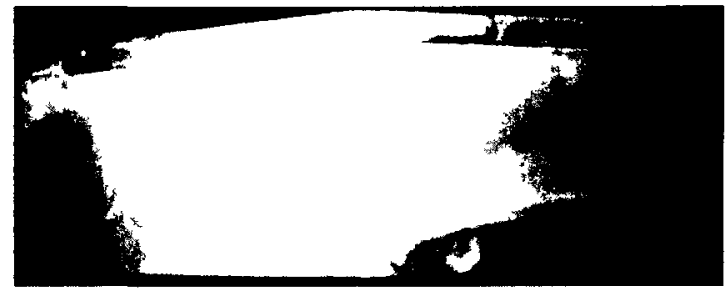

Step 1: Core Preparation/Layup

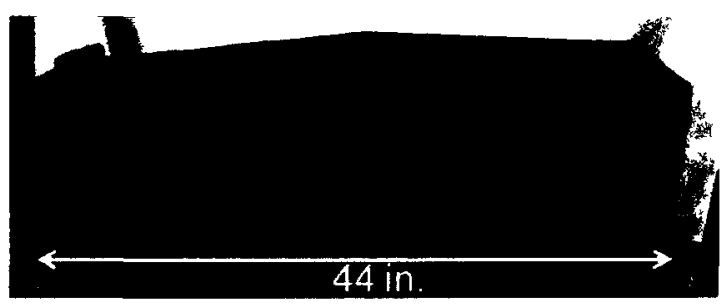

Manufactured Fuselage

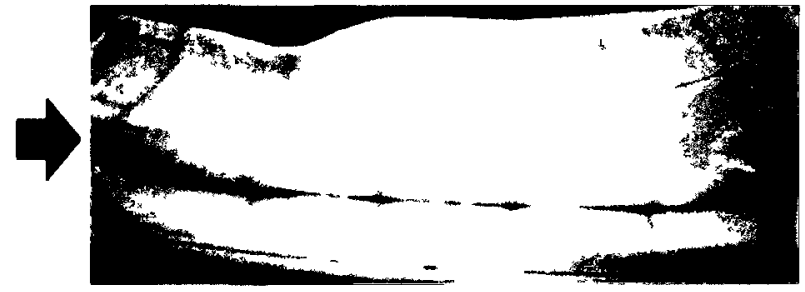

Step 2: Bag Manufacturing

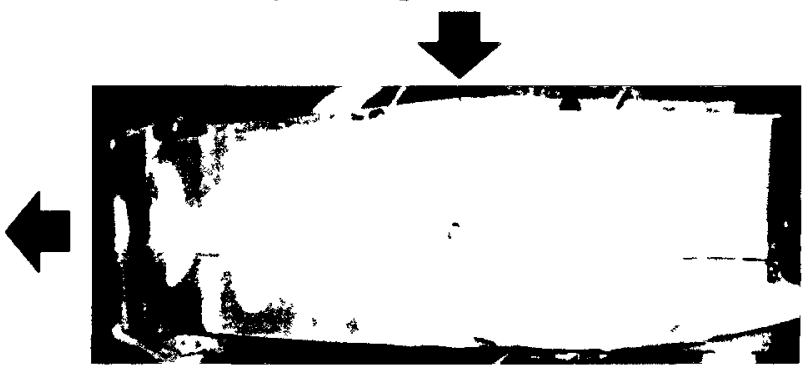

Step 3: CCBM Setup/Infusion

Figure 8.7: Mouldless ССВM Process

Manufacturing of the fuselage began with preparation of the foam core. In this process, required foam parts were machined using a 3 axis-CNC router. The machining process is shown in Figure 8.8 and the machined parts are shown in Figure 8.9. Then rigid FRP inserts (Figure 8.10), were cut to size from FRP rods, sandblasted and bonded into the foam parts using PTM\&W Inc. ES 6220 epoxy (Pot life 4-6 minutes, cure time 15 minutes). The foam parts were then bonded together to build the fuselage structure. A custom designed and built wooden assembly jig, shown in Figure 8.11, was used to hold the foam parts together during the bonding process. The assembly jig and the alignment features included in the foam parts (Figure 8.12) served to develop a robust core structure of the fuselage in a cost efficient and 
repeatable manner. Following assembly of the foam parts, the fuselage was laid-up with carbon fibre fabric (BGF Style\# 94132), in accordance to the optimized layup determined from the FEA (Figure 7.15). A layer of thin fibreglass fabric (BGF Style\# 106) was laid-up around the outer surface of the fuselage to provide fine surface finish and thereby minimize the surface preparation required for painting. The fuselage assembly was wrapped tightly with a layer of peel ply to create uniform surface finish. During layup, extra care was taken to ensure accurate fabric orientations and minimum overlaps on the OML. Additionally, it was ensured that all fabric and peel ply layers were tacked onto the foam core and conformed around the corner regions. This effort was important to generate good surface finish and minimize resin starved regions in the fuselage.

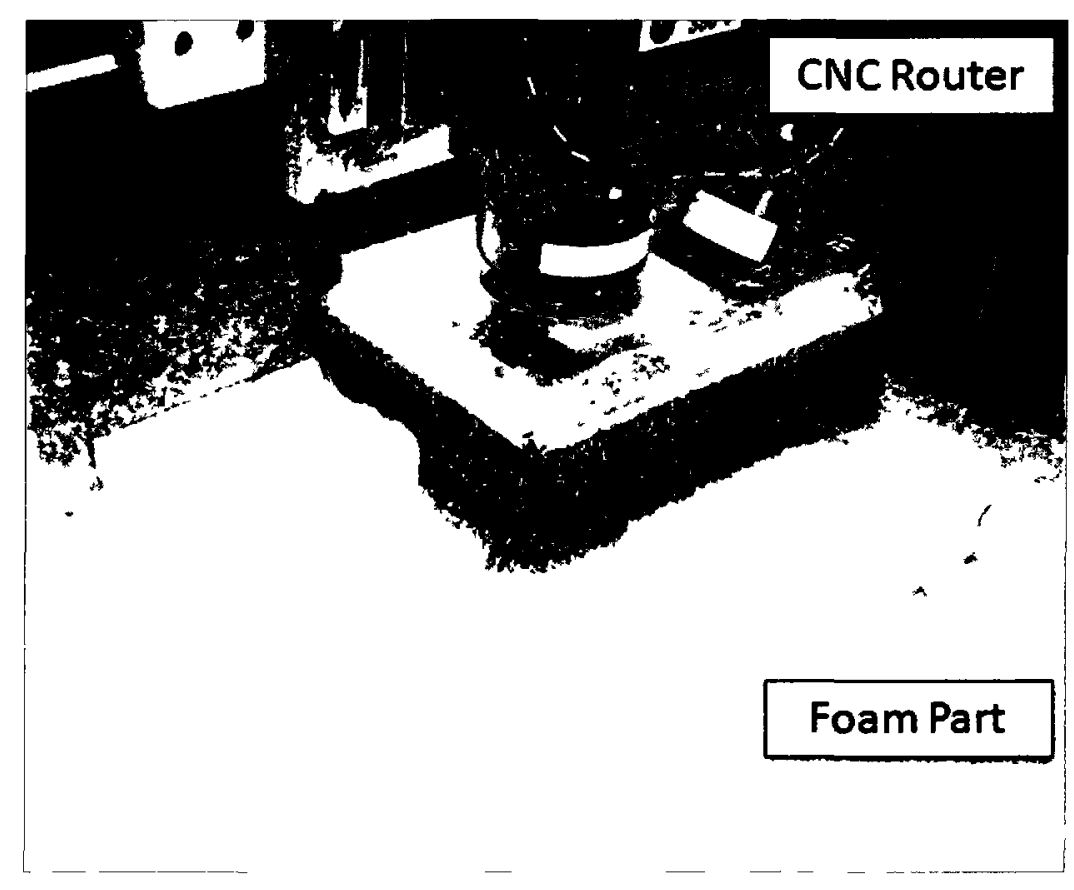

Figure 8.8: Machining of the foam parts on the CNC router table 


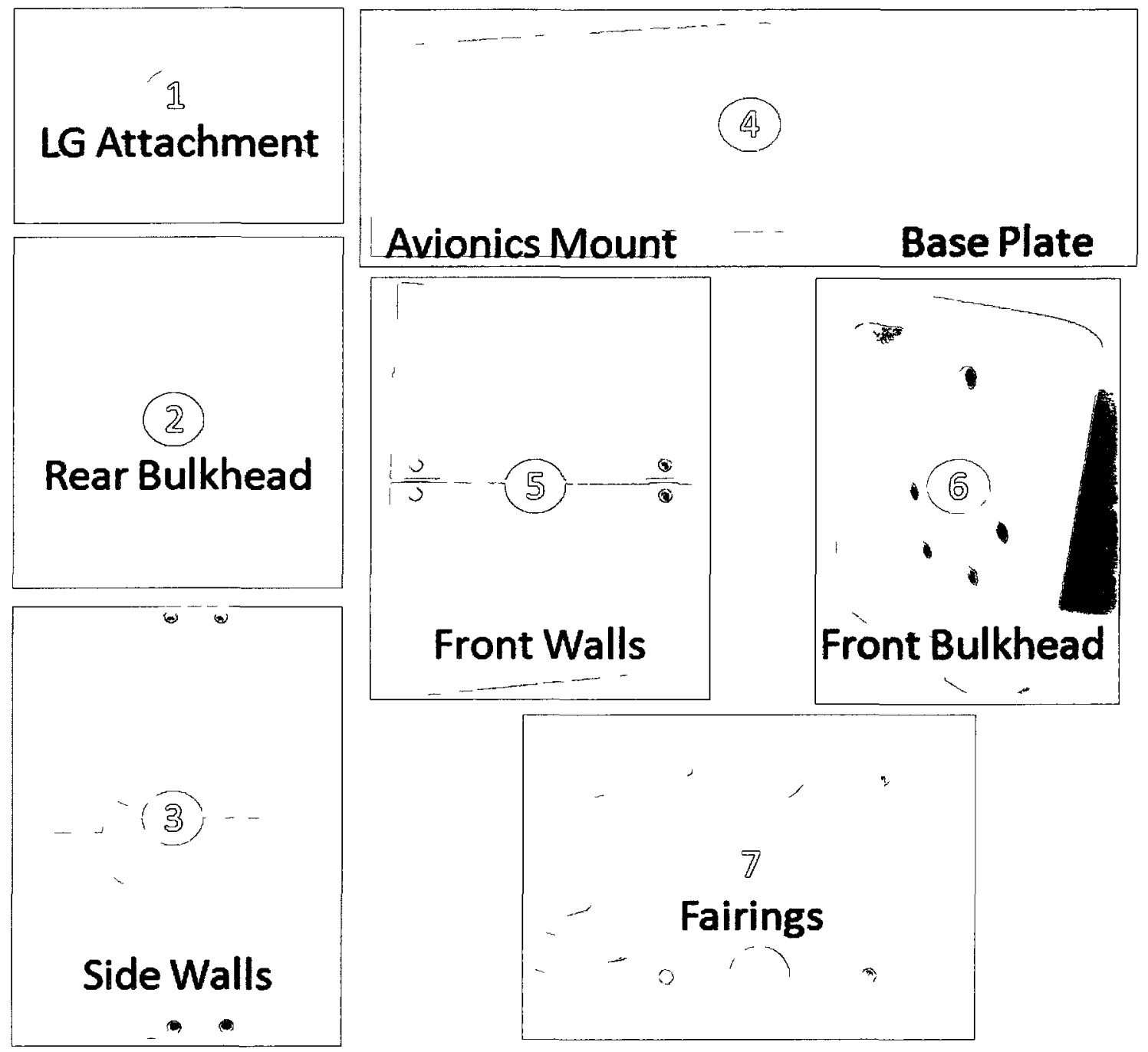

Figure 8.9: Foam parts required for fuselage manufacturoing

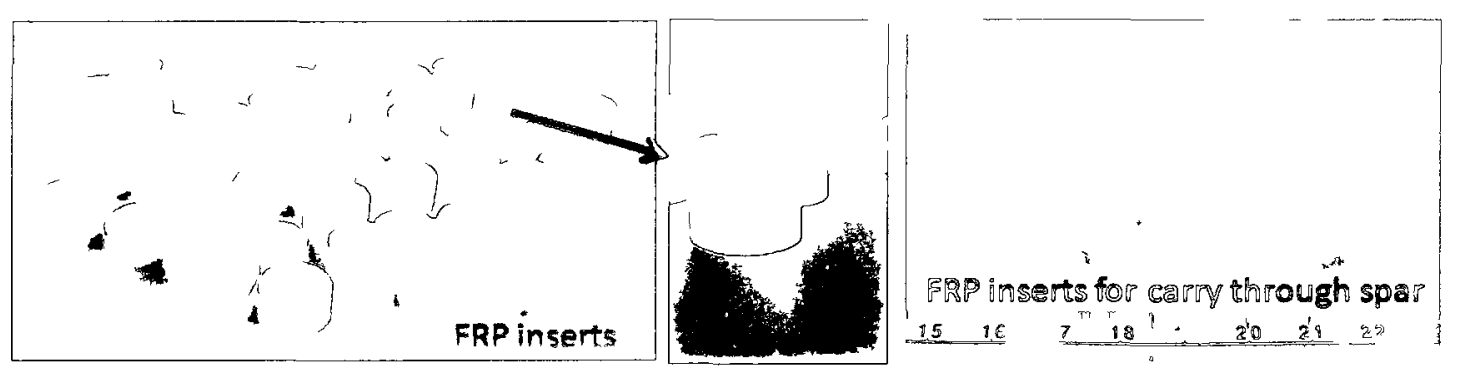

Figure 8.10: FRP inserts for Puselage 
Alignment Fences

$\downarrow$

\section{Bonding Fixture}

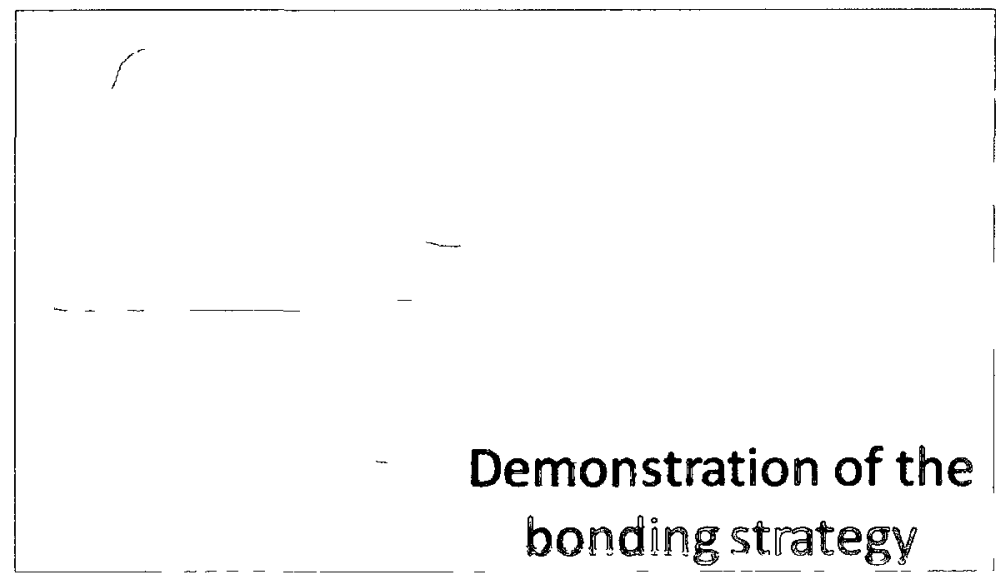

Figure 8.11: Ronding of foam parits in the romure

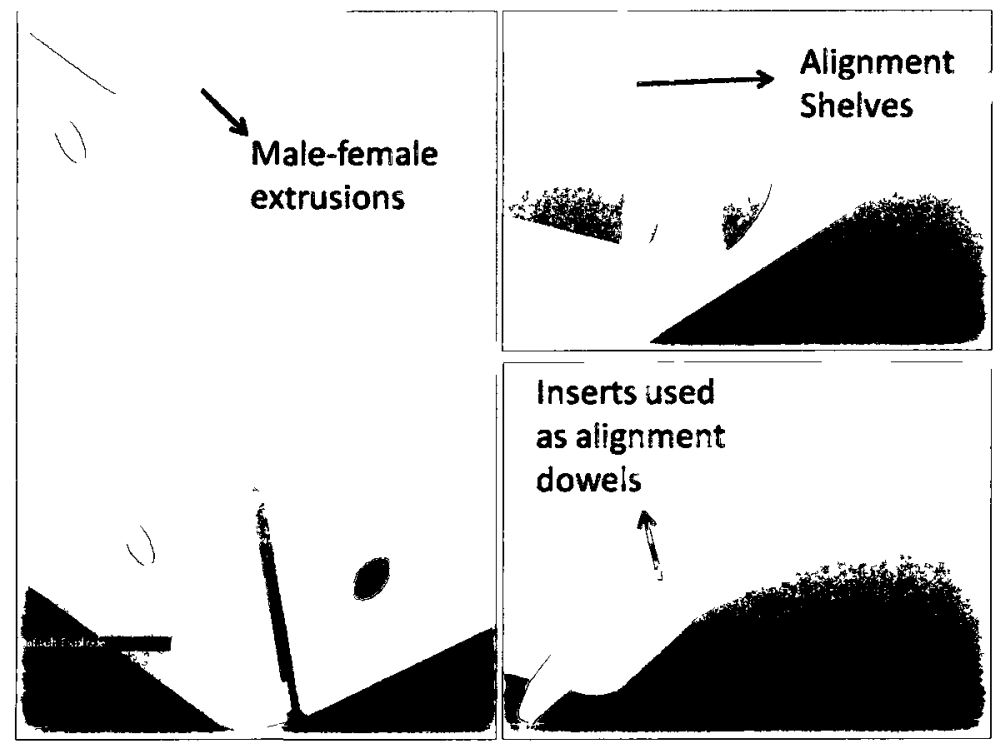

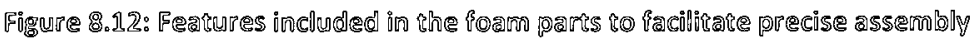


In the next stage of manufacturing, the fuselage core assembly was used as the mould to manufacture the CCBM bag. The techniques employed in bag fabrication were identical to the CCBM trial section manufacturing described in section 8.1. The manufactured CCBM bag was equipped with resin inlets, vacuum outlets and resin distribution channels as illustrated in Figure 8.6. Upon curing, the bag was cut open along the taped surface and liquid mould release was sprayed over the inside surface of the bag. This optional step was included in the manufacturing process to add extra protection to the bag and enhance its self-release capability.

In the final step, the manufactured CCBM bag was installed back onto the fuselage layup and sealed with disposable sealant tape. The outlet lines were attached to the vacuum ports. Upon application of vacuum pressure, the fuselage walls were found to warp inward. The walls were supported using spacers made from turn buckles with swivel feet (Figure 8.13), to correct this warpage. Once the setup was complete, a vacuum integrity check was performed, where 1 inHg/min. was considered an acceptable vacuum loss. The CCBM setup had a vacuum loss of $0.3 \mathrm{inHg} / \mathrm{min}$., a significant improvement upon the previous mouldless VARTM setup (Maley, [3]). 


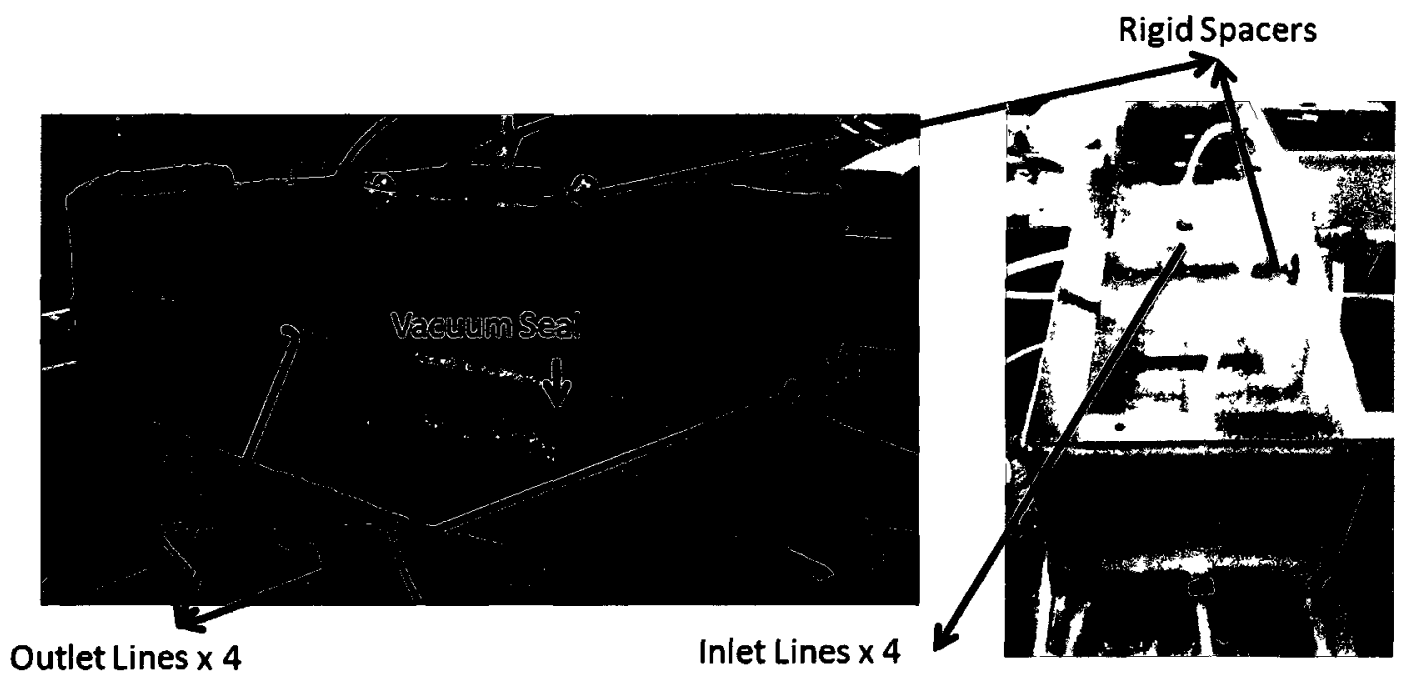

Figure 8.13: Mouldless CCBM setup

After verifying the vacuum integrity of the setup, the fuselage was infused with PT\&W 2712 epoxy. Though the infusion time predicted based on the experiments (section 8.2) was 20 minutes, the actual infusion was completed in approximately 45 minutes. This was primarily due to the resin shortage, which occurred about 10 minutes into the infusion. When this was noticed, the resin feed lines were clamped off, a new batch of resin was mixed and the infusion was resumed after 10 minutes. This slowed down the infusion process and resulted in small resin starved regions in the bottom base plate section, as shown in Figure 8.14. The flow behaviour during the infusion (Figure 8.7-Step 3) was similar to that observed in the flat panel CCBM experiments, where the resin travelled preferentially through the distribution lines and then spread into the fabric. 


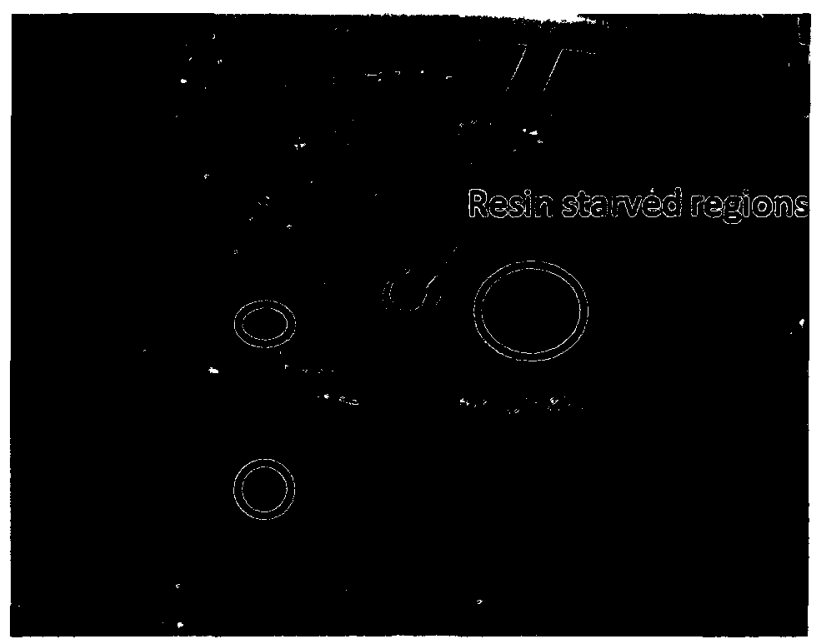

Figure 8.14: Resin starved regions observed during the infusion

Following the infusion, inlet lines were attached to the vacuum ports to remove any excess resin from the part. The part was left to cure under vacuum pressure, for 24 hours. The manufactured fuselage is shown in Figure 8.7. 


\section{CHAPTER 9. MANUFACTURING RESULTS}

The manufactured fuselage was visually inspected to assess the surface quality. The dimensions of the new fuselage were measured and compared against the current fuselage manufactured by mouldless VARTM (Maley, [3]). The weight of the new fuselage was measured and assessed against the FEA predictions. Finally the PVA was revisited to draw conclusions on the process viability. This work is described in the following sections.

\subsection{Surface Finish, Weight and Tolerances}

The manufactured fuselage had a fine peel ply finish with carbon-epoxy skin tightly conformed around the corners. Some of these surfaces are highlighted in Figure 9.1. With the exception of the small resin starved regions found in the base plate, the fuselage was fully infused and showed smooth surface texture. Overall surface finish was better than that observed in previous manufacturing attempts.

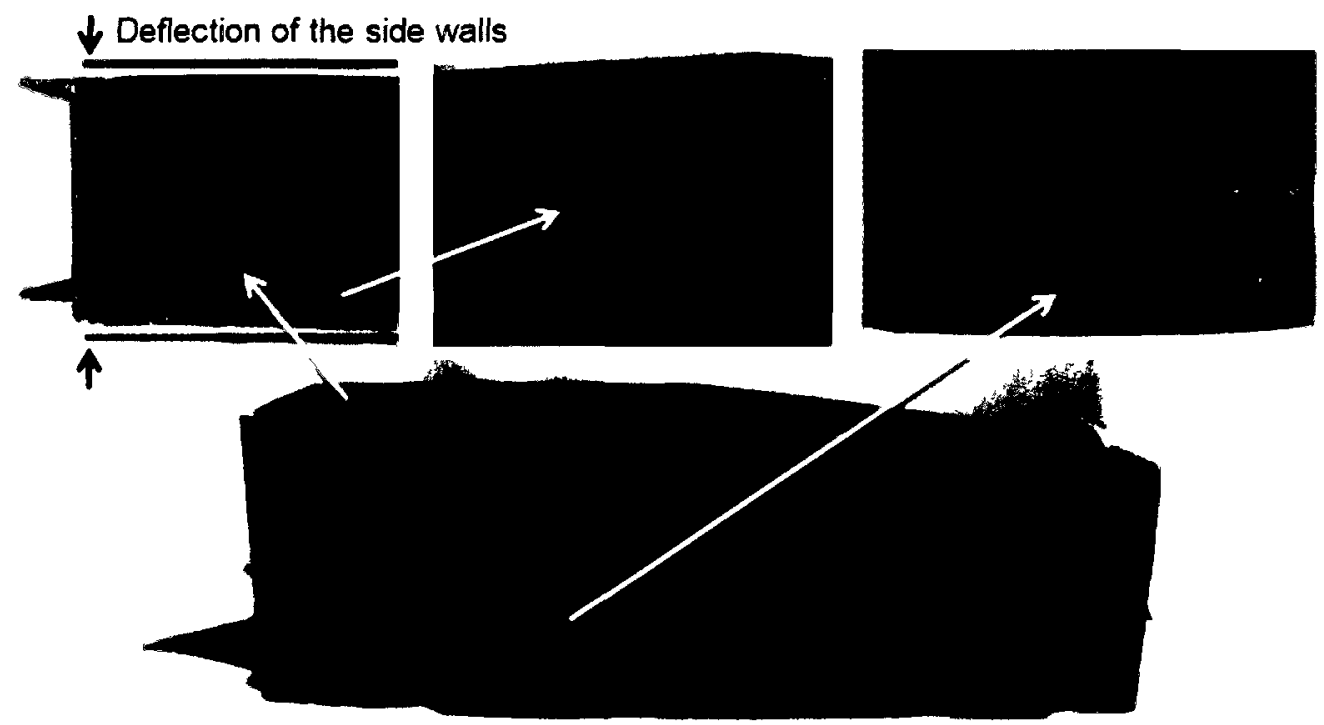

Figure 9.1: Fuselage Manufactured by mouldless CCBM 
There were some issues with the tolerances, although the modified CCBM setup alleviated the wall distortion observed in the previous mouldless VARTM. The side walls near the top-rear section of the fuselage were found to be deflected inward, as shown in Figure 9.1. This deflection was a direct consequence of one turnbuckle spacer falling off, leaving part of the fuselage walls unsupported during the cure. All other walls remained supported throughout the entire process. To better characterize the dimensional tolerances, the OML of the manufactured fuselage was profiled. In this work, the outer dimensions of the fuselage were measured using rulers, to an accuracy of $\pm 1 / 16$ in. Measurements were taken at a sufficient number of points to establish an accurate profile of the final shape. Detailed profiling can be found in Appendix G [61].

Deviations from the target dimensions were below 0.09 in. in most regions, with the exception of the rear walls on the top half of the ' $H$ ' structure and front walls on the bottom half of the ' $H$ ' structure. At these locations the maximum deviations were found to be 0.4 in. and 0.23 in. respectively. Compared to the previously implemented mouldless VARTM, which resulted in surface variations of up to 0.25 in. along most fuselage walls, the tolerances achieved with this manufacturing method better complied with the design targets. This is shown in Table 9.1. However, there is still a need for improved techniques for controlling part dimensions in mouldless manufacturing. Better dimension control can perhaps be achieved with the use of a connected fixture rather than individual spacers (similar to the VARTM setup, [3]). If individual spacers are used, they need to be embedded into the vacuum bag to ensure more accurate positioning. 
Table 9.1: Comparison of major dimensions: fuselage design vs. current and new fuselages

\begin{tabular}{|l|c|c|c|c|}
\hline \multicolumn{1}{|c|}{ Measurement Location } & $\begin{array}{c}\text { Design } \\
\text { (in.) }\end{array}$ & $\begin{array}{c}\text { Measured } \\
\text { dimensions } \\
\text { (new fuselage) } \\
\text { (in. } \pm 1 / 16 \text { in.) }\end{array}$ & $\begin{array}{c}\text { Deviation in the } \\
\text { new fuselage } \\
\text { (in.) }\end{array}$ & $\begin{array}{c}\text { Deviation in the } \\
\text { current fuselage } \\
\text { (in.) }\end{array}$ \\
\hline Rear width & 13.34 & 13.31 & 0.03 & -0.06 \\
\hline Front width & 10.93 & 10.88 & 0.05 & -0.10 \\
\hline Length (Centerline) - Top & 43.03 & 42.97 & 0.06 & 0.20 \\
\hline Length (Left) - Top & 43.08 & 43.06 & 0.02 & 0.01 \\
\hline Length (Right) - Top & 43.08 & 43.03 & 0.05 & 0.05 \\
\hline Length (Centerline) - Bottom & 44.15 & 44.19 & -0.04 & 0.31 \\
\hline Length (Left) - Bottom & 43.02 & 43.06 & -0.04 & 0.07 \\
\hline Length (Right) - Bottom & 43.02 & 43.06 & -0.04 & 0.07 \\
\hline Length - Fairing to Fairing & 15.55 & 15.47 & 0.09 & 0.05 \\
\hline
\end{tabular}

The manufactured fuselage weighs approximately 14.6 lbs. In order to compensate for the material to be removed during the installation of the carry-through spar, $0.5 \mathrm{lbs}$ was deducted from the measured value. Possible weight reduction offered by drilling holes at the locations of inserts was ignored. Thus the effective weight of the new fuselage was estimated to be $14.1 \mathrm{lbs}$. Compared to the current fuselage, the new fuselage offered a total weight saving of $7.9 \mathrm{lbs}$, which was approximately $36 \%$ of the fuselage weight and $4 \%$ of the entire aircraft weight. The actual weight was close to the theoretical weight estimated using the FEA, which is summarized in Table 9.2. The Fibre volume fraction $\left(V_{f}\right)$ of the manufactured fuselage was estimated to be 51\%. The value of $V_{f}$ was not determined using an ASTM standard, but rather an approximate value was estimated based on theory, measured weights and assuming zero void content. Detailed $V_{f}$ calculations are provided in Appendix $\mathrm{H}$. 
Table 9.2: Comparison of the actual weight and predicted weight of the new fuselage

\begin{tabular}{|l|c|}
\hline \multicolumn{2}{|c|}{ FUSELAGE WEIGHT SUMMARY } \\
\hline Current fuselage weight & $22 \mathrm{lbs}$ \\
\hline $\begin{array}{l}\text { Predicted weight of the new fuselage based on } \\
\text { the FEA }\end{array}$ & $12.8 \mathrm{lbs}$ \\
\hline Weight of the new fuselage as manufactured & $14.1 \mathrm{lbs}$ \\
\hline Predicted weight saving & $\begin{array}{c}9.2 \mathrm{lbs} \\
(42 \% \text { of the fuselage, } \\
5 \% \text { of the aircraft) }\end{array}$ \\
\hline & $\begin{array}{c}7.9 \mathrm{lbs} \\
\text { (36\% of the fuselage, } \\
4 \% \text { of the aircraft) }\end{array}$ \\
\hline
\end{tabular}

\subsection{Process Viability}

During manufacturing of the fuselage, it was realized that approximately one week was required to complete the CCBM bag ${ }^{6}$. This contradicted the initial PVA estimates, which accounted only two days for bag manufacturing. Though the CСBM bag could be manufactured within two days using fast-cure, sprayable CCBM systems, it was in the best interest of this research to determine whether the CCBM method employed was cost-effective for producing components in quantities below 10 units. Hence, the PVA was revised to account for a week of bag manufacturing, and the resulting costs at labour rate of $40 \$ / \mathrm{hr}$ are shown in Figure 9.2 . From these results, it is apparent that the method employed in this research, CCBM III, would be an attractive choice for manufacturing more than six fuselages. Thus, the process utilized is viable for mouldless manufacturing of components in low production quantities.

\footnotetext{
${ }^{6}$ Note that in this bag manufacture, some effort was related to the development.
} 


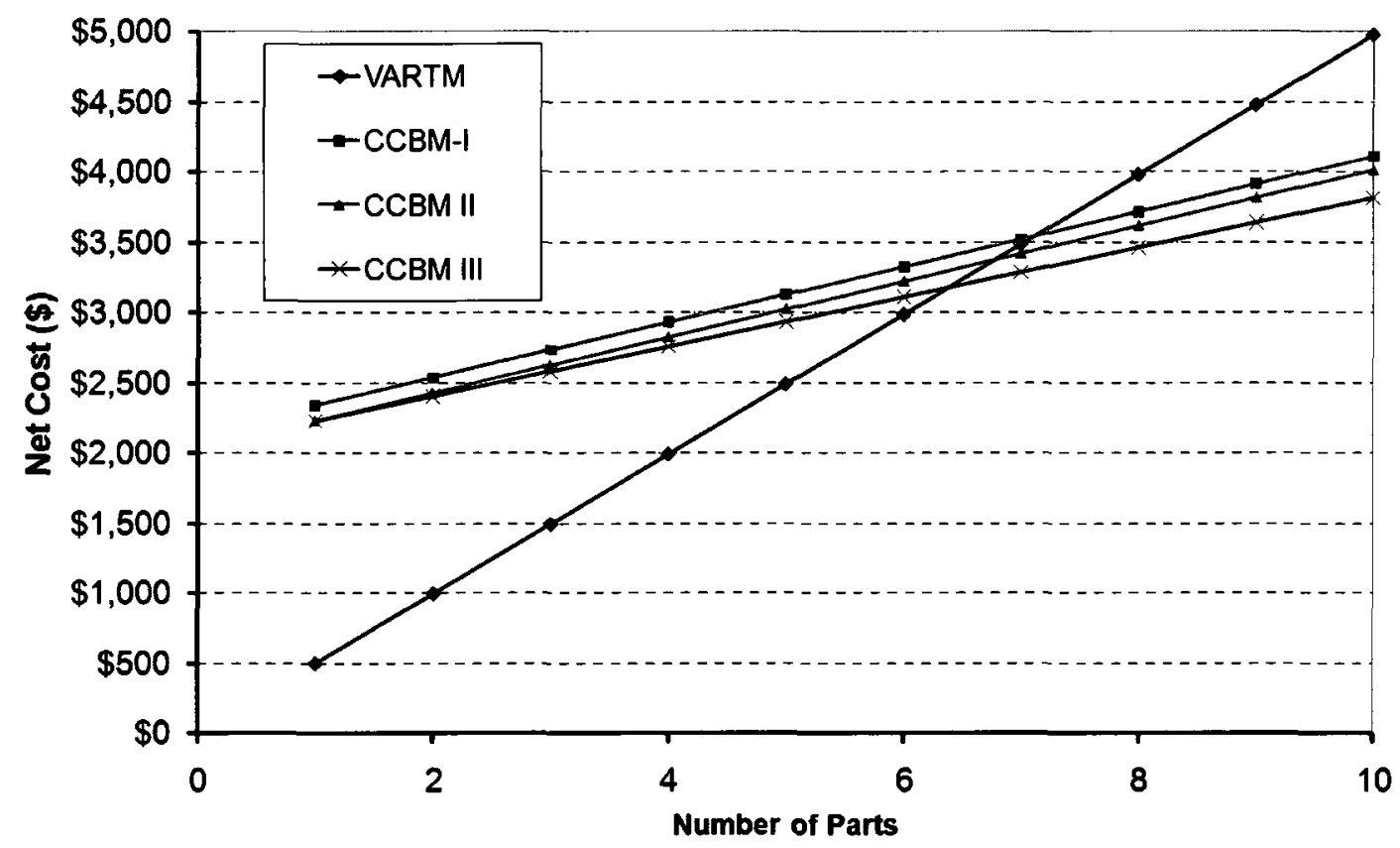

Figure 9.2: Revised PVA cost estimates based on actual labour required for fuselage manufacturing (labour rate $\$ \mathbf{4 0 / h r )}$ 


\section{CHAPTER 10. CONCLUSIONS}

The conclusions drawn from this research and recommendations for future work are discussed in this chapter.

\subsection{Conclusions}

$>$ Based on an in-depth review of the current LCM processes, CCBM was selected for mouldless manufacturing of foam-core composite sandwich components. The initial material and labour cost associated with CCBM is slightly higher than that of conventional VARTM, but this added cost comes with the benefits of improved process robustness, repeatability and part quality. A series of flat-panel experiments followed by a PVA carried out in this research demonstrated that mouldless CCBM with CIB infusion is a viable option for low volume $(<10)$ production of large, complex components.

PVA is an effective tool for determining the feasibility of a process. When several process variants exist, PVA can be used to select the most viable option.

Effective application of DFM and near-net-shape manufacturing principles improves the part quality, tolerances and reduces the overall cost of production, in mouldless manufacturing.

Simplified FEA techniques are fast and effective in determining the optimum layup of a composite structure.

Weight savings of $8 \mathrm{lbs}$ ( $36 \%$ as compared to the current fuselage prototype) were achieved on the GeoSurv II fuselage using design optimization based on DFM principles and FEA, supported by coupon tests. 
$>$ To facilitate the transfer of discrete loads into a sandwich structure, rigid inserts embedded into the foam core prior to resin infusion are a robust solution. Subsequently, holes can be drilled through these local "hard points" and bolted joints can be created. Such joints are typically lighter and more effective in distributing the loads into the surrounding structure as compared to those created by bonding rigid inserts into the manufactured component.

$>$ A new full-scale GeoSurv II fuselage was manufactured to near-net-shape in a single step infusion using an improved mouldless CCBM method. Although the new fuselage showed improved surface quality and dimensional tolerances compared to the current fuselage, some filling and sanding is still required to bring the tolerances closer to the design specifications. However, achieving near-net-shape tolerances with mouldless CCBM is not far from reach.

This research has contributed to several important aspects of low cost composite structures, including structural design with material selection, structural optimization, design for manufacture (DFM), process selection, process value analysis (PVA), manufacturing process planning and development.

\subsection{Recommendations for Future Work}

The dimensional tolerances of mouldless CCBM manufacturing can be improved by embedding rigid spacers into the CСBM bag or with the use of accurate fixtures. In the future, more fuselages will be manufactured using the CCBM bag employed in this research, but with a modified technique for part shape retention. Results from future manufacturing shall be used to verify the process repeatability for complex-shape components. 
Future manufacturing should also consider using fast-cure, sprayable CCBM systems to improve the efficiency of bag manufacturing. If not constrained by the design limitations, the foam core should be designed to withstand the applied vacuum. Thus, the need for additional support fixtures for part shape retention can be eliminated.

Accurate modelling of the bolted joints using a proper contact algorithm is recommended to obtain better correlation between FEA results and experiments, particularly for the out-ofplane bending loads. Additionally, properties of the new matrix and reinforcement materials should be characterized using coupon testing and the material properties used in the FEA of this research should be revised to improve the results. Future FEA work should also consider simulating and optimizing the fuselage under fatigue load and impact loads.

Assumptions used in the FEA were conservative and the MS values were somewhat high at several locations, which mean that there is still room for optimizing the fuselage layup and further reducing weight. Future work should consider testing the new fuselage to failure and optimizing the layup based on the test results and improved FEA methods.

Redesign work in the future should also consider simplifying the geometry to ease the fabric layup procedures. Additionally, the FRP inserts used in this research have directional properties, which are undesirable in the presence of multi-axial loads. Thus, future redesign work should look into isotropic inserts. To further optimize these joints, different insert and joint configurations should be developed and compared against the current joint design. 
Detailed research on flow modelling and developing strategies for optimizing the infusion setup would further improve the capabilities to manufacture arbitrary (complex) structures using CCBM. 


\section{REFERENCES}

1. "Sandwich Panels", Lecture Notes for AERO 4608, Composite Materials, Lecture 14e-Design, Department of Mechanical and Aerospace Engineering, Carleton University, 2008.

2. Diab Inc., Foam Core Materials in the Marine Industry, [Online- Technical Bulletins], 2009, [Cited May 2010] Available:

http://www.diabgroup.com/americas/u literature/u pdf files/u bul pdf/Foam Core Marine TB.pdf.

3. Maley, A.J, "An investigation into low-cost manufacturing of carbon epoxy composites and a novel mouldless technique using the Vacuum Assisted Resin Transfer Moulding (VARTM) method", MASc Thesis, Department of Mechanical and Aerospace Engineering, Carleton University, Ottawa, ON, 2008.

4. Mahendran, M. et al., "Feasibility Study of Closed Cavity Bag Moulding for Novel Mouldless Manufacturing of Carbon-Epoxy Composites", presented at the Canadian Aeronautics and Space Institute AERO '09 Conference- $20^{\text {th }}$ Aerospace Structures and Materials Symposium, Ottawa, ON, 2009.

5. Carleton University Department of Mechanical and Aerospace Engineering and Sander Geophysics Limited. GeoSurv II Unmanned Aerial Vehicle: System Requirements Document (UAV-SRD), Rev. E, 31 March, 2008.

6. Summerscales, J, Searle, T.J, “Low-pressure (vacuum infusion) techniques for moulding large composite structures", Proc. IMechE Vol. 219 Part L: J. Materials: Design and Applications, 07 September 2004.

7. Beckwith, S.W., and Hyland, C.R, "Resin Transfer Moulding: A decade of Technology Advances", SAMPE Journal, Vol. 34, No. 6, November/December, 1998.

8. Rudd, C.D. et al., "Liquid Moulding Technologies, Resin Transfer Moulding, Structural Reaction Injection Moulding and Related Processing Techniques", Woodhead Publishing, 1997, pp. 1-35.

9. J.H.A. van der Woude and E.L. Lawton, "Composite Design and Engineering, Fibreglass and Glass Technology", ISBN 978-1-4419-0735-6. Springer Science+Business Media, LLC, 2010, pp. 125-173.

10. Summerscales, J., "Composites Design and Manufacture- Composites Manufacturing Processes" University of Plymouth- Advanced Composites Manufacturing Centre, MATS 324 Lecture Notes, [Online Version Cited May 2010], Available: http://www.tech.plym.ac.uk/sme/MATS324/MATS324C.htm.

11. Potter, K., "Resin Transfer Moulding", Springer-Verlag, 1997.

12. Pant, S. et al., "Characterization of Double-Bagging Effects on 1-D Permeability for Vacuum Assisted Resin Transfer Moulding (VARTM) Process", presented at the Society for the Advancement of Materials and Process Engineering- SAMPE 2010 Conference, Seattle, WA, May 2010.

13. Mahendran, M. et al., "Feasibility Study of Closed Cavity Bag Moulding (CCBM) for Novel Mouldless Manufacturing of Carbon-Epoxy Composites" presented at Canadian Aeronautics and Space Institute AERO'09 Conference, $20^{\text {th }}$ Aerospace Structures and Materials Symposium, Ottawa, ON, 2009.

14. Seemann, WH. "Unitary Vacuum Bag for Forming Fibre Reinforced Composite Articles". US Patent No. 5, 316, 462; May 21, 1994.

15. DAl J. et al., "A Comparative Study of Vacuum-Assisted Resin Transfer Molding (VARTM) for Sandwich Panels", Polymer Composites, Vol. 24, No. 6, December 2003. 
16 Seemann, WH "Plastıc transfer moldıng technıques for the production of fibre reinforced plastıc structures" US Patent No 4, 902, 215, 1990

$17 \mathrm{LI}, \mathrm{W}$ et al , "Process and Performance Evaluation of the Vacuum-Assisted Process" Journal of Composite Materıals, Vol 38, No 20, 2004

18 Allende, $\mathrm{M}$ et $\boldsymbol{a l}$, "Experımental and Numerical Analysıs of Flow Behavior in the FASTRAC Liquid Composite Manufacturıng Process", Polymer Composites, Vol 25, No 4, August, 2004

19 Niggemann, $\mathrm{C}$ et al, "Experımental Investıgatıon of the Controlled Atmospherıc Pressure Resın Infusıon (CAPRI) Process", Journal of Composite Materials, 42, SAGE Publications, 2008

20 Takeda, F et al, "Research in the Application of the VaRTM Technique to the Fabrication of Primary Aircraft Composite Structures", Mitsubishı Heavy Industries, Ltd Technıcal Review Vol 42 No 5 , December, 2005

21 Kleıneberg, $\mathrm{M}$ et al, "Cost Effectıve CFRP-Fuselage Manufacturıng with Lıquid Resın Infusıon (LRI) Technologıes", Workshop at German Aerospace Centre (DLR) on Final Project of Black Fuselage, Braunschweig, Germany, 2002

22 Louderback et al , "HIgh Performance Infusıon System for VARTM Fabricatıon", U S Patent 6964561 B2 November 15, 2005

23 Gıbson, R F and Ayorınde, E O, "Vibratıon-Assısted Lıquid Composite Mouldıng", ANTEC Conference Proceedings, Society of Plastics Engıneers, Brookfield, CT, vol 2, pp 1544-1547, 2004

24 Arctek Inc , "Closed Cavity Bag Mouldıng Multı-Port Infusıon", CCBM Traınıng Manual, Rev 26 November 1999

25 Fink B K, et al, "Co-Injection Resın Transfer Mouldıng of Vinyl-Ester and Phenolic Composites", The U S Army Research Laboratory Technical Report, ARL-TR-2150, Accession Number ADA 373528, January 2000

26 Bottler, O et al , EC-HLM Honeycomb Lıquid Mouldıng, [Onlıne Document] EURO Composites, 2008, [CIted May 2010] Avallable http //www euro composites com/SiteCollectionDocuments/EC HLM EN pdf

27 Magnum Venus Plastech Ltd, Lıght RTM (LRTM), [Onlıne], 2007, [Cited September 2010], Avaılable http //www plastech co uk/Mt/rtm html

28 JHM Technologies Inc, RTM Light- The Lower Cost Alternative Takes the Lead in the Closed Moulding Industry, [Onlıne], 2009, [Cited September 2010], Avallable http //www rtmcomposites com/|rtm html

29 Thagard, J R, et al , "Resın Infusıon Between Double Flexıble Toolıng Evaluation of Process Parameters", Journal of Reinforced Plastics and Composites 23, 1767, SAGE Publications, 2004

30 Ruiz, E and Trochu, F, "Flexıble Injection A Novel LCM Technology for Low Cost Manufacturıng of High Performance Composites Part I Experımental Investıgatıon", 9th Internatıonal Conference on Flow Processes in Composite Materials (FPCM 9), Montreal, Canada, July 8-10, 2008

31 Qı, B et al, "A Resın Fılm Infusıon Process for Manufacture of Advanced Composite Structures", Composite Structures- 47, pp 471-476, 1999 
32 Airtech Inc., Vacuum Baggin Techniques, [Online] @ 2008, 2009, 2010 - AIRTECH Europe Sarl, [Cited September 2010] Avallable: http//catalogue artech /u/product php?product id=355

33. Airtech Advanced Materıals Group, Airtech Europe S. A., Rubber Silicone Seals, [Online Catalogue], 2008, [Cited 12Jan09], Avallable: http://catalogue.airtech.lu/product.php?product Id=29\&lang=EN.

34. Aaron Miller, CCBM, E-mail communications with Aaron Miller from Composites Canada, Mario Mahendran, Ottawa, 2009.

35. Arctek Inc. CCBM Start-up Kit, [Cited October, 2010], Available: http //www arctekınfusion com/Howtogetstarted htm

36. Crow, K., Value Analysis and Functional Analysis System Technique, DRM Associates, [Online Document], [Cited March 12, 2009], Available: http //www npd-solutıons com/va html

37. Lisa Somanchi, et. al., Value Analysis: Overview, The Quality Portal [Online Document], September 09, 2008, [Cited March 12, 2009], Avallable: http//thequalityportal com/artıcles/value htm

38. Diab Inc., Sandwich Concept, Diab Manuals- Diab Sandwich HandbookDiab, [Online Document], [Cited Apr. 2010], Available:

http //www diabgroup com/europe/literature/e pdf files/man pdf/sandwich hb pdf

39. Allen, H.G., "Analysis and Design of Structural Sandwich Panels", Pergamon Press, New York, 1969.

40. Plantema, F. J., "Sandwich construction; the bending and bucklıng sandwich beams, plates, and shells", Wiley, New York, 1966.

41. Daniel I.M., et. al., "Major Accomplishments in Composite Materials and Sandwich Structures", An Anthology of ONR Sponsored Research, Springer, New York, 2009.

42. Black S., Gettıng to the core of Composite Laminates, Composites Technology, Gardner Publications, Inc, [Online Document], 010ct2003, [Cited 25Jul2008],

Available:http //www compositesworld com/artıcles/gettıng-to-the-core-of-composite-lamınates aspx

43. Nida-Core Corporation, Balsalite Quality Coated Balsa Core,[Online Document], 2008, [Cited July 2008], Avallable: http //www nida-core com/pdfs/pds/nidacore/pds balsalite pdf

44. SP Systems, Core Materials in Polymeric Composites, AZo Journal of Materials Onlıne, AZoM ${ }^{\text {TM }}$, [Online Document], 2009, [Cited Aug08], Available: http //www azom com/detalls asp?ArtıclelD=1092

45 Alcan Composites, Foam - AIREX ${ }^{\circ}$ PXC-Fibre-Reinforced Structural Foam, I.C.A.R.O.H. GmbH/Alcan Composites, [Online Document], 2008, [Cited 27Jul2008], Available:

http //www dibond com/alcan/acsites nsf/pages accm3 en/index htm IOpen\&p=prod foam pxc\&m=4\& type $=h t m$

46. Alcan Composites, Foam - AIREX ${ }^{\circ}$ PXW - FIbre-Reinforced Structural Foam, I.C.A.R.O.H. GmbH/Alcan Composites, [Onlıne Document], 2008, [Cited 27Jul2008], Available:

http //www dibond com/alcan/acsites nsf/pages accm3 en/index htm'Open\&p=prod foam pxw\&m=4\& type $=$ htm

47. Nida-Core Corporation, Structural Honeycombs-Foam Filled, [Online Document], 2008, [Cited Aug08], Available: http //www nıda-core com/english/nıdaprod honev foam htm 
48. MGI Inc., MiKor Foom Filled Honeycomb, [Online Document], [Cited July 2008], Available: http://www.mgicanada.com/honeycomb.htm.

49. Cochrane D., "Fuselage Finite Element Analysis (FEA)", DR-87-05, Carleton University GeoSurv II Unmanned Aircraft System (UAS) project, 24 March, 2008.

50. Corbett, J.,et. al., Design for Manufacture: Strategies, Principles and Techniques, Addison-Wesley Publishing Company, Ontario, 1991.

51. Deshpande V.S. and Feleck N.A., "Multi-Axial Yield Behaviour of Polymer Foams", Acta Mater. 49, pp. 1859-1866, 2001.

52. Russell Elkin, PVC Foam Properties, E-mail communications with Russell Elkin, Senior Technical Service Engineer at 3A Composites USA, Mario Mahendran, Ottawa, 2010.

53. Hart-Smith, L. J., "The ten-percent rule for preliminary sizing of fibrous composite structures", Weight Engineering, vol. 52, no. 2, p. 29-45, 1992.

54. Naik R.A., "Failure Analysis of Woven and Braided Fibre Reinforced Composites", NASA Contractor Report 194981, Contract NASI-19708, Notational Aeronautics and Space Administration, Langley Research Centre, Hampton, Virginia, 23681-0001, September 1994.

55. K. Suraweera. $V$-n Diagram for $150 \mathrm{lb}$ Aircraft and Lift Distribution on a Vertical Tail. Design Report 6310A. Course AERO 4907. 05 April, 2007.

56. Zakurdaev, A., Update Load Analysis and Methodology, DR 83-02, Carleton University GeoSurv II Unmanned Aircraft System (UAS) project, 31 March, 2008.

57. Buschinelli, M., "Fuselage Loads Summary", DR-117-17, Carleton University GeoSurv II Unmanned Aircraft System (UAS) project, 08 December, 2009.

58. Karakuzu, R. et al., "Failure analysis of woven laminated glass-vinylester composites with pin-loaded hole", Composite Structures, 72; pp. 27-32, 2006.

59. Murat, B. and Sayman, O., Failure analysis of pin-loaded aluminum-glass-epoxy sandwich composite plates, Composites Science and Technology; 63 pp. 727-737, 2003.

60. Baba Okutan, B., Behavior of Pin-loaded Laminated Composites, Experimental Mechanics46: pp. 589-600, 2006.

61. Teutsh, J., "DR137-09: Profiling the Final GeoSurv II Fuselage" Carleton University Aerospace Engineering, Ottawa 26 October 2010. 


\section{APPENDICES}

\section{Appendix A: Manufacturing Supplies}

This appendix contains details on the products used in the manufacturing trials and experiments of this research.

\section{Matrix, Reinforcement and Core Materials:}

$>$ Infusion Epoxy: PTM\&W Inc. PR 2712 [1],[2]

$>$ Infusion Epoxy: API SC 780 [3]

$>$ Epoxy Adhesive (Fast Cure): PTM\&W Inc. ES 6220 [1],[2]

$>$ Carbon Fibre Fabric: BGF Style\# 94132-3k, 4H satin [1],[4]

$>$ Carbon Fibre Fabric: Hexcel AGP 370- 6k, 5H satin [5]

$>$ E glass Fabric: BGF Style\#106, 1k plain weave [1],[4]

$>$ Foam Core: Airex C-structural PVC foam [6]

$>$ Inserts: Fibreglass rods [7]

\section{VARTM Supplies:}

Dould Sealant Epoxy - West System Epoxy: Part A 105 and Part B 205 or 206 [1],[8]

$>$ Paste Mould Release: TR 104 High Temperature [1], [9]

$>$ Spray Mould Release: MS-122 AD: PTFE release agent, dry lubricant [10]

$>$ Distribution Medium - Resinflow 60 [1],[11]

$>$ Vacuum Bag - Strechlon 200, Stretchlon 800 [1], [11]

$>$ Sealant Tape-AT-200Y [1], [11]

$>$ Breather - Econoweave 44 [1], [11]

$>$ Peel Ply - Econoply J [1], [11]

$>$ Tubes, Fittings and other consumables- Composites Canada [1], [11]

\section{CCBM Supplies:}

$>$ Arctek CCBM system: Progress Plastics and Compounds, Mississauga, Ontario [12]

$>$ Teflease tape [1]

$1 / 8$ in. diameter wire wax [13]

$>$ Static cling PVC (Type I) film: Translucent, low tack, .002" thick, 12" width, 12'L [7]

$>$ Double-sided cloth tape: (Item \#. 76125A21- Mc-Master Carr) [7]

\section{Suppliers/Distributors:}

[1] Composites Canada, http://www.compositescanada.com/index.php

[2] PTM\&W Industries Inc., http://www.ptm-w.com/

[3] Applied Poleramic Inc., www.appliedpoleramic.com

[4] BGF Industries Inc., http://www.bgf.com/

[5] Hexcel Corporation, www. Hexcel.com

[6] 3a Composites, http://www.corematerials.3acomposites.com/home $h t m \mid P L=1$

[7] Mc-Master Carr, http //www.mcmaster.com/\#

[8] West System, www.westsystem.com

[9] TR Industries, http://www.trindustries.com/

[10] Miller-Stephenson Company Inc, http://www.miller-stephenson.com/

[11] Airtech International, www.airtechonline.com

[12] Arctek Inc., http.//www.arctekınfusion.com/what\%2015\%20CCBM.htm

[13] Kindt-Collins Company LLC, http://www.kındt-collıns.com/ 


\section{Appendix B: CCBM Bag Manufacturing Procedure}

\section{CCBM Manufacturing Trial \#1 \& 2}

1. Prepare the glass tool by cleaning it with Spray-Nine multipurpose cleaner and accurately draw lines to indicate where the seal and resin inlet/outlet lines are to be located ( Figure B 1).

Note: The quality of the bag depends on the surface quality of the tool. Fill-in any rough spots or dents on the tool with modelling clay until a smooth surface is achieved.

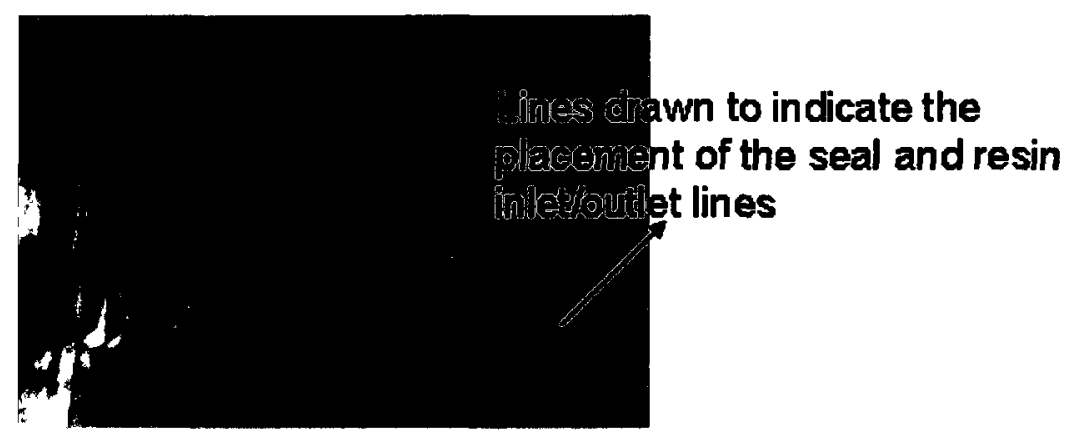

Figure B 1: Tool Preparation

2. Apply three coats of TR-104 High Temperature Mould Release Wax over the surface on which the bag is to be fabricated.

Note: Any non-silicone based mould release in liquid or paste form can be used in this step.

3. Slice a 0.5 in. diameter poly tubing in two halves and secure it on the tool using doublesided tape, at the appropriate location of the inlet/outlet lines (Figure B 2).

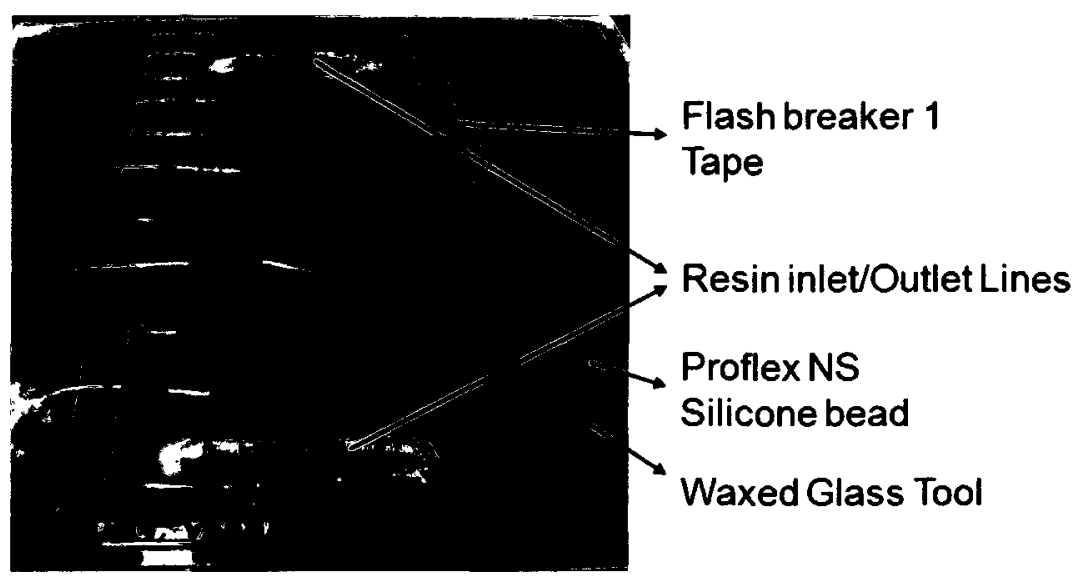

Figure B 2: Applying silicone over the prepared tool 
4. Apply release wax over the poly tubing to ensure easy removal after the bag is cured.

5. Place Airtech Flashbreaker tape upside down along the lines where the bag is to be sealed, using Airtec 2 fast cure spray adhesive.

Note: The use of Airtec 2 spray adhesive to hold the Flashbreaker tape in place contaminated the Flashbreaker tape, causing the sealant tape to permanently adhere to its surface. Hence, in trial \# 2, double-sided tape was used to hold the Flashbreaker tape onto the mould.

6. Install $850 \mathrm{~g}$ Proflex NS Silicone cartridge in a caulking gun and apply approximately 0.25 in. diameter bead of silicone over the tooling surface, in a pattern as shown in Figure B 2.

7. Using econo-bristle brush or plastic squeegees smear the silicone across the tool along the direction specified in Figure B 2, to create the first layer of silicone.

Note: Care must be taken to brush the silicone over the tool as uniformly as possible. Avoid building up this layer over 0.02 in. thick, as it will take longer to cure.

8. Let the first silicone layer completely cure (approximately 1 hour) in air/moisture and apply another layer of silicone over it. This layer of silicone is to balance out any thickness variations from the first layer and also to build up the thickness of the bag.

9. Once the second layer of silicone is cured, apply a very thin layer of silicone over the bag surface and while the silicone layer is wet tack the Confortex fabric onto the bag as shown in Figure $B 3$.

Note: The purpose of this layer is to tack the Confortex fabric over the silicone layers. Apply very thin layer of silicone over the entire part and tack the Confortex fabric immediately while the silicone is wet. Overlaps in fabric may be necessary depending on the complexity of the part.

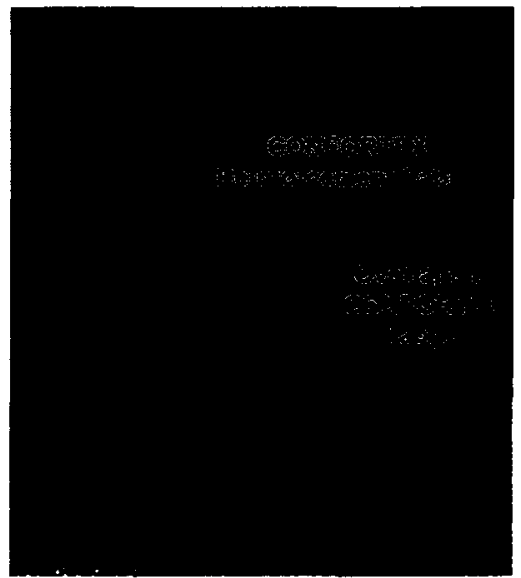

Figure B 3: Laying up the Confortex Reinforcement fabric

10. Once the third layer of silicone (silicone adhesive layer from step 9) is cured, apply a thick layer of silicone over the Confortex fabric and fully impregnate it with silicone. Allow for this layer to cure (approximately 1 hour). 
11. Apply fourth and fifth layer of silicone over the bag surface, as before, to build up the thickness.

Note: The quality of the bag depends on how uniformly the silicone is brushed each time.

12. Apply another layer of Confortex fabric over the resin inlet and outlet lines and repeat Steps 9 to 11 . This step is to locally reinforce the area of inlet and outlet lines to avoid the resin channels collapsing under vacuum pressure.

13. Allow the bag to cure for 24 hours before using it.

\section{Mouldless CCBM Bag Manufacturing: Test Section and Fuselage}

1. Prepare the tool/mould : This process begins with the foam core assembly laid-up with reinforcement.

a. Wrap the entire assembly with a layer of peel ply.

b. Wrap the entire assembly with a layer of PVC film (use Teflease tape as necessary to create a tight wrap around the part).

c. Install the resin inlets and outlets onto the setup using double-sided tape.

d. Install the resin distribution channels using double-sided tape.

2. Follow the sequence of silicone and Confortex fabric application explained in CCBM bag manufacturing Trial \#2.

Note: On large surfaces such as the fuselage walls, apply the silicone over a $2 \mathrm{sq}$. $\mathrm{ft}$. region at a time. Once the region is fully covered with a layer of silicone, move on to the adjacent region. This is done to apply the silicone while it is wet. 


\section{Appendix C: Process Value Analysis}

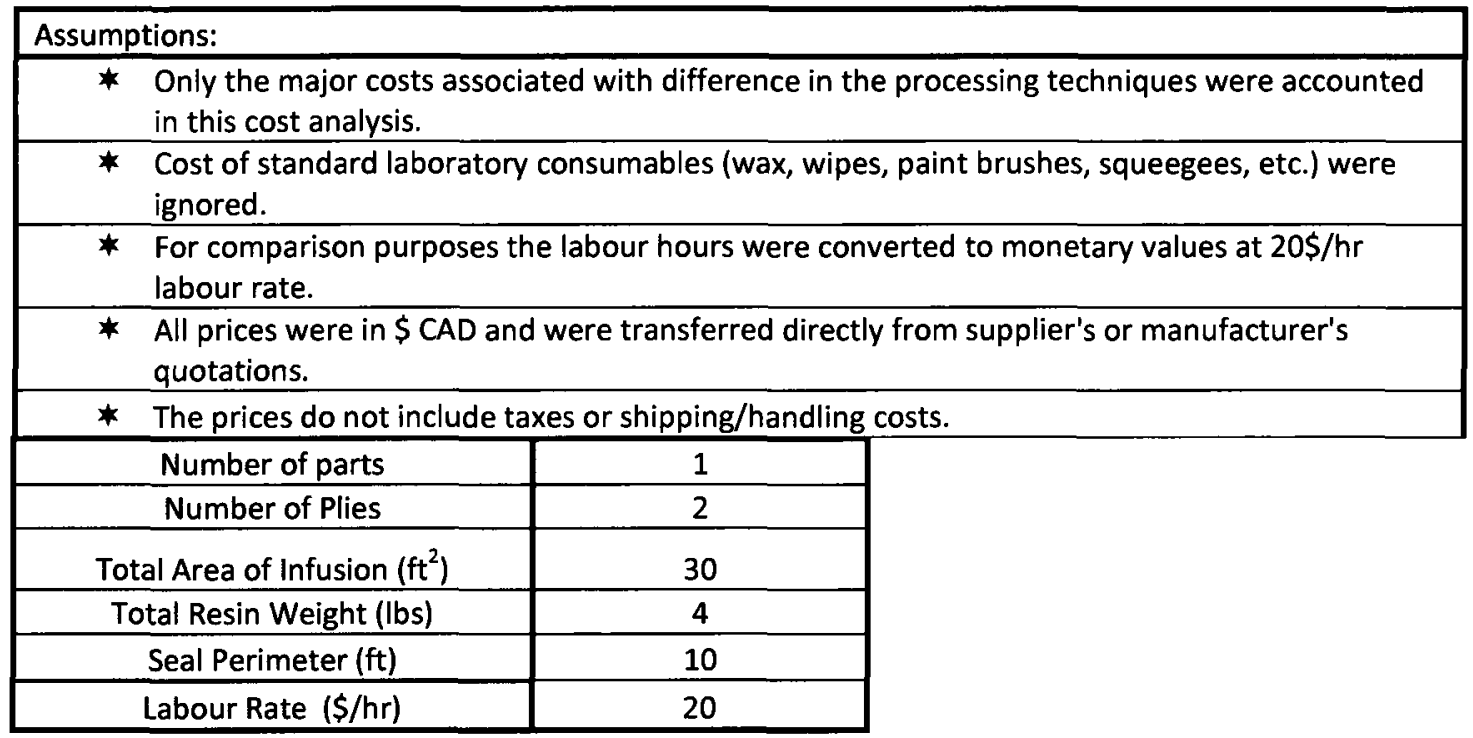

Table C 1: Cost factors for VARTM

\begin{tabular}{|c|c|c|c|}
\hline \multicolumn{4}{|c|}{ Conventional VARTM (Disposable Bagging) } \\
\hline Item & Unit cost (\$) & $\begin{array}{c}\text { Cost (\$)/ unit area }\left(\mathrm{ft}^{2}\right) \\
\text { or length (ft) or weight } \\
\text { (lbs) }\end{array}$ & Total cost \\
\hline Fabric (including $20 \%$ wastage) & $21.97 /$ ly & $\$ 1.83$ & $\$ 131.82$ \\
\hline Resin & $350 / 52$ lbs kit & $\$ 6.73$ & $\$ 26.92$ \\
\hline Distribution media (Resinflow 60) & $100 \mathrm{ly} / \$ 394.30 / \mathrm{roll} /$ & $\$ 0.26$ & $\$ 8.58$ \\
\hline Vacuum bag (Stretchlon 200) & 100ly:\$218.96/ea & $\$ 0.15$ & $\$ 12.75$ \\
\hline Peel ply (Econolease) & 100ly: $\$ 427.05 /$ roll & $\$ 0.28$ & $\$ 9.24$ \\
\hline Sealant tape (AT-200Y) & $4.195 \$ / \mathrm{roll}$ & $\$ 4.20$ & $\$ 8.39$ \\
\hline Total Cost & & & $\$ 197.70$ \\
\hline $\begin{array}{l}\text { Labour hours/part for bagging } \\
\text { (hours) }\end{array}$ & $2.5 \mathrm{hr} \times 3$ people & & 7.50 \\
\hline $\begin{array}{l}\text { Total labour hours for bagging } \\
\text { (hours) }\end{array}$ & & & 7.50 \\
\hline
\end{tabular}


Table C 2: Cost factors for CCBM I

\begin{tabular}{|c|c|c|c|}
\hline \multicolumn{4}{|c|}{ CCBM (Silicone seal) I } \\
\hline Item & Unit cost (\$) & $\begin{array}{c}\text { Cost (\$)/ unit area }\left(\mathrm{ft}^{2}\right) \\
\text { or length (ft) or weight } \\
\text { (lbs) }\end{array}$ & Total cost \\
\hline Fabric (including $20 \%$ wastage) & $21.97 / \mathrm{ly}$ & $\$ 1.83$ & $\$ 131.82$ \\
\hline Resin & $350 / 52$ lbs kit & $\$ 6.73$ & $\$ 26.92$ \\
\hline Silicone seal & $9 \$ / \mathrm{ft}$ & $\$ 9.00$ & $\$ 90.00$ \\
\hline One time part buildup cost & & & $\$ 120.00$ \\
\hline Liquid silicone & $33 \$ /$ cartridge & $\$ 33.25$ & $\$ 332.50$ \\
\hline Distribution media (Resinflow 60) & $100 \mathrm{ly} / \$ 394.30 / \mathrm{roll} /$ & $\$ 0.26$ & $\$ 8.58$ \\
\hline Peel ply (Econolease) & 100ly: \$427.05/roll & $\$ 0.28$ & $\$ 9.24$ \\
\hline Total cost & & & $\$ 719.06$ \\
\hline Labour (hours) & 2 full days & $16 \mathrm{hrs}$ & \\
\hline \multicolumn{3}{|c|}{ One time initial cost } & $\$ 542.50$ \\
\hline \multicolumn{3}{|c|}{ Additional cost per part } & $\$ 176.56$ \\
\hline
\end{tabular}

Table C 3: Cost factors for CCBM II

\begin{tabular}{|c|c|c|c|}
\hline \multicolumn{4}{|c|}{ CCBM (Sealant tape) II } \\
\hline Item & Unit cost (\$) & $\begin{array}{c}\text { Cost }(\$) / \text { unit area }\left(\mathrm{ft}^{2}\right) \\
\text { or length (ft) or weight } \\
\text { (lbs) }\end{array}$ & Total cost \\
\hline Fabric (including $20 \%$ wastage) & $21.97 /$ ly & $\$ 1.83$ & $\$ 131.82$ \\
\hline Resin & $350 / 52$ lbs kit & $\$ 6.73$ & $\$ 26.92$ \\
\hline One time part buildup cost & & & $\$ 100.00$ \\
\hline Liquid silicone & $33 \$ /$ cartridge & $\$ 33.00$ & $\$ 330.00$ \\
\hline Distribution media (Resinflow 60) & $100 \mathrm{ly} / \$ 394.30 / \mathrm{roll} /$ & $\$ 0.26$ & $\$ 8.58$ \\
\hline Peel ply (Econolease) & 100ly: $\$ 427.05 /$ roll & $\$ 0.28$ & $\$ 9.24$ \\
\hline Sealant tape & $4.20 \$ /$ roll & $\$ 4.20$ & $\$ 1.68$ \\
\hline Total cost & & & $\$ 608.24$ \\
\hline Labour (hours) & 2- full days & $15 \mathrm{hrs}$ & \\
\hline Total labour (hours) & & & 15.50 \\
\hline \multicolumn{3}{|c|}{ One time initial cost } & $\$ 430.00$ \\
\hline \multicolumn{3}{|c|}{ Additional cost per part } & $\$ 178.24$ \\
\hline
\end{tabular}


Table C 4: Cost factors for CCBM III

\begin{tabular}{|c|c|c|c|}
\hline \multicolumn{4}{|c|}{ CCBM (Integrated with distribution media) III } \\
\hline Item & Unit cost (\$) & $\begin{array}{l}\text { Cost (\$)/ unit area }\left(\mathrm{ft}^{2}\right) \\
\text { or length (ft) or weight } \\
\text { (lbs) }\end{array}$ & Total cost \\
\hline Fabric (including $20 \%$ wastage) & $21.97 /$ ly & $\$ 1.83$ & $\$ 131.82$ \\
\hline Resin & $350 / 52$ lbs kit & $\$ 6.73$ & $\$ 26.92$ \\
\hline One time part buildup cost & & & $\$ 120.00$ \\
\hline Liquid silicone & $33 \$ /$ cartridge & $\$ 33.00$ & $\$ 330.00$ \\
\hline Sealant tape & $4.20 \$ /$ roll & $\$ 4.20$ & $\$ 1.68$ \\
\hline Total cost & & & $\$ 610.42$ \\
\hline Labour (hours) & 2- full days & $15 \mathrm{hrs}$ & \\
\hline Total labour (hours) & & & 15.50 \\
\hline \multicolumn{3}{|c|}{ One time initial cost } & $\$ 450.00$ \\
\hline \multicolumn{3}{|c|}{ Additional cost per part } & $\$ 160.42$ \\
\hline
\end{tabular}

Table C 5: Total cost calculations

\begin{tabular}{|c|c|c|c|c|c|c|c|c|}
\hline \multicolumn{2}{|c|}{ Conventional bagging } & \multicolumn{2}{|c|}{ CCBMI } & \multicolumn{2}{|c|}{ CCBM II } & \multicolumn{2}{|c|}{ CCBM III } & \multirow[t]{2}{*}{$\begin{array}{c}\text { Part } \\
\text { count }\end{array}$} \\
\hline Cost & $\begin{array}{l}\text { Labour } \\
\text { hours }\end{array}$ & Cost & $\begin{array}{l}\text { Labour } \\
\text { hours }\end{array}$ & Cost & $\begin{array}{c}\text { Labour } \\
\text { hours }\end{array}$ & Cost & $\begin{array}{c}\text { Labour } \\
\text { hours }\end{array}$ & \\
\hline$\$ 197.70$ & 7.50 & $\$ 719.06$ & 16.50 & $\$ 608.24$ & 15.50 & $\$ 610.42$ & 16.00 & 1 \\
\hline$\$ 395.40$ & 15.00 & $\$ 895.62$ & 17.00 & $\$ 786.48$ & 16.00 & $\$ 770.84$ & 16.40 & 2 \\
\hline$\$ 593.10$ & 22.50 & $\$ 1,072.18$ & 17.50 & $\$ 964.72$ & 16.50 & $\$ 931.26$ & 16.80 & 3 \\
\hline$\$ 790.80$ & 30.00 & $\$ 1,248.74$ & 18.00 & $\$ 1,142.96$ & 17.00 & $\$ 1,091.68$ & 17.20 & 4 \\
\hline$\$ 988.50$ & 37.50 & $\$ 1,425.30$ & 18.50 & $\$ 1,321.20$ & 17.50 & $\$ 1,252.10$ & 17.60 & 5 \\
\hline$\$ 1,186.20$ & 45.00 & $\$ 1,601.86$ & 19.00 & $\$ 1,499.44$ & 18.00 & $\$ 1,412.52$ & 18.00 & 6 \\
\hline$\$ 1,383.90$ & 52.50 & $\$ 1,778.42$ & 19.50 & $\$ 1,677.68$ & 18.50 & $\$ 1,572.94$ & 18.40 & 7 \\
\hline$\$ 1,581.60$ & 60.00 & $\$ 1,954.98$ & 20.00 & $\$ 1,855.92$ & 19.00 & $\$ 1,733.36$ & 18.80 & 8 \\
\hline$\$ 1,779.30$ & 67.50 & $\$ 2,131.54$ & 20.50 & $\$ 2,034.16$ & 19.50 & $\$ 1,893.78$ & 19.20 & 9 \\
\hline$\$ 1,977.00$ & 75.00 & $\$ 2,308.10$ & 21.00 & $\$ 2,212.40$ & 20.00 & $\$ 2,054.20$ & 19.60 & 10 \\
\hline$\$ 2,174.70$ & 82.50 & $\$ 2,484.66$ & 21.50 & $\$ 2,390.64$ & 20.50 & $\$ 2,214.62$ & 20.00 & 11 \\
\hline$\$ 2,372.40$ & 90.00 & $\$ 2,661.22$ & 22.00 & $\$ 2,568.88$ & 21.00 & $\$ 2,375.04$ & 20.40 & 12 \\
\hline$\$ 2,570.10$ & 97.50 & $\$ 2,837.78$ & 22.50 & $\$ 2,747.12$ & 21.50 & $\$ 2,535.46$ & 20.80 & 13 \\
\hline$\$ 2,767.80$ & 105.00 & $\$ 3,014.34$ & 23.00 & $\$ 2,925.36$ & 22.00 & $\$ 2,695.88$ & 21.20 & 14 \\
\hline$\$ 2,965.50$ & 112.50 & $\$ 3,190.90$ & 23.50 & $\$ 3,103.60$ & 22.50 & $\$ 2,856.30$ & 21.60 & 15 \\
\hline$\$ 3,163.20$ & 120.00 & $\$ 3,367.46$ & 24.00 & $\$ 3,281.84$ & 23.00 & $\$ 3,016.72$ & 22.00 & 16 \\
\hline$\$ 3,360.90$ & 127.50 & $\$ 3,544.02$ & 24.50 & $\$ 3,460.08$ & 23.50 & $\$ 3,177.14$ & 22.40 & 17 \\
\hline$\$ 3,558.60$ & 135.00 & $\$ 3,720.58$ & 25.00 & $\$ 3,638.32$ & 24.00 & $\$ 3,337.56$ & 22.80 & 18 \\
\hline$\$ 3,756.30$ & 142.50 & $\$ 3,897.14$ & 25.50 & $\$ 3,816.56$ & 24.50 & $\$ 3,497.98$ & 23.20 & 19 \\
\hline$\$ 3,954.00$ & 150.00 & $\$ 4,073.70$ & 26.00 & $\$ 3,994.80$ & 25.00 & $\$ 3,658.40$ & 23.60 & 20 \\
\hline
\end{tabular}




\section{Appendix D: Core Materials and Inserts}

Figure D 1 to Figure D 6 show the compression, shear and tensile properties of various foam materials utilized in VARTM applications. Their costs are compared in Figure D 7.

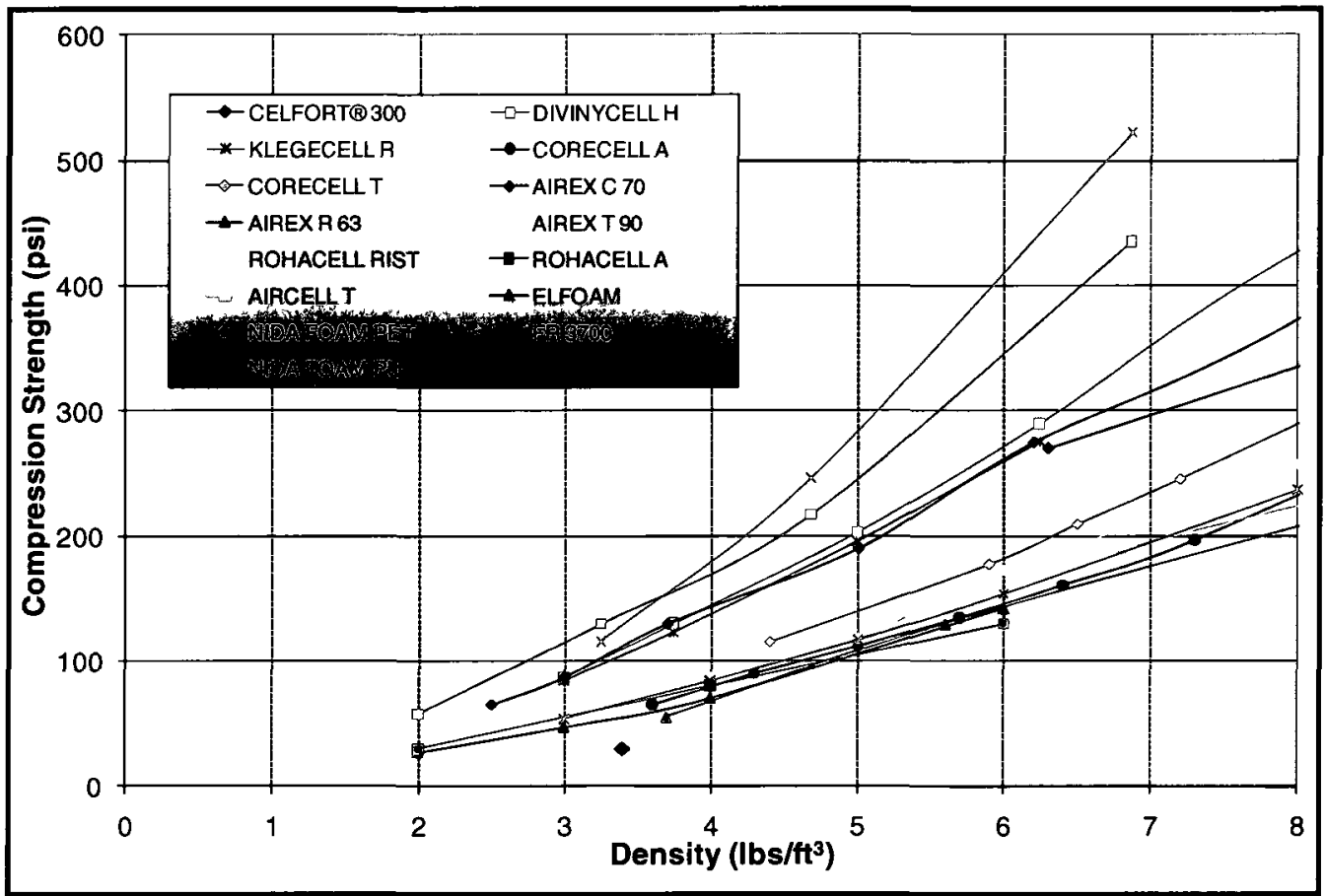

Figure D 1: Compression strengths of foam cores 


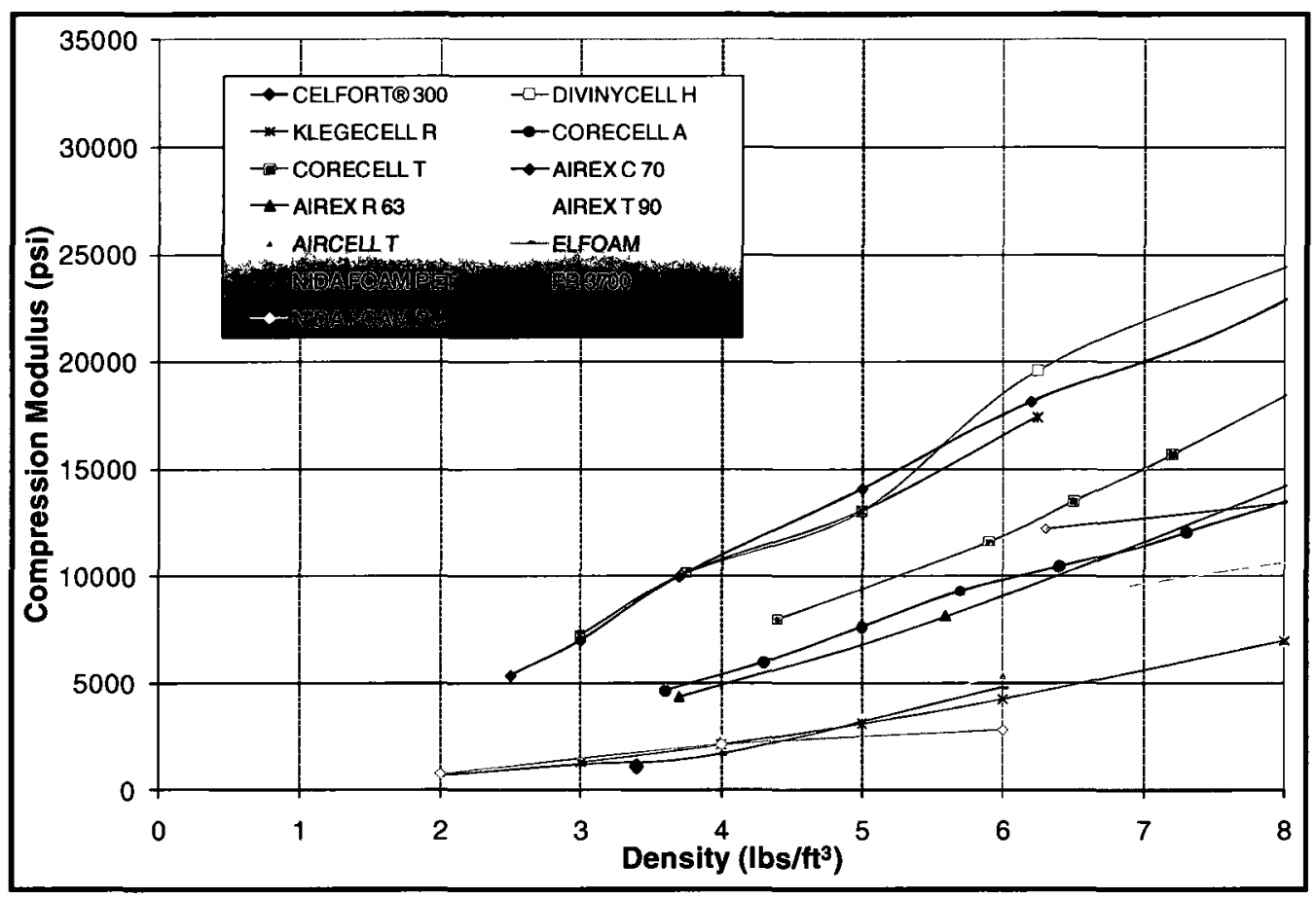

Figure D 2: Compression moduli of foam cores

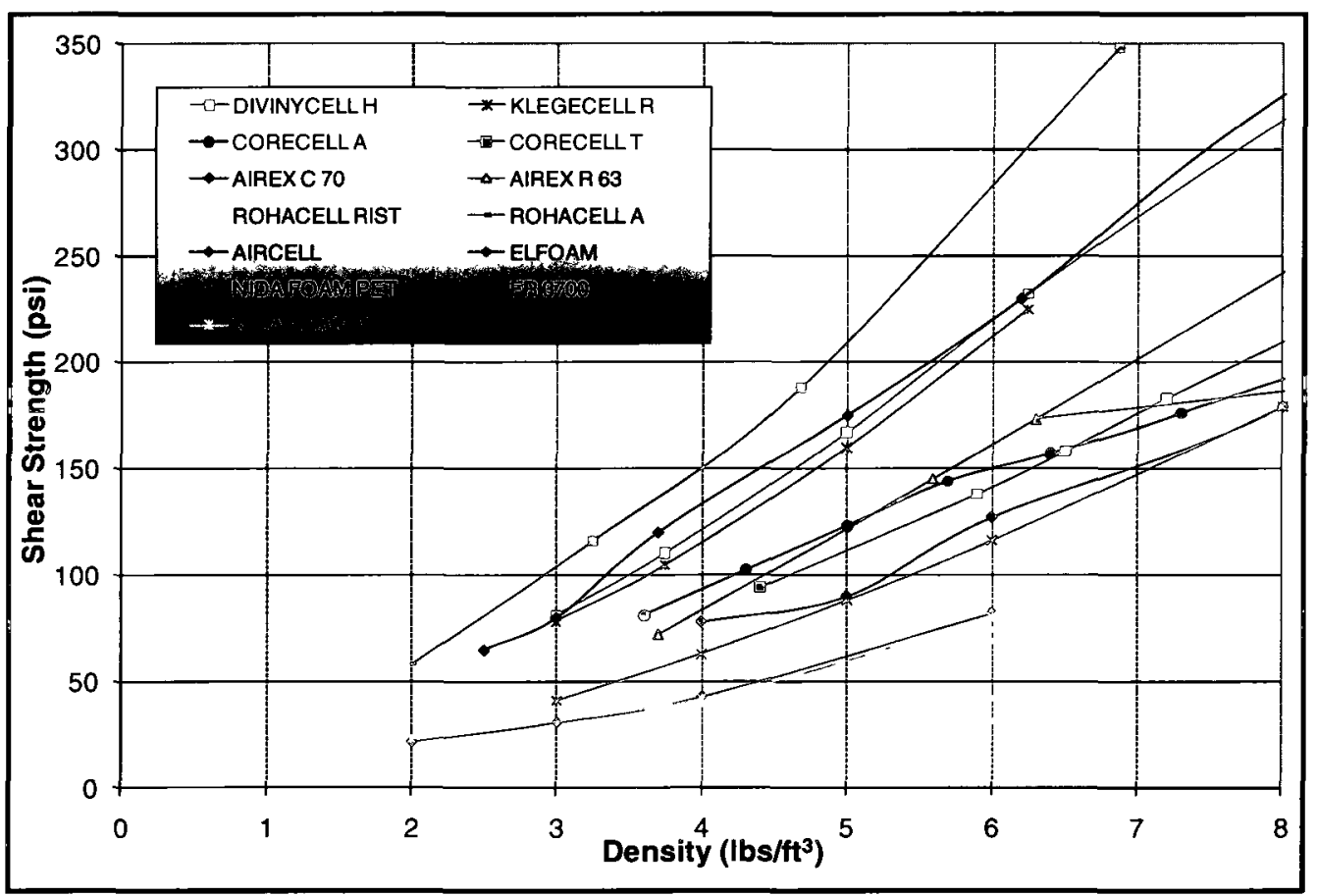

Figure D 3: Shear strengths of foam cores 


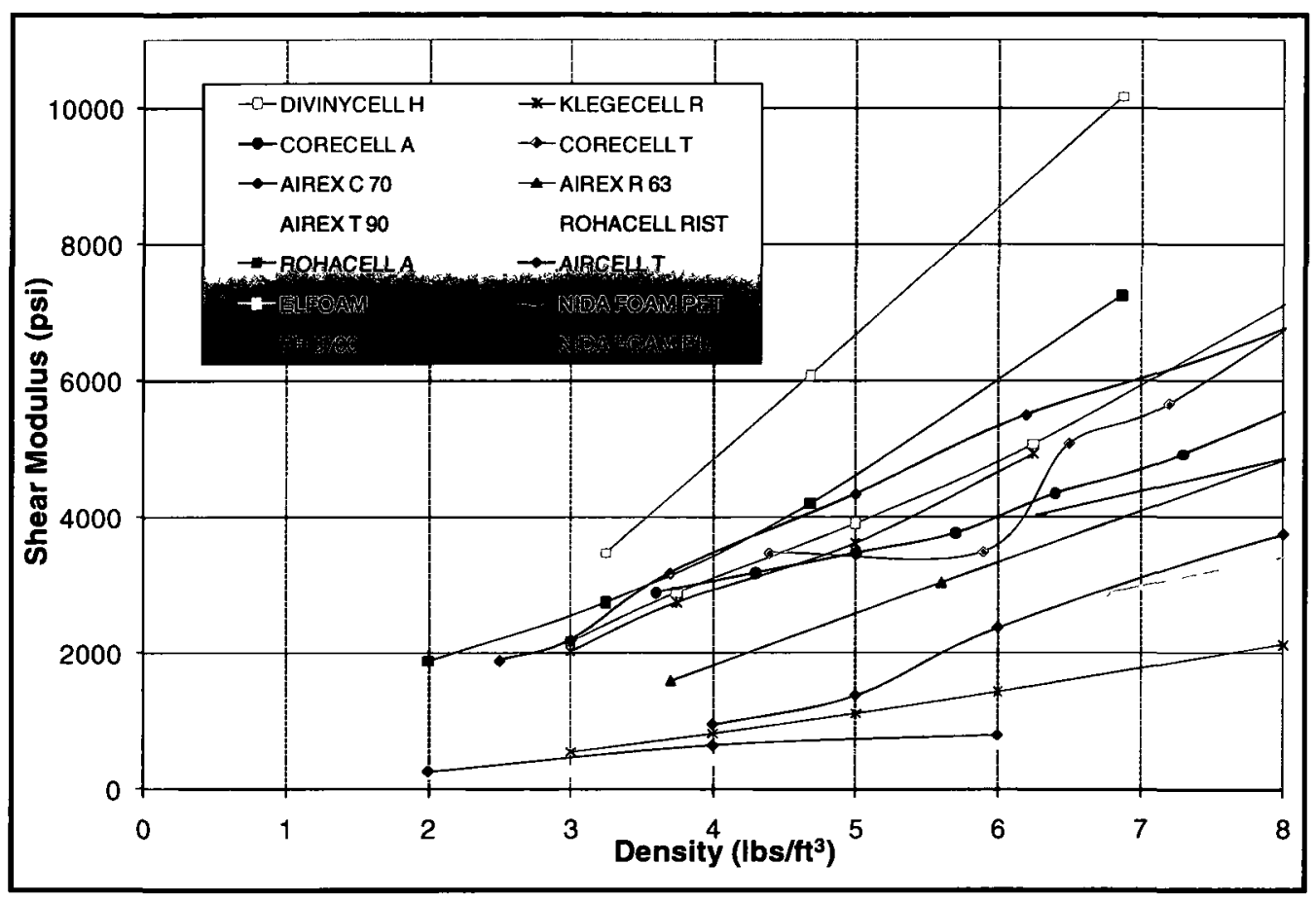

Figure D 4: Shear moduli of foam cores

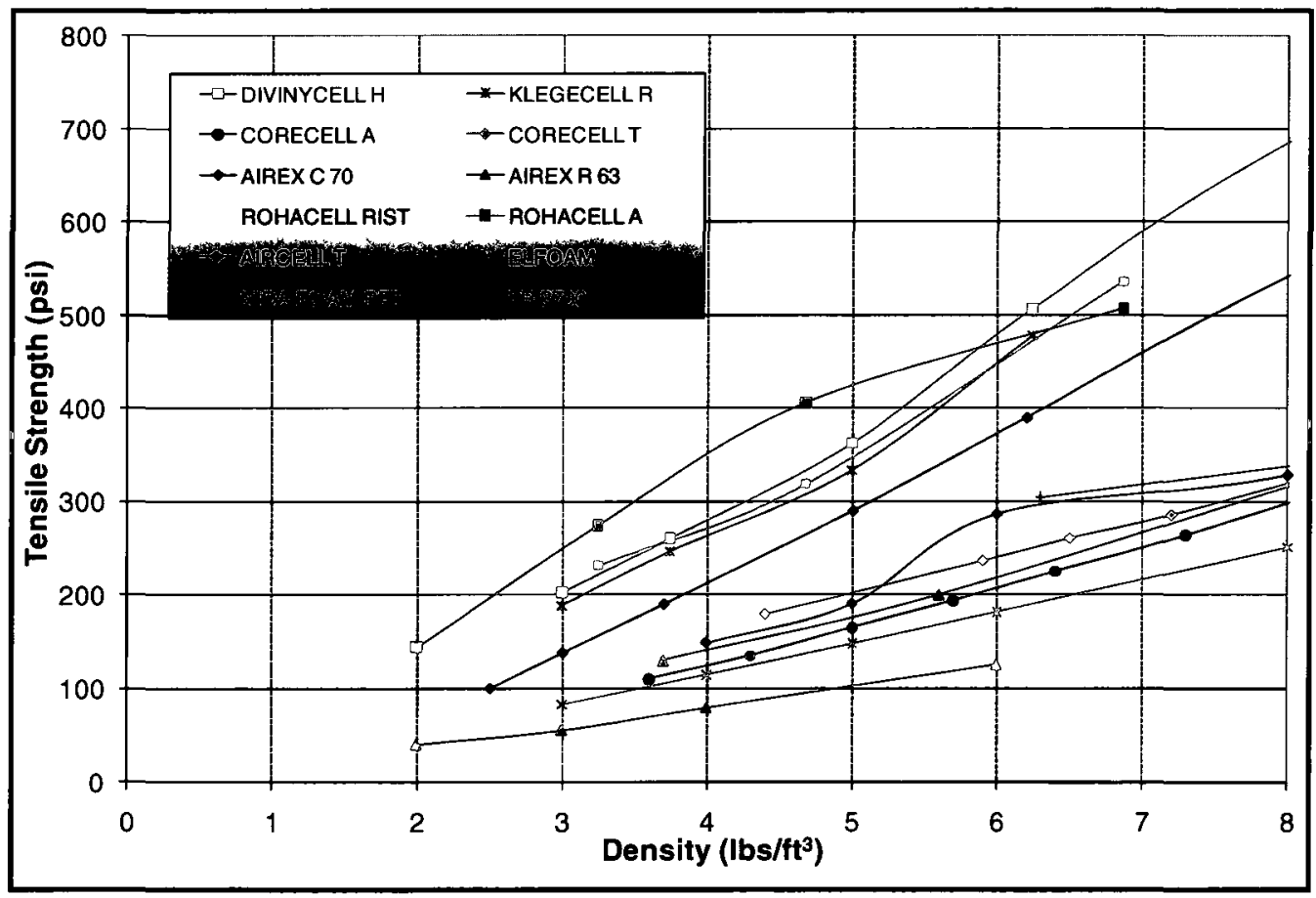

Figure D 5: Tensile strengths of foam cores 


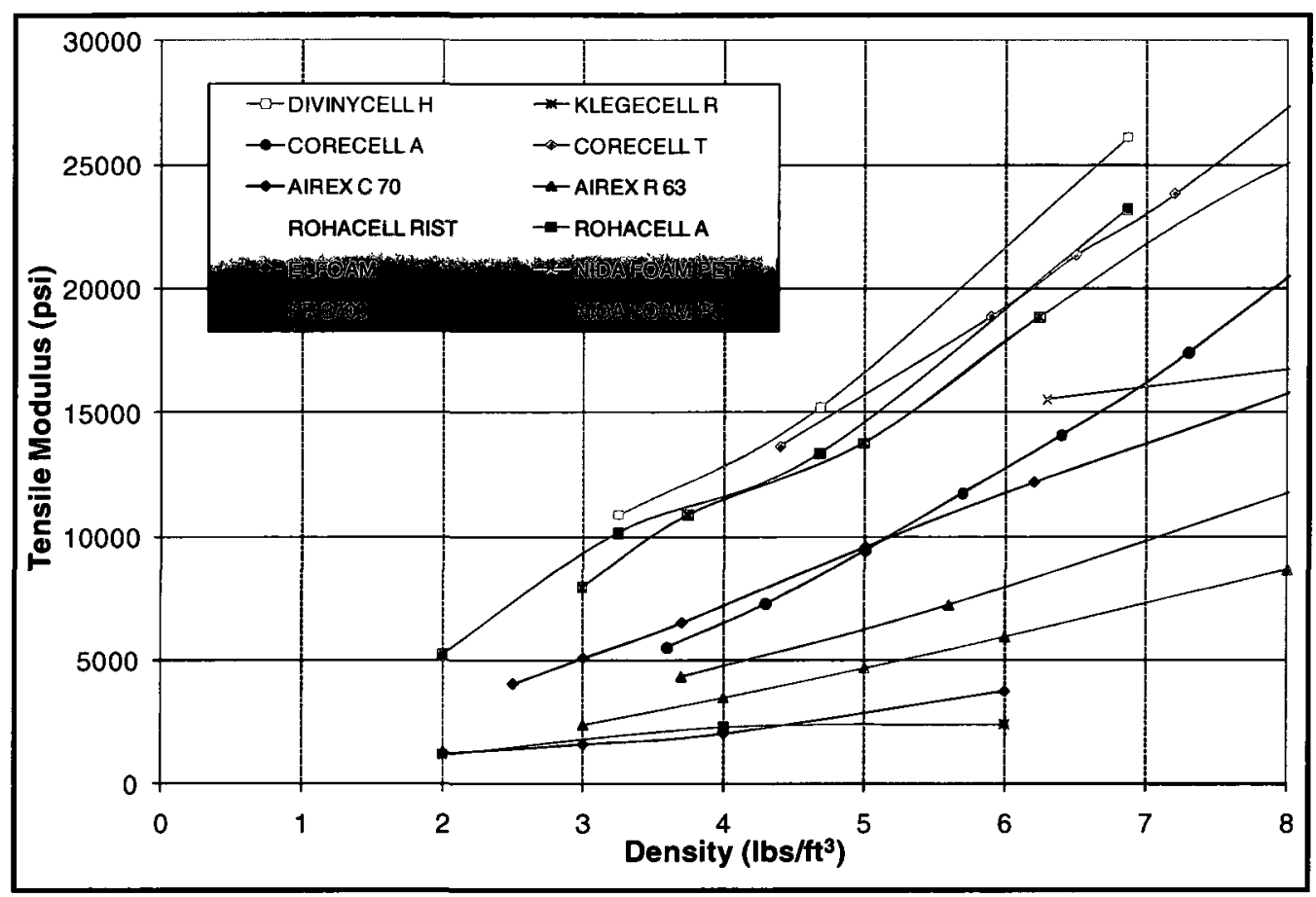

Figure D 6: Tensile moduli of foam cores

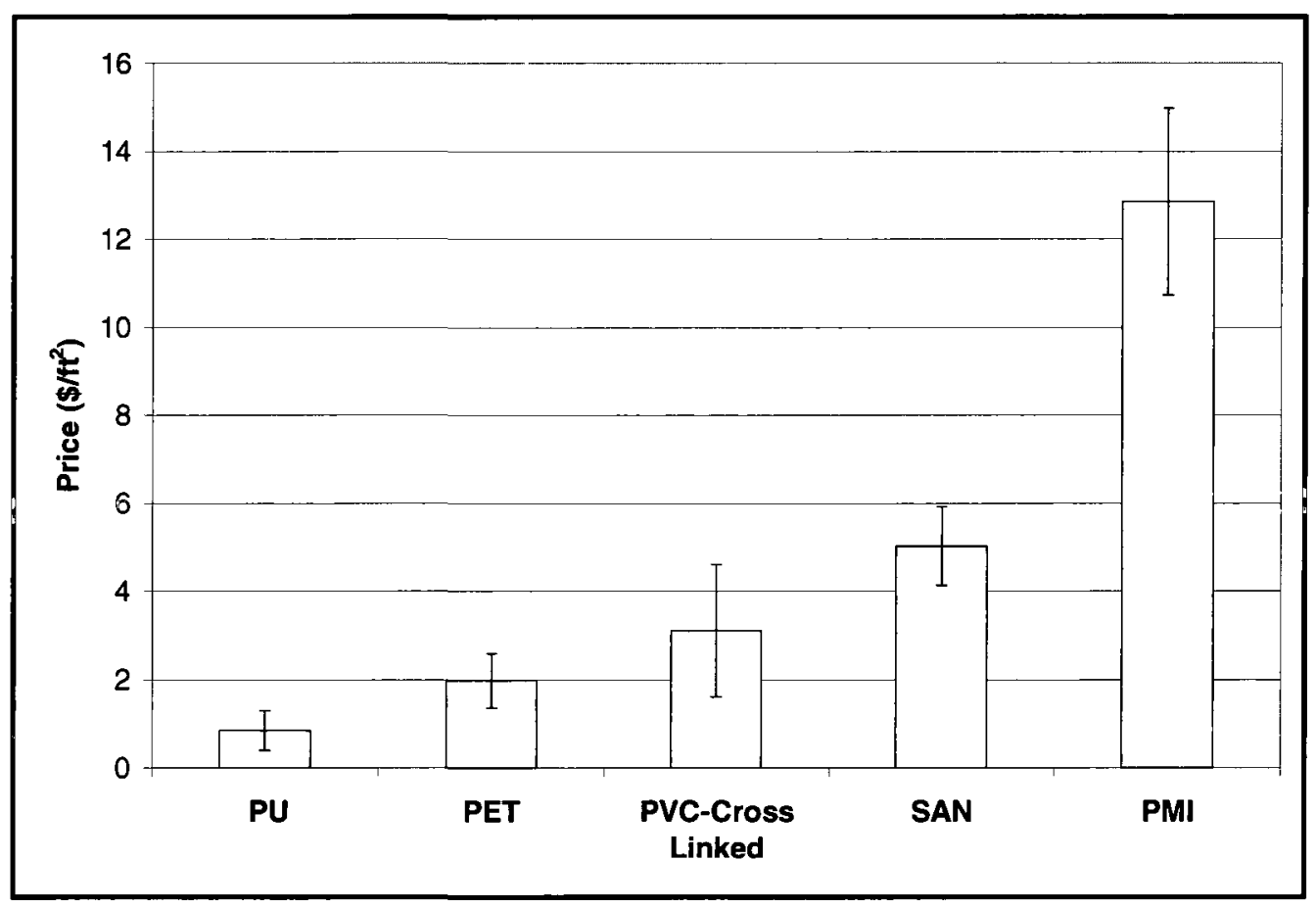

* Prices are for $8 \mathrm{ft} \times 4 \mathrm{ft}, 0.5$ in thick sheets, averaged over density range of $3 \mathrm{lbs} / \mathrm{ft}^{3}$ to $8 \mathrm{lbs} / \mathrm{ft}^{3}$

* All values are based retail market prices as of Aug08, obtained either from the manufacturers or the local distributors

Figure D 7: Average prices of various foam cores 
Figure D 8 to Figure D 13 show the properties of balsa cores in comparision to the structural PMI (Rohacell) foams. The costs of balsa and foam cores are compared in Figure D 14.

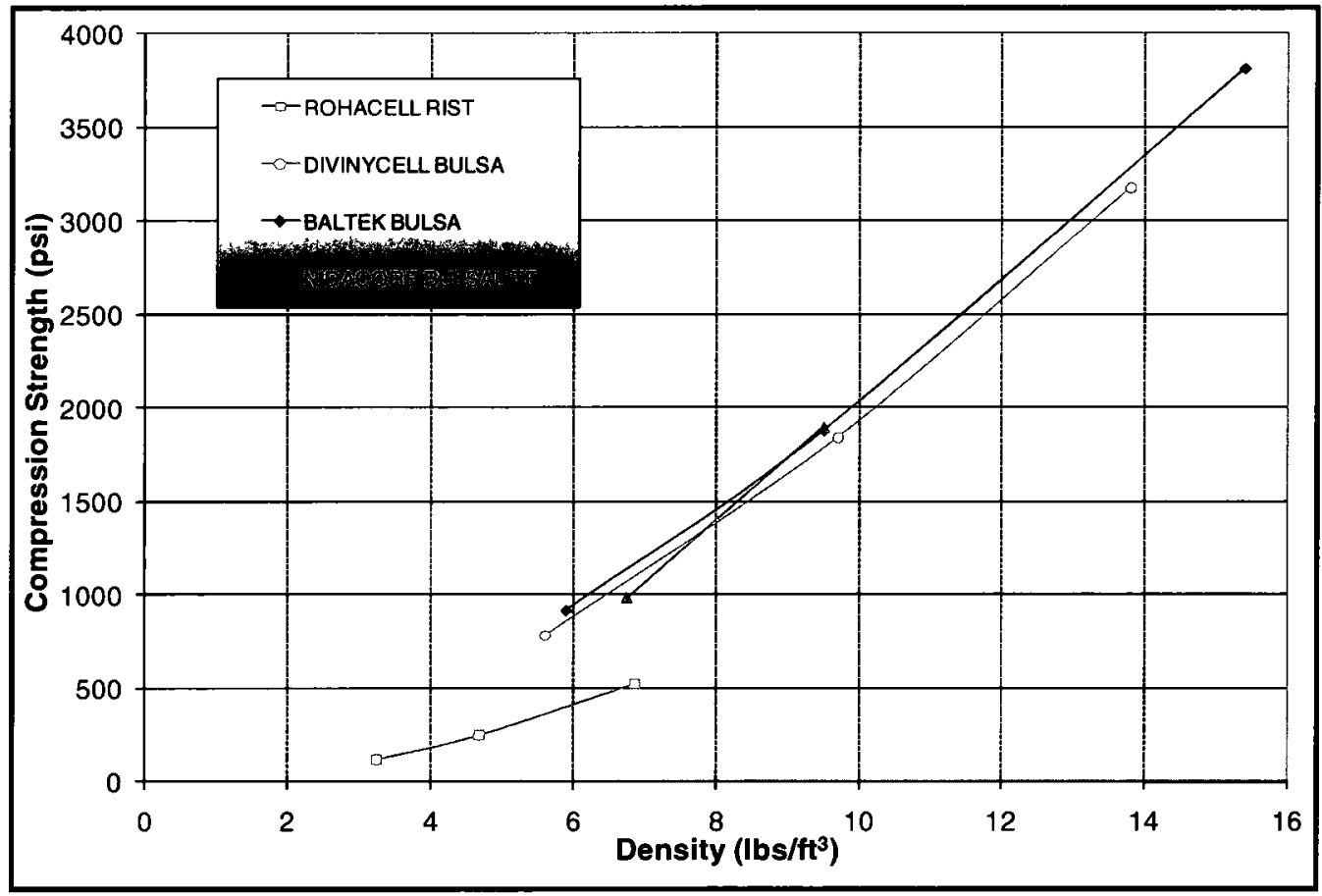

Figure D 8: Compression strengths of balsa cores with reference to PMI foam core 


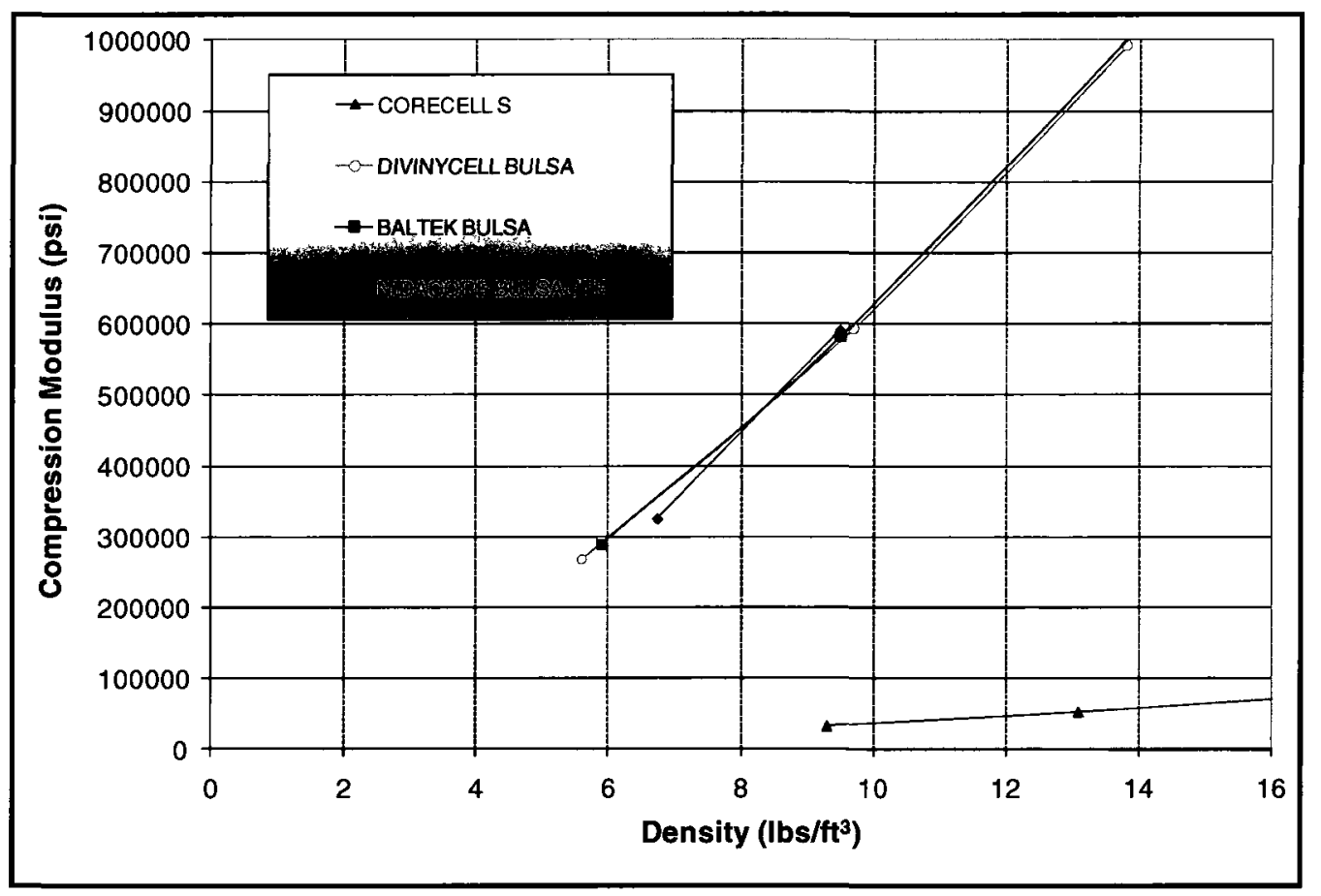

Figure D 9: Compression moduli of balsa cores with reference to SAN foam core

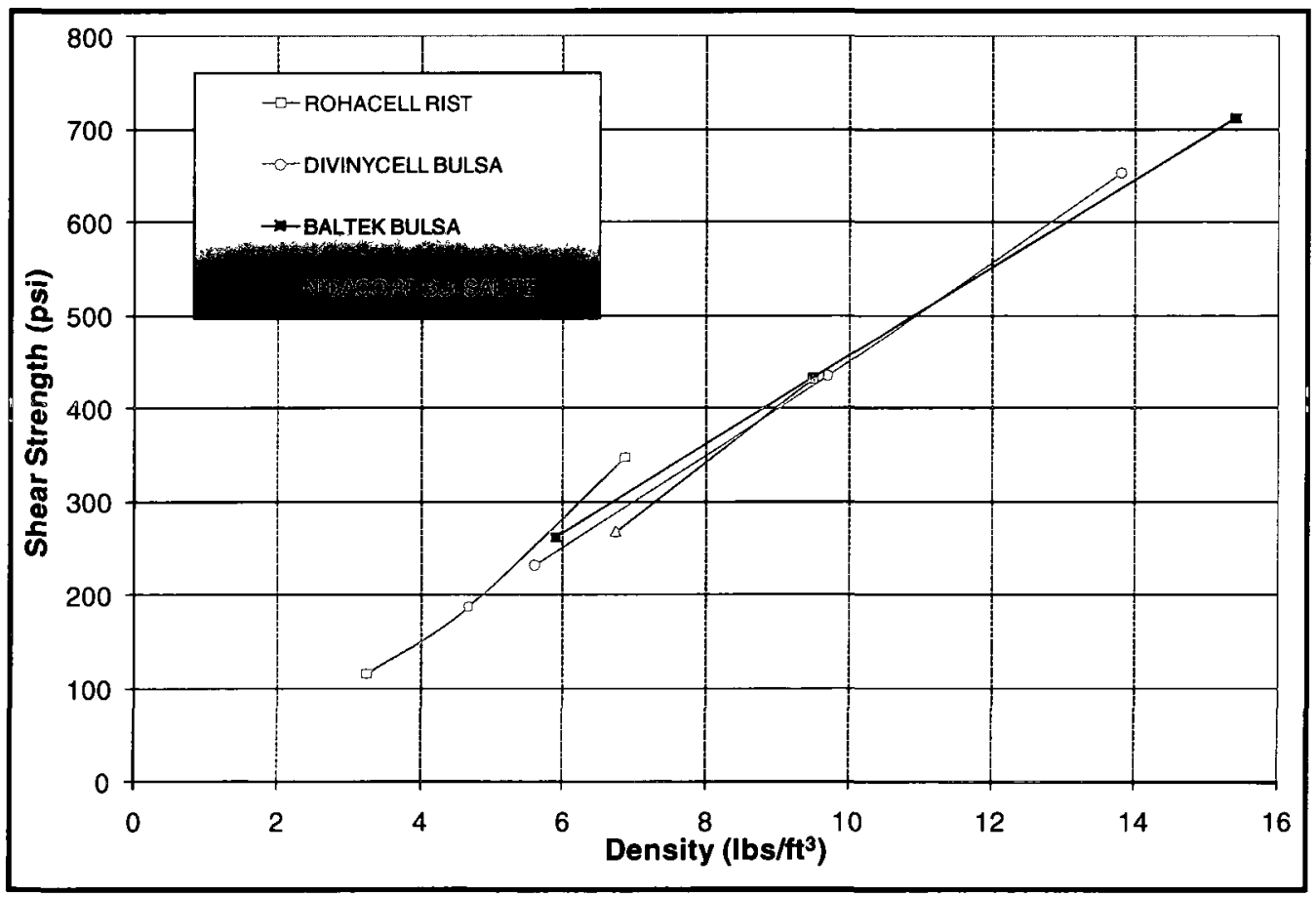

Figure D 10: Shear strengths of balsa cores with reference to PMI foam core 


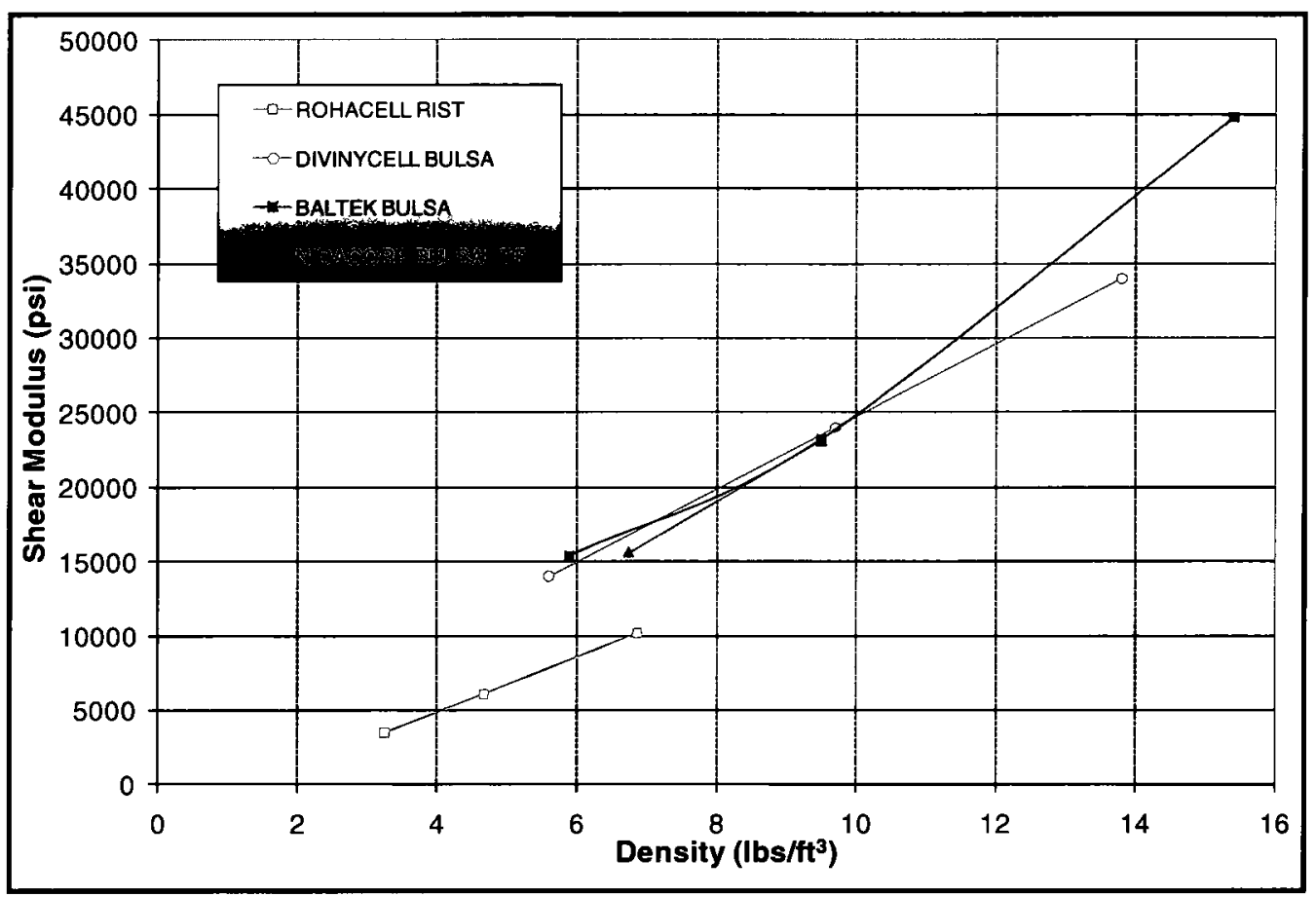

Figure D 11: Shear moduli of balsa cores with reference to PMI foam core

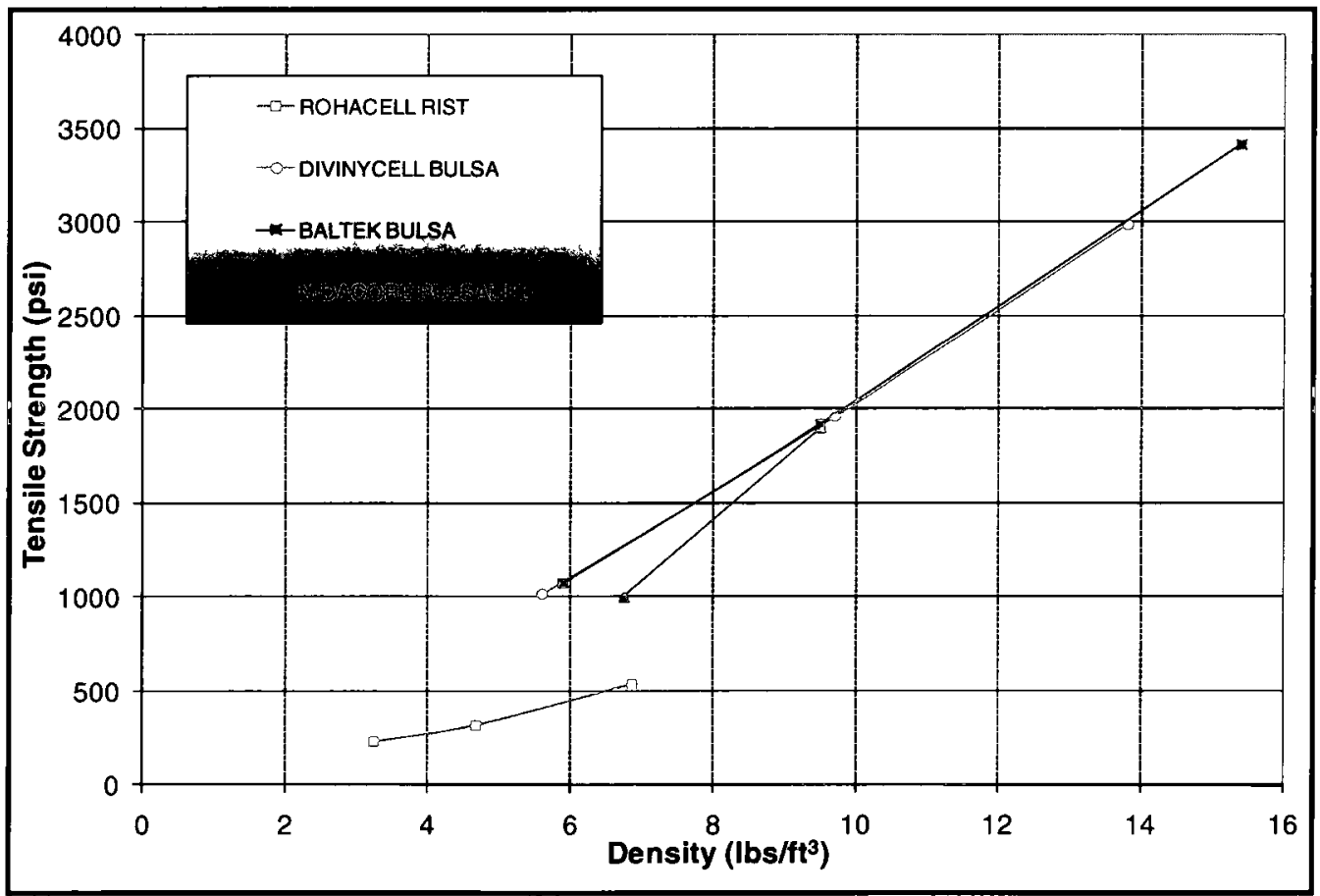

Figure D 12: Tensile strengths of balsa cores with reference to PMI foam core 


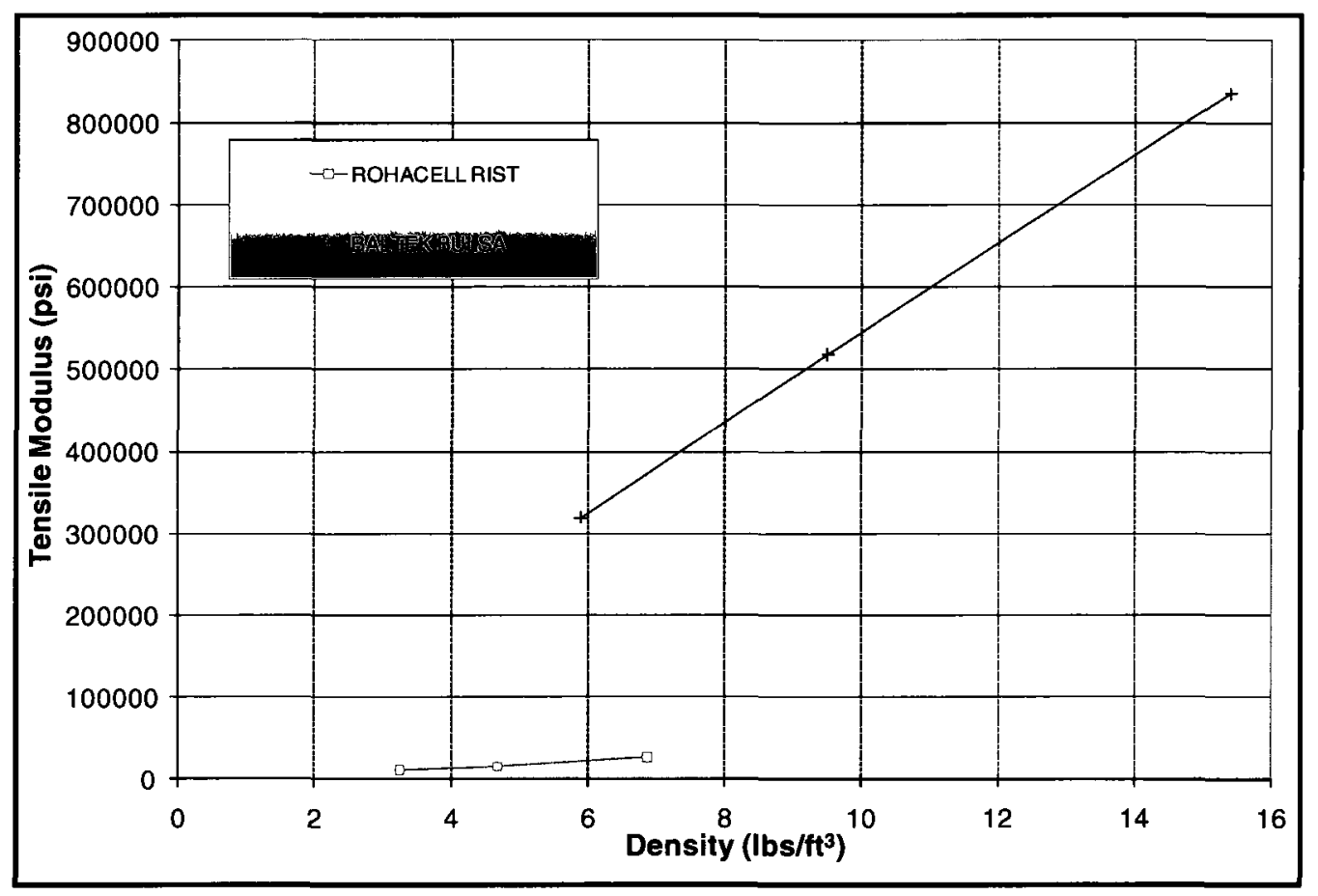

Figure D 13: Tensile moduli of balsa cores with reference to PMI foam core

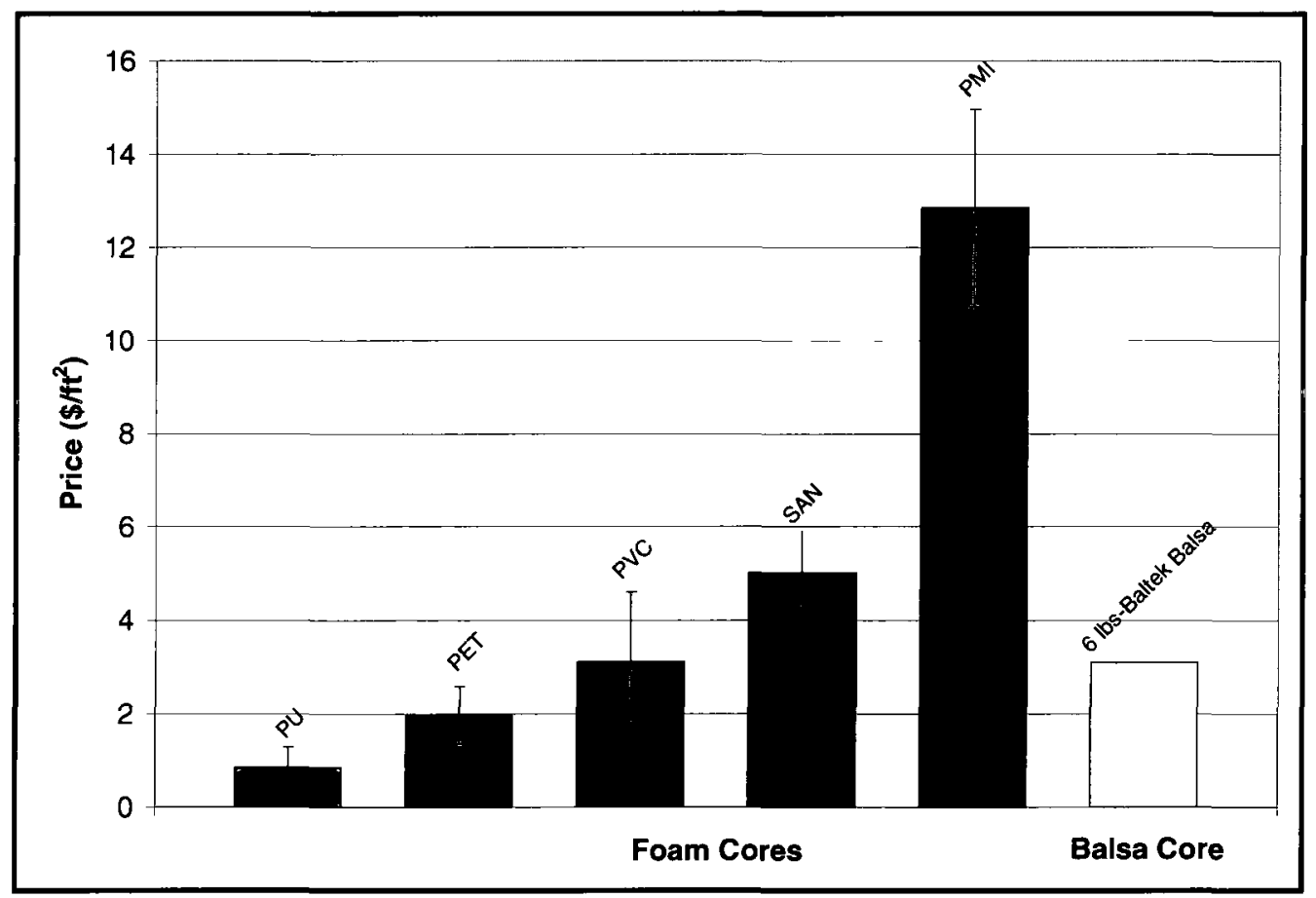

Figure D 14: Cost of balsa core compared to foam cores 
Material Properties of Core Materials:

1. Divinycell: Diab Corporation http://www.diabgroup.com/europe/products/e prods 1.html

2. Alcan Airex: Alcan Composites http://www.corematerials.3acomposites.com/america.html? \&L=0

3. Nida Core PET, PU, Foam Filled Honey Comb: Nida Core Corporation http://www.nidacore.com/english/index.htm

4. Aircell Polyester Foam Cores-Polyumac Inc. http://www.polyumac.com/Aircellmp.htm

5. Elfoam: Elliott Company- http://www.elliottfoam.com/tech.html

6. Corecell: SP Systems- http://www.marineware.com/ccp 2.asp

7. Rohacell: Evonik Industries /Degussa http://www.rohacell.com/en/performanceplastics8344.html

8. Last-A-Foam: General Plastics Inc. http://www.generalplastics.com/products/product detail.php?pid=19

\section{Material Properties of Inserts:}

1. FRP inserts, PEEK, Glass Filled Peek: Mc-Master Carr, http://www.mcmaster.com/\# 


\section{Appendix E: FEA Results and Weight Estimates}

\section{FEA Results:}

Table E 1: FEA Results: In-Flight Analysis Step

\begin{tabular}{|c|c|c|c|c|}
\hline Analysis Step & Location & $\begin{array}{c}\text { Max. Von } \\
\text { Mises Stress } \\
\text { (psi) }\end{array}$ & $\begin{array}{c}\text { Max. In-Plane } \\
\text { Shear Stress, } \\
\mathbf{S}_{\mathbf{1 2}} \text { (psi) }\end{array}$ & $\begin{array}{c}\text { Max In-Plane } \\
\text { Strain. (国) }\end{array}$ \\
\hline In-Flight & $\begin{array}{c}\text { Carry-through } \\
\text { Spar }\end{array}$ & 60,000 & 13,000 & 0.010 \\
\hline In-Flight & Shear Pin & 40,000 & 6,500 & 0.004 \\
\hline In-Flight & Rear Bulkhead & 69,000 & 9,500 & 0.008 \\
\hline In-Flight & Front Bulkhead & 20,000 & 4,000 & 0.003 \\
\hline
\end{tabular}

Table E 2: FEA Results: Landing analysis step

\begin{tabular}{|c|c|c|c|c|}
\hline Analysis Step & Location & $\begin{array}{c}\text { Max. Von } \\
\text { Mises Stress } \\
\text { (psi) }\end{array}$ & $\begin{array}{c}\text { Max. In-Plane } \\
\text { Shear Stress, } \\
\mathbf{S}_{\mathbf{1 2}} \text { (psi) }\end{array}$ & $\begin{array}{c}\text { Max In-Plane } \\
\text { Strain. (国) }\end{array}$ \\
\hline Landing & $\begin{array}{c}\text { Carry-through } \\
\text { Spar }\end{array}$ & 34,000 & 3,500 & 0.007 \\
\hline Landing & Shear Pin & 10,000 & 2,500 & 0.002 \\
\hline Landing & Rear Bulkhead & 30,000 & 4,000 & 0.003 \\
\hline Landing & Front Bulkhead & $\mathbf{2 8 , 0 0 0}$ & 7,000 & 0.005 \\
\hline Landing & $\begin{array}{c}\text { Landing Gear } \\
\text { Attachment }\end{array}$ & 52,000 & 13,500 & 0.011 \\
\hline
\end{tabular}

\section{Weight Estimates:}

Table E 3: Weights of fuselage panels predicted by the FEA

\begin{tabular}{|l|c|c|c|c|c|c|c|c|c|c|}
\hline *(lbs)* $^{*}$ & $\begin{array}{c}\text { Base } \\
\text { plate }\end{array}$ & $\begin{array}{c}\text { Side } \\
\text { walls }\end{array}$ & Fairings & $\begin{array}{c}\text { Front } \\
\text { bulkhead }\end{array}$ & $\begin{array}{c}\text { Rear } \\
\text { bulkhead }\end{array}$ & Bushings & $\begin{array}{c}\text { Landing } \\
\text { gear } \\
\text { bracket }\end{array}$ & $\begin{array}{c}\text { Nose } \\
\text { cone } \\
\text { bridge }\end{array}$ & $\begin{array}{c}\text { Rear } \\
\text { side } \\
\text { walls }\end{array}$ & $\begin{array}{c}\text { Bay } \\
\text { separator } \\
\text { panel }\end{array}$ \\
\hline Skin & 0.79 & 1.54 & 0.29 & 0.29 & 0.44 & 1.71 & 1.99 & 0.15 & 0.92 & 0.17 \\
\hline Core & 0.16 & 0.67 & 0.73 & 0.17 & 0.31 & N/A & 0.42 & 0.07 & 0.46 & 0.05 \\
\hline
\end{tabular}


Appendix F: Microscopic Image Analysis

\section{VARTM Specimens:}

Good $=$ Partially open cells at the skin-core interface are filled with resin.

Bad $=$ Voids at the skin core interface.
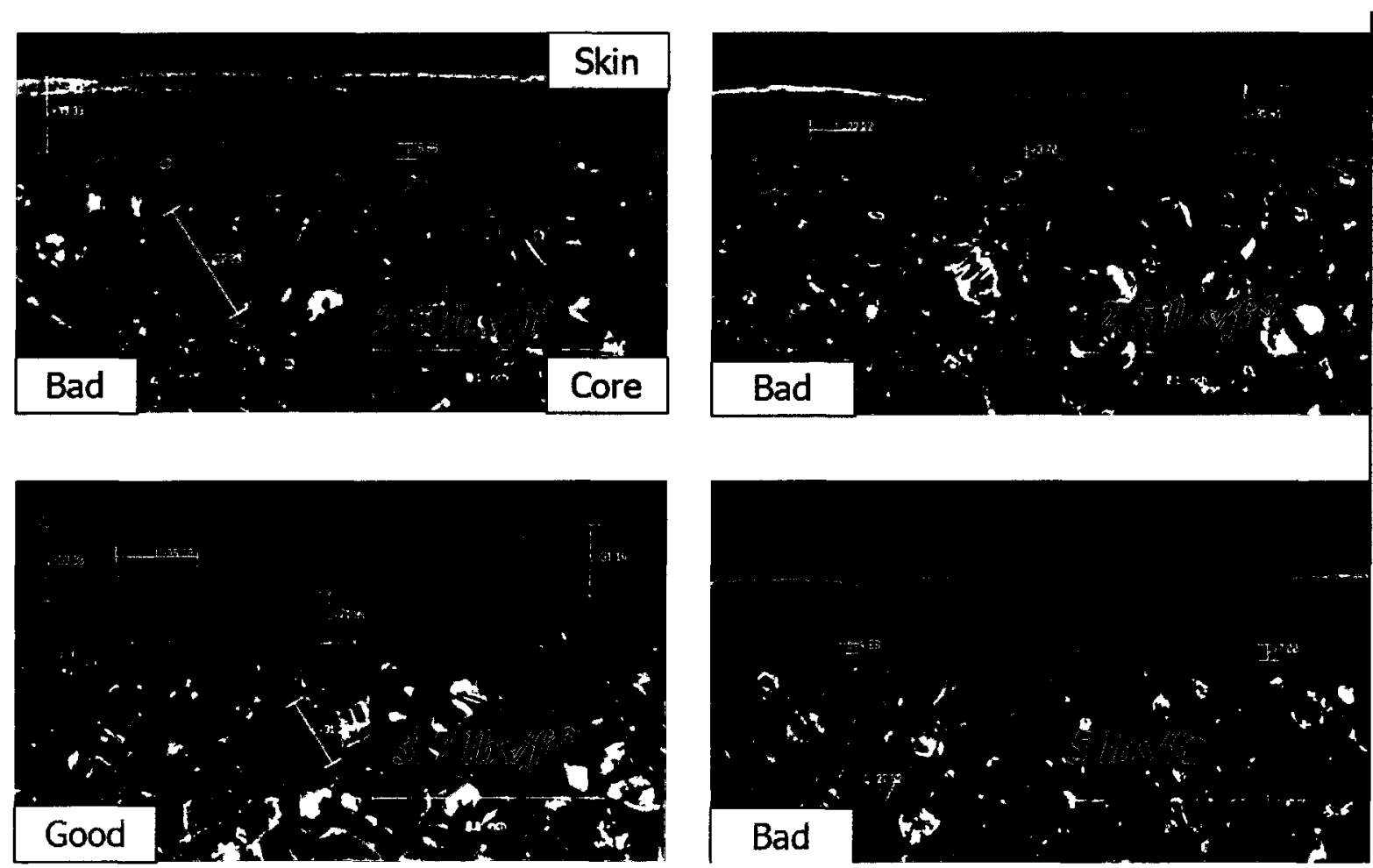

Figure F 1: Sample cross-sections of VARTM specimens 


\section{CCBM Specimens:}
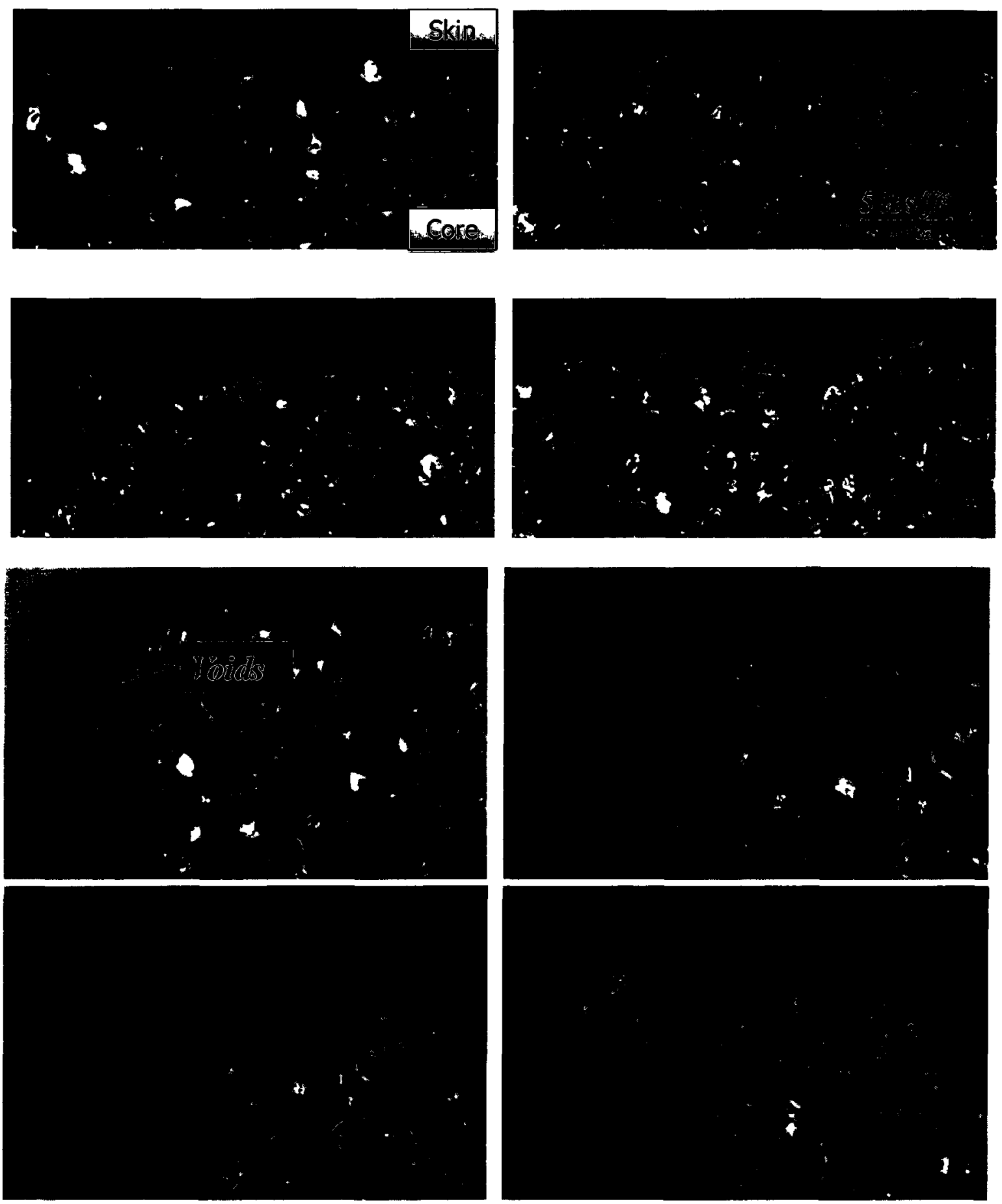

Figure F 2: Images of the CCBM specimens at random locations 


\section{Appendix G: Fuselage Profiling}

The outer mould line (OML) (Figure G 1) of the new fuselage was measured around all of the edges with particular attention to the regions that interface with the access panels. The entire process and results are discussed in the following few sections.
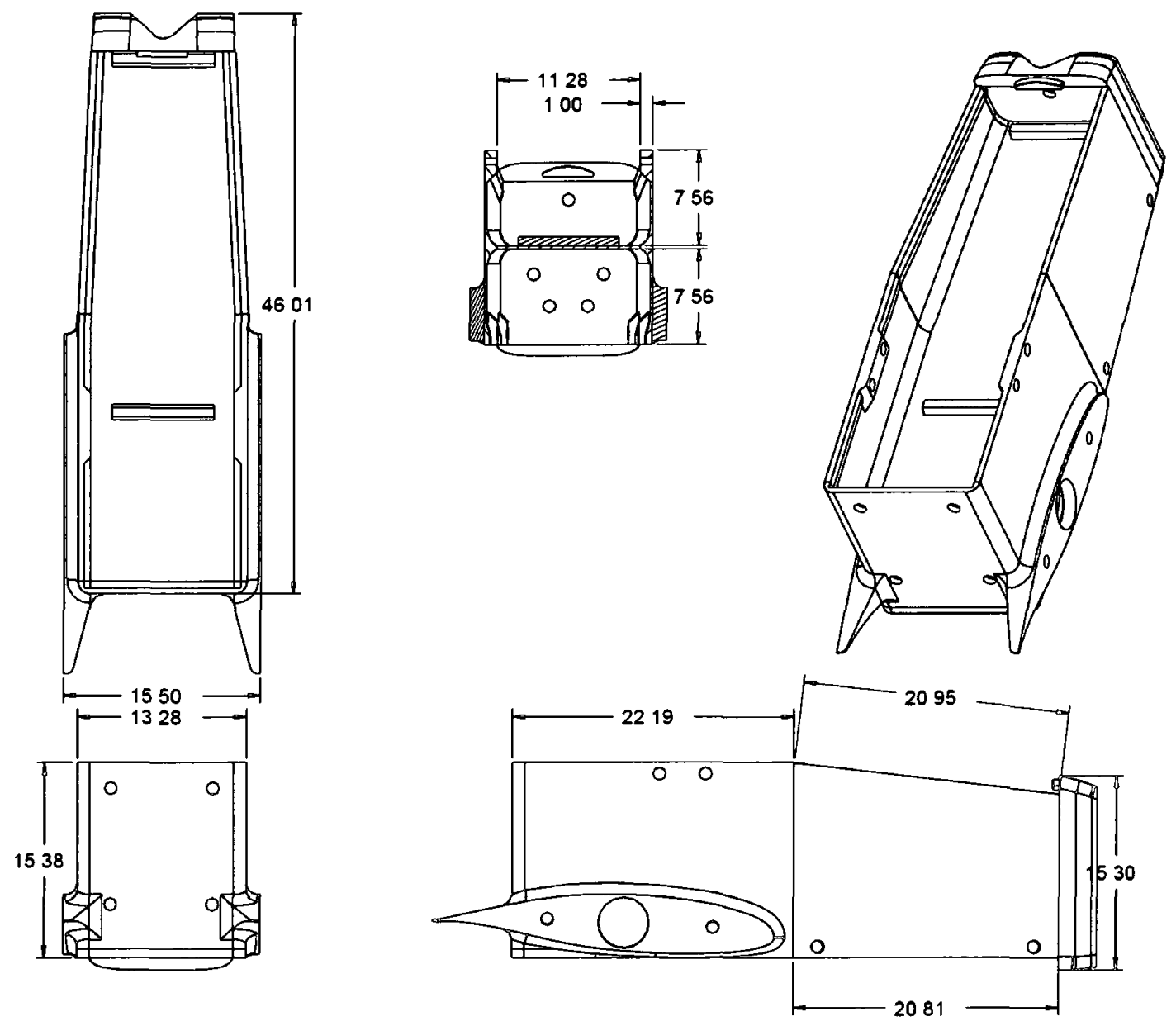

Figure G 1: Overall dimensions of the fuselage assembly 


\section{Procedure:}

The profiling of the fuselage was carried out in a process involving several steps. These steps are outlined below.

1. The Pro/E model of the assembled fuselage (without the carbon fibre skin) was examined and all of the points at which measurements would be taken were determined.

2. The dimensions of the Pro/E model at each of these points were recorded. Experimental skin thickness was added to the Pro/E dimensions to obtain the ideal dimensions listed in Table $\mathbf{G} 1$ through Table $\mathbf{G} 6$.

3. The fuselage was marked with masking tape at each of the points where measurements would be taken, as can be seen in Figure $\mathrm{G} 2$ and Figure $\mathrm{G} 3$.

4. All of the measurements of the fuselage were taken with a shop ruler to a precision of at least $\pm 1 / 16^{\prime \prime}$.

5. All of the data was inserted into a MS Excel ${ }^{\mathrm{TM}}$ template to obtain the deviations found in Table $\mathrm{G} 1$ through Table $\mathrm{G} 6$ and to determine the tolerances for each set of results.

6. The results were used to sketch the actual profiles of the fuselage on top of the ideal profiles as shown in Figure $\mathbf{G} 4$ and Figure $\mathbf{G} 5$. 

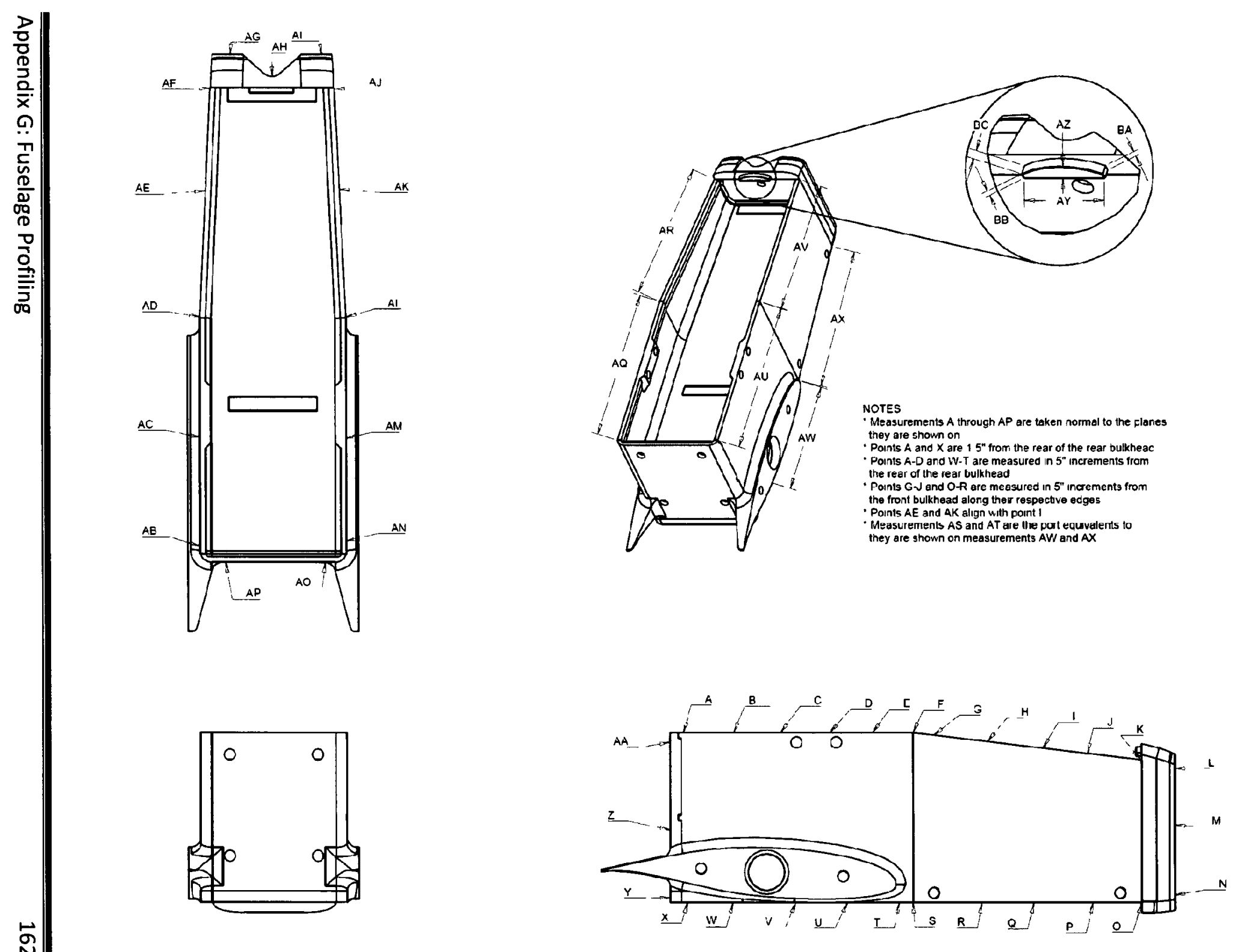


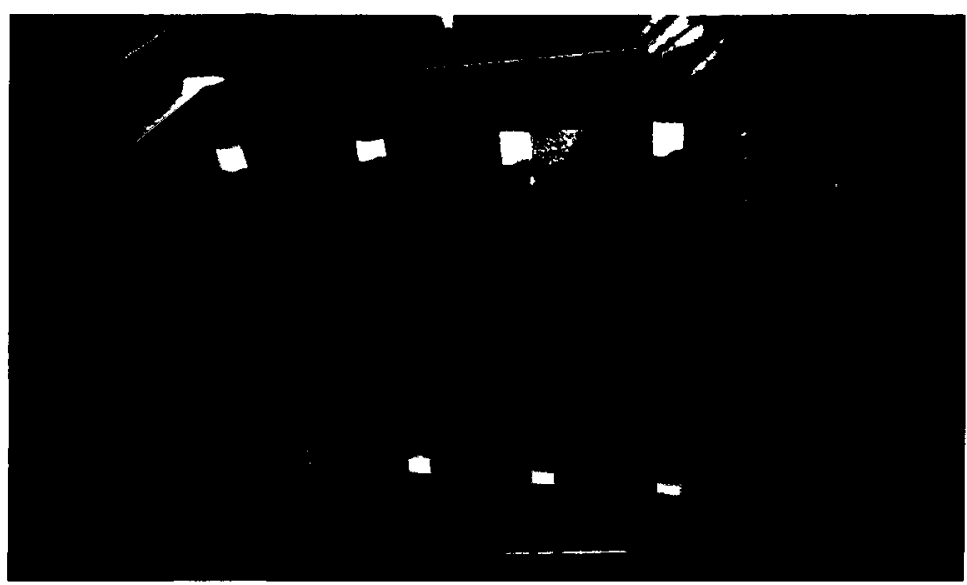

Figure G 3: Marking the fuselage with masking tape to identify the points shown in Figure $\mathbf{G} 2$

\section{Results:}

Table $\mathbf{G} 1$ through Table $\mathrm{G} 6$ show the measured values at the locations illustrated in Figure $\mathbf{G} 2$. The results are split into separate tables according to which part of the fuselage they pertain to. The deviation columns are colour coded by the magnitude of the deviation with the darker red showing the greatest deviation and the brighter green being showing the smallest.

Note that the fuselage widths along the top and the bottom surfaces have the greatest deviations. This is of most interest for the Structures Fuselage Team, since these are the areas that pertain to the attachment of the access panels. Figure $\mathbf{G} 4$ and Figure $\mathbf{G} \mathbf{5}$ show precisely where these measurements were taken and also the show spline curves (in red) connecting where the measurements were taken, in order to give the complete shape profile of the actual fuselage. Note that in creating these spline curves it was assumed that the deviation is symmetric about the centreline of the fuselage. This assumption is not perfect, but is adequate for the purpose of demonstrating the deviation. 
Table G 1: Width results across the top of the fuselage

\begin{tabular}{cccc}
\hline Measurement ID & $\begin{array}{c}\text { Measurement [in.] } \\
( \pm 1 / 16)\end{array}$ & $\begin{array}{c}\text { Ideal [in.] } \\
\text { A-F }( \pm 0.010) \\
\mathbf{G - K}( \pm \mathbf{0 . 0 0 6})\end{array}$ & $\begin{array}{c}\text { Deviation [in.] } \\
\mathbf{A - F}( \pm \mathbf{0 . 0 7 3}) \\
\mathbf{G - K}( \pm \mathbf{0 . 0 6 9})\end{array}$ \\
\hline A & $138 / 32$ & 13.34 & -0.09 \\
B & $130 / 32$ & 13.34 & -0.34 \\
C & $1230 / 32$ & 13.34 & -0.40 \\
D & $130 / 32$ & 13.34 & -0.34 \\
E & $134 / 32$ & 13.34 & -0.21 \\
F & $1312 / 32$ & 13.34 & 0.04 \\
G & $132 / 32$ & 13.22 & -0.16 \\
H & $1220 / 32$ & 12.75 & -0.12 \\
I & $125 / 32$ & 12.28 & -0.12 \\
J & $1121 / 32$ & 11.81 & -0.16 \\
K & $117 / 32$ & 11.34 & -0.12 \\
\hline
\end{tabular}

Table G 2: Width results across the bottom of the fuselage

\begin{tabular}{cccc}
\hline Measurement ID & $\begin{array}{c}\text { Measurement [in.] } \\
( \pm 1 / 16)\end{array}$ & $\begin{array}{c}\text { Ideal [in.] } \\
( \pm 0.006)\end{array}$ & $\begin{array}{c}\text { Deviation [in.] } \\
( \pm 0.069)\end{array}$ \\
\hline O & $118 / 32$ & 11.33 & -0.08 \\
P & $1120 / 32$ & 11.88 & -0.26 \\
Q & $128 / 32$ & 12.36 & -0.11 \\
R & $1230 / 32$ & 12.83 & 0.11 \\
S & $1314 / 32$ & $13.34 \pm 0.010$ & $0.10 \pm 0.073$ \\
T & $1310 / 32$ & $13.34 \pm 0.010$ & $-0.02 \pm 0.073$ \\
U & $1314 / 32$ & $13.38 \pm 0.018$ & $0.05 \pm 0.081$ \\
V & $1310 / 32$ & $13.38 \pm 0.018$ & $-0.07 \pm 0.081$ \\
W & $1314 / 32$ & $13.48 \pm 0.034$ & $-0.04 \pm 0.097$ \\
X & $1313 / 32$ & $13.48 \pm 0.034$ & $-0.07 \pm 0.097$ \\
\hline
\end{tabular}




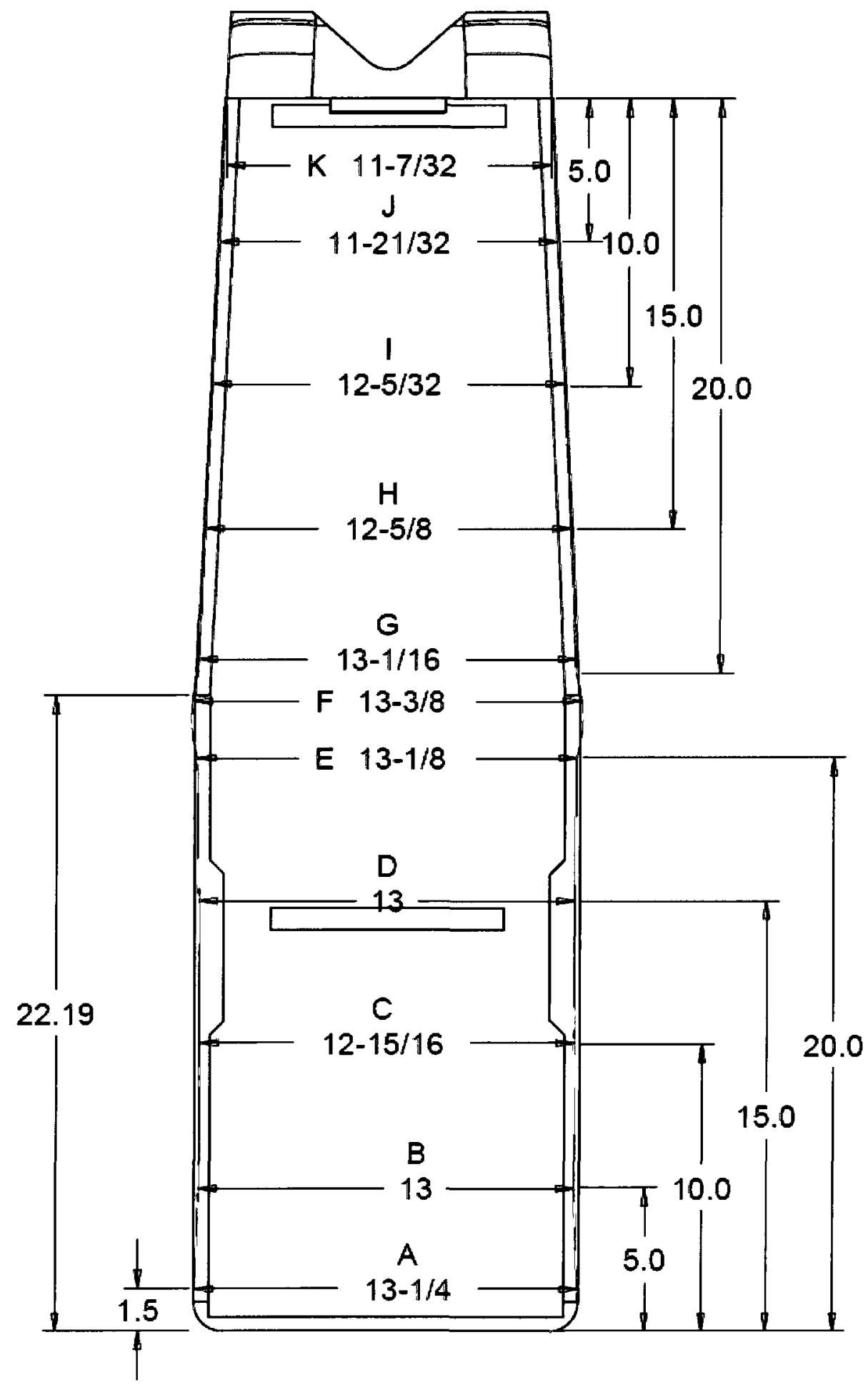

Figure G 4: Outline of top of fuselage showing the actual (in red) and the ideal profiles and the locations of the measurement points shown in Table $\mathbf{G} 1$. The dimensions shown are the measured dimensions. The positions of the measurements are shown relative to the fuselage Outer Mould Line (OML). 


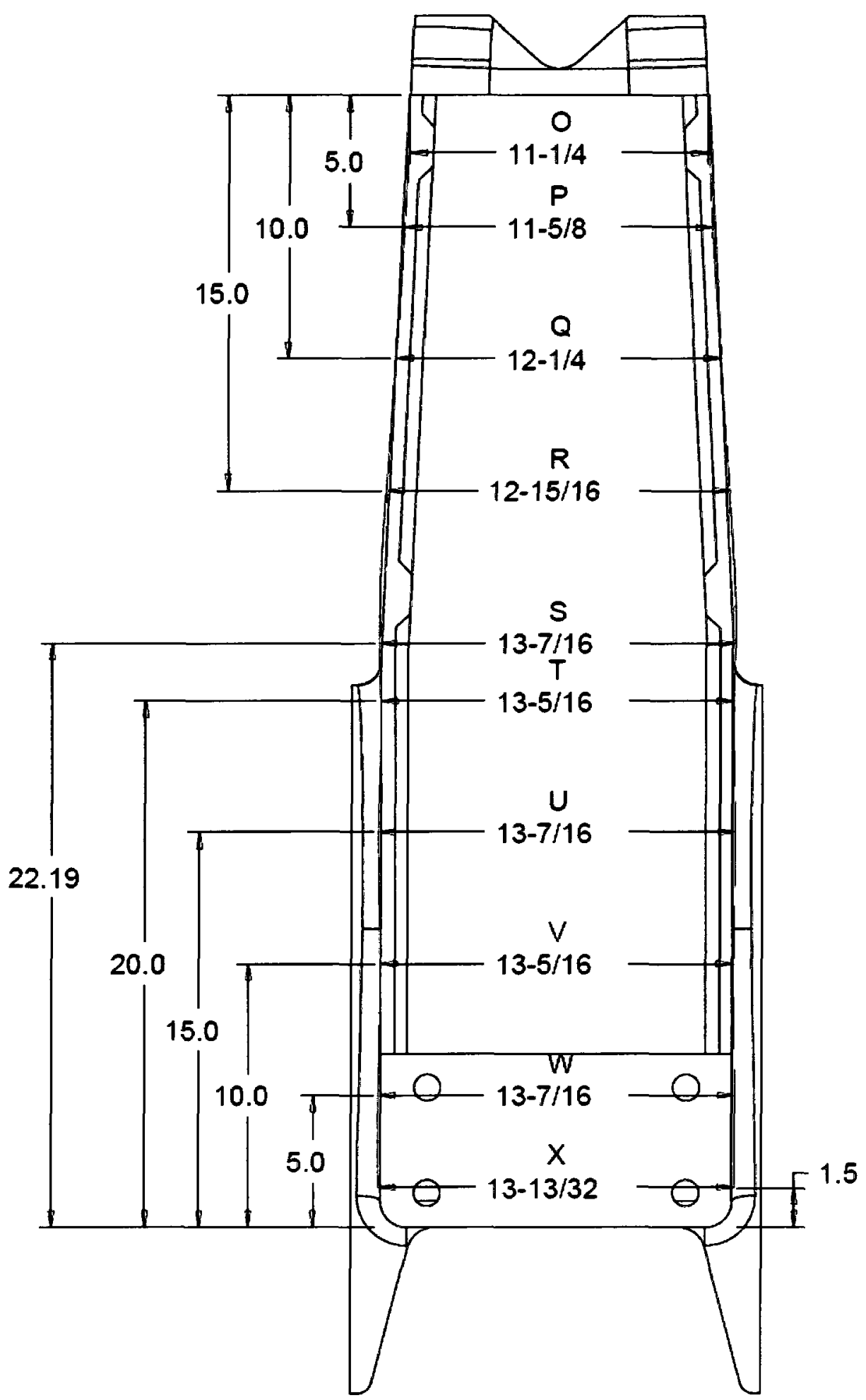

Figure G 5: Outline of bottom of fuselage showing the actual (in red) and the ideal profiles and the locations of the measurement points shown in Table $\mathbf{G} 2$. The dimensions shown are the measured dimensions. The positions of the measurements are shown relative to the fuselage Outer Mould Line (OML). 
Table G 3: Front bulkhead height and width dimensions

\begin{tabular}{ccc|c}
\hline Measurement ID & $\begin{array}{c}\text { Measurement [in.] } \\
( \pm 1 / 16)\end{array}$ & $\begin{array}{c}\text { Ideal [in.] } \\
( \pm 0.01)\end{array}$ & $\begin{array}{c}\text { Deviation [in.] } \\
( \pm \mathbf{0 . 0 7 3 )}\end{array}$ \\
\hline L & $1028 / 32$ & 10.93 & -0.05 \\
M & $1028 / 32$ & 10.93 & -0.05 \\
N & $1028 / 32$ & 10.93 & -0.05 \\
AG & $145 / 32$ & 14.22 & -0.06 \\
AH & $152 / 32$ & 15.10 & -0.03 \\
Al & $145 / 32$ & 14.22 & -0.06 \\
\hline
\end{tabular}

Table G 4: Rear bulkhead height and width dimensions

\begin{tabular}{cccc}
\hline Measurement ID & $\begin{array}{c}\text { Measurement [in.] } \\
( \pm 1 / 16)\end{array}$ & Ideal [in.] & Deviation [in.] \\
\hline Y & $1312 / 32$ & $13.50 \pm 0.034$ & $-0.13 \pm 0.097$ \\
Z & $1310 / 32$ & $13.34 \pm 0.014$ & $-0.05 \pm 0.077$ \\
AA & $1310 / 32$ & $13.34 \pm 0.014$ & $-0.05 \pm 0.077$ \\
AO & $1516 / 32$ & $15.52 \pm 0.022$ & $-0.02 \pm 0.085$ \\
AP & $1516 / 32$ & $15.52 \pm 0.022$ & $-0.02 \pm 0.085$ \\
\hline
\end{tabular}

Table G 5: Front bulkhead tab dimensions

\begin{tabular}{cccc}
\hline Measurement ID & $\begin{array}{c}\text { Measurement [in.] } \\
( \pm \mathbf{0 . 0 0 1 )}\end{array}$ & $\begin{array}{c}\text { Ideal [in.] } \\
( \pm \mathbf{0 . 0 1 )}\end{array}$ & $\begin{array}{c}\text { Deviation [in.] } \\
( \pm \mathbf{0 . 0 1 1 )}\end{array}$ \\
\hline AY & 4.012 & 4.035 & -0.044 \\
AZ & 0.907 & 0.895 & -0.009 \\
BA & 0.386 & 0.355 & 0.010 \\
BB & 0.374 & 0.355 & -0.002 \\
BC & 0.512 & $0.500 \pm 0.00$ & 0.012 \\
\hline
\end{tabular}

Table G 6: Fuselage length results

\begin{tabular}{cccc}
\hline Measurement ID & $\begin{array}{c}\text { Measurement [in.] } \\
( \pm \mathbf{1} / \mathbf{1 6})\end{array}$ & Ideal [in.] & Deviation [in.] \\
\hline AQ & $225 / 16$ & $22.23 \pm 0.007$ & $0.07 \pm 0.070$ \\
AR & $2013 / 16$ & $20.97 \pm 0.005$ & $-0.16 \pm 0.068$ \\
AS & $225 / 16$ & $22.29 \pm 0.017$ & $0.02 \pm 0.080$ \\
AT & $2013 / 16$ & $20.82 \pm 0.005$ & $-0.01 \pm 0.068$ \\
AU & $224 / 16$ & $22.24 \pm 0.007$ & $0.01 \pm 0.070$ \\
AV & $2013 / 16$ & $20.97 \pm 0.005$ & $-0.16 \pm 0.068$ \\
AW & $225 / 16$ & $22.29 \pm 0.017$ & $0.02 \pm 0.080$ \\
AX & $2013 / 16$ & $20.82 \pm 0.005$ & $0.07 \pm 0.068$ \\
\hline
\end{tabular}




\section{Appendix H: Fibre Volume Fraction Calculation}

Weight of resin infused (lbs) =

$\rho_{\text {resin }}=$

$V_{\text {resin }}=$

Likewise,

Weight of fabric on the fuselage (lbs)=

$\rho_{t 300 \text { fibres }}$

$V_{s k i n}$
2.916

$68.64 \frac{l b s}{f t^{3}}$, where $\rho_{\text {resin }}=\frac{M_{\text {resin }}}{V_{\text {resin }}}$

$0.0425 \mathrm{ft}^{3}$

Using, $V_{\text {resin }}+V_{\text {fabric }}=V_{s k i n}$, (zero void content is assumed, and weave effects of the fabric is ignored)

$V_{f} \sim 51 \%$ 